\title{
PHYSICAL ACTIVITY AND SEDENTARY BEHAVIOR DURING THE RETIREMENT TRANSITION
}

\author{
Sydney Allison Jones
}

A dissertation submitted to the faculty at the University of North Carolina at Chapel Hill in partial fulfillment of the requirements for the degree of Doctor of Philosophy in the Department of Epidemiology in the Gillings School of Global Public Health.

Chapel Hill

2018

Approved by:

Kelly R. Evenson

Allison Aiello

Jennifer Leeman

Quefeng Li

Angela O'Rand 
(C) 2018

Sydney Allison Jones

ALL RIGHTS RESERVED 


\section{ABSTRACT \\ Sydney Allison Jones: Physical Activity and Sedentary Behavior During the Retirement Transition}

(Under the direction of Kelly R. Evenson)

The health of older adults is of increasing public health importance given current demographic trends. Physical activity can improve quality of life and delay impairment in later life. However, many older adults are not physically active and engage in large quantities of sedentary behavior (sitting or reclining while awake), which is linked to increased risk of disease. The retirement transition may be an opportune window to promote physical activity in later life. Retirement involves shifts in routines, social networks, and access to resources and has been linked to physical activity and sedentary behavior changes. However, existing research on physical activity and sedentary behavior during the retirement transition lacks socio-economic diversity and excludes non-leisure domains of physical activity. Moreover, social and environmental factors that influence physical activity after retirement remain unexplored.

This research sequentially combined quantitative and qualitative studies to characterize physical activity and sedentary behavior during the retirement transition. First, we described longitudinal patterns in physical activity and television watching by retirement status and socioeconomic position in a diverse cohort of 4,091 United States adults. Retirement was associated with increased recreational walking, household activity, and television watching but decreased overall moderate-to-vigorous physical activity, particularly among persons of lower socioeconomic position. Second, we identified correlates of within-person changes in walking after retirement among 928 retirees from the same cohort. Correlates included health and 
perceptions of the neighborhood environment, and differed for recreational and transport walking. Third, we interviewed 15 retired women to identify facilitators and barriers to physical activity after retirement. Physical activity after retirement was influenced by: leisure-time physical activity habits over the lifespan, prior occupational physical activity, concurrent life transitions, health, social interaction and support, and the community environment.

Together this research provided substantive knowledge regarding patterns of physical activity and television watching associated with retirement, and the first exploration to date of correlates of walking during the retirement transition. These three interrelated studies can benefit community leaders, public health practitioners, and researchers by guiding the development and targeting of interventions among retirees, including prioritizing community-level changes that support physical activity and reduce sedentary behavior among retirees. 


\section{ACKNOWLEDGEMENTS}

I would like to thank Kelly Evenson and the other members of my dissertation committee for their expertise and encouragement. As my advisor, Kelly has provided more than five years of guidance and mentorship. I am particularly grateful that my committee supported my decision to conduct a qualitative study, which provided a valuable learning experience in recruitment and data collection, and significantly enriched this research. To the participants in that study who shared their stories, challenges, and ideas with me: this work is for you.

Many peers, staff, and faculty also provided support throughout my graduate education that was essential to my success. I extend my gratitude to Wayne Rosamond and the Breakfast Club for their advice, and to Ricky Camplain, officemate extraordinaire, for her generosity and friendship. I acknowledge Susan Meny, Megan Peters, Deanna Caruso, and Michael Plante for their assistance with my qualitative research. I also would like to acknowledge Leanne Field and Isabelle Hargrove, who introduced me to public health; Phil Bors and the Active Living by Design team for reminding me why it matters; and Steve Wing, for his inspiring teaching and research.

Most of all, I am grateful to my family and friends for their enduring love, laughter, and light. My parents urged me to head for the moon, even when it meant holding up my own tightrope to walk on. Mom, I'm so glad we're "graduating” together! My sister, Morgan, cheered

me on at every turn. My partner, Michael, walked beside me throughout the dissertation process, cooked warm meals, and helped me celebrate all along the way. 
My graduate education and research were supported by funding from the UNC Royster Society of Fellows, Gillings Dissertation Award, and the National Heart Lung and Blood Institute (NHLBI, NRSA T32-HL007055-38). I also would like to thank the investigators, staff, and participants of the Multi-Ethnic Study of Atherosclerosis (MESA) for their valuable contributions. A full list of participating MESA investigators and institutions can be found at http://www.mesa-nhlbi.org. From the MESA Neighborhood Study, I acknowledge Kari Moore for her contributions to creating and compiling the survey-based measures, Melissa Smiley and Carrick Davis for their role in collecting data from the metropolitan areas, Shannon Brines, Jana Hirsch, Natalie Wowk, and Melissa Zagorski for the creation of Geographic Information System variables, and Amanda Dudley for her support with license agreements and data acquisition. The MESA was supported by contracts HHSN268201500003I, N01-HC-95159, N01-HC-95160, N01-HC-95161, N01-HC-95162, N01-HC-95163, N01-HC-95164, N01-HC-95165, N01-HC95166, N01-HC-95167, N01-HC-95168 and N01-HC-95169 from the NHLBI and by grants UL1-TR-000040 and UL1-TR-001079 from the National Center for Research Resources and 2R01-HL071759 from the NHLBI. 


\section{TABLE OF CONTENTS}

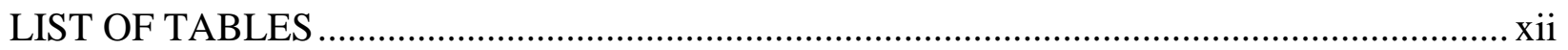

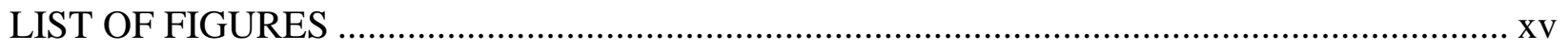

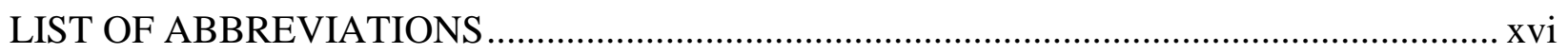

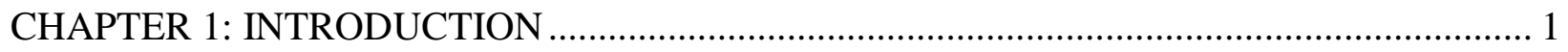

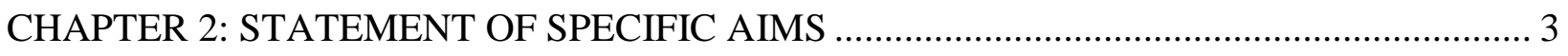

CHAPTER 3: BACKGROUND AND REVIEW OF THE LITERATURE …………………....... 5

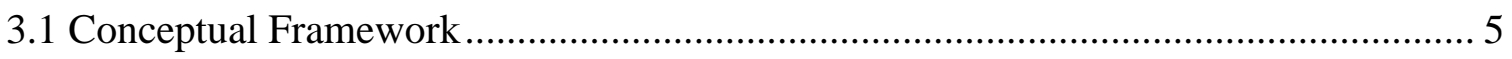

3.1.1 The Life Course Theory .............................................................................. 5

3.1.2 Social Ecological Model ............................................................................. 6

3.2 Physical Activity, Sedentary Behavior, and Health in Later Life................................ 7

3.2.1 Prevalence of Physical Activity and Sedentary Behavior ……............................ 8

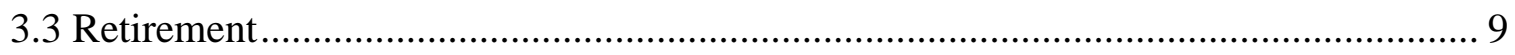

3.3.1 Retirement and Behavior Change …………………....................................... 11

3.3.2 Intervention during the Retirement Transition ................................................ 12

3.4 Physical Activity during the Retirement Transition .................................................. 14

3.4.1 Correlates of Physical Activity at Retirement ................................................. 15

3.4.2 Qualitative Studies of Physical Activity during the Retirement

Transition ....................................................................................................... 16

3.5 Sedentary Behavior during the Retirement Transition ............................................. 23

3.5.1 Correlates of Sedentary Behavior at Retirement ............................................. 23

3.5.2 Qualitative Studies of Sedentary Behavior during the Retirement

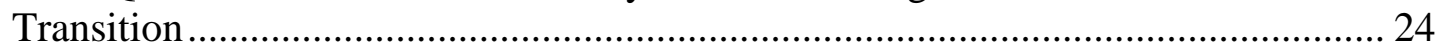




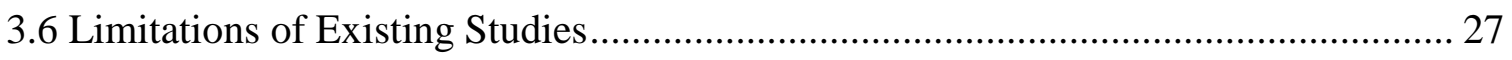

3.6.1 Study Population...................................................................................... 27

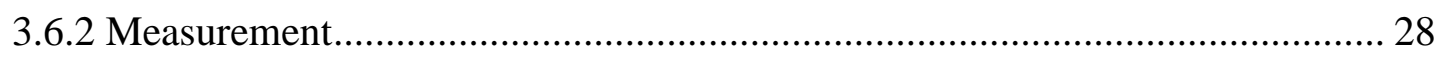

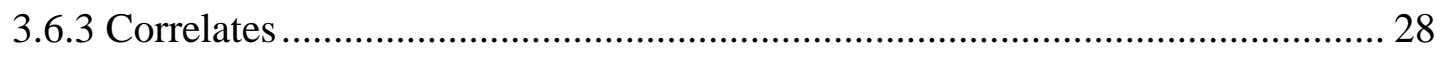

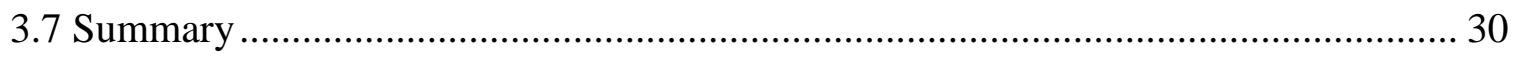

CHAPTER 4: OVERARCHING RESEARCH METHODS .................................................... 32

4.1 Mixed-Methods Approach ...................................................................................... 32

4.2 Research Approach for Quantitative Analyses (Aims 1 and 2) ................................. 32

4.2.1 Study Population........................................................................................ 32

4.2.2 Study Measures........................................................................................... 34

4.2.3 Statistical Analyses ......................................................................................... 44

4.3 Research Approach for Qualitative Analyses (Aim 3) ............................................. 50

4.3.1 Recruitment and Study Population …………………....................................... 50

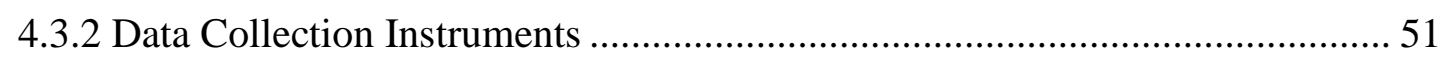

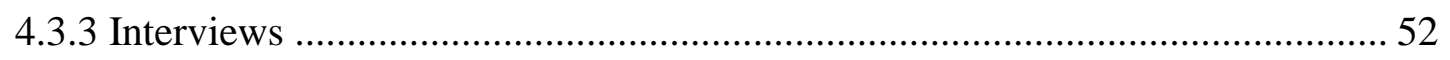

4.3.4 Analyses of Facilitators and Barriers to Physical Activity after

Retirement..................................................................................................... 53

4.4 Dissemination of Findings …………………………........................................... 54

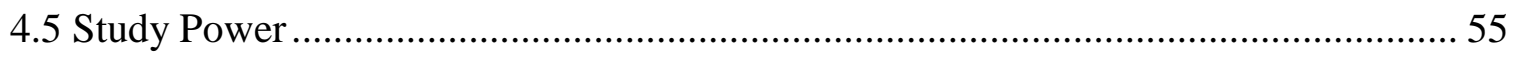

CHAPTER 5. PHYSICAL ACTIVITY, SEDENTARY BEHAVIOR, AND

RETIREMENT: THE MULTI-ETHNIC STUDY OF ATHEROSCLEROSIS ............................. 57

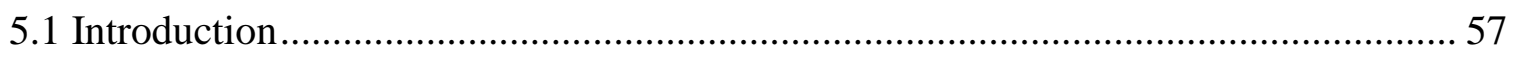

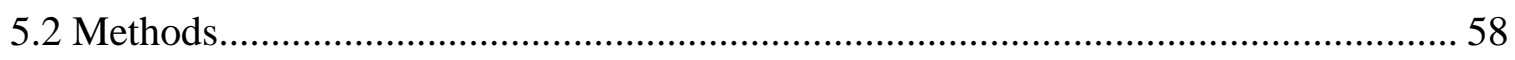

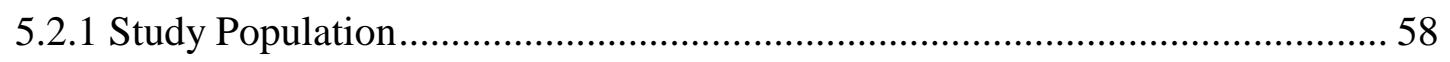

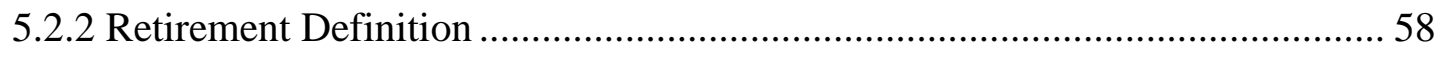

5.2.3 Physical Activity and Sedentary Behavior ........................................................ 59 


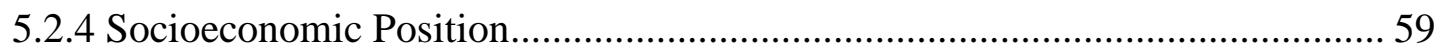

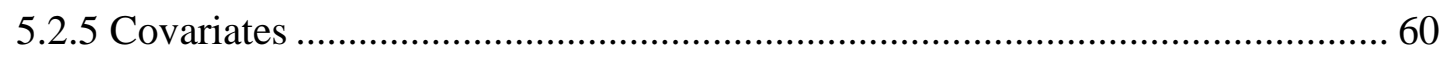

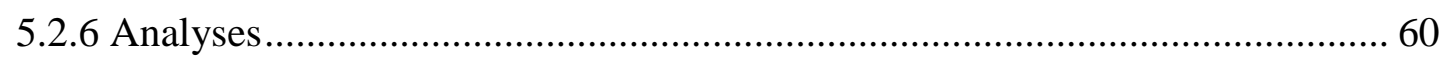

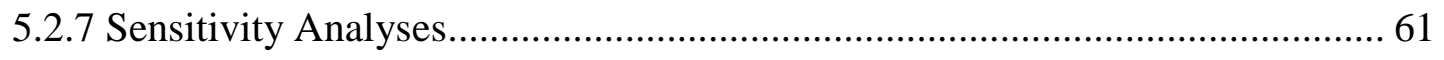

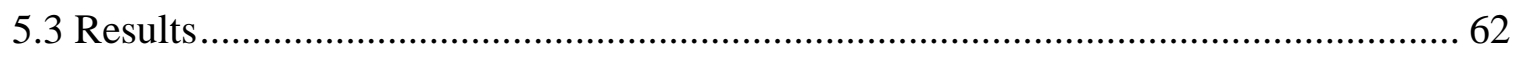

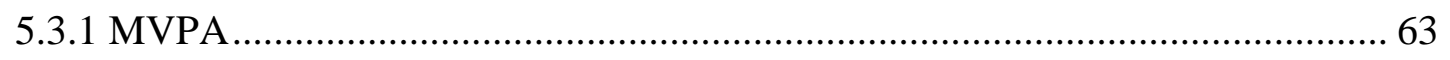

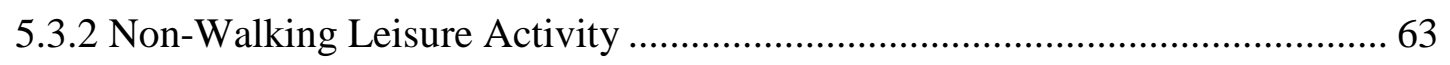

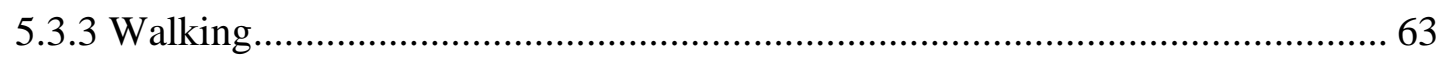

5.3.4 Household / Yard and Caregiving Activity ....................................................... 63

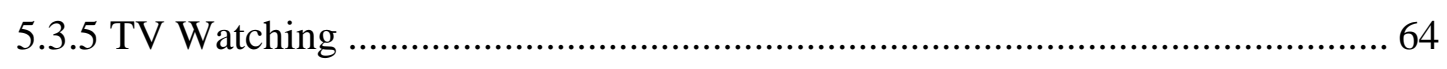

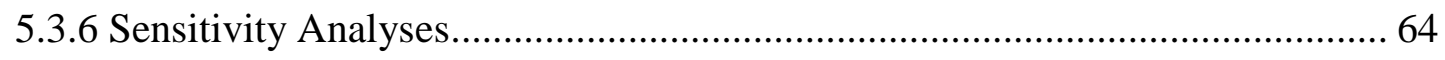

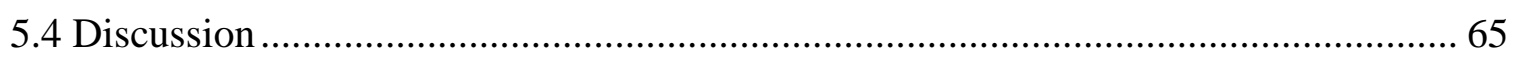

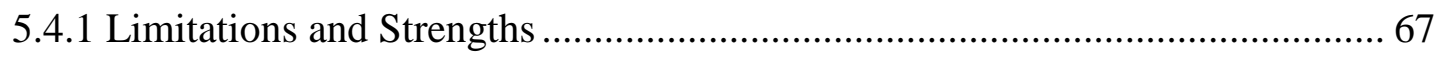

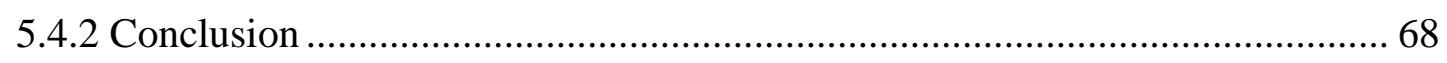

CHAPTER 6. CORRELATES OF CHANGES IN WALKING DURING THE RETIREMENT TRANSITION: THE MULTI-ETHNIC STUDY OF

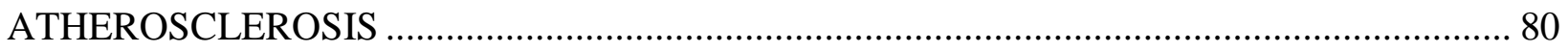

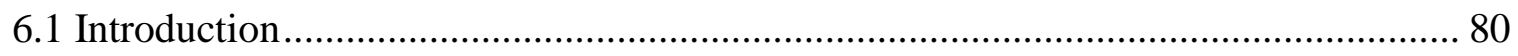

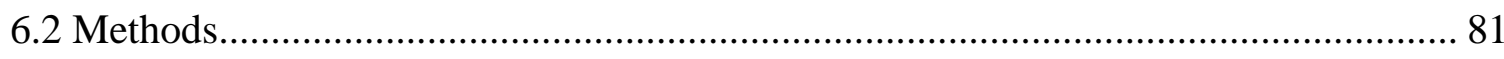

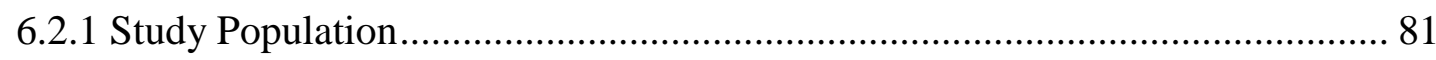

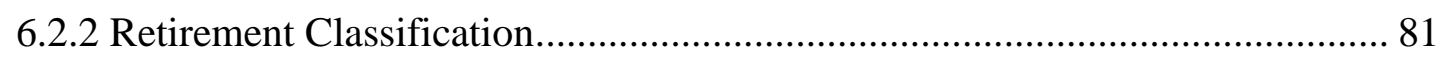

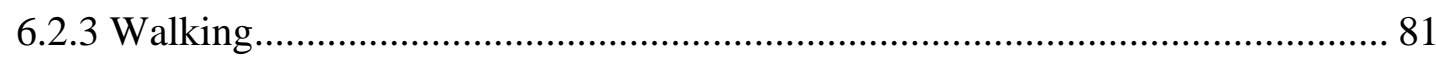

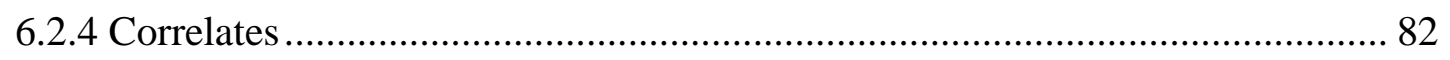

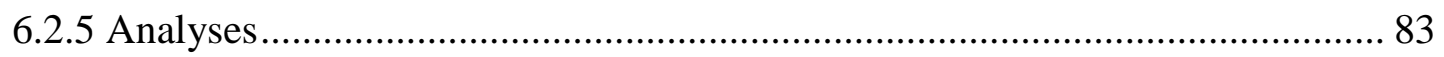

6.2.6 Sensitivity Analyses...................................................................................... 85

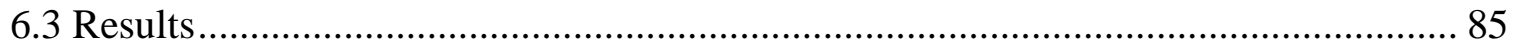




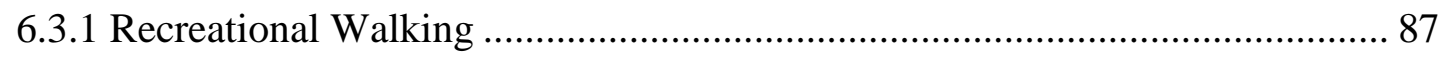

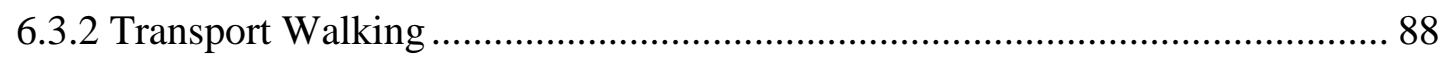

6.3.3 Sensitivity Analyses............................................................................... 89

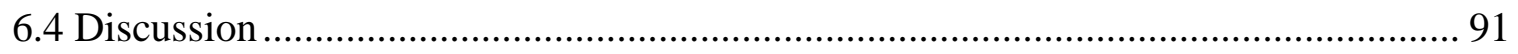

6.4.1 Strengths and Limitations .............................................................................. 94

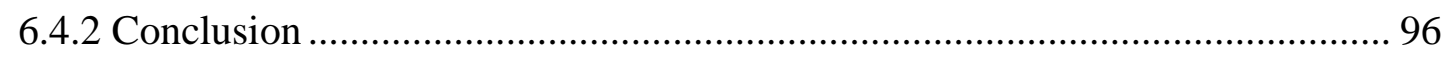

CHAPTER 7. PHYSICAL ACTIVITY FACILITATORS AND BARRIERS

AMONG RETIRED WOMEN: A QUALITATIVE STUDY ................................................... 115

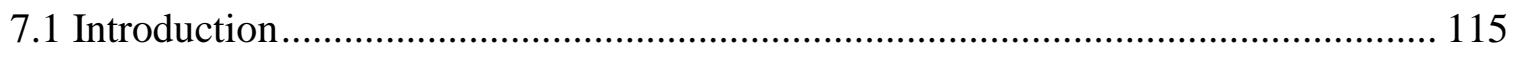

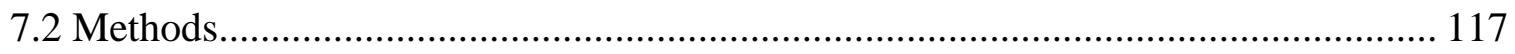

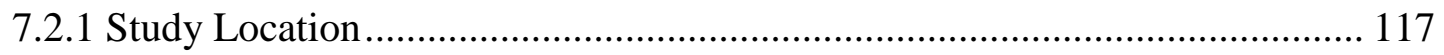

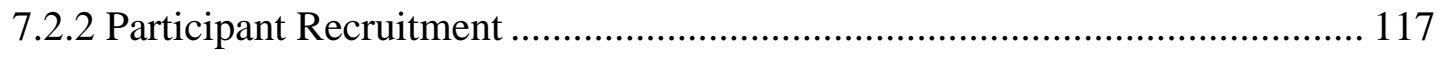

7.2.3 Study Questionnaire................................................................................. 118

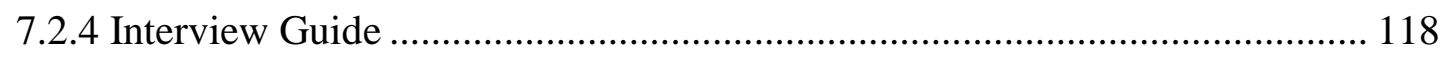

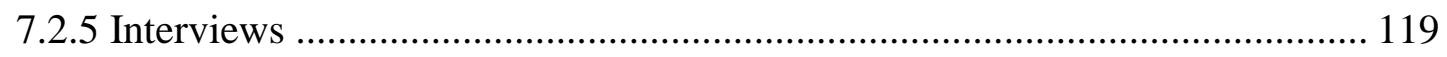

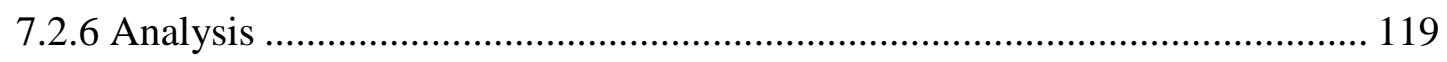

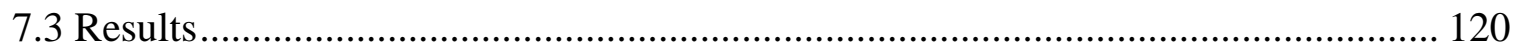

7.3.1 Barriers and Facilitators of Physical Activity after Retirement....................... 121

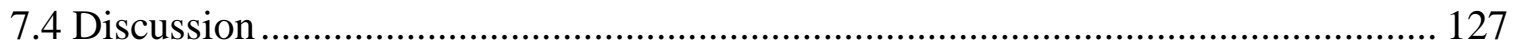

7.4.1 Strengths and Limitations ......................................................................... 131

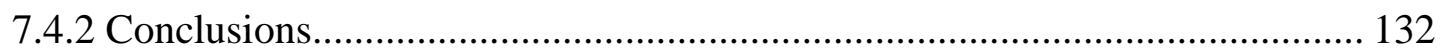

CHAPTER 8: CONCLUSIONS AND PUBLIC HEALTH IMPLICATIONS …........................ 138

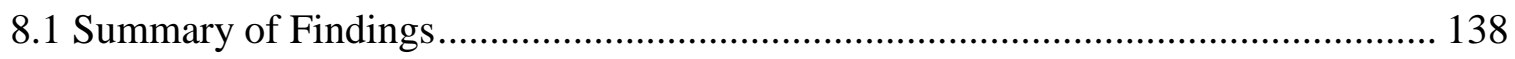

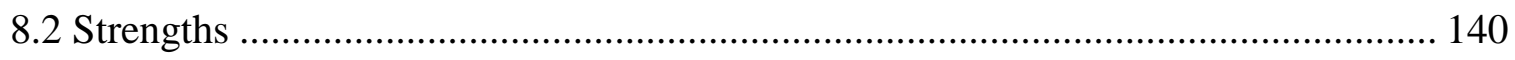

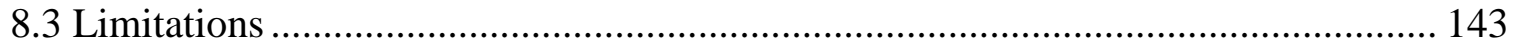

8.4 Public Health Significance................................................................................. 146 


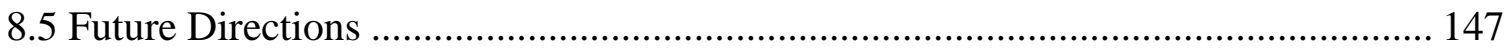

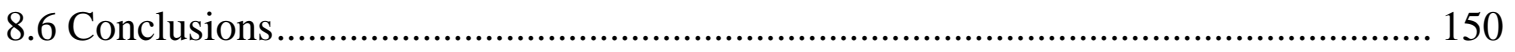

APPENDIX 1: QUALITATIVE DATA COLLECTION TOOLS ....................................... 151

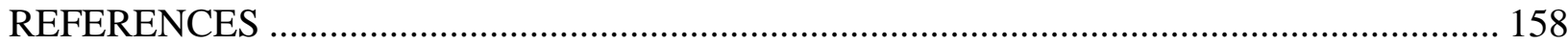




\section{LIST OF TABLES}

Table 1. Definitions of the paradigmatic principles of life course theory and examples of how they may shape the behavioral consequences of retirement

Table 2. Recent longitudinal quantitative studies of physical activity at retirement .................. 18

Table 3. Recent qualitative studies of physical activity in relation to retirement..................... 21

Table 4. Longitudinal quantitative studies of sedentary behavior at retirement........................ 25

Table 5. Qualitative studies of sedentary behavior in relation to retirement ........................... 26

Table 6. Baseline characteristics of MESA participants (2000-2002, N=6,814).................... 32

Table 7. MESA participants, number newly retired, and physical activity

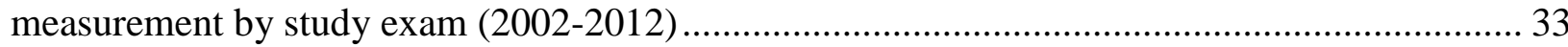

Table 8. Employment status questions in the Multi-Ethnic Study of

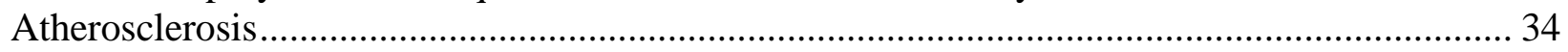

Table 9. Retirement definition in main and sensitivity analyses ....................................... 35

Table 10. MESA domain-specific and summary measures of physical activity and

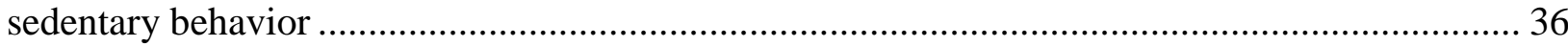

Table 11. Summary of operationalization of physical activity by study aim ........................... 37

Table 12. Measures of neighborhood-level covariates, MESA (2000-2010) ............................. 41

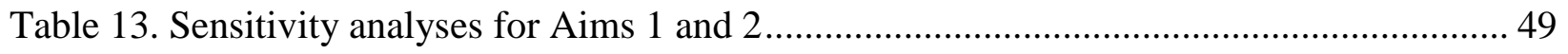

Table 14. Estimated differences in mean physical activity and sedentary behavior

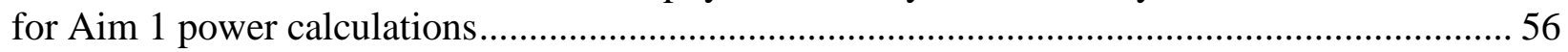

Table 15. Participant characteristics overall by employment status at follow-up, $\operatorname{MESA}(\mathrm{N}=4,091)$.

Table 16. Change a in physical activity and television watching by retirement

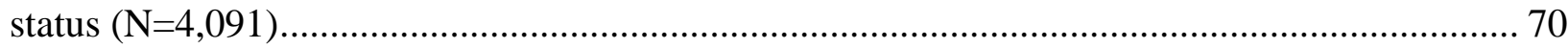

Table 17. Change a in physical activity and television watching by retirement status and socioeconomic position $(\mathrm{N}=4,091)$.

Table 18. Change ${ }^{a}$ in physical activity and television watching by retirement and socioeconomic position in healthy subset ${ }^{\mathrm{b}}(\mathrm{N}=2,085)$....

Table 19. Classification of retirement status by reported employment category in main and four sensitivity analyses 
Table 20. Assignment of metabolic equivalent task (MET) values by domain and

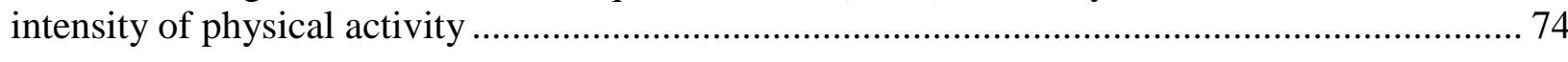

Table 21. Definition of good health throughout follow-up............................................... 74

Table 22. Changes ${ }^{a}$ in physical activity and television watching by retirement

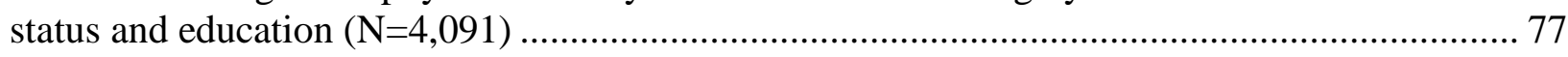

Table 23. Potential correlates of change in walking at retirement, MESA (20002012)

Table 24. Study participant characteristics prior to retirement, overall and among participants reporting no walking for recreation or transport, MESA 2000-2012 $(\mathrm{N}=928)$.

Table 25. Median (interquartile range) of recreational and transport walking (min/week) before and after retirement, overall and by category of change in walking, MESA 2000-2012 (N=919) 100

Table 26. Multivariable logistic regression of individual-, interpersonal-, and community-level correlates associated with change in recreational walking after retirement, MESA 2000-2012 (N=792) 101

Table 27. Multivariable logistic regression of individual-, interpersonal-, and community-level correlates associated with change in transport walking after retirement, MESA 2000-2012 (N=887)

Table 28. Individual-, interpersonal-, and community correlates by category of change in recreational walking after retirement, MESA 2000-2012 (N=792)

Table 29. Individual-, interpersonal-, and community correlates by category of change in transport walking after retirement, MESA 2000-2012 (N=887). 108

Table 30. Multivariable logistic regression of individual-, interpersonal-, and community-level correlates associated with change in recreational walking after retirement among participants who did not move during follow-up, MESA 2000$2012(\mathrm{~N}=623)$.

Table 31. Multivariable logistic regression of individual-, interpersonal-, and community-level correlates associated with change in transport walking after retirement among participants who did not move during follow-up, MESA 2000$2012(\mathrm{~N}=704)$.

Table 32. Participant characteristics, overall and by prior occupational physical activity $(\mathrm{n}=15)$.

Table 33. Physical activity before (work and non-work) and after retirement among participants $(\mathrm{n}=15)$ 
Table 34. Themes and subthemes related to barriers and facilitators of physical

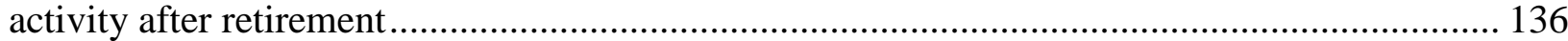




\section{LIST OF FIGURES}

Figure 1. The Social Ecological Model (adapted from [1]) ................................................. 6

Figure 2. Percent Employed Full-time by Age and Late-Life Latent Employment Trajectory, Health and Retirement Study linked to Social Security earnings data (from [2]).

Figure 3. Multi-Ethnic Study of Atherosclerosis timeline

Figure 4. Directed acyclic graph of the relationship between retirement and physical activity and sedentary behavior 46

Figure 5. Estimated physical activity (overall and by domain) and television watching patterns by retirement status in the overall sample $(\mathrm{N}=4,091 \mathrm{MESA}$ participants). Lines represent patterns for the average person who did not retire during follow-up (black line) and who retired at age 63 (median retirement age in this cohort, grey line). Estimates back transformed from fixed-effect models of log-transformed outcomes adjusted for time-varying partnership status, self-rated health, and nine chronic conditions. Note scale of y-axis varies by domain. Data for these figures are presented in Table 16.

Figure 6. Estimated physical activity and television watching patterns by retirement status and socioeconomic position (SEP; N=2003 low SEP; N=2088 high SEP). Lines represent patterns for the average person who did not retire during follow-up (black line) and who retired at 63 (median retirement age in this cohort, grey line). Estimates back transformed from fixed-effect models of logtransformed outcomes stratified by SEP and adjusted for time-varying partnership status, self-rated health, and chronic conditions. SEP was a composite index of education, income, and four indicators of wealth. Note scale of $y$-axis varies by domain. Data for these figures are presented in Table 17.

Figure 7. Adjusted average change associated with retirement (95\% CI) and average 5-year change $(95 \% \mathrm{CI})$ in physical activity and television watching by retirement status and socioeconomic position, overall and by race/ ethnicity. Values are exponentiated coefficients from fixed-effect models of logtransformed physical activity or television watching adjusted for time-varying partnership status, self-rated health, and nine chronic conditions.

Figure 8. Adjusted average change associated with retirement (95\% CI) and average 5-year change $(95 \% \mathrm{CI})$ in physical activity and television watching by retirement status and socioeconomic position, overall and by study site (Los Angeles County, CA; Chicago, IL; Baltimore County, MD; St. Paul, MN; Forsyth County, NC; Northern Manhattan and the Bronx, NY). Values are exponentiated coefficients from fixed-effect models of log-transformed physical activity or television watching adjusted for time-varying partnership status, self-rated health, and nine chronic conditions. 


\section{LIST OF ABBREVIATIONS}

$\begin{array}{ll}\text { BMI } & \text { Body mass index } \\ \text { BRFSS } & \text { Behavioral Risk Factor Surveillance System } \\ \text { CI } & \text { Confidence interval } \\ \text { CVD } & \text { Cardiovascular disease } \\ \text { ESSI } & \text { Enhancing Recovery in Coronary Heart Disease Social Support Inventory } \\ \text { IQR } & \text { Interquartile range } \\ \text { MESA } & \text { Multi-Ethnic Study of Atherosclerosis } \\ \text { MET } & \text { Metabolic equivalent task } \\ \text { MVPA } & \text { Moderate-to-vigorous physical activity } \\ \text { NC } & \text { North Carolina } \\ \text { NETS } & \text { National Establishment Time Series } \\ \text { NHANES } & \text { National Health and Nutrition Examination Survey } \\ \text { NHIS } & \text { National Health Interview Survey } \\ \text { OR } & \text { Odds ratio } \\ \text { SD } & \text { Standard deviation } \\ \text { SEP } & \text { Socioeconomic position } \\ \text { TV } & \text { Television } \\ \text { US } & \text { United States }\end{array}$




\section{CHAPTER 1: INTRODUCTION}

Physical activity includes any bodily movement by skeletal muscle that expends energy and may occur across multiple domains such as intentional exercise, housework, or transportation [3, 4]. Among older adults (aged $\geq 65$ ), physical activity can improve quality of life, delay impairment, and lower healthcare costs [5-7]. However, the prevalence of physical activity among older adults is low, with only one-third reporting sufficient physical activity to meet United States (US) national guidelines [8]. Moreover, large daily quantities of sedentary behavior (time spent sitting or reclining while awake) are common among older adults [9] and linked to increased risk of disease and disability [10].

The retirement transition may be an opportune window to promote the adoption and maintenance of physical activity in older adulthood [11-13]. Retirement is a major life transition involving disruptions in habits, time constraints, financial resources, and social support, which may prompt behavioral changes $[14,15]$. Persons approaching retirement also may shift their priorities toward an increased focus on health, which may make them more receptive to physical activity interventions $[11,16,17]$. Moreover, the retirement transition has been linked to both positive and negative changes in physical activity and sedentary behavior $[18,19]$.

To inform physical activity promotion during the retirement transition, we need a better understanding of changes in behavior and their determinants during this period. Existing studies often used single-item summary measures of physical activity and excluded occupational physical activity, which has contributed to discrepant findings across studies. In addition, behavior change at retirement may vary by socioeconomic position (SEP) because disadvantaged 
adults are more likely to retire due to ill health or job loss rather than voluntarily [20-22].

Existing research does not adequately capture the increasing socio-economic diversity of the US population. Further, frameworks such as the Life Course Theory [23] and Social Ecological Model [24] emphasize the importance of multiple levels of determinants of human behavior, including individual-, interpersonal-, and community-level attributes and context. However, social and environmental correlates of physical activity and sedentary behavior during the retirement transition remain unexplored [18, 19, 25].

This research sequentially combines quantitative and qualitative studies to characterize physical activity and sedentary behavior during the retirement transition. First, we describe longitudinal patterns in overall and domain-specific physical activity and television (TV) watching by retirement status and SEP. Second, we identify correlates of within-person changes in recreational and transport walking after retirement, including individual-, interpersonal-, and community-level attributes. Third, we conduct semi-structured interviews with recently retired women to identify facilitators and barriers to physical activity after retirement. Together, the findings may inform the targeting of strategies to promote physical activity among retirementaged adults.

The health of retirement-aged adults is of increasing public health relevance. Older adults are among the fastest growing demographic groups in the United States (US) and projected to account for $20 \%$ of Americans by 2030, totaling 72 million people [26, 27]. Older adults also suffer a high burden of preventable chronic disease, including cardiovascular disease (CVD) and physical and cognitive impairments [27-29]. Therefore, promoting physical activity in later life may substantially contribute to health and wellbeing in communities in coming decades [30]. 


\section{CHAPTER 2: STATEMENT OF SPECIFIC AIMS}

Specific Aim 1: Describe longitudinal patterns in overall moderate-to-vigorous and domainspecific physical activity and TV watching among US adults by retirement status, overall and within strata of socioeconomic position.

Hypothesis 1.1: participation in non-walking leisure, household, and caring physical activity and walking for recreation will decrease less over time among retirees compared to workers.

Hypothesis 1.2: participation in walking for transportation and overall moderate-tovigorous physical activity (MVPA) will decrease more among retirees compared to workers.

Hypothesis 1.3: TV watching will increase more among retirees compared to workers.

Specific Aim 2: Identify individual-, interpersonal-, and community-level correlates of withinperson change in walking for recreation and walking for transportation before and after retirement among US adults who retired during follow-up.

Hypothesis 2.1: individual-level correlates of increased walking for recreation will include female gender, higher education, younger age at retirement, better self-rated health, and lower prior occupational physical activity.

Hypothesis 2.2: individual-level correlates of increased walking for transportation will include male gender, lower education, younger age at retirement, better self-rated health, and higher prior occupational physical activity. 
Hypothesis 2.3: interpersonal-level correlates of increased walking for recreation will include living with a partner and higher social support.

Hypothesis 2.4: interpersonal-level correlates of increased walking for transportation will include living with a partner.

Hypothesis 2.5: community-level correlates of increased walking for recreation will include living in a neighborhood with more walking destinations, more destinations for social engagement, more physical activity resources (parks and recreational facilities), greater street connectivity, and perceiving one's neighborhood to be safer, more socially cohesive, and more supportive of walking.

Hypothesis 2.6: community-level correlates of increased walking for transportation will include living in a neighborhood with more walking destinations, more destinations for social engagement, greater street connectivity, and perceiving one's neighborhood to be more supportive of walking.

Specific Aim 3: Identify facilitators and barriers to physical activity among recently retired women residing in Forsyth County, NC.

Research question 3.1: What are facilitators and barriers to physical activity after retirement?

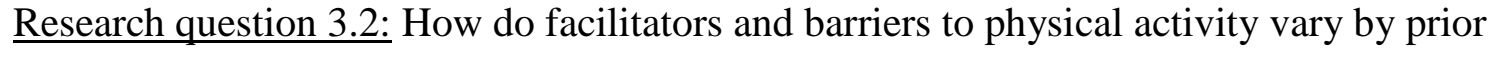
occupational physical activity level? 


\section{CHAPTER 3: BACKGROUND AND REVIEW OF THE LITERATURE}

\subsection{Conceptual Framework}

This research is informed by two theoretical frameworks: the Life Course Theory [23] and the Social Ecological Model [24]. The Life Course Theory provides a theoretical underpinning to understand behavior change at retirement. The Social Ecological Model distinguishes multiple levels of influence on human behavior, which can guide the development of physical activity interventions. Both frameworks emphasize connections between individual behavior with social and physical context, which may help us to understand physical activity and sedentary behavior during the retirement transition.

\subsubsection{The Life Course Theory}

In the Life Course Theory, retirement is a conceptualized as a transition. Transitions are defined as changes in state or role between durations of relative stability in a person's lived experience (e.g., working life) [23]. In the case of the retirement, the transition is characterized by reduction or loss of occupational routines, income, social contacts, and status [31, 32]. This alteration in personal and social obligations and identity may stimulate behavior changes, including in physical activity and sedentary behavior [23].

The principles of the Life Course Theory further suggest that individual, social, and geographical contexts may influence the impact of retirement on physical activity and sedentary behavior (Table 1). Variation at the individual level may be linked to the development of physical activity and sedentary behavior patterns over the lifespan, the timing of retirement at younger or older ages, and human agency within the constraints and opportunities of social 
Table 1. Definitions of the paradigmatic principles of life course theory and examples of how they may shape the behavioral consequences of retirement

\begin{tabular}{|c|c|c|}
\hline Principle & Definition $^{\text {a }}$ & Example \\
\hline $\begin{array}{l}\text { Life-span } \\
\text { development }\end{array}$ & $\begin{array}{l}\text { Patterns of late-life adaptation are linked to the } \\
\text { formative years of life course development. }\end{array}$ & $\begin{array}{l}\text { Continuation of earlier life physical activities after } \\
\text { retirement [33-35]. }\end{array}$ \\
\hline Timing & $\begin{array}{l}\text { The consequences of life transitions vary depending } \\
\text { on when they occur in life. }\end{array}$ & $\begin{array}{l}\text { Larger magnitude change in physical activity after } \\
\text { retirement among younger compared to older retirees } \\
\text { [36]. }\end{array}$ \\
\hline Agency & $\begin{array}{l}\text { Individuals construct their life course through the } \\
\text { choices they take within the opportunities and } \\
\text { constraints of history and social context. }\end{array}$ & $\begin{array}{l}\text { Differences in opportunities for and patterns of } \\
\text { physical activity after retirement by socio-economic } \\
\text { status [37]. }\end{array}$ \\
\hline Linked Lives & $\begin{array}{l}\text { Lives are lived interdependently, such that } \\
\text { transitions in one life entail transitions for others. }\end{array}$ & $\begin{array}{l}\text { Caregiving responsibilities limit post-retirement } \\
\text { physical activity [38]. }\end{array}$ \\
\hline $\begin{array}{l}\text { Time and } \\
\text { Place }\end{array}$ & $\begin{array}{l}\text { The life course of individuals is embedded in the } \\
\text { historical time and places they experience. }\end{array}$ & $\begin{array}{l}\text { Lack of access to physical activity facilities limits } \\
\text { physical activity after retirement [39]. }\end{array}$ \\
\hline
\end{tabular}

${ }^{\text {a }}$ Definitions adapted from [23]

context. In addition, because lives are lived interdependently and embedded within historical and geographical contexts, the behavioral consequences of retirement may vary depending on the cooccurrence of transitions among family members (e.g., spousal retirement, illness of relatives) and the characteristics of a place (e.g., availability of physical activity facilities).

\subsubsection{Social Ecological Model}

The Social Ecological Model identifies determinants of health behaviors at four levels from the individual- to the society-level (Figure 1) [1]. Individual-level determinants have been the focus of most research to date on physical activity and sedentary behavior during the retirement transition. However, interventions focused exclusively on individual-level determinants (e.g., knowledge or skills) are resource intensive and have limited effect on health behaviors at the population level [24]. In contrast, the US Community Preventive Task Force recommends changes to environments and policies at the community- and societylevels because of the potential to facilitate population-

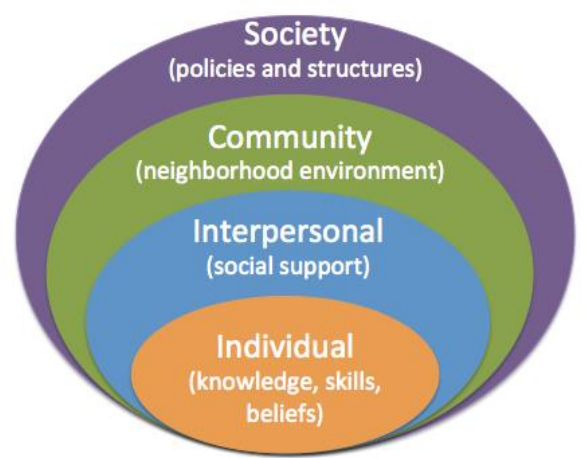

Figure 1. The Social Ecological Model (adapted from [1]) 
level shifts in behavior [40]. Moreover, interventions are most likely to effect change in health behaviors by targeting determinants from multiple levels [24]. To inform multi-level interventions, we need to better understand how interpersonal-, community-, and society-level factors may influence physical activity and sedentary behavior during the retirement transition [41].

\subsection{Physical Activity, Sedentary Behavior, and Health in Later Life}

Participation in regular physical activity is associated with numerous health benefits in later life. Physical activity lowers the risk of myocardial infarction, stroke, and diabetes [5, 42]. Physical activity also is associated with lower incidence of breast and colon cancer, fewer falls, and improved maintenance of physical functioning and independence into older ages [5, 6, 43]. Some of the pathways through which physical activity contributes to physical health include increased muscle strength, balance, fibrinolysis, and myocardial function, decreased myocardial work and oxygen demand, and improved energy balance and lipoprotein profile [44].

In addition to physical health benefits, a physically active lifestyle is associated with improved mental health. Participation in regular physical activity is associated with lower risk of depression and may help to prevent cognitive decline [6]. Structured physical activity among older adults is associated with improved happiness, self-efficacy, and physical self-concept [4547]. In light of these physical and mental health benefits, it is unsurprising that greater physical activity among older adults has been associated with reduced healthcare utilization and lower Medicare costs [48].

In contrast to physical activity, sedentary behavior is a risk factor for chronic disease, including CVD and diabetes [10, 49, 50]. Sedentary behavior involves prolonged periods of minimal energy expenditure. During sedentary behavior, lack of contractile muscle stimulation may lead to suppression of skeletal muscle lipoprotein lipase activity (reducing clearance of 
plasma triglycerides) and reduced glucose uptake [10]. Cross-sectional and longitudinal studies using accelerometer and self-reported measures of sedentary behavior have identified adverse associations between higher sedentary time and abnormal glucose metabolism, high density lipoprotein cholesterol, and waist circumference, including among physically active individuals $[10,51]$. These findings have led to calls for public health action to reduce sedentary behavior $[10,51,52]$.

\subsubsection{Prevalence of Physical Activity and Sedentary Behavior}

Many older Americans engage in behavior patterns that include little physical activity and large amounts of sedentary behavior on all days of the week [53]. Few older adults meet the 2008 Physical Activity Guidelines for Americans, which recommend $\geq 150$ minutes per week of aerobic MVPA and muscle strengthening activities involving all major muscle groups at least

twice per week [6]. The Guidelines specify that older adults with chronic conditions should "be as physically active as their abilities and conditions allow" because some physical activity is better than none [6]. In the most recent waves of the National Health and Nutrition Examination Survey (NHANES) for which accelerometer data were available (2005-2006), 6-9\% of adults aged 60 or older met the Guideline for aerobic physical activity, although estimates varied depending on the cut points applied $[54,55]$. Based on self-reported measures from the 20112012 NHANES, 2012 National Health Interview Survey (NHIS), and 2012 Behavioral Risk Factor Surveillance System (BRFSS), between $27 \%$ and $44 \%$ of older adults ( $\geq 65$ years) met national guidelines for aerobic physical activity and $17 \%$ to $22 \%$ met muscle strengthening guidelines [56]. Walking is the most commonly reported aerobic activity among older adults [57].

The prevalence of physical activity is lower among women compared to men. Older adult women are less likely than men to meet the aerobic and muscle strengthening physical activity 
guidelines [56]. In addition, women are more likely than men to reduce their physical activity as they age [58]. In the 2014 BRFSS, $26 \%$ of men and $29 \%$ of women aged $\geq 50$ reported no leisure-time physical activity [52]. The prevalence of walking also was lower among older women (55\%) compared to older men (62\%) in the 2015 NHIS [59].

In contrast to physical activity, sedentary behavior is highly prevalent. Americans aged 60 or older averaged 8.5 hours/day of sedentary behavior based on accelerometer data [55]. Common sedentary activities include watching TV, sitting at a desk, computer use, electronic games, and riding in cars [10]. TV watching is the most commonly reported sedentary behavior among older adults, and retirees report more TV watching than employed adults [35, 60, 61].

The low prevalence of physical activity and high prevalence of sedentary behavior among older adults have led to calls for public health action [30, 62]. Older adults suffer a high burden of preventable chronic disease and disability. Over one-third of older Americans reported some type of disease or disability in 2013; the most frequently reported conditions were: arthritis (49\%), heart diseases (31\%), cancer (25\%), diabetes (21\%), and hypertension (71\%) [63]. Interventions targeted to the retirement transition may help to reduce this burden of disease through promotion of physical activity and reduction of sedentary behavior in later life.

\subsection{Retirement}

Retirement is defined as withdrawal from one's occupation or working life. Retirement is shaped by social norms and policies (e.g., Social Security eligibility criteria), which may affect the timing, reasons for, and pattern of withdrawal from employment [64].

In the $20^{\text {th }}$ century, state institutions and growing wealth contributed to standardization of the timing of retirement [21]. Now, variability in the timing of retirement is increasing as policies to extend working life have been adopted and pension structures have weakened [2, 21]. The average retirement age has risen since the 1990s [65]. In 2010, American women retired on 
average at age 62 and men at age 64 [66]. Even as average retirement ages have risen, longer and healthier lives mean that retirement is decreasingly a marker of old age [67]. An American retiring at age 65 can now expect to live on average 18-20 years after retirement, compared to 13-15 years in 1950 [65]. Retirement also is less likely to be a permanent transition away from work. Approximately 15-25\% of older Americans return to the labor force after retiring, frequently motivated by a need for income $[45,68]$. In the current context, earlier life opportunities and disadvantages are major determinants of individuals' retirement decisions [2, 45, 67].

Common considerations for the timing of retirement in the US include health and healthcare costs, income, and wellbeing [45]. Poor health may require workers to retire earlier due to inability to continue working [45] or the need to care for family members [64]. However, workers may delay retirement if they anticipate high future healthcare costs or depend on their employer for health insurance [66]. On the other hand, good health can motivate workers to retire early while they are able to fully enjoy the freedoms of a retired lifestyle [45]. Regardless of health status, adequate retirement income is associated with earlier retirement [45]. Persons with dependent children at home, more debt, or lower income are more likely to delay retirement [64]. At the community level, higher unemployment may lead to earlier retirement among persons with low-income, in part due to involuntary job loss $[64,68]$. However, economic downturn was associated with delayed retirement among higher-income people [64]. Apart from health and income, workers also may be motivated to retire by a desire to spend more time with family or to coordinate retirement with a spouse [65]. 
In addition to variation in timing and reasons for retirement, there are also variations in patterns of retirement. Four typical retirement patterns were identified in the US Health and Retirement Study according to adults' employment status at age 50 to 75 (Figure 2) [2]. Gradual retirees (35\% of sample) worked full-time to age 62 or older, and then gradually declined in their rate of full-time work. This retirement pattern, also described as "phased retirement", is typically voluntary and increasingly popular in the US [45, 69]. The early retirement pattern (29\% of sample) was characterized by full-time work until age 62 followed by complete retirement [2]. Gradual and early retirees generally had more resources to control the timing of retirement. Intermittent workers (27\% of sample) experienced mixed unemployment, disability, part-, and full-time work until retiring by age 65 , when eligible for Medicare [2]. Intermittent workers were more likely to be women of color

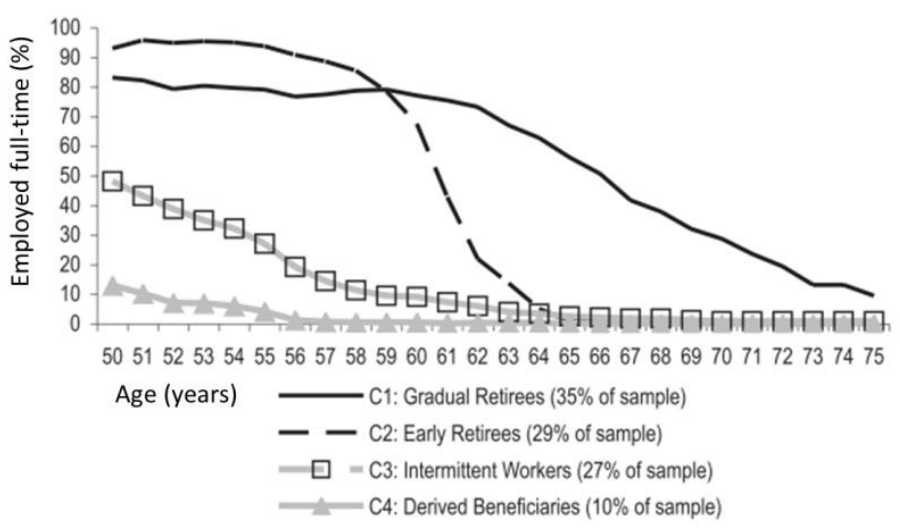

with lower levels of education. Derived Figure 2. Percent Employed Full-time by Age and Late-Life Latent Employment Trajectory, Health and Retirement Study beneficiaries $(10 \%$ of sample) received linked to Social Security earnings data (from [2]).

pension income primarily as dependent spouses of workers and were mostly women [2].

\subsubsection{Retirement and Behavior Change}

After retirement, adults may change their behavior in response to new daily routines, habits, social networks, and self-perceptions. For example, by relaxing time constraints, retirement may increase opportunities for engaging in physical activity and sedentary behavior $[16,70,71]$. Indeed, some retirees come to rely on physical activities to provide structure for post-retirement routines [46, 72]. Loss of work routine also can disrupt habits. Habits are semiautomatic responses to environmental cues that may be disrupted if new routines alter the 
environmental cues encountered [15]. Sedentary behavior may be highly habitual [73]. To date, there is little understanding of the factors that determine whether sedentary work time is replaced by active or sedentary pursuits after retirement [25].

For many adults, employment also provides routine social contact and may contribute to a sense of purpose in life [31, 32]. After retirement, engaging in group physical activities can help retirees to build and maintain social networks $[46,72]$. However, a weak social network may be a barrier to physical activity after retirement [31, 39]. Greater geographic movement and rising rates of divorce and childlessness may increase the number of people entering retirement with weak non-work social networks [46]. Also, retirement may prompt unconscious or conscious reappraisal of self [11]. Recent retirees reported sudden increased awareness of aging and increased concerns for health and independence [12]. Some retirees respond by prioritizing health, including physical activity, to slow physical and mental declines [12]. However, other retirees felt that it was too late to adopt a physically active lifestyle because of health concerns or social norms that emphasized sedentariness in later life or put a low value on leisure physical activity $[15,34,70,74]$.

Thus, alteration of routines, habits, social networks, and self-perceptions during the retirement transition may prompt adjustments in physical activity and sedentary behavior. Interventions targeted to this period could help to promote more positive behavior changes to facilitate physically active lifestyles after retirement.

\subsubsection{Intervention during the Retirement Transition}

There is precedence for the effectiveness of health promotion among retirees [75]. A multi-component intervention improved self-reported physical activity over a 2 -year period (1988-1990) among Bank of America retirees [76]. The Experience Corps intervention also improved perceived social support, physical activity, and strength among retirees $[77,78]$. 
However, recent systematic reviews identified only one physical activity intervention since 1990 specifically targeted to the retirement transition $[39,79]$. In this cluster randomized controlled trial, Dutch men $(\mathrm{N}=352)$ and women $(\mathrm{N}=61)$ aged 55 to 65 years were recruited in preretirement workshops offered by employers [80]. The intervention comprised five modules on energy balance, diet, and physical activity delivered over a 12-month period. Modules included printed and electronic resources, a pedometer, personalized feedback, and an online program. The control group received regular newsletters. Physical activity was assessed by questionnaire (Physical Activity Scale for the Elderly) at baseline, 12-, and 24-months follow-up. On average, participants in both the intervention and control groups increased their physical activity and differences between the groups were small and mostly not statistically significant. The authors concluded that participation in research or the impact of retirement overshadowed the intervention effect. Recall bias also may have occurred. A pilot study of a web-based intervention to promote physical activity, healthy eating, and social engagement also showed promising feasibility and acceptability in British men and women [81].

More research is needed to provide evidence of how interventions targeting the retirement transition retirement could support a physically active lifestyle among growing retiree populations [39]. Physical activity interventions targeted to adults age 55-69 years often have not reported on the retirement status of participants [39]. Qualitative studies provide insight into promising strategies including emphasizing multiple benefits of physical activity (e.g., social connectedness, self-efficacy and independence, fall prevention, health), promoting continuation of life long activities, and using short bouts to fit busy schedules [12, 39]. Barriers reported by retirees that could be addressed include lack of access to high-quality, affordable physical activity resources, lack of social support, and the belief that it is too late to change behaviors or 
feelings of embarrassment $[31,39]$. In communities where leisure-time physical activity is not normative or valued, interventions could focus on community improvement projects [12, 74]. Health promotion also could be incorporated into retirement planning resources [82]. Many employers offer financially focused retirement planning resources and programs [45]. These programs could be expanded to help workers plan for post-retirement physical activity [17, 31]. However, racial/ethnic minorities and women may have less access to retirement planning resources and be more likely to retire without the opportunity to plan (e.g., unexpected retirement due to poor health, layoff, or family illness) [45]. Thus, multiple strategies, including community-based interventions, may be needed to avoid exacerbation of health inequities.

\subsection{Physical Activity during the Retirement Transition}

Physical activity during the pre- to post-retirement period has been described in longitudinal observational studies. A systematic review identified 19 articles published through July 2010 [19]. Thirteen additional articles were published since this review [22, 32, 36, 70, 8391] (Table 2). Most of these 32 articles evaluated self-reported leisure-time physical activity among adults who retired during follow-up compared to those who continued working. Retirement was associated with increased participation leisure-time physical activity. Common physical activities practiced by retirees were walking, gardening, and yard work [92].

In the combined literature to date, the association between retirement and overall physical activity remains unclear because some domains of physical activity were not commonly measured. Many studies focused on a single summary measure of leisure-time MVPA. Only three studies included measures of domain-specific physical activity $[83,86,90]$. Retirement was associated with increased household physical activity among British and French retirees [83, 86], and decreased transport physical activity among British retirees [83]. Longitudinal changes in household and transport physical activity did not differ between Belgian adults who retired 
during follow-up compared to adults retired at baseline [90]. In studies without measures of occupational and other non-leisure physical activity (e.g., transport), it is not clear whether increased leisure-time physical activity after retirement was sufficient to compensate for the loss of occupational physical activity [19].

\subsubsection{Correlates of Physical Activity at Retirement}

Individual-level correlates of leisure-time physical activity during the retirement transition were explored in some quantitative studies (Table 2). The direction of association between retirement and leisure-time physical activity may differ by socioeconomic position (SEP) $[37,70,83,88,90]$ and prior occupational physical activity [19, 83]. Leisure-time physical activity increased after retirement among persons of high SEP or retiring from sedentary jobs whereas it decreased among persons of low SEP or retiring from physically demanding jobs. However, three studies did not find differences by education or SEP [84, 85, 87]. In addition, leisure-time physical activity increases were greater among younger compared to older retirees $[36,87]$ and men compared to women $[19,83,89]$, although these differences were not consistently identified across studies [36, 70, 84, 87, 88, 90, 91, 93]. Health [88], race/ethnicity [92], and reason for retirement $[22,88,94]$ also may be correlates of physical activity at retirement. For example, early retirement due to poor health or disability may be associated with decreased physical activity [22].

In addition, one study of 180 Belgian adults explored 18 psychosocial, interpersonal-, and community-level correlates of self-reported physical activity during the retirement transition [95]. Increased active transportation after retirement was associated with higher residential density and lower aesthetics, and increased leisure-time physical activity after retirement was associated with higher self-efficacy. Social support, neighborhood social cohesion, land use mix diversity and access, street connectivity, cycling / walking infrastructure, and traffic and crime 
safety were not statistically significantly associated with changes in transport or leisure-time physical activity. There were no differences in correlates by gender, but there was limited variation by education level. No other quantitative studies have investigated interpersonal- or community-level correlates of physical activity during the retirement transition.

\subsubsection{Qualitative Studies of Physical Activity during the Retirement Transition}

Qualitative studies, primarily in the United Kingdom, also explored physical activity during the retirement transition. Three themes identified by a systematic review included: conceptualization of physical activity, motives for physical activity after retirement, and barriers to physical activity after retirement [12]. Retirees conceptualized physical activity as encompassing both recreation and household chores. Motives for being physically active after retirement included expected health benefits, continuation of lifelong patterns of physical (in)activity, and broader benefits such as establishing a new routine or social connection. Reasons for physical inactivity after retirement included lack of time, believing it was too late to become physically active, and a low personal value on physical activity. Ten recent qualitative studies published after the systematic review supported these conclusions (Table 3) [11, 16, 17, 31, 38, 72, 96-99]. Recent studies also highlighted the importance of social support [17, 72, 96] and access to high-quality, affordable physical activity facilities [16, 17, 38, 99] as facilitators of post-retirement physical activity. Additional barriers to physical activity after retirement identified in recent studies include low income $[11,16,31,96]$ and higher levels of prior occupational physical activity $[98,99]$. 
Among studies included in the systematic review and published since, most used a semistructured interview format (five included focus groups) and only one was conducted in the US (among 15 older adult members of a fitness center) [12,33]. Participants in qualitative studies were predominately non-Hispanic white and of middle to higher socio-economic status (professional and managerial professions and college educated) [12, 15, 17, 31, 38, 96-98], with persons of lower income better represented in two recent studies [16, 72]. 
Table 2. Recent longitudinal quantitative studies of physical activity at retirement ${ }^{\text {a }}$

\begin{tabular}{|c|c|c|c|c|c|c|}
\hline $\begin{array}{l}\text { Author } \\
\text { (Year) } \\
\text { Journal }\end{array}$ & $\begin{array}{l}\text { Location } \\
\text { (Dates) } \\
\text { Cohort }\end{array}$ & $\begin{array}{l}\text { Participants } \\
\text { (N, age, gender, } \\
\text { retirement status) }\end{array}$ & $\begin{array}{l}\text { Physical activity } \\
\text { (no. times measured) }\end{array}$ & $\begin{array}{l}\text { Retirement } \\
\text { to PA } \\
\text { measure }\end{array}$ & Modifiers & Main findings \\
\hline $\begin{array}{l}\text { Barnett et al. } \\
(2013) \\
\text { J Epidemiol } \\
\text { Comm Health } \\
\text { [83] }\end{array}$ & $\begin{array}{l}\text { United } \\
\text { Kingdom } \\
(1997-2007) \\
\text { EPIC- } \\
\text { Norfolk }\end{array}$ & $\begin{array}{l}\mathrm{N}=3,334 \\
\sim 55 \text { years } \\
52 \% \text { female } \\
\text { All employed at } \\
\text { baseline, } 785 \text { retired } \\
\text { during follow-up }\end{array}$ & $\begin{array}{l}\text { Self-reported frequency \& duration } \\
\text { Household } \\
\text { Transport } \\
\text { Recreational } \\
\text { Occupational } \\
\text { (2) }\end{array}$ & $\begin{array}{l}\text { mean } 3.5 \\
\text { years from } \\
\text { retirement }\end{array}$ & $\begin{array}{l}\text { Sex } \\
\text { Social class } \\
\text { (occupation) }\end{array}$ & $\begin{array}{l}\text { Decline in overall, transport, and occupational physical } \\
\text { activity } \\
\text { Greater declines among manual compared to non-manual } \\
\text { social classes and men compared to women } \\
\text { Increase in recreational and household physical activity } \\
\text { Greater increases among men compared to women }\end{array}$ \\
\hline
\end{tabular}

$\begin{array}{llll}\begin{array}{l}\text { Ding et al. } \\ \text { (2016) }\end{array} & \begin{array}{l}\text { Australia } \\ (2006-2010)\end{array} & \begin{array}{l}\mathrm{N}=27,257 \\ \text { mean } 55 \text { years }\end{array} & \begin{array}{l}\text { Self-reported total time (Active } \\ \text { Australia Questionnaire) }\end{array} \\ \begin{array}{ll}\text { Am J Prev } \\ \text { Med [36] }\end{array} & \text { SEEF } & \begin{array}{l}\text { W0\% female } \\ \text { All employed at } \\ \text { baseline, 3,106 retired } \\ \text { during follow-up }\end{array} & \begin{array}{l}\text { Moderate physical activity } \\ \text { Vigorous physical activity } \\ \text { (bouts } \geq 10 \text { min) }\end{array}\end{array}$

Feng et al. US N=5,754

(2016) (2004-2010) mean 58 years

BMC Public HRS $53 \%$ female

Health [22] All employed at

baseline, $10 \%$ fully

and $7 \%$ partly retired

at follow-up

\begin{tabular}{|c|c|c|}
\hline $\begin{array}{l}\text { Holstila et al. } \\
\text { (2017) }\end{array}$ & $\begin{array}{l}\text { Finland } \\
(2000-2012)\end{array}$ & $\begin{array}{l}\mathrm{N}=2902 \\
\text { mean } 54 \text { years }\end{array}$ \\
\hline BMC Public & Helsinki & $79 \%$ female \\
\hline Health [91] & $\begin{array}{l}\text { Health } \\
\text { Study }\end{array}$ & $\begin{array}{l}\text { All employed at } \\
\text { baseline, } 851 \text { retir } \\
\text { during follow-up }\end{array}$ \\
\hline $\begin{array}{l}\text { Kampfen \& } \\
\text { Maurer }\end{array}$ & $\begin{array}{l}\text { US } \\
(2004-2010)\end{array}$ & $\begin{array}{l}\mathrm{N}=13,491 \\
\text { mean } 65 \text { years }\end{array}$ \\
\hline (2015) & HRS & $57 \%$ female \\
\hline
\end{tabular}

(2)

Self-reported frequency $(<2$

times/wk vs. $\geq 2$ times/wk) of 3

intensity categories

Vigorous

Moderately energetic

(2)

Mildly energetic physical activity
$<3.3$ years Age

Sex

vs. non-retirees) and moderate physical activity (59 vs. 24

Urban/rural $\mathrm{min} / \mathrm{wk})$. No difference in change in vigorous physical Education activity (1 vs. $-4 \mathrm{~min} / \mathrm{wk}$ )

Country of birth Larger effect among younger participants and those who Work hours/wk at worked full time before retirement baseline

Self-reported frequency \& duration > 6 months Sex of leisure-time MVPA (min/week)

Self-reported frequency \& intensity Estimated compliance with 2008

Guidelines based on leisure-time

(mean 3.5)
Education
Sex

Wealth

(disability, semi- least active at baseline

retirement, full- Odds of $\geq 2$ time/wk increased at all physical activity retirement) intensity levels among persons transitioning to full or semi-retirement and decreased among persons leaving work due to disability compared to those who remained employed

Retirement associated with 15 to $30 \mathrm{~min} /$ week increase in leisure-time MVPA

Among persons who retired in first follow-up period, increased MVPA did not persist in second follow-up period

No modification by sex

$37 \%$ increased probability of meeting 2008 Physical Activity Guidelines after compared to before retirement Increase greater among most educated and most wealthy No modification by sex 


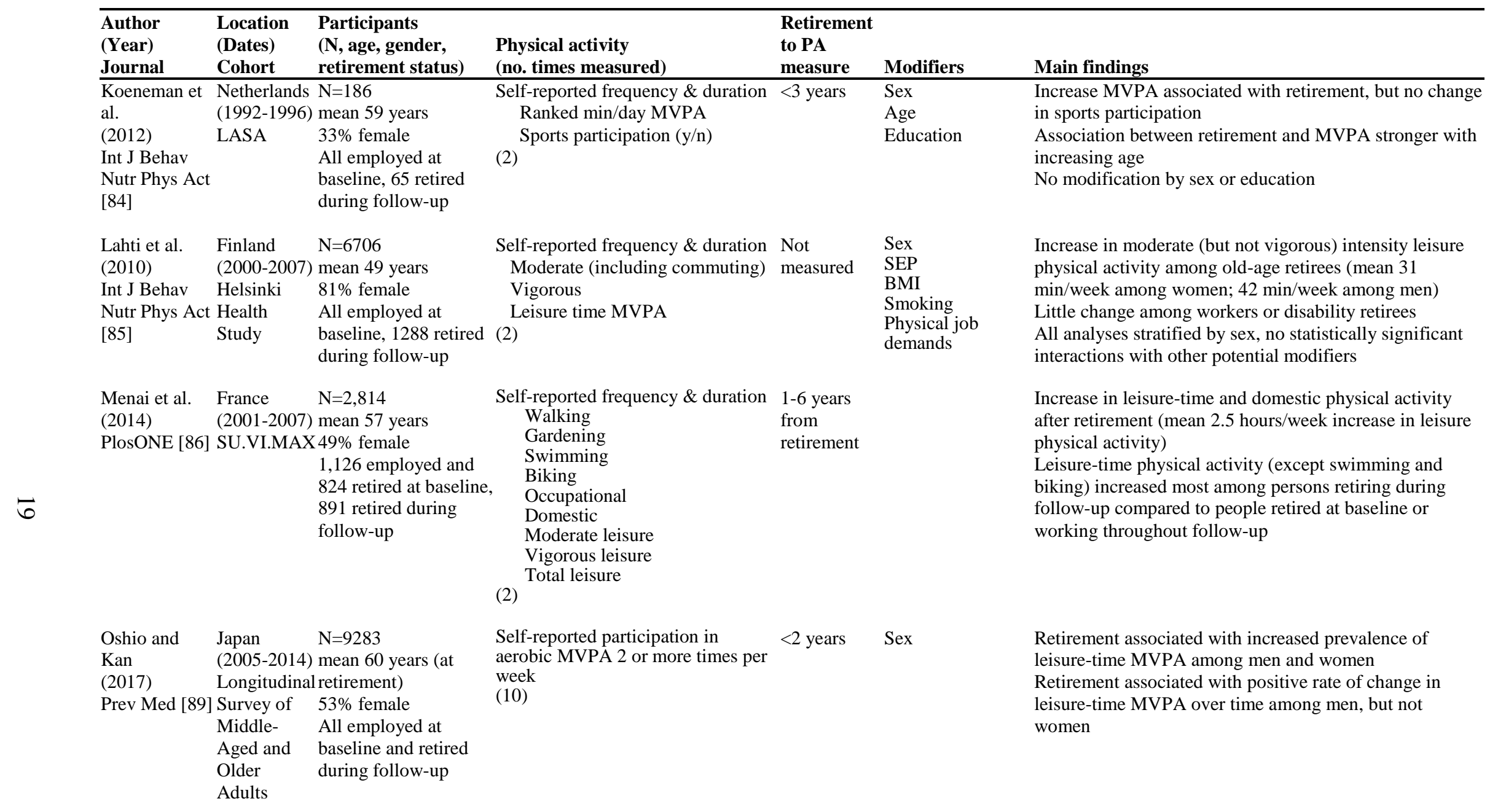




\begin{tabular}{|c|c|c|c|c|c|c|}
\hline $\begin{array}{l}\text { Author } \\
\text { (Year) } \\
\text { Journal }\end{array}$ & $\begin{array}{l}\text { Location } \\
\text { (Dates) } \\
\text { Cohort }\end{array}$ & $\begin{array}{l}\text { Participants } \\
\text { (N, age, gender, } \\
\text { retirement status) }\end{array}$ & $\begin{array}{l}\text { Physical activity } \\
\text { (no. times measured) }\end{array}$ & $\begin{array}{l}\text { Retirement } \\
\text { to PA } \\
\text { measure }\end{array}$ & Modifiers & Main findings \\
\hline $\begin{array}{l}\text { Sjosten et al. } \\
\text { (2012) } \\
\text { BMJ Open } \\
{[87]}\end{array}$ & $\begin{array}{l}\text { France } \\
(2000-2008) \\
\text { GAZEL }\end{array}$ & $\begin{array}{l}\mathrm{N}=3,812 \\
\text { mean } 56-58 \text { years at } \\
\text { retirement } \\
25-37 \% \text { female } \\
\text { All employed at } \\
\text { baseline and retired } \\
\text { during follow-up }\end{array}$ & $\begin{array}{l}\text { Self-reported } \\
\text { Walking } \geq 5 \text { vs. }<5 \mathrm{~km} / \mathrm{wk} \\
\text { Leisure-time sport activity: } \\
\text { (some vs. none, moderate vs. } \\
\text { low frequency, group vs. alone) } \\
\text { (3) }\end{array}$ & $\begin{array}{l}\text { 1-4 years } \\
\text { from } \\
\text { retirement }\end{array}$ & $\begin{array}{l}\text { Sex } \\
\text { Socio-economic } \\
\text { status } \\
\text { Age } \\
\text { Fatigue } \\
\text { Work demands } \\
\text { BMI } \\
\text { Smoking } \\
\text { Depression }\end{array}$ & $\begin{array}{l}\text { Prevalence of walking } \geq 5 \mathrm{~km} / \text { wk was higher after vs. } \\
\text { before retirement, large difference among women } \\
\text { compared to men } \\
\text { Odds of participating in sport, moderate frequency of } \\
\text { sport, and group sport were higher after vs. before } \\
\text { retirement }\end{array}$ \\
\hline $\begin{array}{l}\text { Stenholm et } \\
\text { al. } \\
(2016) \\
\text { Int J Behav } \\
\text { Nutr Phys Act } \\
\text { [88] }\end{array}$ & $\begin{array}{l}\text { Finland } \\
(2000-2013) \\
\text { Finnish } \\
\text { Public } \\
\text { Sector Study }\end{array}$ & $\begin{array}{l}\mathrm{N}=9,488 \\
\text { mean } 60 \text { years } \\
80 \% \text { female } \\
\text { All employed at } \\
\text { y baseline and retired } \\
\text { during follow-up }\end{array}$ & $\begin{array}{l}\text { Self-reported leisure and commuting } \\
\text { activity } \\
\text { Moderate physical activity } \\
\text { Vigorous physical activity } \\
\text { Total leisure activity (MET) } \\
\text { (4) }\end{array}$ & g 2-10 years & $\begin{array}{l}\text { Age } \\
\text { Sex } \\
\text { Occupational } \\
\text { status } \\
\text { Number of chronic } \\
\text { conditions }\end{array}$ & $\begin{array}{l}\text { Statutory retirement (but not disability or part-time } \\
\text { retirement) associated with increased moderate (but not } \\
\text { vigorous) physical activity in the } 4 \text { year peri-retirement } \\
\text { period } \\
\text { Older retirement age, higher occupational status, and } \\
\text { fewer chronic diseases associated with greater increase }\end{array}$ \\
\hline $\begin{array}{l}\text { Syse et al. } \\
\text { (2015) } \\
\text { J Aging and } \\
\text { Health [32] }\end{array}$ & $\begin{array}{l}\text { Norway } \\
(2002-2007) \\
\text { NorLAG }\end{array}$ & $\begin{array}{l}\mathrm{N}=426 \\
\text { mean } 65 \text { years (at } \\
\text { retirement) } \\
47 \% \text { female } \\
\text { All employed at } \\
\text { baseline, } 267 \text { retired } \\
\text { during follow-up }\end{array}$ & $\begin{array}{l}\text { Self-reported } \\
\text { Active (weekly indoor or daily } \\
\text { outdoor physical activity) vs. } \\
\text { inactive } \\
\text { (2) }\end{array}$ & 2 years & & $\begin{array}{l}\text { Compared to remaining employed, more retirees reported } \\
\text { an increase in outdoor activity and more retirees reported } \\
\text { a larger magnitude increase in physical activity }\end{array}$ \\
\hline $\begin{array}{l}\text { Van Dyck et } \\
\text { al. } \\
(2016) \\
\text { BMC Public } \\
\text { Health } \\
{[90]}\end{array}$ & $\begin{array}{l}\text { Belgium } \\
(2012-2015)\end{array}$ & $\begin{array}{l}\mathrm{N}=446 \\
\text { mean } 62 \text { years } \\
47 \% \text { female } \\
341 \text { retired at baseline, } \\
105 \text { retired during } \\
\text { follow-up }\end{array}$ & $\begin{array}{l}\text { Self-reported frequency \& duration } \\
\text { (International Physical Activity } \\
\text { Questionnaire) } \\
\text { Transport cycling } \\
\text { Transport walking } \\
\text { Household activity } \\
\text { Gardening MVPA } \\
\text { Volunteer/work walking } \\
\text { Volunteer/work MVPA } \\
\text { Leisure cycling } \\
\text { Leisure walking } \\
\text { Leisure MVPA } \\
\text { (2) }\end{array}$ & $\begin{array}{l}>6 \text { months to } \\
<5 \text { years }\end{array}$ & $\begin{array}{l}\text { Sex } \\
\text { Education }\end{array}$ & $\begin{array}{l}\text { Leisure cycling increased among adults who retired } \\
\text { during follow-up but decreased among adults retired at } \\
\text { baseline } \\
\text { (Volunteer) work-related walking and MVPA decreased } \\
\text { among adults retiring during follow-up but increased } \\
\text { slightly among adults retired at baseline } \\
\text { Transport cycling and walking, gardening, and leisure } \\
\text { walking and MVPA did not differ between adults retired } \\
\text { at baseline and during follow-up } \\
\text { Largest decrease in transport walking among least } \\
\text { educated adults who retired during follow-up } \\
\text { Almost no moderating effects of sex }\end{array}$ \\
\hline
\end{tabular}

Abbreviations: BMI body mass index; MVPA: moderate-to-vigorous physical activity; PA physical activity; SEP socioeconomic position

a Table restricted to longitudinal quantitative studies published since July, 2010 to capture studies not included in most recent systematic review [19] 
Table 3. Recent qualitative studies of physical activity in relation to retirement ${ }^{\mathrm{a}}$

\begin{tabular}{|c|c|c|c|c|c|}
\hline $\begin{array}{l}\text { Author } \\
\text { (Year) } \\
\text { Journal }\end{array}$ & $\begin{array}{l}\text { Location } \\
\text { Setting }\end{array}$ & $\begin{array}{l}\text { Participants } \\
\text { (N, age, gender, } \\
\text { retirement status) }\end{array}$ & Aims & Design & Conclusions \\
\hline $\begin{array}{l}\text { Berg et al. } \\
\text { (2014) } \\
\text { J Transport } \\
\text { Geog [16] }\end{array}$ & $\begin{array}{l}\text { Sweden } \\
\text { Pensioner } \\
\text { association } \\
\text { and large } \\
\text { employer }\end{array}$ & $\begin{array}{l}\mathrm{N}=24 \\
61-67 \text { years } \\
50 \% \text { women } \\
\text { All retired } \sim 1 \text { year }\end{array}$ & $\begin{array}{l}\text { Explore mobility } \\
\text { patterns in transition to } \\
\text { retirement, influence of } \\
\text { space-time constraints } \\
\text { on meaning and } \\
\text { experience of mobility }\end{array}$ & $\begin{array}{l}\text { Semi- } \\
\text { structured } \\
\text { interviews } \\
\text { Travel } \\
\text { diaries }\end{array}$ & $\begin{array}{l}\text { Mobility used to structure day (conscious choice rather than routine) } \\
\text { Facilitators: proximity to destinations, health benefits, leaving the house } \\
\text { Barriers: reliance on others, health concerns, lower income, limited } \\
\text { transportation options }\end{array}$ \\
\hline $\begin{array}{l}\text { Barnett et al. } \\
\text { (2013) } \\
\text { BMC Public } \\
\text { Health [72] }\end{array}$ & $\begin{array}{l}\text { United } \\
\text { Kingdom } \\
\text { EPIC-Norfolk } \\
\text { study } \\
\text { participants }\end{array}$ & $\begin{array}{l}\mathrm{N}=14 \\
63-70 \text { years } \\
50 \% \text { women } \\
\text { All retired 2-6 years }\end{array}$ & $\begin{array}{l}\text { Describe how couples } \\
\text { influence each other's } \\
\text { physical activity in } \\
\text { retirement }\end{array}$ & $\begin{array}{l}\text { Semi- } \\
\text { structured } \\
\text { interviews }\end{array}$ & $\begin{array}{l}\text { Active persons had lifelong active habits } \\
\text { Spouses provide provided encouragement, understanding, and practical } \\
\text { support but were not active together due to different goals (personal } \\
\text { challenge vs. social support) and appreciation of time apart }\end{array}$ \\
\hline $\begin{array}{l}\text { Carmichael et al. } \\
\text { (2014) } \\
\text { Sport in Society } \\
{[38]}\end{array}$ & $\begin{array}{l}\text { United } \\
\text { Kingdom } \\
\text { Age and } \\
\text { Employment } \\
\text { Network }\end{array}$ & $\begin{array}{l}\mathrm{N}=30 \\
51-76 \text { years } \\
100 \% \text { women } \\
10 \text { retired, } 12 \text { semi- } \\
\text { retired, } 8 \text { working }\end{array}$ & $\begin{array}{l}\text { Explore the relationship } \\
\text { between work and } \\
\text { physical activity and } \\
\text { factors that enable, } \\
\text { motivate and constrain } \\
\text { activity }\end{array}$ & $\begin{array}{l}\text { Semi- } \\
\text { structured } \\
\text { interviews }\end{array}$ & $\begin{array}{l}\text { Enablers for participation in physical activity were linked to motivation } \\
\text { while barriers were often linked to supply-side factors } \\
\text { Facilitators: socializing, enjoyment, health, past experiences with activity, } \\
\text { support from friends or family (or dogs) } \\
\text { Barriers: lack of friends to participate with, limited opportunities or lack of } \\
\text { facilities, caring responsibilities, ill health, lack of time due to work }\end{array}$ \\
\hline $\begin{array}{l}\text { Heaven et al. } \\
\text { (2014) } \\
\text { Gerontologist } \\
\text { [97] }\end{array}$ & $\begin{array}{l}\text { United } \\
\text { Kingdom } \\
\text { Employer and } \\
\text { national } \\
\text { charity }\end{array}$ & $\begin{array}{l}\mathrm{N}=48 \\
53-77 \text { years } \\
71 \% \text { women } \\
34 \text { retired (2-18 } \\
\text { years), } 4 \text { working } \\
\text { reduced hours, } 10 \\
\text { working }\end{array}$ & $\begin{array}{l}\text { Explore views on health } \\
\text { and well-being through } \\
\text { the retirement transition } \\
\text { and acceptability of } \\
\text { intervening during this } \\
\text { period }\end{array}$ & $\begin{array}{l}\text { Focus } \\
\text { groups } \\
(\mathrm{N}=6), \\
\text { individual } \\
(\mathrm{N}=13) \& \\
\text { dyad } \\
(\mathrm{N}=4) \\
\text { interviews }\end{array}$ & $\begin{array}{l}\text { Diverse retirement transitions were shaped by unanticipated events. The } \\
\text { ability to use resources to achieve desired outcomes is central to wellbeing } \\
\text { Lifestyle interventions that address challenges within the retirement } \\
\text { transition and provide assistance to use resources to address personal goals } \\
\text { may be acceptable. Inducements to change behavior based on possible } \\
\text { long-term outcomes may be less appealing }\end{array}$ \\
\hline $\begin{array}{l}\text { Kenter et al. } \\
\text { (2015) } \\
\text { Psych Health } \\
\text { [11] }\end{array}$ & $\begin{array}{l}\text { Netherlands } \\
\text { Older adult } \\
\text { community } \\
\text { organizations }\end{array}$ & $\begin{array}{l}\mathrm{N}=17 \\
60-82 \text { years } \\
59 \% \text { women } \\
2 \text { retired }\end{array}$ & $\begin{array}{l}\text { Explore the influence of } \\
\text { life events at older ages, } \\
\text { earlier life experience, } \\
\text { and current and future } \\
\text { self-conceptions on } \\
\text { physical activity }\end{array}$ & $\begin{array}{l}\text { Semi- } \\
\text { structured } \\
\text { interviews }\end{array}$ & $\begin{array}{l}\text { How physical activity changed after life events depended on physical } \\
\text { activity in earlier life and perceptions of aging / future } \\
\text { Active persons had lifelong active habits or saw activity as essential to lead } \\
\text { their current life } \\
\text { Inactive persons found barriers insurmountable or did not believe physical } \\
\text { activity was necessary at older ages } \\
\text { Barriers: lower income, lack of opportunities or companions, social norms }\end{array}$ \\
\hline
\end{tabular}




\begin{tabular}{|c|c|c|c|c|c|}
\hline $\begin{array}{l}\text { Author } \\
\text { (Year) } \\
\text { Journal } \\
\end{array}$ & $\begin{array}{l}\text { Location } \\
\text { Setting }\end{array}$ & $\begin{array}{l}\text { Participants } \\
\text { ( } \mathrm{N}, \text { age, gender, } \\
\text { retirement status) }\end{array}$ & Aims & Design & Conclusions \\
\hline $\begin{array}{l}\text { Kosteli et al. } \\
\text { (2016) } \\
\text { Psych Health } \\
\text { [96] }\end{array}$ & $\begin{array}{l}\text { United } \\
\text { Kingdom } \\
\text { Local } \\
\text { community } \\
\text { organizations }\end{array}$ & $\begin{array}{l}\mathrm{N}=37 \\
54-79 \text { years } \\
46 \% \text { women } \\
13 \text { retired }<1 \text { year or } \\
\text { will retire in }<3 \text { years } \\
18 \text { retired } 2-5 \text { years } \\
6 \text { retired }>10 \text { years }\end{array}$ & $\begin{array}{l}\text { Understand reasons and } \\
\text { motives for some } \\
\text { retired individuals to be } \\
\text { sufficiently active while } \\
\text { others are not }\end{array}$ & $\begin{array}{l}\text { Focus } \\
\text { groups } \\
(\mathrm{N}=7)\end{array}$ & $\begin{array}{l}\text { Major determinants of physical activity: self-efficacy beliefs and } \\
\text { perceptions of benefits and barriers to physical activity (which varied by } \\
\text { activity level) } \\
\text { Important motivators: social support, positive outcome expectations and } \\
\text { self-regulatory strategies } \\
\text { Barrier: lack of time/structure in daily routine, pain, adverse weather, lack } \\
\text { of exercise partners, financial constraints }\end{array}$ \\
\hline $\begin{array}{l}\text { Lietchy et al. } \\
\text { (2017) } \\
\text { Ann Leisure Res } \\
{[98]}\end{array}$ & $\begin{array}{l}\text { Canada } \\
\text { Public } \\
\text { community } \\
\text { spaces and } \\
\text { local } \\
\text { employers }\end{array}$ & $\begin{array}{l}\mathrm{N}=25 \\
47-66 \text { years } \\
80 \% \text { women } \\
\sim 50 \% \text { retired }\end{array}$ & $\begin{array}{l}\text { Explore everyday } \\
\text { experiences of } \\
\text { physically active leisure } \\
\text { during the transition to } \\
\text { retirement }\end{array}$ & $\begin{array}{l}\text { Blogs } \\
(\mathrm{N}=3) \& \\
\text { focus } \\
\text { groups } \\
(\mathrm{N}=5 \text { with } \\
16 \text { adults })\end{array}$ & $\begin{array}{l}\text { Increased freedom in daily schedules associated with appreciation of } \\
\text { spontaneity and desire for structure. } \\
\text { Physical activity was one of multiple health priorities and leisure options } \\
\text { Physical activity more likely continued if connected to meaningful } \\
\text { outcomes (enjoying the outdoors, stress relief, socializing, dog walking) } \\
\text { Barriers: loss of social networks and work-related physical activity }\end{array}$ \\
\hline $\begin{array}{l}\text { McDonald et al. } \\
\text { (2015) } \\
\text { Int J Behav Nutr } \\
\text { Phys Act [17] }\end{array}$ & $\begin{array}{l}\text { United } \\
\text { Kingdom } \\
\text { Community } \\
\text { sample }\end{array}$ & $\begin{array}{l}\mathrm{N}=28 \\
55-67 \text { years } \\
54 \% \text { women } \\
15 \text { retired, } 13 \\
\text { working + within } 2 \\
\text { years of retirement }\end{array}$ & $\begin{array}{l}\text { Explore and compare } \\
\text { perceptions of factors } \\
\text { that impact physical } \\
\text { activity during the } \\
\text { retirement transition }\end{array}$ & $\begin{array}{l}\text { Semi- } \\
\text { structured } \\
\text { interviews }\end{array}$ & $\begin{array}{l}\text { Most people anticipated or experienced increased physical activity after } \\
\text { retirement } \\
\text { Facilitators: increased time, energy, fewer conflicting goals, increased } \\
\text { availability of resources for physical activity, likeminded friends } \\
\text { Barriers: loss of daily structure, competing obligations }\end{array}$ \\
\hline $\begin{array}{l}\text { Smeaton et al. } \\
\text { (2016) } \\
\text { J Aging Health } \\
\text { [31] }\end{array}$ & $\begin{array}{l}\text { United } \\
\text { Kingdom } \\
\text { Community } \\
\text { sample }\end{array}$ & $\begin{array}{l}\mathrm{N}=55 \\
54-70 \text { years } \\
40 \% \text { women } \\
\text { Working with plan to } \\
\text { retire within } 1 \text { year }\end{array}$ & $\begin{array}{l}\text { Establish whether the } \\
\text { transition to retirement } \\
\text { is anticipated or } \\
\text { planned to include } \\
\text { changes in health } \\
\text { behaviors }\end{array}$ & $\begin{array}{l}\text { Semi- } \\
\text { structured } \\
\text { interviews } \\
\text { and time } \\
\text { use grid }\end{array}$ & $\begin{array}{l}\text { Retirement viewed either as an opportunity for change or expected to make } \\
\text { little difference in health behaviors (other life events had already resulted in } \\
\text { changed behavior, or satisfied with current patterns) } \\
\text { Facilitators: increased time } \\
\text { Barriers: lack of companions, living alone, lack of access, bad weather, } \\
\text { limited income, lack of enjoyment of physical activity }\end{array}$ \\
\hline $\begin{array}{l}\text { Van Dyck et al. } \\
(2016) \\
\text { J Aging Phys } \\
\text { Act } \\
\text { [99] }\end{array}$ & $\begin{array}{l}\text { Belgium } \\
\text { Subsample of } \\
\text { participants in } \\
\text { longitudinal } \\
\text { study }\end{array}$ & $\begin{array}{l}\mathrm{N}=37 \\
\text { Mean } 63 \text { years } \\
51 \% \text { women } \\
\text { Retired }>6 \text { months } \\
\text { and }<5 \text { years }\end{array}$ & $\begin{array}{l}\text { Identify determinants of } \\
\text { physical activity } \\
\text { during early retirement, } \\
\text { opinions on existing } \\
\text { physical activity } \\
\text { interventions, and needs } \\
\text { and wishes regarding } \\
\text { new interventions }\end{array}$ & $\begin{array}{l}\text { Focus } \\
\text { groups } \\
(\mathrm{N}=4)\end{array}$ & $\begin{array}{l}\text { Changes in physical activity at retirement depended on earlier life leisure- } \\
\text { time and occupational physical activity } \\
\text { Participants felt forgotten: too old for regular physical activity programs } \\
\text { and too young for senior programs } \\
\text { Facilitators: access to opportunities, affordability } \\
\text { Barriers: lack of time or too much time, lack of environmental supports for } \\
\text { active transportation, poor weather, lack of companions, financial } \\
\text { constraints }\end{array}$ \\
\hline
\end{tabular}




\subsection{Sedentary Behavior during the Retirement Transition}

It is unclear how sedentary behavior may change during the retirement transition $[25,83]$. A systematic review identified four articles on retirement and longitudinal sedentary behavior published through 2014 [25] and three additional articles were published since [36, 86, 90] for a total of seven quantitative, longitudinal studies (Table 4). Sedentary behavior usually was measured as TV watching, with four studies of total sitting time or including non-TV watching domains of sedentary behavior [36, 86, 90, 100]. Retirement was associated with greater increases in overall sitting or TV watching compared to continuing to work in some longitudinal $[83,86,92,93]$ and cross-sectional studies [35]. For example, among French retirees, the mean increase in sedentary behavior after retirement ( 8.4 hours/week) was three times the magnitude of the mean increase in leisure-time physical activity (2.5 hours/week) [86]. However, other studies identified an inverse association between retirement and sedentary behavior [36, 100, 101], including in a cross-sectional accelerometer-based study [102].

\subsubsection{Correlates of Sedentary Behavior at Retirement}

Individual-level correlates of sedentary behavior during the retirement transition were explored in five quantitative studies [36, 83, 90, 92, 93]. Age and sex were not correlates among British adults, nor was sex a correlate among Belgian retirees [90, 102]. However, younger Australian retirees reported a larger decline in sitting time after retirement than older retirees [36]. Retiring from a full-time compared to part-time job, living in an urban vs. rural area, and having higher vs. lower education also were associated with a larger magnitude decrease in sitting time after retirement among Australian retirees [36]. African American (vs. non-Hispanic white) race [92] and retirement from a physically demanding (vs. sedentary) job [83] were associated with a larger magnitude increase in TV watching among American and British retirees, respectively. Lower socio-economic status also was associated with a larger increase or 
smaller decrease in sedentary behavior after retirement compared with higher socio-economic status $[36,83,90]$. Health also may be a correlate, with retirement due to poor health or disability associated with increased sedentary behavior [22].

Multi-level correlates of sedentary behavior during the retirement transition were explored in two quantitative studies of Belgian and Australian adults [73, 95]. Among Australian adults, social support from friends was associated with less weekend sitting, regardless of retirement status [73]. Social support from family, personal safety, and neighborhood social cohesion, aesthetics, and destinations were not statistically significantly associated with weekend sitting. Among Belgian adults, positive perceptions of old age and less street connectivity were associated with increased screen time after retirement, while modeling from friends and lower land use mix were associated with increased car use after retirement [90]. No other quantitative studies have explored correlates of sedentary behavior during the retirement transition.

\subsubsection{Qualitative Studies of Sedentary Behavior during the Retirement Transition}

Only two qualitative studies addressed sedentary behavior during the retirement transition [99, 103](Table 5). Interviews with Dutch older adults suggested that retirement was associated with increased TV watching for some but not all adults, with variation by prior TV watching habits and motivation for watching TV [103]. Among retired Belgian adults, perceived changes in sedentary behavior after retirement varied by prior occupational physical activity: persons retired from sedentary jobs perceived their sedentary behavior to have decreased whereas retirees from active jobs perceived increased sedentary behavior after retirement [99]. Retired Belgians were not aware of the risks associated with prolonged sedentary behavior and so were not motivated to reduce the time they spent sitting [99]. 
Table 4. Longitudinal quantitative studies of sedentary behavior at retirement

\begin{tabular}{|c|c|c|c|c|c|c|}
\hline $\begin{array}{l}\text { Author } \\
\text { (Year) } \\
\text { Journal }\end{array}$ & $\begin{array}{l}\text { Location } \\
\text { (follow-up) } \\
\text { Cohort }\end{array}$ & $\begin{array}{l}\text { Participants } \\
\text { (N, age, gender, retirement } \\
\text { status) }\end{array}$ & $\begin{array}{l}\text { Sedentary behavior } \\
\text { (No. times measured) }\end{array}$ & $\begin{array}{l}\text { Retirement } \\
\text { to } S B \\
\text { measure }\end{array}$ & Modifiers & Main findings \\
\hline $\begin{array}{l}\text { Barnett et al. } \\
(2013) \\
\text { J Epidemiol } \\
\text { Comm Health } \\
\text { [83] }\end{array}$ & $\begin{array}{l}\text { United } \\
\text { Kingdom } \\
(1997-2007) \\
\text { EPIC- } \\
\text { Norfolk }\end{array}$ & $\begin{array}{l}\mathrm{N}=3,334 \\
\sim 55 \text { years } \\
52 \% \text { female } \\
\text { All employed at baseline, } 785 \\
\text { retired during follow-up }\end{array}$ & $\begin{array}{l}\text { Self-reported } \\
\text { TV watching } \\
\text { (2) }\end{array}$ & $\begin{array}{l}\text { Mean } 3.5 \\
\text { years from } \\
\text { retirement }\end{array}$ & $\begin{array}{l}\text { Sex } \\
\text { Social class } \\
\text { (occupation) }\end{array}$ & $\begin{array}{l}\text { Increase in TV watching } \\
\text { Greater increase among manual compared to non- } \\
\text { manual social classes }\end{array}$ \\
\hline $\begin{array}{l}\text { Clark et al. } \\
(2014) \\
\text { Prev Med } \\
{[100]}\end{array}$ & $\begin{array}{l}\text { Australia } \\
(2000-2010) \\
\text { ALSWH }\end{array}$ & $\begin{array}{l}\mathrm{N}=6,973 \\
\text { mean } 52 \text { years } \\
100 \% \text { female } \\
1,157 \text { retired during follow-up }\end{array}$ & $\begin{array}{l}\text { Self-reported total } \\
\text { sitting time per day on } \\
\text { usual weekday and } \\
\text { weekend day } \\
\text { (4) }\end{array}$ & $\begin{array}{l}\text { Not } \\
\text { measured }\end{array}$ & & $\begin{array}{l}\text { Median change in sitting time was } 0.43 \mathrm{~h} / \text { day over } \\
10 \text { years } \\
\text { Retiring associated with decreased }(\geq 2 \text { hours less) } \\
\text { compared to stable sitting time (OR } 1.70,95 \% \text { CI } \\
1.39,2.07)\end{array}$ \\
\hline $\begin{array}{l}\text { Ding et al. } \\
\text { (2016) } \\
\text { Prev Med [36] }\end{array}$ & $\begin{array}{l}\text { Australia } \\
(2006-2010) \\
\text { SEEF }\end{array}$ & $\begin{array}{l}\mathrm{N}=27,257 \\
\text { mean } 55 \text { years } \\
50 \% \text { female } \\
\text { All employed at baseline, } \\
3,106 \text { retired during follow-up }\end{array}$ & $\begin{array}{l}\text { Self-reported total } \\
\text { time usually spent } \\
\text { sitting per day } \\
\text { (2) }\end{array}$ & $<3.3$ years & $\begin{array}{l}\text { Age } \\
\text { Sex } \\
\text { Urban/rural } \\
\text { Education } \\
\text { Birth } \\
\text { Country } \\
\text { Work h/wk }\end{array}$ & $\begin{array}{l}\text { Larger decrease in sitting time (-67 vs. }-27 \mathrm{~min} / \mathrm{day} \text { ) } \\
\text { among retirees compared to non-retirees } \\
\text { Stronger effect of retirement among younger, more } \\
\text { educated, full-time workers, and city dwellers } \\
\text { Retiring for health or to care for others increased } \\
\text { odds of excessive sitting ( }>7 \mathrm{~h} / \text { day) compared to } \\
\text { retiring for lifestyle reasons or age }\end{array}$ \\
\hline $\begin{array}{l}\text { Evenson et al. } \\
(2002) \\
\text { Am J } \\
\text { Epidemiol } \\
{[92]}\end{array}$ & $\begin{array}{l}\text { USA } \\
1986-1995 \\
\text { ARIC }\end{array}$ & $\begin{array}{l}\mathrm{N}=7,782 \\
45-64 \text { years at baseline } \\
50 \% \text { female } \\
\text { All employed at baseline, } \\
2,293 \text { retired during follow-up }\end{array}$ & $\begin{array}{l}\text { Self-reported } \\
\text { frequency of TV } \\
\text { watching } \\
\text { (2) }\end{array}$ & $\begin{array}{l}3-6 \text { years } \\
\text { from } \\
\text { retirement }\end{array}$ & $\begin{array}{l}\text { Sex } \\
\text { Race }\end{array}$ & $\begin{array}{l}\text { Retirement was associated with a significant } \\
\text { increase in watching } \mathrm{TV} \text { often or very often among } \\
\text { all groups defined by sex and race }\end{array}$ \\
\hline $\begin{array}{l}\text { Menai et al. } \\
(2014) \\
\text { PlosONE [86] }\end{array}$ & $\begin{array}{l}\text { France } \\
(2001-2007) \\
\text { SU.VI.MAX }\end{array}$ & $\begin{array}{l}\mathrm{N}=2,814 \\
\text { mean } 57 \text { years } \\
49 \% \text { female } \\
\text { Employed }(1,126) \text { or retired at } \\
\text { baseline }(824), 891 \text { retired } \\
\text { during follow-up }\end{array}$ & $\begin{array}{l}\text { Self-reported } \\
\text { TV watching } \\
\text { Computer use } \\
\quad \text { (leisure) } \\
\text { Reading } \\
\text { Domestic sitting } \\
\text { Occupational } \\
\text { sitting } \\
\text { Total leisure sitting }\end{array}$ & $\begin{array}{l}1-6 \text { years } \\
\text { from } \\
\text { retirement }\end{array}$ & & $\begin{array}{l}\text { Increase in all sedentary behaviors after retirement } \\
\text { except occupational sitting } \\
\text { Mean } 8.4 \text { hours/week increase in overall sedentary } \\
\text { behavior) } \\
\text { Overall sedentary behavior, TV watching and } \\
\text { computer use increased more among people retiring } \\
\text { during follow-up compared to people retired at } \\
\text { baseline or working throughout follow-up }\end{array}$ \\
\hline
\end{tabular}




\begin{tabular}{|c|c|c|c|c|c|c|}
\hline $\begin{array}{l}\text { Author } \\
\text { (Year) } \\
\text { Journal } \\
\end{array}$ & $\begin{array}{l}\text { Location } \\
\text { (follow-up) } \\
\text { Cohort } \\
\end{array}$ & $\begin{array}{l}\text { Participants } \\
\text { (N, age, gender, retirement } \\
\text { status) }\end{array}$ & $\begin{array}{l}\text { Sedentary behavior } \\
\text { (No. times measured) }\end{array}$ & $\begin{array}{l}\text { Retirement } \\
\text { to } S B \\
\text { measure } \\
\end{array}$ & Modifiers & Main findings \\
\hline $\begin{array}{l}\text { Touvier et al. } \\
\text { (2010) } \\
\text { Int J Behav } \\
\text { Nutr Phys Act } \\
\text { [93] }\end{array}$ & $\begin{array}{l}\text { France } \\
(1998-2001) \\
\text { SU.VI.MAX }\end{array}$ & $\begin{array}{l}\mathrm{N}=1,389 \\
\text { mean } 53 \text { years } \\
50 \% \text { female } \\
\text { All employed at baseline, } 248 \\
\text { retired during follow-up }\end{array}$ & $\begin{array}{l}\text { Self-reported } \\
\text { TV watching } \\
\text { (2) }\end{array}$ & $<3$ years & $\begin{array}{l}\text { Sex } \\
\text { Job physical } \\
\text { demands } \\
\text { Walking } \\
\text { level }\end{array}$ & $\begin{array}{l}\text { Retirement was associated with an increase in time } \\
\text { spent watching TV ( } 30-40 \text { min/day) among retirees } \\
\text { from less physically demanding jobs } \\
\text { Among women who walked more after retirement, } \\
\text { time watching TV decreased }\end{array}$ \\
\hline $\begin{array}{l}\text { Van Dyck et } \\
\text { al. } \\
(2016) \\
\text { BMC Public } \\
\text { Health } \\
\text { [90] }\end{array}$ & $\begin{array}{l}\text { Belgium } \\
(2012-2015)\end{array}$ & $\begin{array}{l}\mathrm{N}=446 \\
\text { mean } 62 \text { years } \\
47 \% \text { female } \\
341 \text { retired at baseline, } 105 \\
\text { retired during follow-up }\end{array}$ & $\begin{array}{l}\text { Self-reported } \\
\text { frequency \& duration } \\
\text { Passive transport } \\
\text { TV watching } \\
\text { Computer use } \\
\text { Sitting hobbies } \\
\text { Sitting chores } \\
\text { Sitting meals }\end{array}$ & $\begin{array}{l}>6 \text { months to } \\
<5 \text { years }\end{array}$ & $\begin{array}{l}\text { Sex } \\
\text { Education }\end{array}$ & $\begin{array}{l}\text { Computer use increased more among adults who } \\
\text { retired during follow-up compared to those retired at } \\
\text { baseline } \\
\text { TV and computer used increased most among adults } \\
\text { with low education who retired during follow-up } \\
\text { Almost no moderating effects by sex }\end{array}$ \\
\hline
\end{tabular}

Table 5. Qualitative studies of sedentary behavior in relation to retirement

\begin{tabular}{|c|c|c|c|c|c|}
\hline $\begin{array}{l}\text { Author } \\
\text { (Year) } \\
\text { Journal }\end{array}$ & $\begin{array}{l}\text { Location } \\
\text { Setting }\end{array}$ & $\begin{array}{l}\text { Participants } \\
\text { (N, age, gender, } \\
\text { retirement status) }\end{array}$ & Aims & Design & Conclusions \\
\hline $\begin{array}{l}\text { van der Goot et } \\
\text { al. } \\
(2012) \\
\text { Aging Society } \\
{[103]}\end{array}$ & $\begin{array}{l}\text { Netherlands } \\
\text { Social } \\
\text { contacts of } \\
\text { interviewers }\end{array}$ & $\begin{array}{l}\mathrm{N}=86 \\
65-92 \text { years } \\
64 \% \text { women } \\
83 \text { retired, } 3 \\
\text { employed }\end{array}$ & $\begin{array}{l}\text { Provide insight into the } \\
\text { meanings of television } \\
\text { in older adults' } \\
\text { lives }\end{array}$ & $\begin{array}{l}\text { Semi- } \\
\text { structured } \\
\text { interviews }\end{array}$ & $\begin{array}{l}\text { Retirement often led to increases in television watching. } \\
\text { Increased television watching was positive if related to freedom to do what } \\
\text { one wanted, but negative if linked to loss of social contacts or lack of } \\
\text { activities } \\
\text { Retirement led to decreased television watching if people took up many } \\
\text { new activities after retirement }\end{array}$ \\
\hline $\begin{array}{l}\text { Van Dyck et al. } \\
(2016) \\
\text { J Aging Phys } \\
\text { Act } \\
{[99]}\end{array}$ & $\begin{array}{l}\text { Belgium } \\
\text { Subsample of } \\
\text { participants in } \\
\text { longitudinal } \\
\text { study }\end{array}$ & $\begin{array}{l}\mathrm{N}=37 \\
\text { Mean } 63 \text { years } \\
51 \% \text { women } \\
\text { Retired }>6 \text { months } \\
\text { and }<5 \text { years }\end{array}$ & $\begin{array}{l}\text { Identify determinants of } \\
\text { sedentary behavior } \\
\text { during early retirement, } \\
\text { opinions on existing } \\
\text { sedentary behavior } \\
\text { interventions, and needs } \\
\text { and wishes regarding } \\
\text { new interventions }\end{array}$ & $\begin{array}{l}\text { Focus } \\
\text { groups } \\
(\mathrm{N}=4)\end{array}$ & $\begin{array}{l}\text { Participants not aware of health risks associated with sedentary behavior so } \\
\text { were not motivated to decrease their sedentary behavior } \\
\text { Retirement was associated with increased sedentary behavior among adults } \\
\text { who retired from active jobs but decreased sedentary behavior among } \\
\text { adults who retired from sedentary jobs }\end{array}$ \\
\hline
\end{tabular}




\subsection{Limitations of Existing Studies}

Studies of physical activity and sedentary behavior during the retirement transition have lacked racial/ethnic and socio-economic diversity, employed crude self-reported measures of behavior, and have not comprehensively explored correlates of behavior change, including differences by gender.

\subsubsection{Study Population}

Much existing research on physical activity and sedentary behavior during the retirement transition was conducted in Europe and among non-Hispanic white, higher SEP populations. Findings from these studies may not be transportable to the increasingly diverse population of American retirees [104]. First, European countries typically have stricter retirement regulations and provide more pension support compared to the US [2, 32]. These policy differences contribute to differences in the timing, reasons for, and pattern of retirement, which may affect the impact of retirement on behavior. Second, the impact of retirement on behavior may differ by race/ethnicity and SEP due to accumulated (dis)advantages [68, 70]. Earlier life physical activity habits are important determinants of physical activity after retirement [17], but physical activity opportunities in earlier life may be limited among racial/ethnic minorities and persons with low income $[13,105,106]$. Further, illness and disability are more common reasons for retirement among persons of minority race/ethnicity and low SEP, and were associated with patterns of limited physical activity and large amounts of sedentary behavior [20,53]. Moreover, the proportion of older adults of minority race/ethnicity is projected to increase from 18\% (2003) to $28 \%$ by 2030 [104]. Thus, research including racially/ ethnically and socio-economically diverse US populations is needed in this area. 


\subsubsection{Measurement}

Physical activity and sedentary behavior are commonly measured via self-report questionnaire or using accelerometers, which are small wearable devices that register changes in acceleration. Except one cross-sectional accelerometer study [102], physical activity and sedentary behavior during the retirement transition have been measured by self-report. Many self-reported measures were based on a single item [19]. Measures consisting of a single item may be less sensitive to change over time, and do not permit domain-specific exploration of physical activity or sedentary behavior [30, 107]. Quantifying behavior by domain is important because behavioral determinants are frequently domain-specific [107], and domain-specific measures may elucidate underlying mechanisms of behavior change [36]. Further, most studies have not measured pre-retirement occupational physical activity, so it is unclear whether postretirement changes in leisure-time physical activity recouped lost occupational activity [19].

Self-reported measures of physical activity and sedentary behavior are subject to recall and social desirability bias. These biases typically lead to over-reporting of physical activity and underreporting of sedentary behavior, so researchers have advocated for use of sensor-based measures $[4,108]$. However, current sensor technologies do not capture the domain of behavior and few longitudinal studies of retirement-aged adults have repeated accelerometer measures [109]. Studies of self-reported physical activity and sedentary behavior during the retirement transition can be improved by using validated, domain-specific questionnaires $[19,110]$.

\subsubsection{Correlates}

Correlates of physical activity during the retirement transition are under-researched [13]. Although many studies have identified individual-, interpersonal-, and community-level correlates of older adults' physical activity behavior, including walking [111-117], most did not distinguish working from retired persons [39]. Correlates of physical activity likely differ by 
retirement status. For instance, during the retirement transition, shifting social networks may make social support for physical activity particularly important, especially among minority racial/ethnic groups and women [39]. Neighborhood characteristics also may influence physical activity differently among retirees compared to non-retirees [118]. For example, the home neighborhood may have a greater influence on physical activity among retirees because they often spend more time and engage in more physical activity near home [119]. Existing evidence from quantitative studies specific to the retirement transition is limited primarily to individuallevel correlates of physical activity $[19,79]$. A better understanding of interpersonal and community-level correlates is needed to inform development of interventions [79].

Investigation of community-level factors is especially important because of their greater potential to impact population level physical activity compared to individual level factors [120]. Community-level changes are a key component of the National Prevention Strategy [121] and recommended by the US Community Preventive Service Task Force to promote physical activity [40]. Identifying community-level correlates of physical activity at retirement may help communities prioritize changes that will benefit growing retiree populations.

Developing effective interventions requires both identification of salient correlates and understanding of the mechanisms linking correlates to behaviors. For example, different mechanisms underlying the association between SEP and physical inactivity at retirement would point to distinct intervention strategies. If low value of leisure-time physical activity is the mechanism linking low SEP to physical inactivity after retirement, then an effective intervention strategy might include utilitarian physical activity opportunities (e.g., community improvements) as opposed to focusing on leisure activities [74]. On the other hand, if poor access to physical activity resources is contributing to physical inactivity among retired persons of low SEP, then 
neighborhood improvements (e.g., addition or updating of parks) may be an effective intervention strategy [122]. Qualitative inquiry can help to elucidate mechanisms underlying the association between correlates and behavior [123]. Thus, qualitative studies of barriers and facilitators of physical activity after retirement complement quantitative analyses to maximize insight for the targeting of public health interventions.

Further, interventions may need to address gender-specific barriers and facilitators for physical activity [39]. For example, women are more likely to serve in caregiving roles than men, which may pose unique barriers to physical activity [38, 124]. Preferences for physical activity also may vary by gender, with retired women more likely to prefer group activities compared to retired men [72]. Women are more likely to decrease physical activity at older ages and may be less likely to increase physical activity after retirement compared to men $[19,58]$. However, only one recent study focused specifically on barriers and facilitators of physical activity among retired women [38]. Thus, it is particularly important to understand how to promote physical activity among retired women to ensure that interventions address their unique barriers and facilitators.

\subsection{Summary}

Retirement is a major transition in later life that involves changes in daily routines and habits as well as shifts in social networks and the spaces where people spend time. This transitional period may be an important opportunity for changes to physical activity and sedentary behavior patterns established in younger adulthood. Recent retirees may be receptive to behavior change due to perceived reduction in barriers to physical activity (e.g., time) and an increased focus on health. Behavior patterns established at retirement may exert an important influence on late life physical activity and sedentary behavior and thus the prevalence of chronic disease and disability among older adults. However, existing studies of physical activity and 
sedentary behavior during the retirement transition do not adequately represent the racial/ethnic and socioeconomic diversity of Americans, often relied on poor measures of leisure-time physical activity, and devoted little attention to potentially important interpersonal- and community-level correlates of behavior. This research, guided by Life Course Theory and the Social Ecological Model, expands our understanding of overall and domain-specific physical activity and TV watching during the retirement transition (Aim 1) and leverages rich contextual data to identify multi-level correlates of changes in walking after retirement (Aim 2) among a diverse US cohort. Further, a qualitative study provides insight into facilitators and barriers to physical activity after retirement to inform physically active promotion among recently retired women (Aim 3). 


\section{CHAPTER 4: OVERARCHING RESEARCH METHODS}

\subsection{Mixed-Methods Approach}

This dissertation was conducted using a mixed-methods approach that sequentially combined quantitative and qualitative research [123]. Quantitative analyses were used to estimate the associations between retirement and longitudinal patterns of physical activity and sedentary behavior (Aim 1), and between correlates and within-person changes in walking (Aim 2). Findings from quantitative analyses informed the design of a qualitative study (Aim 3), which yielded insight into the mechanisms underlying the observed quantitative associations.

\subsection{Research Approach for Quantitative Analyses (Aims 1 and 2)}

\subsubsection{Study Population}

The MESA is a prospective cohort study of the progression of subclinical CVD [125].

Adults aged 45 to 84 years and free of clinical CVD were recruited in 2000-2002 at six sites: Forsyth County, NC, Northern Manhattan and the Bronx, NY, Baltimore City and Baltimore County, MD, the southern part of St. Paul, MN, Chicago and Maywood, IL, and Los Angeles County, CA. MESA specifically sought to include African-Americans, Asian (Chinese) Americans, and Hispanics (Table 6). MESA exclusion criteria were: history of physician-diagnosed CVD or related medical procedures, current atrial fibrillation, active cancer treatment or serious

\begin{tabular}{lc}
\multicolumn{2}{l}{ Table 6. Baseline characteristics of MESA } \\
participants (2000-2002, N=6,814) \\
\hline Socio-demographic Characteristic \\
\hline Age & $\mathbf{N}(\%)$ \\
45-54 & $1948(29)$ \\
$55-64$ & $1884(28)$ \\
$65-74$ & $2017(30)$ \\
$75-84$ & $965(14)$ \\
Gender & \\
Female & $3601(53)$ \\
Male & $3213(47)$ \\
Race/Ethnicity & \\
African American & $1891(28)$ \\
Chinese American & $804(12)$ \\
Hispanic & $1496(22)$ \\
Non-Hispanic white & $2623(39)$ \\
Employment Status & \\
Employed (full or part time) & $3268(48)$ \\
Unemployed & $156(2)$ \\
Homemaker & $784(12)$ \\
Retired & $2585(38)$ \\
\hline
\end{tabular}


medical conditions that Table 7. MESA participants, number newly retired, and physical activity measurement by study exam (2002-2012)

would limit participation

\begin{tabular}{ccccc}
\hline Exam & Date & N (\%) & Newly Retired & Physical Activity Measure \\
\hline 1 & $2000-2002$ & $6814(100)$ & 2584 (at baseline) & Yes \\
2 & $2002-2004$ & $6239(92)$ & 216 & Yes \\
3 & $2004-2005$ & $5946(87)$ & 176 & Yes \\
4 & $2005-2007$ & $5818(85)$ & 170 & No \\
5 & $2010-2012$ & $4655(68)$ & 500 & Yes \\
\hline
\end{tabular}

inability, speaking only

languages other than English, Spanish, Cantonese, or Mandarin, plans to leave the community in the next 5-years, or living in or on a waiting list for a nursing home. At baseline (years 20002002), the MESA cohort consisted of 6,814 healthy participants (Table 7). Four follow-up exams were conducted (2002-2004, 2004-2005, 2005-2007, and 2010-2012). Participation in follow-up exams was relatively high. Attrition occurred due to both losses to follow-up and deaths $(\mathrm{N}=1161)$.

Aim 1 analyses included MESA participants who were not retired at baseline and had complete data on employment status, physical activity, or covariates ( $\mathrm{N}=4,091)$. Like other studies on this topic $[83,84]$, we excluded participants who were retired at baseline $(\mathrm{N}=2,584)$. Pre-retirement physical activity and sedentary behavior measures were not available for these MESA participants and their date of retirement was unknown.

Aim 2 analyses were restricted to MESA participants who retired during follow-up and had both pre- and post-retirement measures of walking $(\mathrm{N}=1,008)$. Persons missing data on covariates of interest were further excluded $(\mathrm{N}=80)$ for a final sample size of 928. Data were missing due to non-response on MESA questionnaires, inability to geocode the participant's address, residence outside of the MESA study area, or non-participation in the MESA Neighborhood ancillary study, which collected built environment data. 


\subsubsection{Study Measures}

The MESA measured many participant characteristics, including individual attributes and characteristics of participants' neighborhoods. Three essential measures used in this dissertation included time-varying measures of employment status, physical activity and sedentary behavior. In addition, individual-, interpersonal-, and neighborhood-level covariates were used to control for confounding (Aim 1) and/or were potential correlates of changes in walking (Aim 2).

\subsubsection{Retirement Classification}

Retirement status was derived from self-reported employment status. Employment status was self-reported by MESA participants at each study visit in three questionnaire items (Table 8). Participants who responded to the 2014-2015 follow-up telephone call also were asked to report the date that they retired or partially retired. Participants were classified as retired if they report being retired and not working, retired and working, or retired and volunteering. Participants were classified as retired for all visits after the first instance of reporting to be retired. Retirement date was estimated as the mid-point between the last exam where a participant reported working and the first exam where they reported being retired. The number of newly retired participants at each MESA

exam is shown in Table 7.

Published estimates of the validity and reliability of self-reported retirement status are not available in MESA or elsewhere. However, literature on selfreported work history suggests that dates of employment are reported with $80 \%$
Table 8. Employment status questions in the Multi-Ethnic Study of Atherosclerosis

\begin{tabular}{|c|c|}
\hline Question & Response Option \\
\hline $\begin{array}{l}\text { 1. Has your employment } \\
\text { status changed since } \\
\text { your last MESA visit? }\end{array}$ & $\begin{array}{l}0=\text { No } \\
1=\text { Yes }\end{array}$ \\
\hline $\begin{array}{l}\text { 2. Choose one of the } \\
\text { following that best } \\
\text { describes your current } \\
\text { occupation }\end{array}$ & $\begin{array}{l}1=\text { Homemaker }(\text { skip to \#3) } \\
2=\text { Employed full time } \\
3=\text { Employed part time } \\
4=\text { Employed, on leave for health } \\
\text { reasons } \\
5=\text { Employed, temp. away from job } \\
6=\text { Unemployed }<6 \text { months } \\
7=\text { Unemployed }>6 \text { months } \\
8=\text { Retired, not working } \\
9=\text { Retired, working } \\
10=\text { Retired, volunteering }\end{array}$ \\
\hline $\begin{array}{l}\text { 3. If homemaker, did you } \\
\text { previously work outside } \\
\text { the home? }\end{array}$ & $\begin{array}{l}0=\text { No } \\
1=\text { Yes }\end{array}$ \\
\hline
\end{tabular}


accuracy [126], job title with $89 \%$ accuracy [127], and repeatability of current or last job occupational status was at least $70 \%$ [128]. Self-reported receipt of retirement pension benefits had sensitivity and specificity $>98 \%$ in a Norwegian population [129]. These results suggest that most people accurately report their current employment status.

Alternative methods to classify retirement status include receipt of pension income [87, 88] and eligibility for Social Security benefits [70]. Pension and employer records were not available for MESA participants. Classifying retirement status by Social Security benefit eligibility age could misclassify MESA participants differentially by race/ethnicity, socioeconomic status, and gender [68]. Because increased discretionary time is hypothesized as a major pathway through which retirement impacts physical activity and sedentary behavior, one study defined retirement as not working for pay and reporting no occupational activity [83]. However, identifying as "retired" may capture aspects of self-perception that influence behavior including among persons who continue to work or volunteer [130].

To explore the robustness of findings to the selected definition of retirement, sensitivity analyses were conducted using alternative retirement definitions in Aim 1 (Table 9). First, differences were explored between those working for pay after retirement and those not working Table 9. Retirement definition in main and sensitivity analyses

\begin{tabular}{|c|c|c|c|}
\hline & & Definition of "retired" & Time-varying \\
\hline 芯 & Primary & $\begin{array}{l}\text { Self-reported employment status at visits 2-5: } \\
\text { retired from usual occupation and not working, } \\
\text { retired and working for pay, or } \\
\text { retired and volunteering. }\end{array}$ & $\begin{array}{l}\text { Participants classified as retired for all visits } \\
\text { after first visit meeting retirement definition }\end{array}$ \\
\hline \multirow{4}{*}{ 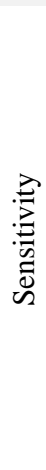 } & 2-tierd & $\begin{array}{l}\text { Subdivide those meeting the primary retirement } \\
\text { definition into those not working or volunteering } \\
\text { (tier 1) or working for pay (tier } 2 \text { ) }\end{array}$ & Participants reclassified at each visit \\
\hline & Strict & $\begin{array}{l}\text { Classify as retired only participants who report being } \\
\text { retired and do not report any occupational physical } \\
\text { activity, and report zero hours worked }\end{array}$ & Participants reclassified at each visit \\
\hline & $\begin{array}{l}\text { Fully time- } \\
\text { varying }\end{array}$ & $\begin{array}{l}\text { Self-reported employment status at visits } 2-5 \text { : } \\
\text { retired from usual occupation and not working, } \\
\text { working for pay, or volunteering. }\end{array}$ & Participants reclassified at each visit \\
\hline & $\begin{array}{l}\text { Exclude } \\
\text { homemakers }\end{array}$ & $\begin{array}{l}\text { Same as primary definition, exclude homemakers } \\
\text { and persons on-leave from work or unemployed }\end{array}$ & $\begin{array}{l}\text { Participants classified as retired for all visits } \\
\text { after first visit meeting retirement definition }\end{array}$ \\
\hline
\end{tabular}


for pay after retirement (two-tiered retirement definition). Second, a strict definition of retirement was used, requiring full retirement (retired and volunteering or not working), reporting zero work hours, and no occupational physical activity. Third, a fully time-varying definition of retirement allowed for un-retirement (rejoining the labor force after retirement) by re-classifying retirement status at each MESA exam. Fourth, homemakers and persons on leave from work or unemployed were excluded, as in prior studies [83].

\subsubsection{Physical Activity}

Physical activity was self-reported by MESA participants at exams 1,2,3, and 5. The MESA physical activity questionnaire was adapted from the Cross-Cultural Activity Participation Study [131]. The questionnaire included 23 items and asked participants to report whether they participated in six domains of physical activities in a typical week of the last month (Table 10). For each domain of physical activity, participants were asked the frequency (days/week) and duration (minutes/day) of behavior. Light, moderate, and vigorous intensity activities were reported separately for household and yard, caregiving, individual, and occupational activities.

Among a sample of women, the testretest reliability and validity of the interviewadministered questionnaire were acceptable [132]. The physical activity questionnaire was typically self-administered in MESA. However, interviewers administered the questionnaire to some participants who had cognitive or visual impairments or were uncomfortable with
Table 10. MESA domain-specific and summary measures of physical activity and sedentary behavior

\begin{tabular}{|c|c|}
\hline & Measures \\
\hline \multirow{8}{*}{ 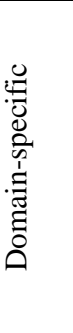 } & Walking for leisure/recreation (min/week) \\
\hline & Walking for transportation/to get places (min/week) \\
\hline & Household (min/week) \\
\hline & Household chores and yard work \\
\hline & Caring for others (min/week) \\
\hline & Non-walking leisure activities (min/week) \\
\hline & $\begin{array}{l}\text { Dance, dual and team sports, individual and } \\
\text { conditioning activities (e.g., yoga) }\end{array}$ \\
\hline & Occupational/volunteer activity (MET-min/week) \\
\hline 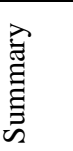 & $\begin{array}{l}\text { Moderate-to-vigorous physical activity } \\
\text { Sum of MET-min/week moderate or vigorous } \\
\text { intensity physical activity reported across all } \\
\text { domains }\end{array}$ \\
\hline 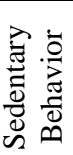 & Television watching (min/week) \\
\hline
\end{tabular}

Abbreviations: MESA Multi-Ethnic Study of

Atherosclerosis; MET metabolic equivalent task 
computers. Persons who self-administered the questionnaire had higher levels of physical activity overall, thus mode of administration was adjusted for in sensitivity analyses.

In Aim 1, physical activity was operationalized as six domain-specific measures and one summary measure of physical activity (Table 11). The summary measure was overall MVPA, which was calculated in three steps. First, physical activities were assigned metabolic equivalent task (MET) values by domain and intensity level. A MET is a ratio of working to resting metabolic rate of oxygen consumption of a seated adult [44]. Resting metabolic rate is approximately $3.5 \mathrm{ml}$ of oxygen per kilogram of body weight per minute for adults [44]. Second, assigned MET values were multiplied by reported duration of activity to calculate METmin/week. Third, MET-min/week of moderate and vigorous intensity physical activities were summed across all domains to estimate overall MVPA.

Both domain-specific and summary measures of physical activity may be relevant during the retirement transition. The transition to retirement impacts domains of physical activity in distinct ways [19]. For example, British retirees reported increased household and leisure-time but not transport physical activity after retirement [83]. Also, information on domain-specific physical activity changes may better inform interventions, which are more likely effective if targeted to specific domains of physical activity [133]. For example, an environmental change such as building sidewalks is unlikely to impact household physical activity but may support walking for recreation or transportation. Nonetheless, a summary of overall MVPA may be the most relevant

Table 11. Summary of operationalization of physical activity by study aim

\begin{tabular}{ll}
\hline Aim & Operationalization \\
\hline Aim 1 & $\begin{array}{l}\text { Log-transformed domain-specific measures (min/week): } \\
\text { recreational walking, transport walking, non-walking leisure } \\
\text { activity, household/yard activity, caregiving activity, and } \\
\text { occupational/volunteer MVPA (MET-min/week) }\end{array}$ \\
& $\begin{array}{l}\text { Log-transformed summary measure of overall MVPA } \\
\text { (MET-min/week) }\end{array}$ \\
Aim 2 & $\begin{array}{l}\text { Categorized within-person change in walking for recreation } \\
\text { and for transport after retirement (decrease } \geq 60 \text { min/week, } \\
\text { maintain within } 60 \text { min/week, increase } \geq 60 \text { min/week) }\end{array}$ \\
& $\begin{array}{l}\text { Abbreviations: MET metabolic equivalent task; MVPA moderate to } \\
\text { vigorous physical activity }\end{array}$
\end{tabular}


measure of physical activity for health benefits [6].

Aim 2 focused on walking, which is the most frequently reported physical activity among older Americans [57]. Within-person changes in walking after retirement were calculated separately for recreational and transportation walking. Change in walking was the difference in min/week between self-reported walking at the first post-retirement MESA exam minus selfreported walking at the last pre-retirement MESA exam. Changes in walking were categorized as decreased ( $\leq-60 \mathrm{~min} /$ week), maintained (within $60 \mathrm{~min} /$ week of pre-retirement walking), or increased ( $\geq 60 \mathrm{~min} /$ week).

\subsubsection{Sedentary Behavior}

In one question of the physical activity questionnaire, MESA participants were asked to report the frequency and duration of sitting or reclining to watch TV. Frequency and duration were multiplied to calculate min/week of TV watching. MESA did not measure overall sedentary behavior (including occupational and other sitting). However, leisure sitting is a major component of and may be correlated with overall sedentary behavior among older adults [134]. Screen time (small device, computer, and TV use) comprised over one-third of objectively measured sedentary time among UK older adults, and TV watching comprised $84 \%$ of screen time [134]. Among a sample of women, the interview-administered physical activity questionnaire, which included the TV watching item, had acceptable test-retest reliability and validity [132].

\subsubsection{Individual-Level Covariates}

MESA measured time-fixed and time-varying individual-level socio-demographic characteristics. Time-fixed characteristics included gender, highest education completed (eight categories), race/ethnicity (non-Hispanic white, non-Hispanic black, Chinese American, 
Hispanic), and MESA study site (NC, CA, IL, NY, MD, MN). Participants self-reported these attributes at study enrollment. Time-varying socio-demographic characteristics were age, income, and four indicators of wealth. Household income was self-reported in 13 categories at each exam. Four indicators of wealth were assessed at MESA exams 2 and 3: home ownership, car ownership, investments, and ownership of other land/property. A composite measure of socioeconomic position (SEP) was calculated from education $(\leq$ high school, some college but no degree, associate or bachelor's degree, graduate/professional degree $)$, income $(<\$ 25,000$, $\$ 25,000-39,999, \$ 40,000-74,999, \geq \$ 75,000)$, and wealth measures [135]. SEP ranged from zero (low) to ten (high) and was time-fixed for each participant using the earliest available measures (income at exam 1, wealth indicators at exam 2). Post-retirement income may not accurately reflect the status of persons with accumulated assets and resources.

In addition to socio-demographics, health data were collected throughout MESA followup. Self-rated health was participants' perception of their health relative to others their age (better, same, worse). Body mass index (BMI, $\mathrm{kg} / \mathrm{m}^{2}$ ) was calculated from measured height and weight measured according to a standardized protocol. Chronic diseases were assessed at each exam: emphysema, asthma, arthritis flare up in the past two weeks, diabetes, hypertension, high cholesterol, kidney disease, CVD, or cancer. Emphysema, asthma, and arthritis were selfreported. Diabetes and hypertension were self-reported or based on measured hemoglobin A1c and blood pressure, respectively. Cholesterol was measured according to standardized protocols. Kidney disease and CVD were identified from medical records and adjudicated by MESA investigators. CVD included coronary heart disease, angina, coronary artery revascularization, stroke, congestive heart failure, and peripheral vascular disease. Hospitalization due to cancer was verified through review of medical records for International Classification of Disease, Ninth 
Revision codes 140-208.92 [111]. For Aim 2, participants were categorized as having none, one, or more than one chronic condition at each exam.

\subsubsection{Interpersonal-level Covariates}

Interpersonal-level covariates include partnership status (married or living with a partner vs. not), social support, and caregiving. Partnership status was reported at MESA exams 1, 3, 4, and 5 and imputed for exam 2 using data from the closest exam [111]. Social support was measured at MESA exams 1 and 3 with the Enhancing Recovery in Coronary Heart Disease Social Support Inventory (ESSI), which has good internal consistency (Cronbach's alpha 0.86) and convergent validity with the Perceived Social Support Scale ( $r=0.62)$ [136]. The scale measures availability of emotional support using six items, each rated on a 5-point scale from "none of the time" (1) to "all of the time" (5). Total scores (range 6 to 30) were set to missing if any items were missing. Scores $\leq 12$ were consistent with low levels of social support [137]. Caregiving status was defined as providing $\geq 150 \mathrm{~min} /$ week of care for children or adults, as reported on the physical activity questionnaire.

\subsubsection{Neighborhood-level Covariates}

Features of MESA participants' neighborhoods were measured in an ancillary study (MESA Neighborhood Study). Neighborhood environment data were collected from local governments, business databases, and MESA participants. Participant's neighborhoods were characterized using both 'objective measures' (government / business records) and participant perceptions. Objective and perceived measures may be differently associated with walking [138140]. Perceptions of the environment may be particularly relevant to older adults' physical activity $[138,139]$. In this study, we focused on neighborhood characteristics associated with walking in prior research $[111,113,141-143]$ : availability of parks, recreational facilities, 
walking and social engagement destinations, street connectivity, population density, and

perceived walking environment, aesthetics, safety, and social cohesion (Table 12).

Objective environmental features were assessed for ZIP codes where five or more MESA

participants were living from 2000-2010. Participants provided their home addresses from first

contact at exam 1 to last contact or January 2012. Addresses were geocoded with TeleAtlas using

a 5-foot offset from major roadways with $96 \%$ geocoded to the street level, $3 \%$ to the ZIP code

level, and $<1 \%$ unable to be geocoded. Public parks were identified in parts of 36 counties,

Table 12. Measures of neighborhood-level covariates, MESA (2000-2010)

\begin{tabular}{|c|c|}
\hline $\begin{array}{l}\text { Measure } \\
\text { (source, operationalization) }\end{array}$ & Components \\
\hline $\begin{array}{l}\text { Objective Measures } \\
\text { Public parks } \\
\text { (local agencies + ESRI, 1-mile } \\
\text { densities) }\end{array}$ & $\begin{array}{l}\text { Public parks excluding walking trails, dog parks, ornamental parks, and parks with only } \\
\text { walking trails and dog parks. }\end{array}$ \\
\hline $\begin{array}{l}\text { Recreational facilities } \\
\text { (NETS, 1-mile densities) }\end{array}$ & $\begin{array}{l}\text { Commercial locations for adult physical activity including indoor conditioning, recreational, } \\
\text { team/racquet sports, and water activities. Includes instructional facilities. }\end{array}$ \\
\hline $\begin{array}{l}\text { Walking destinations } \\
\text { (NETS, 1-mile densities) }\end{array}$ & $\begin{array}{l}\text { Postal offices, drug store/pharmacy, bank/credit union, food sales, eating places, non-alcoholic } \\
\text { drinking places (based on [144]) }\end{array}$ \\
\hline $\begin{array}{l}\text { Social engagement } \\
\text { destinations } \\
\text { (NETS, 1-mile densities) }\end{array}$ & $\begin{array}{l}\text { Barber/beauty shops, performance based entertainment, participatory entertainment clubs, } \\
\text { sport/professional entertainment, exercise facility, gambling, amusement park/carnival, } \\
\text { membership sport/recreation club, libraries, museum/art galleries, zoo/aquarium, } \\
\text { civil/social/political club, religious institution, eating place, night club/bar (based on [144] }\end{array}$ \\
\hline $\begin{array}{l}\text { Street connectivity } \\
\text { (StreetMap, proportion) }\end{array}$ & $\begin{array}{l}\text { Network ratio: proportion of 1-mile Euclidean buffer covered by 1-mile network buffer } \\
\text { (network buffer is distance traveled along roadways)[111] }\end{array}$ \\
\hline $\begin{array}{l}\text { Population density } \\
\text { (US Census, people / } \mathrm{mi}^{2} \text { ) }\end{array}$ & Total population divided by area in miles within 1-mile circular buffer of participants' homes \\
\hline $\begin{array}{l}\text { Perceived Measures } \\
\text { Walking environment } \\
\text { (MESA Exams } 2 / 3 \text { and } 5)\end{array}$ & $\begin{array}{l}\text { 5-point scale strongly agree (1) to strongly disagree (5): } \\
\text { - It is pleasant to walk in my neighborhood } \\
\text { - } \quad \text { In my neighborhood it is easy to walk places } \\
\text { - } \quad \text { I often see other people walking in my neighborhood } \\
\text { - } \quad \text { I often see other people exercise in my neighborhood }\end{array}$ \\
\hline $\begin{array}{l}\text { Aesthetics } \\
\text { (MESA Exams 2/3 and 5) }\end{array}$ & $\begin{array}{l}\text { 5-point scale strongly agree (1) to strongly disagree (5): } \\
\text { - There is a lot of noise in my neighborhood } \\
\text { - } \quad \text { There is a lot of trash and litter on the streets in my neighborhood } \\
\text { - } \quad \text { My neighborhood is attractive }\end{array}$ \\
\hline $\begin{array}{l}\text { Safety } \\
(\text { MESA Exams } 2 / 3 \text { and 5) }\end{array}$ & $\begin{array}{l}\text { 5-point scale strongly agree (1) to strongly disagree (5): } \\
\text { - I feel safe walking in my neighborhood at day or at night } \\
\text { - } \quad \text { Violence is a problem in my neighborhood }\end{array}$ \\
\hline $\begin{array}{l}\text { Social cohesion } \\
\text { (MESA Exams } 1 \text { and } 5 \text {, } \\
\text { summed 4-item score) }\end{array}$ & $\begin{array}{l}\text { 5-point scale strongly agree (1) to strongly disagree (5): } \\
\text { - People around here are willing to help their neighbors } \\
\text { - } \quad \text { People in this neighborhood generally do not get along with each other } \\
\text { - } \quad \text { People in this neighborhood can be trusted } \\
\text { - } \quad \text { People in this neighborhood do not share the same values }\end{array}$ \\
\hline
\end{tabular}

Abbreviations: MESA Multi-Ethnic Study of Atherosclerosis; NETS National Establishment Time Series database 
including areas where 95\% of MESA participants resided. As described previously [145], geographic information system shapefiles were obtained from local governments between 20092012 and from a commercial source (Esri, Redlands, CA) in 2010. Investigators verified park locations. Trails located outside of parks were excluded due to inconsistent data availability across sites.

Locations of commercial recreational facilities, popular walking, and social engagement destinations were derived from the National Establishment Time Series (NETS) database (20002010) [146]. NETS data were purchased from Walls \& Associates and based on Dun \& Bradstreet data. Businesses of interest were selected using an a priori list of 640 Standard Industrial Classification codes [144] (Table 12). NETS data were geocoded (using geocodes from Dun and Bradstreet or TeleAtlas EZ-Locate) with 97-98\% located at the street segment or block face level for each year from 2000 to 2010 .

Densities of parks, recreational facilities, popular walking destinations, and social engagement destinations were calculated using ArcGIS (Redlands, CA). Park polygons were converted to point lattices for density calculations. Simple and kernel (quadratic distribution) densities were calculated using circular buffers around participants' homes with radii of one quarter-mile, half-mile, and one-, three-, and five-miles. Simple 1-mile densities were used in primary analyses. MESA participants reported being active within 1-mile of home and one-mile represents a reasonable walking distance [147]. Simple densities have a straightforward interpretation and were highly correlated with kernel densities. Kernel densities give more weight to resources closer to the participant's home, reflecting decreasing access with increasing distance. One-mile kernel densities were used in sensitivity analyses. Additional sensitivity 
analyses were conducted using simple densities for half-mile and 3-mile buffers around participants' homes.

Street connectivity was defined as the network ratio, with values ranging from zero (less connectivity) to one (greater connectivity) [111]. Street connectivity data were from StreetMap and StreetMap Premium for ArcGIS (Esri) for 2003 and 2012. StreetMap provided uniform data quality across MESA sites but may be less accurate than street network data obtained directly from municipalities [148]. Population density was calculated from Census 2000 and Census 2010 SF1 data as total population divided by total area in square miles for 1-mile buffers around participants' homes.

Perceptions of the neighborhood environment were measured in four domains: walking environment, aesthetics, safety, and social cohesion (Table 12). The neighborhood was defined as "the area within about a 20-minute walk (or about a mile) from your home". Walking environment, aesthetics, and safety were assessed at exams 2 or 3, and 5. Participants rated their agreement on a five-point scale from strongly disagree (1) to strongly agree (5) with four statements about the walking environment, three about aesthetics, and two about safety. Responses were dichotomized as favorable versus unfavorable/neutral. Social cohesion was measured at exams 1 and 5. Participants rated four statements on a five-point scale from strongly disagree (1) to strongly agree (5). After reverse coding so that a higher number corresponded to greater cohesion for all statements, the social cohesion score was calculated as the sum for all measures and categorized as low (0 to 11$)$, moderate (12 to 15$)$, or high (>15). 


\subsubsection{Statistical Analyses}

Statistical analyses for Aims 1 and 2 were conducted using SAS Version 9.3 (Cary, NC) and are described next.

\subsubsection{Analyses of Longitudinal Patterns in Physical Activity and Sedentary Behavior by Retirement Status (Aim 1)}

First, baseline sociodemographic characteristics, domain-specific and summary physical activity, and TV watching were described. Characteristics were compared by retirement status during follow-up using Chi-squared and Kruskal-Wallis tests, as appropriate.

Second, linear fixed-effect models were used to estimate longitudinal patterns in domainspecific and overall MVPA and TV watching by retirement status. Separate models were constructed for each domain of physical activity, overall MVPA, and TV watching. Continuous measures of physical activity and sedentary behavior were log transformed to fit model assumptions. The time scale for models was age, centered at 63 years (median retirement age among MESA participants). Models also included an indicator of retirement status, time since retirement, and covariates to adjust for confounding. The coefficients of primary interest were for retirement status, age, and age + time since retirement. These coefficients represented the mean difference in physical activity or TV watching associated with transitioning to retirement and the rate of change in physical activity or sedentary behavior among non-retired and retired participants, respectively. Comparing patterns among people who did and did not retire allowed us to control for age-related and other changes in physical activity and TV watching that may not be related to the retirement transition [32]. Models were stratified by SEP (dichotomized at the median) to explore differences among persons of low and high SEP.

Fixed-effects models leveraged longitudinal data while correcting for dependence between repeated measures on each participant. Fixed-effect models do not require the same 
number of observations across

participants or equal intervals between

observations. Physical activity and TV

watching were not assessed at equal

intervals during MESA follow-up

(Figure 3). MESA exams also were not

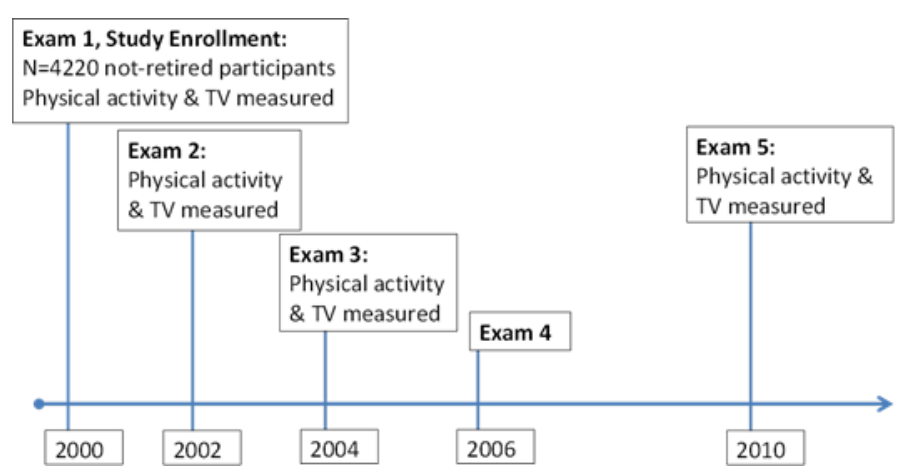

Figure 3. Multi-Ethnic Study of Atherosclerosis timeline scheduled at equal intervals relative to retirement. Time since retirement was included in models to control for the potential impact of variation in timing of physical activity and TV watching measures relative to retirement because behavior patterns may change with longer time since retirement $[87,88]$.

Potential confounders were identified through analysis of a directed acyclic graph (Figure 4) [149]. The same graph was used for both physical activity and sedentary behavior. Potential confounders were: age, race/ethnicity, gender, SEP, prior occupational physical activity, partnership status, self-rated health, and chronic conditions. Of these, only time-varying confounders (partnership status, self-rated health, and chronic conditions) were included in models because fixed-effect models focus on within subject variation, thereby tightly controlling for confounding by time-fixed covariates. Age was the time scale for the model. Time-varying confounders were modeled using dummy indicator coding. 


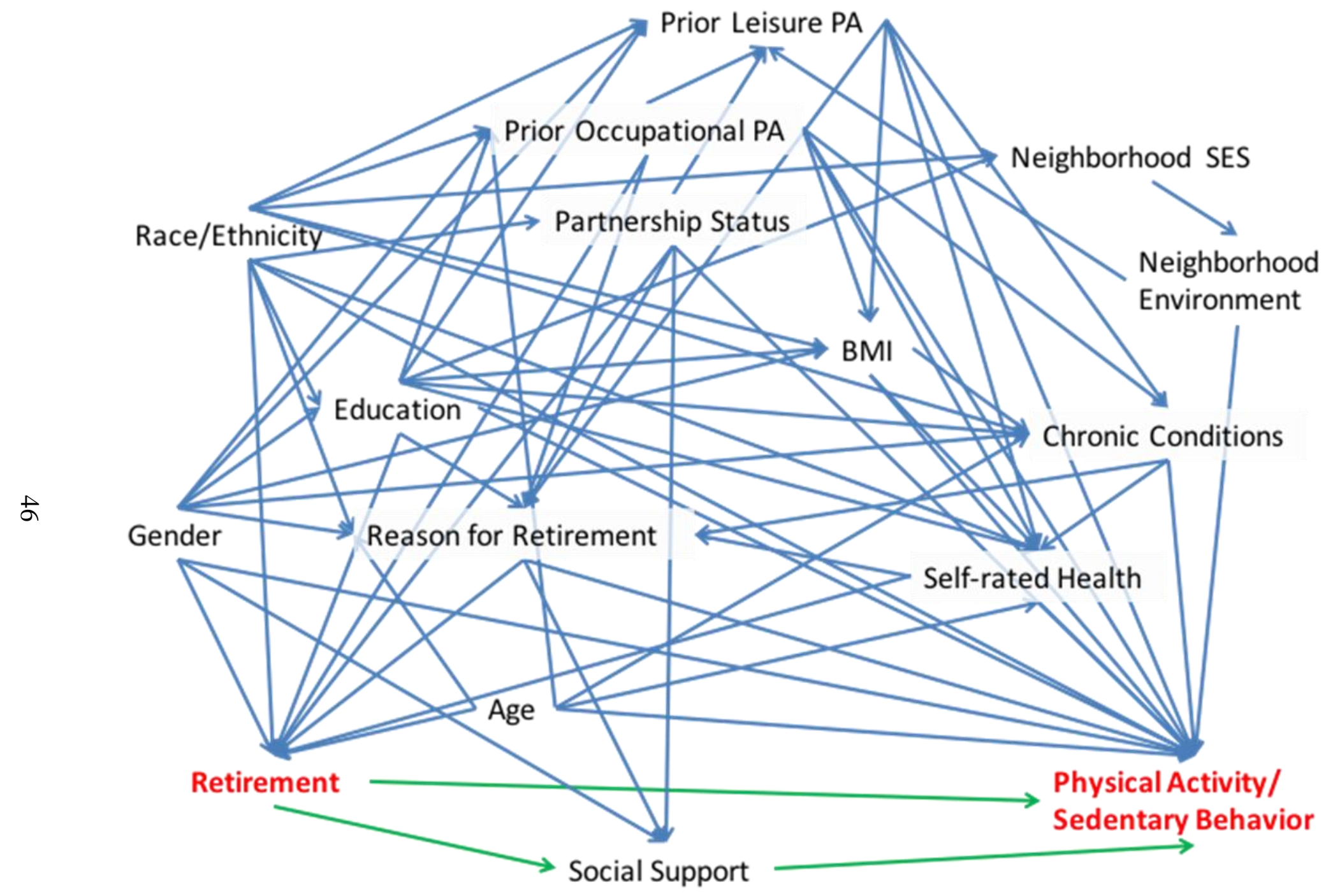

Figure 4. Directed acyclic graph of the relationship between retirement and physical activity and sedentary behavior Abbreviations: BMI body mass index; PA physical activity; SES socioeconomic status 


\subsubsection{Analyses of Correlates of Changes in Walking at Retirement (Aim 2)}

Potential correlates of changes in walking were identified from existing literature [12, $110,112,150,151]$ and were categorized according to levels of the Social Ecological Model: individual $(n=10)$, interpersonal $(n=3)$, or community / neighborhood $(n=16)$. Individual correlates were retirement age, gender, race/ethnicity, SEP, MESA site, car ownership, selfreported occupational physical activity, change in self-rated health, change in number of chronic conditions, and change in BMI. Changes in health and BMI were calculated as the difference between pre- and post-retirement exams). Interpersonal correlates were change in partnership status, change in caregiver status, and social support. Community correlates were observed and perceived neighborhood environment characteristics (Table 12). Neighborhood environment measures corresponding to the MESA exam closest to the estimated retirement date were used. For items measured repeatedly, we explored correlation between measures at the pre-retirement and post-retirement to understand the extent to which MESA participants' built environment changed during the retirement transition (e.g., due to new construction or moving).

In Aim 2 analyses, we first described the distribution of within-person changes in recreational and transport walking after retirement and potential correlates. Collinearity between correlates at each level (individual, interpersonal, community) was assessed. Substantive knowledge and existing literature were used to select among highly collinear correlates ( $\mathrm{r}$ > $0.65)$.

Second, multivariable logistic regression models were constructed to identify correlates of changes in recreational and transport walking after retirement separately. Four total models were constructed, two each for changes in recreational and transport walking. Separate models compared participants who increased $(\geq 60 \mathrm{~min} /$ week) and decreased $(\leq-60 \mathrm{~min} /$ week) versus 
maintained walking levels after retirement. Participants who reported no walking before and after retirement were excluded from models $(\mathrm{N}=136$ for recreational walking, $\mathrm{N}=41$ for transport walking). All potential correlates were entered in initial models. Then a backward selection strategy was used to sequentially remove correlates using likelihood ratio tests to compare nested models $(\alpha=0.2)$. Eight core variables were retained in all models (gender, retirement age, race/ethnicity, SEP, MESA site, season of pre- and post-retirement exams, and tertile of preretirement recreational walking (in recreational walking models) or transport walking (in transport walking models)). Categorical correlates were coded using dummy indicator variables. Continuous correlates were entered in models as linear terms or categorized if a non-linear relationship was identified in exploratory analyses with more flexible model forms (e.g., splines).

\subsubsection{Sensitivity Analyses}

Five sensitivity analyses were conducted to explore the robustness of findings from Aim 1 (Table 13). First, onset of disease may prompt retirement and result in reduction of physical activity and increased sedentary behavior $[20,53]$. Thus, confounding by indication was explored in sensitivity analyses restricted to persons who were healthy throughout follow-up [152], and separately, among persons with chronic conditions. Second, four alternative definitions of retirement were used, as described in Table 9. Third, due to concerns regarding over reporting of physical activity, we excluded persons reporting $\geq 18$ hours/day of physical activity and models were adjusted for method of physical activity questionnaire administration (self vs. interviewer) and season of exam. Fourth, to account for attrition over time, inverse probability of censoring weights were used to weight fixed-effect models [153]. Estimates from weighted models were compared to findings from the primary analyses. Fifth, to explore 
potential demographic and geographic variation in findings, models were stratified by SEP and race/ethnicity and site, and models were stratified by education in place of SEP.

Eight sensitivity analyses were used to explore findings from Aim 2 analyses (Table 13).

First, to explore whether associations between correlates and changes walking varied among demographic groups, interaction terms were added to models between correlates and gender, retirement age, SEP, and education. Second, to determine whether associations between walking and SEP were driven by specific components of the composite measure, we replaced the SEP measure in models with the component variables. Third, models were adjusted for recreational walking were adjusted for change in transport walking and vice-versa in case changes in one walking domain were prompted by changes in the other walking domain. Fourth, to address potential misclassification of retirement status, models were restricted to participants who were

Table 13. Sensitivity analyses for Aims 1 and 2

\begin{tabular}{|c|c|}
\hline Potential issue & Description \\
\hline \multicolumn{2}{|l|}{ Aim 1} \\
\hline Confounding by indication due to ill-health & Restrict analyses to individuals in good health throughout follow-up \\
\hline Misclassification due to retirement definition & Repeat analyses with alternative retirement definitions (see Table 9) \\
\hline Over-reporting of physical activity & $\begin{array}{l}\text { Exclude persons who report }>18 \text { hours/day of physical activity } \\
\text { Adjust for method of physical activity questionnaire administration } \\
\text { (interview vs. self-administered) and season of exam }\end{array}$ \\
\hline Attrition & Apply stabilized, time-varying inverse probability of censoring weights \\
\hline Effect measure modification & Stratify models by SEP and (separately) race/ethnicity and MESA study site \\
\hline & Stratify models by education in place of SEP \\
\hline \multicolumn{2}{|l|}{$\operatorname{Aim} 2$} \\
\hline Demographic variation in correlates & $\begin{array}{l}\text { Add interaction terms to final models between correlates and gender, } \\
\text { retirement age, SEP, and education }\end{array}$ \\
\hline Relevance of SEP components & $\begin{array}{l}\text { Replace SEP variable with separate variables for each component } \\
\text { (education, income, and ownership of home, car, investments, and property) }\end{array}$ \\
\hline Changes in other walking domain & Adjust recreation walking models for transportation walking and vice-versa \\
\hline Misclassification of retirement status & Exclude participants who reported working after retirement \\
\hline Population density & Adjust models for population density \\
\hline Relevant scale for access to resources & $\begin{array}{l}\text { Repeat analyses with } 1 / 2 \text {-mile and } 3 \text {-mile simple densities } \\
\text { Repeat analyses with } 1 \text {-mile kernel instead of } 1 \text {-mile simple densities }\end{array}$ \\
\hline Public parks & Add park density to models for the subset of participants with parks data \\
\hline $\begin{array}{l}\text { Misclassification of neighborhood } \\
\text { environment }\end{array}$ & $\begin{array}{l}\text { Exclude participants who moved between pre- and post-retirement MESA } \\
\text { exams }\end{array}$ \\
\hline
\end{tabular}

Abbreviations: MESA Multi-Ethnic Study of Atherosclerosis; SEP socioeconomic position 
not working. Fifth, models were adjusted for population density. Sixth, because associations between built environment characteristics and physical activity may depend on the geographic scale at which the environment is measured [111,154], 1-mile density measures were replaced with $1 / 2$-mile and 3-mile measures. Also, because the relevance of destinations may decline with distance, simple density measures were replaced with kernel density measures. Seventh, density of public parks was added to models for the subset of participants where the data were available. Eighth, we excluded persons who moved between the pre- and post-retirement exams because although we used environmental characteristics for each participant corresponding to the exam closest to their estimated retirement date, if a participant moved between that exam and retirement, there is potential for misclassification of environmental measures.

\subsection{Research Approach for Qualitative Analyses (Aim 3)}

Aim 3 was accomplished via qualitative analyses of semi-structured interviews addressing facilitators and barriers to physical activity after retirement. The qualitative study was designed to illuminate findings from quantitative analyses in Aims 1 and 2. Reflecting the exploratory nature of this study, there were no pre-specified hypotheses for this aim [155].

\subsubsection{Recruitment and Study Population}

Forsyth County, NC was selected as the catchment area for this study because it was one of the six MESA sites. We recruited a purposeful sample of 15 recently retired women living in Forsyth County, NC. Participants were recruited through community events and flyers announcing the study. Flyers were posted at local venues serving older adults, including libraries, senior centers, and recreation centers. Flyers were posted electronically to social media by religious networks and distributed in the senior center e-newsletter. Interested women were directed to contact the study investigator by phone or email to confirm eligibility and receive more information about the study. Eligible participants were invited to schedule an interview. 
Recruitment continued until data saturation was reached [156], with a total sample size of 15 participants.

Eligibility criteria were female gender, age 55 to 75, residing in Forsyth County, NC, and retired within the previous five years. The age window corresponds to typical retirement ages in the US. Women within one to five years post-retirement were expected to have adapted to retirement [67], and this window was consistent with prior studies (Table 3). To match the demographic characteristics of MESA participants from NC, we sought a socio-economically and racially/ethnically diverse sample. We also sought to include women who worked jobs with varying levels of occupational physical activity to better understand how prior occupational physical activity was related to physical activity after retirement.

\subsubsection{Data Collection Instruments}

Data collection instruments included a study questionnaire, semi-structured interview guide, and field notes.

\subsubsection{Study Questionnaire}

Each participant completed a brief study questionnaire prior to the interview (APPENDIX 1). Questionnaire items were adapted from MESA. The questionnaire had three parts. First, women were asked to report socio-demographic information including age, race/ethnicity, highest education achieved, marital status, time since retirement, prior job title and occupational physical activity level (mostly sitting, standing, walking, or moderate effort). The second part of the questionnaire assessed women's perception of the walking environment, aesthetic quality, safety, and social cohesion in their neighborhood. The third part of the questionnaire asked women to report their current physical activity. Neighborhood and physical activity questionnaire items were identical to those described above in Sections 4.1.2.6 and 4.1.2.2, respectively. 
In addition to the questionnaire, each participant's home address was used to look up their neighborhood Walk Score ${ }^{\circledR}$. Walk Score ${ }^{\circledR}$ reflects the walkability of the neighborhood environment and was positively associated with walking among MESA participants in a previous study [117].

\subsubsection{Semi-structured Interview Guide}

A semi-structured interview guide was developed based on the literature and study goals to inform the targeting of interventions (APPENDIX 1). Interview questions were guided by Life Course Theory and the Social Ecological Model [23, 24]. Participants were asked to describe their current and pre-retirement participation in physical activity, barriers and facilitators of physical activity after retirement, and ideas for supporting physical activity among retired women. The terms "physical activity" and "sedentary behavior" were defined by the interviewer immediately prior to questions about these behaviors. The interview guide was piloted with two retired women.

\subsubsection{Field Notes}

Consistent with best practice recommendations [157, 158], field notes were maintained throughout the study. Field notes comprised information on recruitment efforts including refusals, impressions of the quality of interactions with participants and/or nonverbal communication, and reflections on issues that influence the accuracy and completeness of interview data [158]. In addition, a summary sheet was created after each interview to summarize key points and emergent ideas [158].

\subsubsection{Interviews}

Participants were interviewed at the location of their choice. Two interviews took place in person whereas the other 13 interviews were conducted by phone. Participants provided verbal consent prior to the interview. Interviews were conducted according to the interview guide, 
which provided consistency in the topics raised. The semi-structured format allowed follow-up or adaptation of questions to comprehensively explore the topics in each interview [159]. Interviews lasted an average of 40 minutes and were digitally recorded. At completion of the interview, participants received an incentive (\$20) to thank them for their time. Interview recordings were transcribed verbatim and transcripts were reviewed for accuracy. Audio files were destroyed after transcripts were checked. All data were saved using study identifiers to ensure participants' anonymity. Transcripts were uploaded to ATLAS.ti (Berlin, German) for analysis.

\subsubsection{Analyses of Facilitators and Barriers to Physical Activity after Retirement}

Study questionnaire data were summarized across participants. Participants' demographic characteristics, neighborhood perceptions, and physical activity were compared to those of female MESA participants from NC who retired during follow-up ( $\mathrm{n}=97)$. This comparison facilitated understanding of the similarities between the quantitative and qualitative study samples analyzed in this dissertation.

Interview transcripts were reviewed using a pragmatic approach [160] to directed content analysis [161]. Each transcript was independently coded by two trained coders. An a priori list of codes was developed based on research questions, existing theory, and literature [161]. Codes were revised and added throughout the analysis process. As codes were added or revised, previously coded transcripts were reviewed to ensure consistent coding across the sample [162]. In most cases, entire paragraphs were coded to maintain context. Not all text was coded. A codebook was used to record code definitions, modifications, and example quotations.

Themes related to facilitators and barriers to physical activity were developed based on review and discussion of coded quotations. Similarities and differences were explored between women who retired from physically active $(n=7)$ and sedentary $(n=8)$ occupations. Matrices and 
network displays facilitated development of themes through linking and grouping of quotations [162]. In addition, memos were used to document emergent ideas, decisions, and modifications [163].

\subsubsection{Analytic Quality: Reflexivity, Validity, and Reliability}

A number of strategies were employed to protect the quality and rigor of the analysis. Content validity of interview questions was established in pilot interviews [164]. Potential issues that could affect the quality or completeness of data were recorded in field notes (e.g., related to rapport with participants) [162]. Transcripts were checked against audio recordings and independently double coded [162]. Discrepancies in coding were resolved through consensus. Throughout data collection and analysis, ideas, challenges, and developments were documented in reflexive memos [158]. Direct evidence (quotations) were provided to support inferences and transcripts were examined for deviant cases (i.e. counter examples) that did not fit overall themes [162]. Further, the study was reported consistent with the Consolidated Criteria for Reporting Qualitative Research checklist [157].

\subsection{Dissemination of Findings}

Findings from this dissertation were disseminated to researchers interested in physical activity/sedentary behavior among retirement aged adults through peer-reviewed publications and presentation of Aim 1 findings at a national meeting (American College of Sports Medicine 2017 Annual Meeting). In addition, findings were shared via the Workplace Health Research Network and the Physical Activity Policy Research Network Plus, which are networks of researchers and practitioners funded by the Centers for Disease Control and Prevention. Dissemination efforts were intended to enhance the potential impact of this research on real world practice. In addition, a lay summary of findings was distributed to participants and stakeholders in Forsyth County, NC who assisted with recruitment. 


\subsection{Study Power}

Estimates of statistical power are traditionally used to define sample size goals in quantitative observational and experimental studies [165]. For this dissertation, the sample size for quantitative analyses was fixed because the data already were collected. However, estimates of statistical power still may be informative regarding the magnitude of detectable effects, assuming such effects exist. Power analyses were conducted in R version 3.2 (Vienna, Austria) using package pwr [166].

For Aim 1, estimates of power for fixed-effect models with longitudinal repeated measures and a time varying exposure are not straightforward. Thus, simplified power analyses were conducted to estimate the effect size detectable with $80 \%$ power comparing retired to nonretired participants without accounting for longitudinal repeated measures. Power calculations were conducted under the following assumptions: sample size of 3,200 non-retired and 900 retired participants based on preliminary data, alpha $=0.05$, and a two-sided test of the null hypothesis of no difference between retired and non-retired participants. With $80 \%$ power, the estimated effect size was 0.11 . Assuming standard deviations for each measure of physical activity and sedentary behavior as indicated (Table 14), this effect size corresponded to differences of 25 to $108 \mathrm{~min} /$ week in mean physical activity and $14 \mathrm{~min} /$ week in mean TV watching comparing retirees to non-retirees. Estimated differences in means were comparable or smaller in magnitude to the effect of retirement estimated in a prior study of domain-specific physical activity [83]. 
Table 14. Estimated differences in mean physical activity and sedentary behavior for Aim 1 power calculations

\begin{tabular}{lll}
\hline Activity Domain & Standard deviation ${ }^{\text {a }}$ & Difference in means \\
\hline Recreational walking & $240 \mathrm{~min} /$ week [111] & 25 min/week \\
Transport walking & $375 \mathrm{~min} /$ week [11] & 39 min/week \\
Household activity & 17 hours/week & 1.8 hours/week \\
Caring for others & 17 hours/week & 1.8 hours/week \\
Intentional exercise & $420 \mathrm{~min} /$ week [167] & 45 min/week \\
Moderate to vigorous physical activity & 17 hours/week [167] & 1.8 hours/week \\
Television watching & $132 \mathrm{~min} /$ week [168] & 14 min/week \\
\hline${ }^{a}$ Based on published estimates from the MESA cohort with estimates for household, caring, and leisure activity assumed to be equal to the \\
estimate for moderate to vigorous physical activity. Standard deviations were assumed to be equal among retired and non-retired participants.
\end{tabular}

For Aim 2, the effect size for categorical and continuous correlates that would be detectable with $80 \%$ power was estimated. Power calculations were conducted assuming a sample size of 900 participants based on preliminary data, an alpha of 0.05 , and a two-sided hypothesis test. Small effect sizes were detectable with $80 \%$ power for both categorical and continuous correlates. For continuous correlates, the estimated detectable linear correlation coefficient $(r)$ was 0.09 . For categorical correlates, based on a balanced one-way analysis of variance test, the estimated detectable effect size $(f)$ varied from 0.09 to 0.11 for variables with two to five levels, with larger effect sizes for a higher number of levels. For example, for a binary correlate (e.g., gender) assuming an equal distribution (e.g., 50\% men and 50\% women) and a standard deviation of $240 \mathrm{~min} /$ week for recreational walking [111], there would be $80 \%$ power to detect a difference of $45 \mathrm{~min} /$ week recreational walking. Note that these power estimates do not account for adjustment for other correlates. 


\section{CHAPTER 5. PHYSICAL ACTIVITY, SEDENTARY BEHAVIOR, AND RETIREMENT: THE MULTI-ETHNIC STUDY OF ATHEROSCLEROSIS ${ }^{1}$}

\subsection{Introduction}

Retirement is a major later life transition involving disruption in daily activities, time constraints, social support, and priorities $[14,15]$. Maintenance of a healthy lifestyle after retirement can improve quality of life, delay impairment, and lower healthcare costs $[5,6,48]$. Regular physical activity is an important component of a healthy lifestyle [5, 6]. However, the prevalence of physical activity among retirees is low, with $45 \%$ of American retirees reporting no physical activity [169]. Understanding behavior change at retirement could inform interventions to support physical activity after retirement $[11,12]$.

Retirement has been associated with positive and negative changes in both physical activity and sedentary behavior $[19,79]$. Leisure-time physical activity and TV watching increased after retirement with inconsistent changes in overall physical activity $[19,25,83,110]$. Without measures of occupational physical activity, many prior studies could not determine whether increased leisure-time physical activity was sufficient to replace lost occupational activity [19]. Utilitarian domains of physical activity, such as transportation activity, have not been well studied [19]. Describing domain-specific changes in physical activity is important to guide intervention development. Interventions are more likely effective if targeted to specific physical activity domains [133].

\footnotetext{
${ }^{1}$ This chapter appears as an article in the American Journal of Preventive Medicine: Jones SA, et al. Physical activity, sedentary behavior and retirement: the MESA. Am J Prev Med. In press.
} 
Patterns of behavior change at retirement may vary by SEP [37, 70, 83]. Socioeconomically disadvantaged adults are more likely to retire due to ill health or job loss rather than voluntarily, and to live alone and with disabilities, making prevention of chronic disease a priority among disadvantaged elders $[20-22,104,170]$. This study aimed to describe longitudinal patterns in overall MVPA and domain-specific physical activity and TV watching among participants in the MESA by retirement status, overall and within strata of SEP.

\subsection{Methods}

\subsubsection{Study Population}

The MESA is a prospective, longitudinal cohort study of subclinical CVD [125]. Briefly, 6,814 adults aged 45 to 84 years and free of clinical CVD were recruited at six sites: Forsyth County, NC, Northern Manhattan and the Bronx, NY, Baltimore City and Baltimore County, MD, St. Paul, MN, Chicago, IL, and Los Angeles County, CA. Participants who were retired at baseline $(\mathrm{N}=2,584)$ were excluded $[83,84]$. Pre-retirement physical activity and TV watching measures were not available for these participants and their date of retirement was unknown. Participants with missing data on employment status, physical activity, or covariates at all time points also were excluded $(\mathrm{N}=139)$. For the remaining 4,091 participants, data were analyzed from five study exams (2000-2002, 2002-2004, 2004-2005, 2005-2007, 2010-2012), and five follow-up phone calls (2007-2012).

\subsubsection{Retirement Definition}

MESA participants self-reported employment status at each exam and five follow-up calls. Participants who reported being retired and not working, retired and working, or retired and volunteering were classified as retired. All other participants were classified as not retired (Table 19). Retirement date was estimated as the midpoint between the last non-retired and first 
retired exam. Participants were classified as retired for all exams after the first exam at which they reported being retired [171].

\subsubsection{Physical Activity and Sedentary Behavior}

Physical activity and sedentary behavior were self-reported at exams 1, 2, 3, and 5. The MESA physical activity questionnaire (https://www.mesa-nhlbi.org/PublicDocs/010101011231/MESABaselineExamForms/physactivity.pdf) was adapted from the Cross-Cultural Activity Participation Study,[131] which had acceptable test-retest reliability (Intra-Class Correlation coefficients 0.55 to 0.75$)$ and validity ( $r=0.45$ to 0.51$)$ among women.[132] Participants reported whether they participated in multiple domains of physical activity and sedentary behavior in a typical week of the last month. Participants reported frequency (days/week) and duration (min/day) of activity by domain and by perceived intensity for household/yard, caregiving, conditioning, and occupational/volunteer activities.

This study analyzed one overall and five domain-specific physical activity measures. To calculate overall MVPA, MET were assigned (Table 20), and MET-min/week were summed for moderate and vigorous walking, household/yard, caregiving, non-walking leisure, and occupational/volunteer activities. Domain-specific measures were: min/week of recreational walking, transport walking, household/yard activity, caregiving activity, non-walking leisure activity (sports, conditioning, and individual activities). TV watching (min/week) was the only sedentary behavior assessed consistently across exams.

\subsubsection{Socioeconomic Position}

SEP was calculated as previously in MESA based on self-reported education $(\leq$ high school, some college but no degree, associate/bachelor's degree, graduate/professional degree), household income $(<\$ 25,000, \$ 25,000-39,999, \$ 40,000-74,999, \geq \$ 75,000)$, and four indicators 
of wealth (ownership of a home, car, land/property, or investments) [135]. The SEP score (range 0-10) was the sum of scores for education ( $0-3$ from lowest to highest), income ( $0-3$ from lowest to highest), and one point for each wealth indicator.

\subsubsection{Covariates}

Self-rated health relative to others of the same age (worse, same, better) and partnership status (married/ living with partner vs. not) were self-reported at study exams. Partnership status was not assessed at exam 2, so it was imputed from the closer of exams 1 or 3 . At each exam nine chronic conditions were assessed: self-reported asthma, emphysema, or arthritis flare up in the previous two weeks, measured high cholesterol or hypertension, self-reported or measured diabetes, and kidney disease, cancer, and CVD ascertained from medical records and hospital billing claims $[125,172]$.

\subsubsection{Analyses}

Participant characteristics were described for the overall study population and by retirement status during follow-up. Participant characteristics were compared by retirement status using Chi-squared and Kruskal-Wallis tests.

Longitudinal patterns in physical activity and TV watching were described using fixedeffect regression [173]. Fixed-effect models focus on within-person variation to control for confounding by measured and unmeasured time-fixed characteristics (e.g., race/ethnicity, gender) and account for dependence between repeated measures. The timescale for analyses was age, which is meaningful for people who did and did not retire and accommodated repeated measures taken at unequal intervals. Longitudinal models in this study had the form:

$$
Y_{i j}=\beta_{1} a g e_{i j}+\beta_{2} R_{i j}+\beta_{3} t_{i j}+\sum_{k} \beta_{k} Z_{i j k}+\alpha_{i}+\varepsilon_{i j}
$$


Age was centered at age $63 . R_{i j}$ was a time-varying indicator of retirement, and $t_{i j}$ represented time since retirement $\left(t_{i j}=0\right.$ if $R_{i j}=0, t_{i j}=a g e_{i j}$-retirement age if $\left.R_{i j}=1\right)$. The vector $Z_{i j k}$ was dummy indicator variables for time-varying covariates (partnership status, self-rated health, chronic conditions). $\alpha_{i}$ was an individual-specific intercept and $\varepsilon_{i j}$ was an error term. $Y_{i j}$ represented the log-transformed outcome measure for individual $i$ at time $j$. Prior to log-transformation, a small value was added to account for zeros in the data. Exponentiated model coefficients represented the percentage change in the outcome associated with retirement $\left(\beta_{2}\right)$, and percentage change in the outcome per five-year increase in age among not retired $\left(\beta_{1}\right)$ and retired $\left(\beta_{1}+\beta_{3}\right)$ participants, conditional on fixed values of the adjustment variables. Each physical activity measure and TV watching were modeled separately for the entire sample and stratified by SEP (dichotomized at the median). There was no evidence for variation by gender or non-linear changes in outcomes over time. Crude and adjusted estimates were nearly identical so only adjusted estimates are presented. Analyses were conducted in 2017 using SAS Version 9.3 (Cary, NC).

\subsubsection{Sensitivity Analyses}

To address potential residual confounding by health problems that could force retirement and reduce physical activity, a sensitivity analysis was conducted among participants in good health. Good health throughout follow-up was defined as survival free of CVD, depression, cognitive impairment, cancer, and chronic obstructive pulmonary disease (Table 21) [152].

To explore the robustness of findings, retirement was redefined in four sensitivity analyses (Table 19). First, retirement status was defined in three-levels: not retired (referent), retired and working for pay $(\mathrm{N}=184$ people), and retired and volunteering or not working $(\mathrm{N}=828$ people). Second, retirement status was reassigned at each exam to accommodate retirees who returned to work ( $\mathrm{N}=141,14 \%$ of retirees). Third, retirement was strictly defined as selfidentifying as retired, reporting zero work hours, and no occupational physical activity ( $\mathrm{N}=717$, 
$71 \%$ of retirees). Fourth, persons who ever identified as homemakers ( $\mathrm{N}=866)$, on leave from work, or unemployed ( $\mathrm{N}=855$ observations) were excluded.

To further explore differences by SEP, three additional sensitivity analyses were conducted. First, models were stratified by education (less than college degree vs. Associates degree or higher) in place of SEP. Second models were stratified by race/ethnicity and SEP, and third, by MESA site and SEP, to explore potential racial/ethnic and geographic differences.

Additional sensitivity analyses were conducted to assess self-reported physical activity measures and attrition. Persons reporting $\geq 18$ hours/day of physical activity were excluded and models were additionally adjusted for method of physical activity questionnaire administration (self vs. interviewer) and season of exam. To explore potential selection bias, models were weighted by inverse probability of attrition [153].

\subsection{Results}

These analyses included 4,091 MESA participants who were not retired at baseline out of the total MESA sample size of 6,814. Participants in this study were younger, more likely female and of higher SEP, and at baseline had fewer chronic conditions, watched less TV, and engaged in more MVPA compared to excluded participants. At baseline, participants had an average age of 57 years, $56 \%$ were female, $40 \%$ were non-Hispanic white, $51 \%$ had a college degree or higher, $65 \%$ lived with a partner, and 62\% were employed full time (Table 15). Participants reported a median of $10 \mathrm{~min} /$ week non-walking leisure activity, $90 \mathrm{~min} / \mathrm{wk}$ recreational walking, $180 \mathrm{~min} / \mathrm{wk}$ transport walking, $13.5 \mathrm{hr} /$ week household activity, and $12 \mathrm{hr} / \mathrm{wk}$ TV watching.

During a median of 9 years of follow-up, 1,012 participants (25\%) retired. Median retirement age was 63 years. Compared to participants who did not retire, retirees were more likely male, non-Hispanic white or black, of higher SEP, older, in better health, employed full 
time, and reported more MVPA and transport walking at baseline (Table 15). There were 435 retirees with low SEP and 577 with high SEP.

Domain-specific patterns of physical activity and TV watching by retirement status, overall (Table 16)and by SEP (Table 17), are described next. Findings are presented graphically in Figure 5 and Figure 6.

\subsubsection{MVPA}

Retirement was associated with a 10\% decrease in MVPA (95\% confidence interval (CI): $-15 \%,-5 \%$ ) (Table 16). MVPA declined over time regardless of retirement status at a rate of $-4 \%$ to $-6 \%$ per five years. Stratified by SEP, retirement was associated with a $24 \%$ decrease in MVPA among persons of low but not high SEP (Table 17).

\subsubsection{Non-Walking Leisure Activity}

Retirement was associated with a 9\% increase (95\% CI: 3\%, 14\%) in non-walking leisure activity in the overall sample (Table 16) and 16\% increase (95\% CI: 8\%, 24\%) among persons of high SEP (Table 17). The average change in non-walking leisure activity per five years was small, except for an increase among low SEP retirees.

\subsubsection{Walking}

Retirement was associated with a 13\% (95\% CI: 7\%, 20\%) increase in recreational walking (Table 16), and among persons of low and high SEP (17\% and 11\% increase, respectively) (Table 17). Recreational walking increased at a rate of $8 \%$ per five years in the overall sample with small differences between SEP strata. Retirement was not associated with changes in transport walking in the overall sample or within SEP strata (Table 16 and Table 17).

\subsubsection{Household / Yard and Caregiving Activity}

At retirement, household and yard activity increased by an average of $29 \%$ (95\% CI: $22 \%, 36 \%$ ) in the overall sample (Table 16) and increased in both SEP strata (Table 17). 
Household and yard activity changed little over time. In the overall sample, retirement was not associated with changes in caregiving (Table 16). Caregiving activity declined with age among persons of low but not high SEP (Table 17).

\subsubsection{TV Watching}

Retirement was associated with a $15 \%$ increase in TV watching (95\% CI: $8 \%, 21 \%)$ in the overall sample (Table 16) and increases in both strata of SEP (Table 17). TV watching increased by $11-17 \%$ per five years in all retirement and SEP groups.

\subsubsection{Sensitivity Analyses}

Among 2,085 participants who were healthy throughout follow-up, 611 retired (226 low and 385 high SEP). In this healthy subset, retirement was associated with a smaller decrease in MVPA among persons of low SEP and larger increase in household/yard activity in both SEP strata (Table 18). Other results were similar to the overall sample.

Employing alternative retirement definitions made little impact on the pattern of results (data not shown). Among people "retired and working" $(\mathrm{N}=184)$, retirement was not associated with change in MVPA, recreational walking, or non-walking leisure activity. Other findings were similar among retirees who were and were not working. Findings from models stratified by education were consistent with SEP stratified analyses (Table 22). Although there was some variation in SEP-stratified findings by race/ethnicity and MESA site, estimates were imprecise due to small numbers (Figure 7 and Figure 8). Adjustment for mode of physical activity questionnaire administration and season of exam, exclusion of persons reporting excessive activity, and weighting by inverse probability of attrition did not alter the pattern of results (data not shown). 


\subsection{Discussion}

In this US cohort, retirement was associated with increased recreational walking, household/yard activities, and TV watching. Among persons of low SEP, retirement was associated with declines in overall MVPA. Overall MVPA was stable during the retirement transition among persons of high SEP who reported more non-walking leisure activity after retirement. These findings are consistent with increased leisure-time physical activity after retirement observed among persons of high SEP but not low SEP [19, 37, 70, 83]. These findings suggest that the retirement transition may be an important period for physical activity promotion, particularly among persons of low SEP [30].

Among retirees of low SEP, declines in occupational activity at retirement were not recouped by increases in other physical activity domains, resulting in decreased overall MVPA. Poor heath is one explanation for this finding. Illness and disability are more common reasons for retirement among persons of low SEP [20] and associated with limited physical activity [53]. Retirement may be associated with larger decreases in MVPA among persons with chronic diseases. However, persistence of a negative association of retirement with MVPA among healthy retirees of low SEP suggests that poor health does not entirely account for MVPA declines associated with retirement. Future studies could be strengthened by exploring the role of physical function, which was not consistently measured in MESA.

SEP is a multidimensional construct that can be measured at different points in the lifespan [174]. In this study, adult SEP was measured prior to retirement as a composite of education, income, and wealth [135]. Stratification by education instead of SEP yielded consistent results. Cumulative disadvantage was not measured in this study; however, earlier life opportunities are key determinants of retirement and physical activity [2, 13, 17, 45]. Persons with more debt or lower income are less likely to be able to retire and more likely to return to 
work after retirement [45, 64]. Low SEP can constrain earlier life physical activity through limited leisure-time, disposable income, and the demands of physical labor [13, 74, 105]. After retirement, low SEP may be associated with not owning exercise equipment, greater sensitivity to gym costs, and residence in a neighborhood lacking physical activity supports (e.g., few parks) [122], while age discrimination may discourage activity in public [175].

In the US, race/ethnicity and SEP are closely linked with persons of color more likely to be of low SEP compared to non-Hispanic whites [174]. Estimates stratified by race/ethnicity and SEP were imprecise due to small numbers of retirees in some subgroups. However, the relationship between retirement and physical activity may vary by race/ethnicity due to effects of discrimination, segregation, and cultural diversity in addition to SEP [174]. These factors should be considered in future research on this topic and particularly in development of interventions.

The feasibility of intervening to promote physical activity during the retirement transition is not well established [39]. Ninety percent of large worksites offer one or more health promotion programs; however, retirees often are excluded [176]. In addition, although employers assist with financial planning, few resources are available to help workers prepare for post-retirement physical activity [45]. Existing retirement planning resources could be expanded to include health promotion materials $[17,31]$. However, racial/ethnic minorities and women have less access to retirement planning and are more likely to retire without the opportunity to plan (e.g., due to job loss) [45]. Thus, multiple strategies, including community-based interventions, are needed to avoid exacerbation of health inequities. Experience Corps was a successful intervention among low-income retirees in Baltimore that improved physical activity and strength [77]. In addition to programming, environmental supports may enable retirees by 
physically active [75]. However, despite a strong theoretical rationale, it is not clear how environmental changes affect retirees' physical activity [120, 177].

Retirement was associated with increased TV watching in this sample, which is consistent with findings in other studies $[35,83,86,92,93]$. There was little difference by SEP, contrary to some studies $[83,93]$. TV watching is the most commonly reported sedentary behavior among older adults $[35,61]$. It is unclear how retirement affects other domains of sedentary behavior not measured in MESA. For example, internet and social media could promote sedentary behavior but may be a source of information for physical activity. Also, factors that determine whether sedentary work time is replaced by active or sedentary pursuits after retirement have not been identified [25]. Overall sedentary behavior increased at retirement among French [86] but decreased among Australian retirees [36, 100]. Future work should explore correlates of sedentary behavior change at retirement.

\subsubsection{Limitations and Strengths}

Limitations to this work include reliance on self-reported retirement, physical activity, and TV watching. Perceptions of what it means to be "retired" may vary among participants. Some retirees continued to work. Sensitivity analyses restricted to retirees reporting zero hours of work did not appreciably change results. However, physical activity differences at retirement were attenuated among "retired and working" participants, perhaps because retirement influences behavior partly through changes in discretionary time $[22,70]$. Self-report typically overestimates physical activity and underestimates sedentary behavior relative to accelerometer measures $[4,108]$. It is not clear whether measurement error in self-reported physical activity or sedentary behavior varied by retirement status. Combined use of self-report and accelerometer measures would strengthen future studies. 
The generalizability of findings may be limited because at baseline MESA participants were free of clinical CVD and willing to participate in a longitudinal research study and about $25 \%$ of the sample died or was lost-to-follow-up [125]. However, median retirement age of 63 and $14 \%$ rate of return to work after retirement are consistent with US averages $[45,66,68]$. Findings were robust after statistical adjustment for attrition.

Strengths of this study include prospective follow-up of a diverse US cohort with repeated measures of multiple physical activity domains and TV watching. Domain-specific changes in physical activity were explored, which may improve targeting of interventions. Also, fixed-effect models tightly controlled for confounding by time-invariant characteristics by design and were adjusted for time-varying confounders. Further, multiple sensitivity analyses explored the robustness of the findings.

\subsubsection{Conclusion}

The health of retirement age adults is of increasing public health importance given demographic trends. Almost one quarter of the American workforce is aged 55 or older [178] and 72 million Americans will be aged 65 or older by 2030 [27]. Although retirement is increasingly viewed as an active phase of life [13], the prevalence of physical activity among retirees remains low [169]. Interventions during the retirement transition may help to support active lifestyles in later life. To inform intervention development, future research is needed on the determinants of behavior change after retirement, particularly among persons of low SEP. 
Table 15. Participant characteristics overall by employment status at follow-up, MESA $(\mathrm{N}=4,091)$

\begin{tabular}{|c|c|c|c|}
\hline \multirow[b]{2}{*}{ Baseline characteristics } & \multirow[b]{2}{*}{$\begin{array}{c}\text { Overall }^{\mathrm{a}} \\
(\mathrm{N}=4,091)\end{array}$} & \multicolumn{2}{|c|}{ Retirement Status at Follow-Up } \\
\hline & & Not Retired $^{\mathrm{a}}(\mathrm{N}=3,079)$ & $\begin{array}{c}\text { Retired }^{\mathrm{a}} \\
(\mathrm{N}=1,012)\end{array}$ \\
\hline Age (years), mean \pm SD & $57.3 \pm 8.9$ & $56.9 \pm 9.4$ & $58.4 \pm 6.9$ \\
\hline Female & $2309(56 \%)$ & $1768(57 \%)$ & $541(53 \%)$ \\
\hline \multicolumn{4}{|l|}{ Race/ethnicity } \\
\hline Non-Hispanic white & $1628(40 \%)$ & $1193(39 \%)$ & $435(43 \%)$ \\
\hline Chinese American & $522(13 \%)$ & $416(14 \%)$ & $106(10 \%)$ \\
\hline Non-Hispanic black & $975(24 \%)$ & $680(22 \%)$ & $295(29 \%)$ \\
\hline Hispanic & $966(24 \%)$ & $790(26 \%)$ & $176(17 \%)$ \\
\hline \multicolumn{4}{|l|}{ Education } \\
\hline$<$ High school & $684(17 \%)$ & $581(19 \%)$ & $103(10 \%)$ \\
\hline Some college, no degree & $1303(32 \%)$ & $950(31 \%)$ & $353(35 \%)$ \\
\hline$\geq$ Bachelor's degree & $2102(51 \%)$ & $1547(50 \%)$ & $555(55 \%)$ \\
\hline Low SEP & $2003(49 \%)$ & $1568(51 \%)$ & $435(43 \%)$ \\
\hline Married / with partner & $2636(65 \%)$ & $1994(65 \%)$ & $642(64 \%)$ \\
\hline \multicolumn{4}{|l|}{ Baseline job } \\
\hline Homemaker & $749(18 \%)$ & $694(23 \%)$ & $55(5 \%)$ \\
\hline Employed full time & $2549(62 \%)$ & $1799(58 \%)$ & $750(74 \%)$ \\
\hline Employed part time & $570(14 \%)$ & $411(13 \%)$ & $159(16 \%)$ \\
\hline On leave or unemployed & $221(5 \%)$ & $174(6 \%)$ & $47(5 \%)$ \\
\hline \multicolumn{4}{|l|}{ Self-rated health } \\
\hline Better & $2131(53 \%)$ & $1554(51 \%)$ & $577(57 \%)$ \\
\hline Same & $1612(40 \%)$ & $1261(41 \%)$ & $351(35 \%)$ \\
\hline Worse & $316(8 \%)$ & $239(8 \%)$ & $77(8 \%)$ \\
\hline \multicolumn{4}{|l|}{ MESA Site } \\
\hline Forsyth, NC & $594(15 \%)$ & $383(12 \%)$ & $211(21 \%)$ \\
\hline New York City, NY & $653(16 \%)$ & $488(16 \%)$ & $165(16 \%)$ \\
\hline Baltimore, MD & $584(14 \%)$ & $442(14 \%)$ & $142(14 \%)$ \\
\hline St. Paul, MN & $713(17 \%)$ & $527(17 \%)$ & $186(18 \%)$ \\
\hline Chicago, IL & $743(18 \%)$ & $543(18 \%)$ & $200(20 \%)$ \\
\hline Los Angeles, CA & $804(20 \%)$ & $696(23 \%)$ & $108(11 \%)$ \\
\hline \multicolumn{4}{|l|}{ Physical activity, median (IQR) } \\
\hline MVPA (MET-min/wk) & $4590(2190,8475)$ & $4425(2098,8370)$ & $5220(2513,9025)$ \\
\hline Non-walking leisure (min/wk) & $10(0,180)$ & $3(0,180)$ & $15(0,180.0)$ \\
\hline Recreation walking (min/wk) & $90(0,225)$ & $90(0,225)$ & $90(0,240.0)$ \\
\hline Transport walking (min/wk) & $180(45,420)$ & $150(35,375)$ & $180(60,420.0)$ \\
\hline Household/yard (min/wk) & $810(420,1370)$ & $815(420,1380)$ & $765(390,1290)$ \\
\hline \multirow{3}{*}{$\begin{array}{l}\text { Caregiving }(\mathrm{min} / \mathrm{wk}) \\
\text { Occupational/volunteer MVPA } \\
\text { (MET-min/wk) }\end{array}$} & $0(0,180)$ & $0(0,180.0)$ & $0(0,165)$ \\
\hline & $0(0,2880)$ & $0(0,2700)$ & $450(0,3600)$ \\
\hline & $12(5,18)$ & $12(5,19)$ & $12(6,18)$ \\
\hline TV watching (h/wk), median (IQR) & & & \\
\hline
\end{tabular}


Table 16. Change ${ }^{a}$ in physical activity and television watching by retirement status $(\mathrm{N}=4,091)$

\begin{tabular}{lccc}
\hline Behavior & $\begin{array}{c}\text { Mean change associated } \\
\text { with retirement } \\
(\mathbf{9 5 \%} \mathbf{~ C I})\end{array}$ & Not retired & $\begin{array}{c}\text { Mean 5-year change } \\
\text { (95\% CI) }\end{array}$ \\
\hline MVPA & $0.90(0.85,0.95)$ & $0.94(0.92,0.96)$ & $0.96(0.90,1.02)$ \\
Non-walking Leisure & $1.09(1.03,1.14)$ & $1.01(1.00,1.03)$ & $1.02(0.97,1.08)$ \\
Recreation Walking & $1.13(1.07,1.20)$ & $1.08(1.06,1.10)$ & $1.08(1.01,1.14)$ \\
Transport Walking & $0.99(0.93,1.06)$ & $1.02(0.99,1.04)$ & $0.97(0.91,1.02)$ \\
Household / Yard Activity & $1.29(1.22,1.36)$ & $1.02(1.00,1.04)$ & $0.94,1.08)$ \\
Caregiving Activity & $1.00(0.93,1.07)$ & $0.98(0.96,1.00)$ & $1.14(1.08,1.21)$ \\
\hline
\end{tabular}

Abbreviations: CI Confidence interval; MVPA moderate to vigorous physical activity; TV television

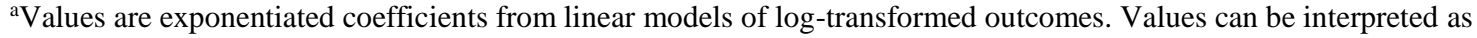
percentage differences, for example 1.07 represents a $7 \%$ increase in the outcome associated with retirement, conditional on adjustment variables (self-reported health, partnership status, and 9 chronic conditions: asthma, emphysema, arthritis flare up, high cholesterol, hypertension, diabetes, kidney disease, cancer, cardiovascular disease). Data presented graphically in Figure 5.

${ }^{b}$ Exponentiated mean difference in log-transformed outcome associated with retirement, conditional on adjustment variables. ${ }^{c}$ Exponentiated mean difference in log-transformed outcome associated with 5-year increase in age among retired and not retired participants, conditional on adjustment variables. 
Table 17. Change ${ }^{a}$ in physical activity and television watching by retirement status and socioeconomic position (N=4,091)

\begin{tabular}{|c|c|c|c|c|c|c|}
\hline \multirow[b]{3}{*}{ Behavior } & \multicolumn{3}{|c|}{$\begin{array}{c}\text { Low socioeconomic position } \\
(\mathrm{N}=2003)\end{array}$} & \multicolumn{3}{|c|}{$\begin{array}{l}\text { High socioeconomic position } \\
(\mathrm{N}=2088)\end{array}$} \\
\hline & \multirow{2}{*}{$\begin{array}{l}\text { Mean change } \\
\text { associated with } \\
\text { retirement } \\
(95 \% \mathrm{CI})\end{array}$} & \multicolumn{2}{|c|}{$\begin{array}{c}\text { Mean 5-year change }{ }^{\mathrm{c}} \\
(95 \% \mathrm{CI})\end{array}$} & \multirow{2}{*}{$\begin{array}{l}\text { Mean change } \\
\text { associated with } \\
\text { retirement }{ }^{\mathrm{b}} \\
(95 \% \mathrm{CI})\end{array}$} & \multicolumn{2}{|c|}{$\begin{array}{c}\text { Mean 5-year change }{ }^{\mathrm{c}} \\
(95 \% \mathrm{CI})\end{array}$} \\
\hline & & Not retired & Retired & & Not retired & Retired \\
\hline MVPA & $0.76(0.68,0.84)$ & $0.89(0.86,0.92)$ & $0.96(0.87,1.07)$ & $1.01(0.95,1.09)$ & $0.98(0.96,1.00)$ & $0.95(0.89,1.02)$ \\
\hline Non-walking Leisure & $1.00(0.92,1.08)$ & $1.01(0.99,1.04)$ & $1.09(1.01,1.18)$ & $1.16(1.08,1.24)$ & $1.02(1.00,1.04)$ & $0.98(0.91,1.05)$ \\
\hline Recreation Walking & $1.17(1.06,1.29)$ & $1.06(1.03,1.09)$ & $1.04(0.94,1.15)$ & $1.11(1.03,1.19)$ & $1.09(1.07,1.12)$ & $1.10(1.02,1.19)$ \\
\hline Transport Walking & $0.99(0.89,1.10)$ & $1.02(0.99,1.06)$ & $1.02(0.91,1.13)$ & $1.00(0.92,1.08)$ & $1.01(0.98,1.04)$ & $1.00(0.92,1.09)$ \\
\hline $\begin{array}{l}\text { Household / Yard } \\
\text { Activity }\end{array}$ & $1.20(1.09,1.32)$ & $0.99(0.96,1.02)$ & $0.97(0.88,1.06)$ & $1.36(1.27,1.45)$ & $1.05(1.02,1.07)$ & $0.97(0.91,1.04)$ \\
\hline Caregiving Activity & $1.08(0.96,1.22)$ & $0.94(0.91,0.98)$ & $0.83(0.73,0.95)$ & $0.94(0.86,1.03)$ & $1.01(0.98,1.04)$ & $1.09(0.99,1.19)$ \\
\hline TV Watching & $1.13(1.03,1.24)$ & $1.15(1.12,1.19)$ & $1.11(1.00,1.22)$ & $1.16(1.08,1.24)$ & $1.13(1.11,1.16)$ & $1.17(1.09,1.26)$ \\
\hline
\end{tabular}

Abbreviations: CI Confidence interval; MVPA moderate to vigorous physical activity; SEP socioeconomic position; TV television

${ }^{a}$ Values are exponentiated coefficients from linear models of log-transformed outcomes. Values can be interpreted as percentage differences, for example 1.07 represents a $7 \%$ increase in the outcome associated with retirement, conditional on adjustment variables (self-reported health, partnership status, and 9 chronic conditions: asthma, emphysema, arthritis flare up, high cholesterol, hypertension, diabetes, kidney disease, cancer, cardiovascular disease). Data are presented graphically in Figure 6.

${ }^{b}$ Exponentiated mean difference in log-transformed outcome associated with retirement, conditional on adjustment variables.

${ }^{c}$ Exponentiated mean difference in log-transformed outcome associated with 5-year increase in age among retired and not retired participants, conditional on adjustment

variables. 
Table 18. Change ${ }^{\mathrm{a}}$ in physical activity and television watching by retirement and socioeconomic position in healthy subset ${ }^{\mathrm{b}}(\mathrm{N}=2,085)$

\begin{tabular}{|c|c|c|c|c|c|c|}
\hline \multirow[b]{3}{*}{ Behavior } & \multicolumn{3}{|c|}{$\begin{array}{c}\text { Low socioeconomic position } \\
(\mathrm{N}=828)\end{array}$} & \multicolumn{3}{|c|}{$\begin{array}{l}\text { High socioeconomic position } \\
(\mathrm{N}=1257)\end{array}$} \\
\hline & \multirow{2}{*}{$\begin{array}{l}\text { Mean change } \\
\text { associated with } \\
\text { retirement }{ }^{\mathrm{c}}\end{array}$} & \multicolumn{2}{|c|}{ Mean 5-year change ${ }^{\mathrm{d}}$} & \multirow{2}{*}{$\begin{array}{l}\text { Mean change } \\
\text { associated with } \\
\text { retirement }{ }^{\mathrm{c}}\end{array}$} & \multicolumn{2}{|c|}{ Mean 5-year change ${ }^{d}$} \\
\hline & & Not retired & Retired & & Not retired & Retired \\
\hline MVPA & $0.81(0.71,0.93)$ & $0.88(0.85,0.92)$ & $0.93(0.81,1.07)$ & $1.06(0.97,1.15)$ & $0.98(0.96,1.01)$ & $0.93(0.86,1.01)$ \\
\hline $\begin{array}{l}\text { Non-walking } \\
\text { Leisure }\end{array}$ & $0.97(0.97,1.08)$ & $1.00(0.97,1.03)$ & $1.09(0.97,1.21)$ & $1.14(1.05,1.24)$ & $1.03(1.00,1.05)$ & $1.00(0.92,1.09)$ \\
\hline $\begin{array}{l}\text { Recreation } \\
\text { Walking }\end{array}$ & $1.15(1.02,1.33)$ & $1.08(1.04,1.13)$ & $1.02(0.89,1.17)$ & $1.15(1.05,1.26)$ & $1.11(1.08,1.14)$ & $1.09(1.00,1.19)$ \\
\hline $\begin{array}{l}\text { Transport } \\
\text { Walking }\end{array}$ & $1.02(0.88,1.18)$ & $1.00(0.96,1.05)$ & $1.01(0.87,1.16)$ & $1.01(0.91,1.11)$ & $1.01(0.98,1.04)$ & $0.99(0.90,1.09)$ \\
\hline $\begin{array}{l}\text { Household / Yard } \\
\text { Activity }\end{array}$ & $1.33(1.17,1.50)$ & $1.00(0.97,1.04)$ & $0.90(0.80,1.02)$ & $1.44(1.33,1.56)$ & $1.06(1.03,1.08)$ & $0.96(0.89,1.04)$ \\
\hline $\begin{array}{l}\text { Caregiving } \\
\text { Activity }\end{array}$ & $1.19(1.00,1.42)$ & $0.94(0.89,0.99)$ & $0.75(0.63,0.89)$ & $1.01(0.91,1.13)$ & $1.03(0.99,1.06)$ & $1.01(0.91,1.12)$ \\
\hline TV Watching & $1.11(0.98,1.26)$ & $1.16(1.12,1.21)$ & $1.11(0.97,1.26)$ & $1.19(1.10,1.30)$ & $1.12(1.09,1.15)$ & $1.11(1.03,1.21)$ \\
\hline
\end{tabular}

Abbreviations: CI Confidence interval; MVPA moderate to vigorous physical activity; SEP socioeconomic position; TV television

${ }^{a}$ Values are exponentiated coefficients from linear models of log-transformed outcomes. Values can be interpreted as percentage differences, for example 1.07 represents a $7 \%$ increase in the outcome associated with retirement, conditional on adjustment variables (self-reported health, partnership status, and 9 chronic conditions: asthma, emphysema, arthritis flare up, high cholesterol, hypertension, diabetes, kidney disease, cancer, cardiovascular disease).

${ }^{b}$ Restricted to participants present at study exam 5 and free of cardiovascular disease, depression, cognitive impairment, cancer, and chronic obstructive pulmonary disease throughout follow-up.

${ }^{c}$ Exponentiated mean difference in log-transformed outcome associated with retirement, conditional on adjustment variables.

${ }^{\mathrm{d}}$ Exponentiated mean difference in log-transformed outcome associated with 5-year increase in age among retired and not retired participants, conditional on adjustment

variables. 
Table 19. Classification of retirement status by reported employment category in main and four sensitivity analyses

\begin{tabular}{|c|c|c|c|c|c|}
\hline \multirow[b]{2}{*}{ MESA employment category } & \multirow[b]{2}{*}{$\begin{array}{c}\text { Main } \\
\text { Analyses }\end{array}$} & \multicolumn{4}{|c|}{ Separate Sensitivity Analyses } \\
\hline & & Two-tiered & $\begin{array}{c}\text { Fully time } \\
\text { varying }\end{array}$ & Strict & $\begin{array}{l}\text { Exclude non- } \\
\text { workers }\end{array}$ \\
\hline 1. Employed (or self-employed) full-time & \multirow{4}{*}{ Not retired } & \multirow{4}{*}{ Not retired } & \multirow{4}{*}{ Not retired } & \multirow{4}{*}{ Not retired } & \multirow[b]{3}{*}{ Not retired } \\
\hline 2. Employed (or self-employed) part-time & & & & & \\
\hline $\begin{array}{l}\text { 3. Employed, but on leave for health reasons } \\
\text { 4. Employed but temporarily away from job (other than } \\
\text { health reasons) }\end{array}$ & & & & & \\
\hline $\begin{array}{l}\text { 5. Unemployed or laid off, }<6 \text { months } \\
\text { 6. Unemployed or laid off, } \geq 6 \text { months } \\
\text { 7. Homemaker, not working outside home }\end{array}$ & & & & & Excluded \\
\hline $\begin{array}{l}\text { 8. Retired from usual occupation and not working } \\
\text { 9. Retired from usual occupation and volunteering }\end{array}$ & \multirow[t]{2}{*}{ Retired } & $\begin{array}{l}\text { Retired and not } \\
\text { working }\end{array}$ & \multirow[t]{2}{*}{ Retired } & \multirow{2}{*}{$\begin{array}{l}\text { Retired if reported } 0 \\
\text { working hours \& } 0 \\
\text { occupational physical } \\
\text { activity }\end{array}$} & \multirow[t]{2}{*}{ Retired } \\
\hline 10. Retired from usual occupation and working for pay & & Retired and working & & & \\
\hline Variation of retirement status over time & $\begin{array}{l}\text { Retired for all visits } \\
\text { after first meeting } \\
\text { retirement definition }\end{array}$ & \multicolumn{3}{|c|}{$\begin{array}{l}\text { Retired only at visits meeting retirement definition; participants may } \\
\text { be reclassified as employed after being classified as retired }\end{array}$} & $\begin{array}{l}\text { Retired for all visits } \\
\text { after first meeting } \\
\text { retirement definition }\end{array}$ \\
\hline
\end{tabular}


Table 20. Assignment of metabolic equivalent task (MET) values by domain and intensity of physical activity

\begin{tabular}{lll}
\hline Domain & Example Activity & MET value \\
\hline Non-walking leisure & Dancing & 5.0 \\
activities & Team and dual sports & 7.0 \\
& Individual activities & 3.5 \\
& Conditioning activity (moderate effort) & 5.5 \\
& Conditioning activity (vigorous effort) & 7.0 \\
Walking & & 3.5 \\
& Recreational walking (for exercise) & 3.0 \\
& Transport walking (to get places) & 2.5 \\
Household/yard activities & Cooking, dishes, shopping (light effort) & 4.0 \\
& Scrubbing, mopping, mowing, raking (moderate effort) & 6.5 \\
Digging, shoveling snow (vigorous effort) & 2.5 \\
Caregiving activities & & 4.0 \\
\hline
\end{tabular}

Abbreviations: MET metabolic equivalent task

Table 21. Definition of good health throughout follow-up ${ }^{\text {a }}$

\section{Participation in MESA exam 5 and survival free from:}

Cardiovascular disease

\section{Definition}

Coronary heart disease, angina, coronary artery revascularization, stroke, congestive heart failure, or peripheral vascular disease based physician review of abstracted medical records

Depression

Cognitive impairment

Cancer

Self-report of cancer other than non-melanoma skin cancer

Chronic obstructive pulmonary disease

ICD-9 codes from hospital records

${ }^{a}$ Definition of good health adapted from Shea et al., PLoS One 2016;11(11) [152] 


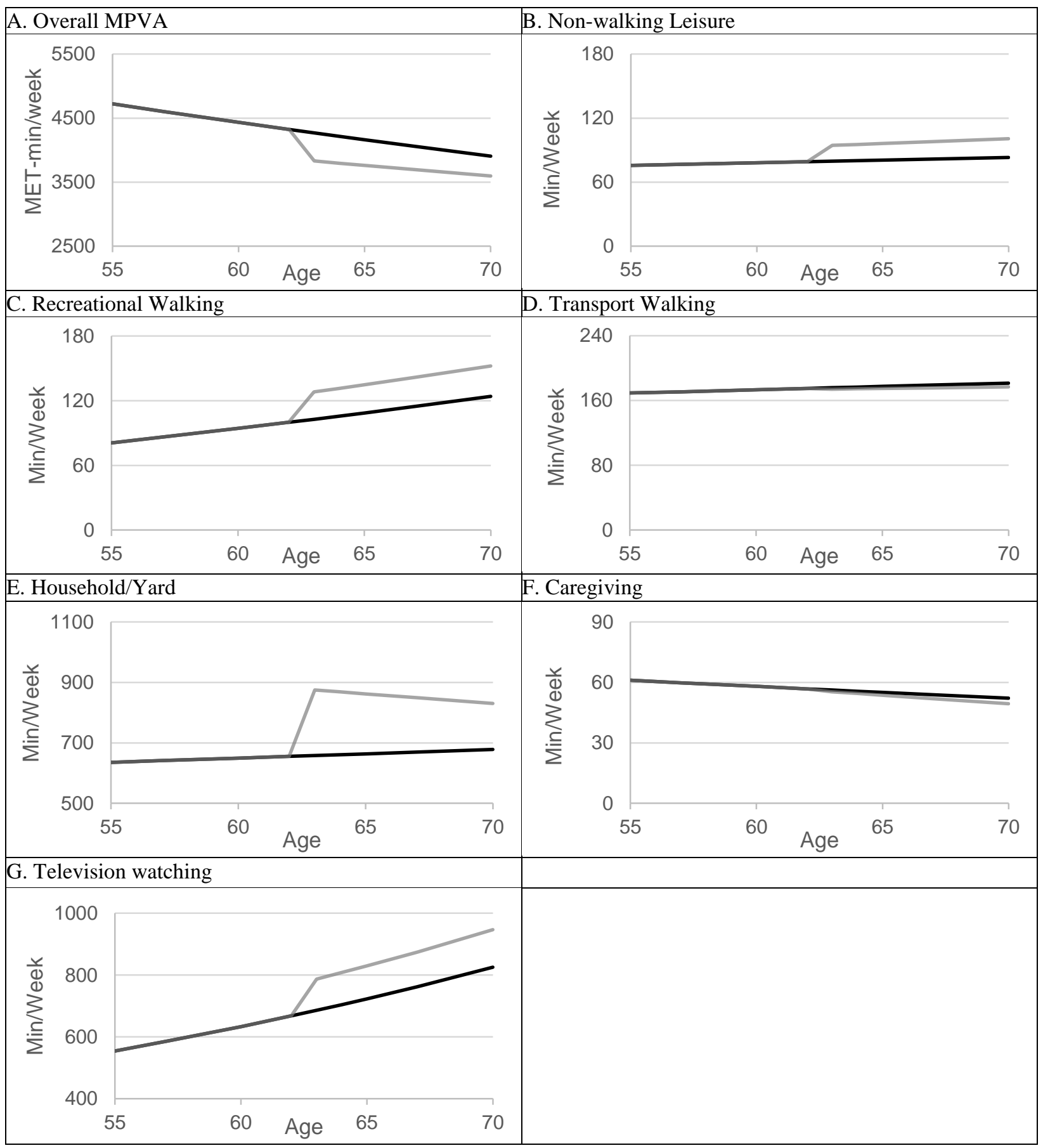

Legend: Not retired $=$ Retired at age 63

Abbreviations: MET metabolic equivalent task; MVPA moderate-to-vigorous physical activity

Figure 5. Estimated physical activity (overall and by domain) and television watching patterns by retirement status in the overall sample ( $\mathrm{N}=4,091$ MESA participants). Lines represent patterns for the average person who did not retire during follow-up (black line) and who retired at age 63 (median retirement age in this cohort, grey line). Estimates back transformed from fixed-effect models of log-transformed outcomes adjusted for time-varying partnership status, self-rated health, and nine chronic conditions. Note scale of y-axis varies by domain. Data for these figures are presented in Table 16. 


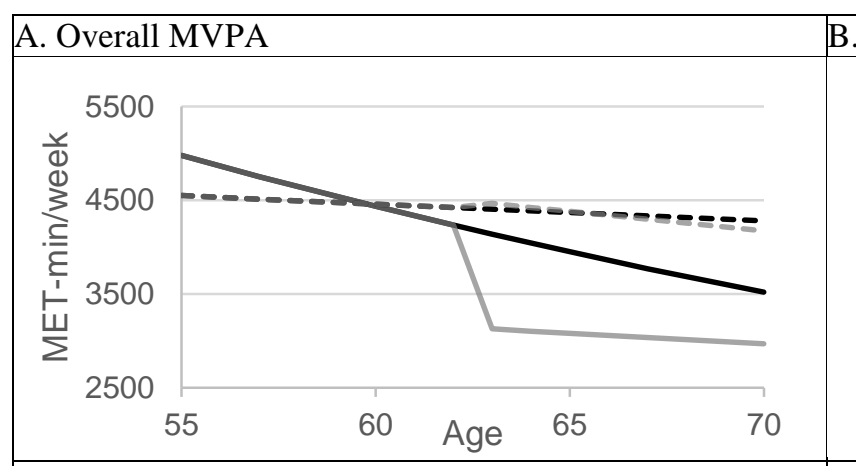

B. Non-walking Leisure
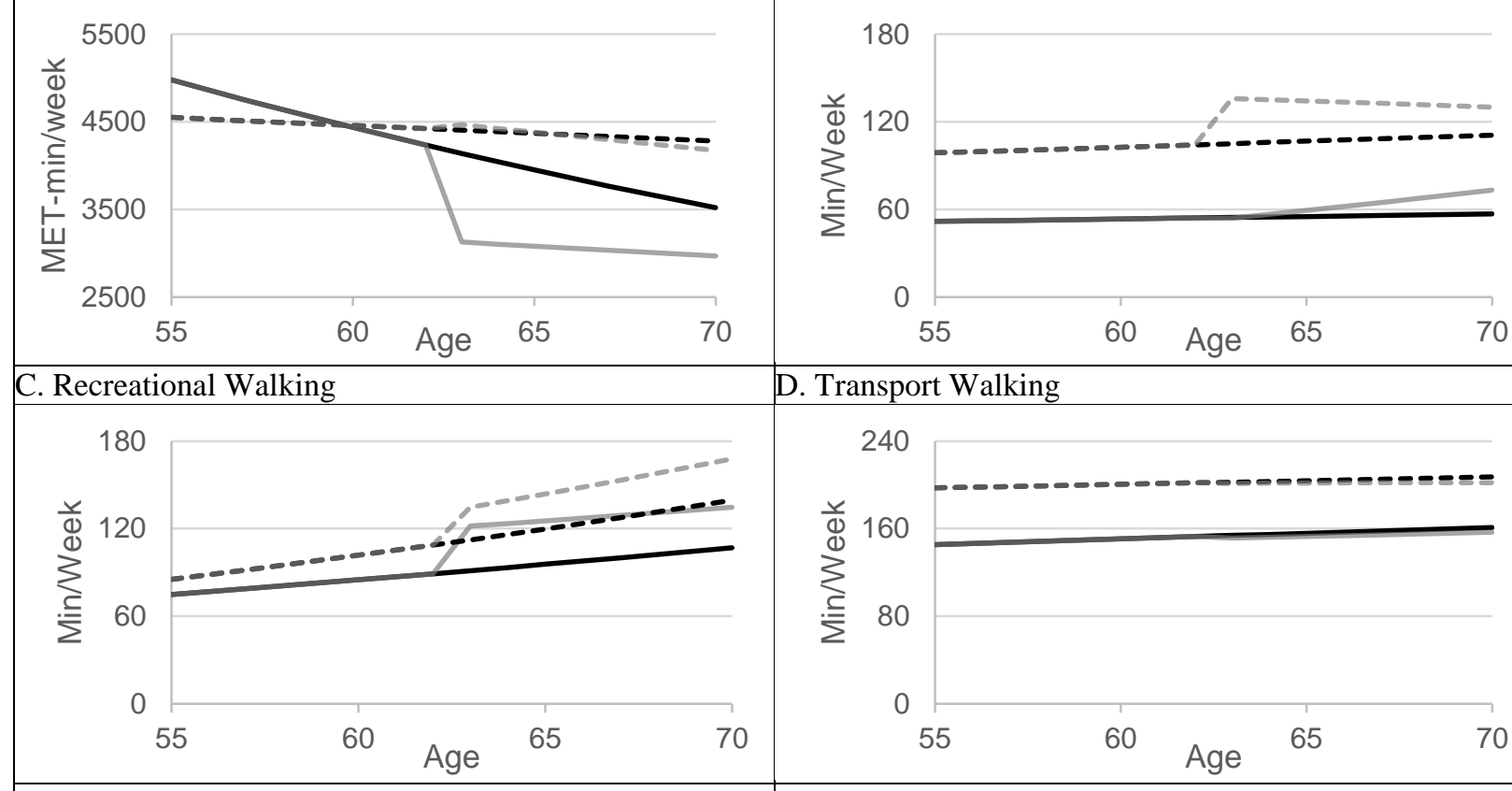

D. Transport Walking
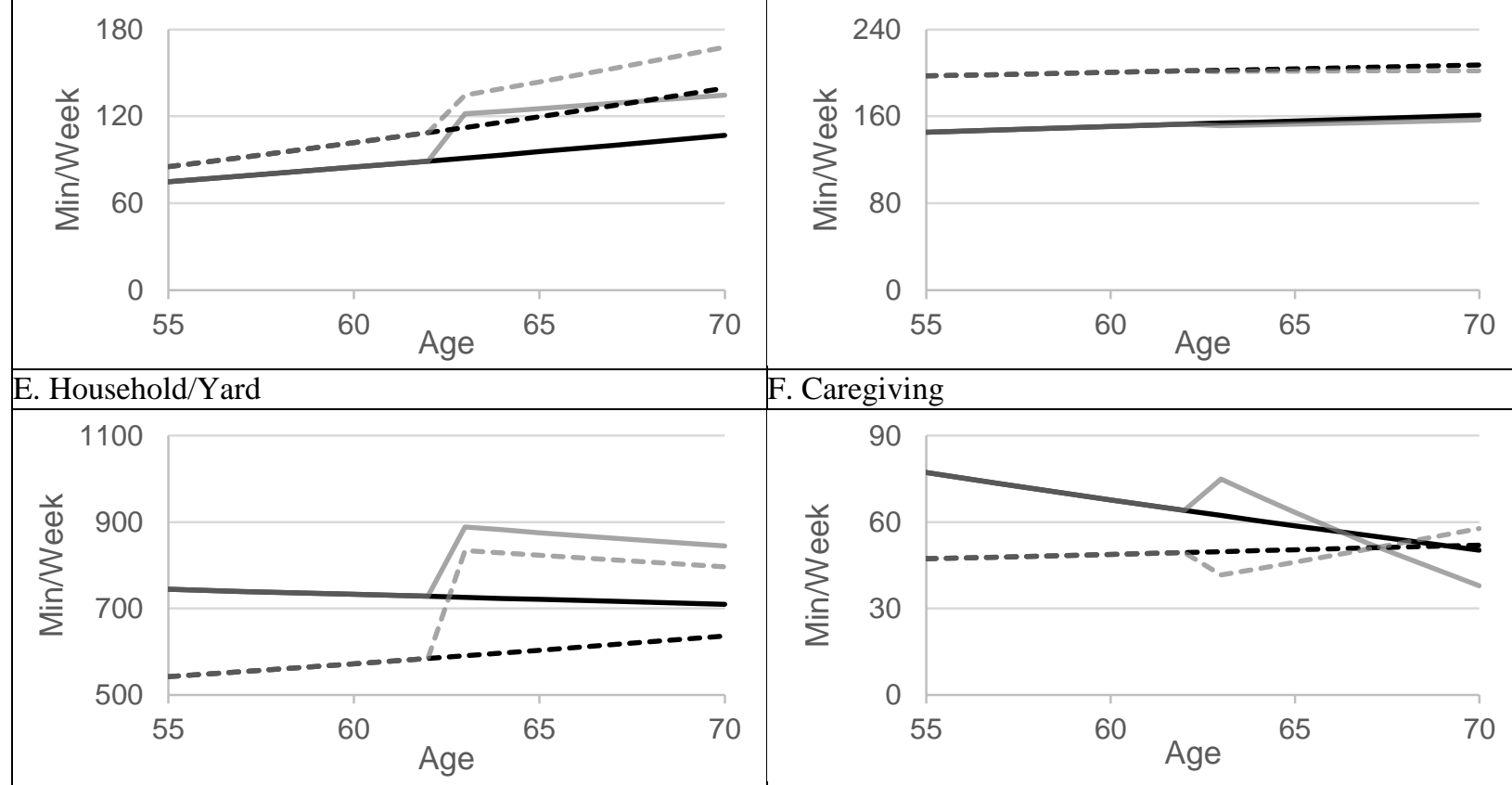

\section{G. Television watching}
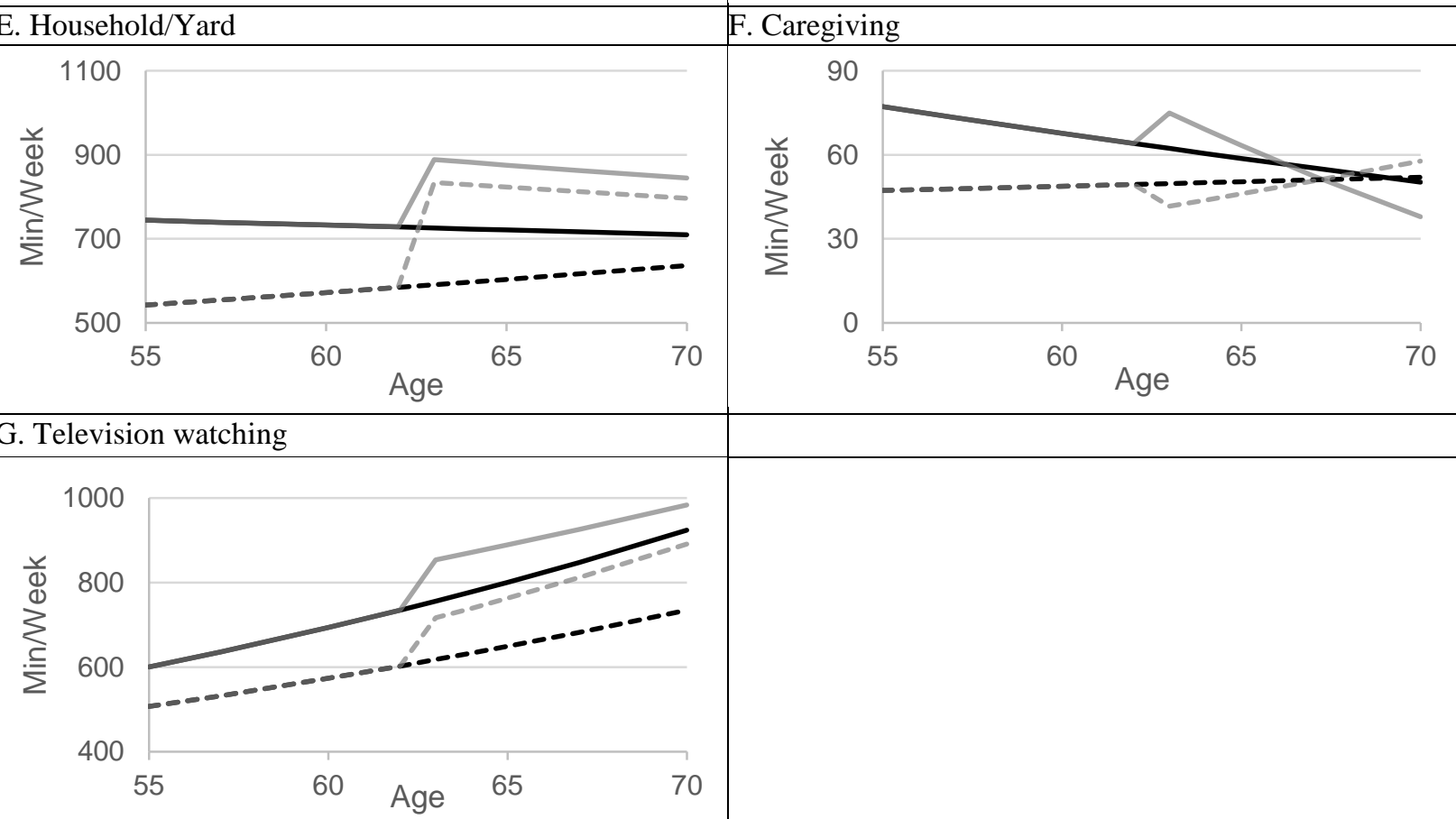

Legend: Low socioeconomic position

High socioeconomic position

Not retired

- - Not retired

Retired at age 63

$-=-$ Retired at age 63

Abbreviations: MET metabolic equivalent task; MVPA moderate-to-vigorous physical activity

Figure 6. Estimated physical activity and television watching patterns by retirement status and socioeconomic position (SEP; $\mathrm{N}=2003$ low SEP; $\mathrm{N}=2088$ high SEP). Lines represent patterns for the average person who did not retire during follow-up (black line) and who retired at 63 (median retirement age in this cohort, grey line). Estimates back transformed from fixed-effect models of log-transformed outcomes stratified by SEP and adjusted for timevarying partnership status, self-rated health, and chronic conditions. SEP was a composite index of education, income, and four indicators of wealth. Note scale of y-axis varies by domain. Data for these figures are presented in Table 17 
Table 22. Changes ${ }^{a}$ in physical activity and television watching by retirement status and education $(\mathrm{N}=4,091)$

\begin{tabular}{|c|c|c|c|c|c|c|}
\hline \multirow[b]{3}{*}{ Behavior } & \multicolumn{3}{|c|}{$\begin{array}{l}\text { Less than College Education } \\
\qquad(\mathrm{N}=2291)\end{array}$} & \multicolumn{3}{|c|}{$\begin{array}{c}\text { Associates Degree or Higher } \\
\qquad(\mathrm{N}=1800)\end{array}$} \\
\hline & \multirow{2}{*}{$\begin{array}{l}\text { Mean change } \\
\text { associated with } \\
\text { retirement }{ }^{b}\end{array}$} & \multicolumn{2}{|c|}{ Mean 5-year change ${ }^{c}$} & \multirow{2}{*}{$\begin{array}{l}\text { Mean change } \\
\text { associated with } \\
\text { retirement }{ }^{\mathrm{b}} \\
\end{array}$} & \multicolumn{2}{|c|}{ Mean 5-year change ${ }^{c}$} \\
\hline & & Not retired & Retired & & Not retired & Retired \\
\hline MVPA & $0.80(0.73,0.87)$ & $0.91(0.88,0.93)$ & $0.93(0.85,1.02)$ & $1.02(0.94,1.10)$ & $0.97(0.95,1.00)$ & $0.99(0.92,1.07)$ \\
\hline $\begin{array}{l}\text { Non-walking } \\
\text { Leisure }\end{array}$ & $1.07(1.00,1.15)$ & $1.01(0.98,1.03)$ & $1.00(0.93,1.08)$ & $1.10(1.03,1.19)$ & $1.02(1.00,1.05)$ & $1.06(0.98,1.14)$ \\
\hline $\begin{array}{l}\text { Recreation } \\
\text { Walking }\end{array}$ & $1.16(1.07,1.27)$ & $1.05(1.02,1.08)$ & $1.05(0.96,1.14)$ & $1.09(1.01,1.19)$ & $1.11(1.08,1.14)$ & $1.11(1.02,1.21)$ \\
\hline $\begin{array}{l}\text { Transport } \\
\text { Walking }\end{array}$ & $0.96(0.88,1.06)$ & $1.04(1.01,1.07)$ & $1.03(0.93,1.13)$ & $1.03(0.95,1.13)$ & $0.99(0.96,1.02)$ & $0.99(0.90,1.08)$ \\
\hline $\begin{array}{l}\text { Household / Yard } \\
\text { Activity }\end{array}$ & $1.21(1.12,1.32)$ & $1.00(0.97,1.03)$ & $0.96(0.89,1.05)$ & $1.38(1.29,1.48)$ & $1.04(1.01,1.06)$ & $0.98(0.91,1.05)$ \\
\hline $\begin{array}{l}\text { Caregiving } \\
\text { Activity }\end{array}$ & $1.03(0.93,1.15)$ & $0.94(0.90,0.97)$ & $0.92(0.83,1.03)$ & $0.97(0.88,1.06)$ & $1.03(1.00,1.06)$ & $1.03(0.94,1.13)$ \\
\hline TV Watching & $1.14(1.05,1.24)$ & $1.15(1.12,1.18)$ & $1.14(1.05,1.25)$ & $1.16(1.07,1.25)$ & $1.13(1.10,1.16)$ & $1.13(1.04,1.23)$ \\
\hline
\end{tabular}

Abbreviations: CI Confidence interval; MVPA moderate to vigorous physical activity; TV television

${ }^{a}$ Values are exponentiated coefficients from linear models of log-transformed outcomes. Values can be interpreted as percentage differences, for example 1.07 represents a $7 \%$ increase in the outcome associated with retirement, conditional on adjustment variables (self-reported health, partnership status, and 9 chronic conditions: asthma, emphysema, arthritis flare up, high cholesterol, hypertension, diabetes, kidney disease, cancer, cardiovascular disease).

${ }^{b}$ Exponentiated mean difference in log-transformed outcome associated with retirement, conditional on adjustment variables.

${ }^{c}$ Exponentiated mean difference in log-transformed outcome associated with 5-year increase in age among retired and not retired participants, conditional on adjustment variables. 


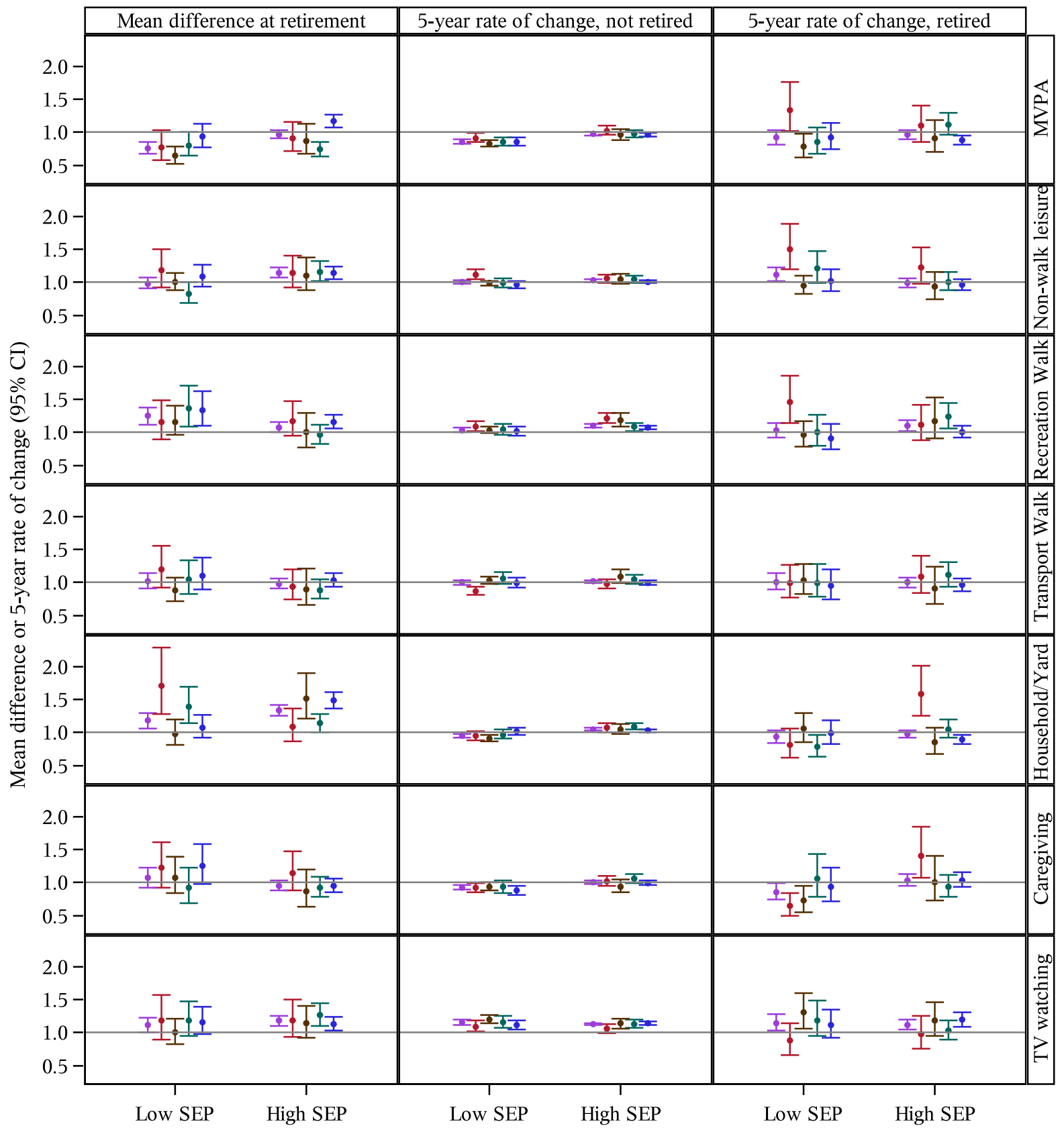

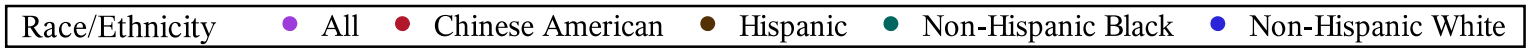

Abbreviations: CI confidence interval; MVPA moderate-to-vigorous physical activity; SEP socioeconomic position; TV television

Figure 7. Adjusted average change associated with retirement $(95 \% \mathrm{CI})$ and average 5-year change (95\% CI) in physical activity and television watching by retirement status and socioeconomic position, overall and by race/ ethnicity. Values are exponentiated coefficients from fixed-effect models of log-transformed physical activity or television watching adjusted for time-varying partnership status, self-rated health, and nine chronic conditions. 


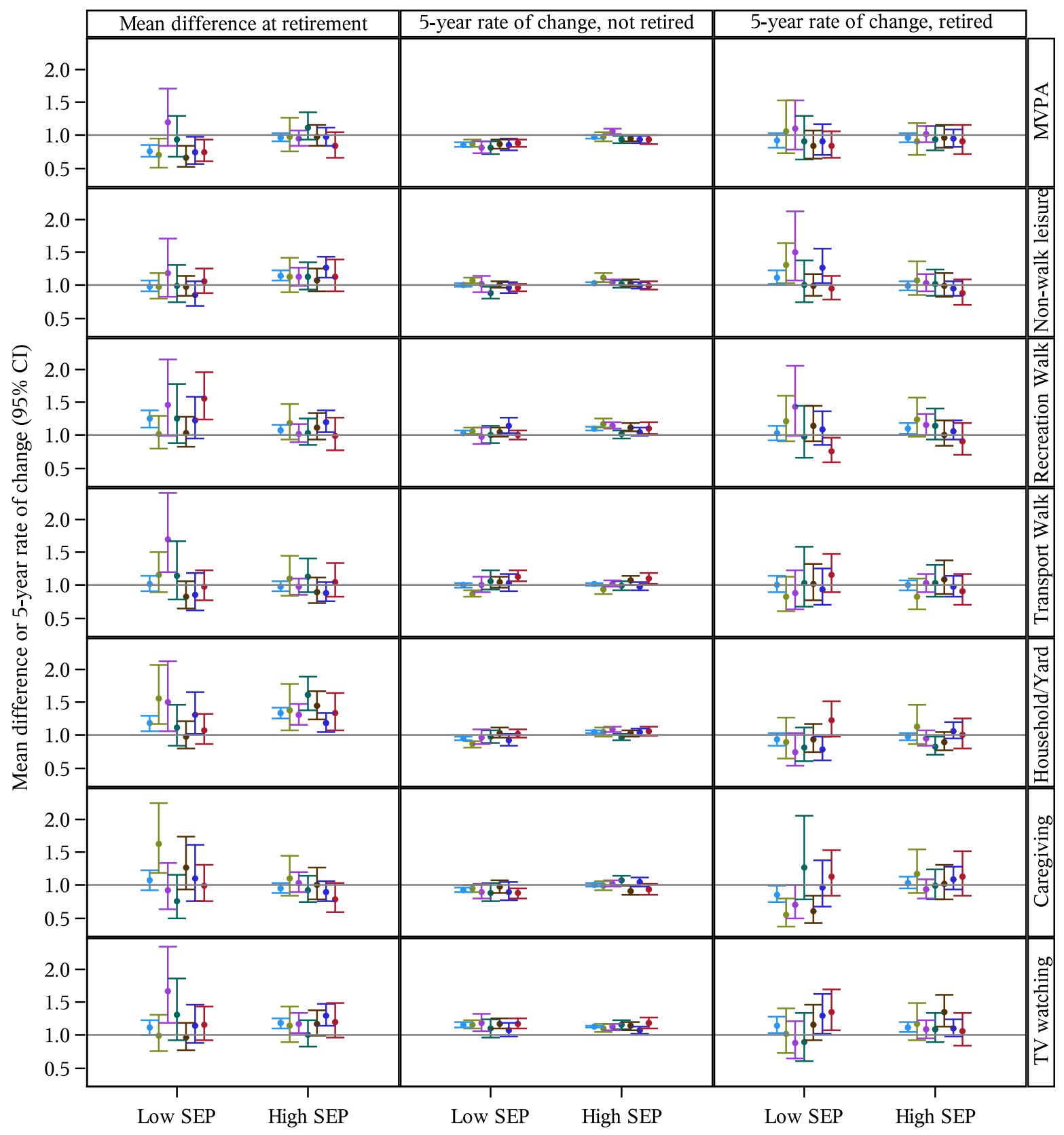

\begin{tabular}{|lllllll}
\hline Study Site $\bullet$ All $\bullet \mathrm{CA}$ & $\bullet \mathrm{IL}$ & $\bullet \mathrm{MD}$ & $\bullet \mathrm{MN}$ & $\bullet \mathrm{NC}$ & $\bullet \mathrm{NY}$ \\
\hline
\end{tabular}

Abbreviations: CI confidence interval; MVPA moderate-to-vigorous physical activity; SEP socioeconomic position; TV television

Figure 8. Adjusted average change associated with retirement (95\% CI) and average 5-year change (95\% CI) in physical activity and television watching by retirement status and socioeconomic position, overall and by study site (Los Angeles County, CA; Chicago, IL; Baltimore County, MD; St. Paul, MN; Forsyth County, NC;

Northern Manhattan and the Bronx, NY). Values are exponentiated coefficients from fixed-effect models of logtransformed physical activity or television watching adjusted for time-varying partnership status, self-rated health, and nine chronic conditions. 


\section{CHAPTER 6. CORRELATES OF CHANGES IN WALKING DURING THE RETIREMENT TRANSITION: THE MULTI-ETHNIC STUDY OF ATHEROSCLEROSIS}

\subsection{Introduction}

Retirement from employment is associated with disruption in daily routines and social networks and increased focus on maintaining health [14-17]. These shifts in routine and focus may provoke changes in health-related behaviors including physical activity [19]. Physical activity changes associated with retirement may be positive or negative [19]. Promoting positive changes in physical activity at retirement could help to reduce the burden of chronic disease in later life [5-7].

Promoting positive changes in physical activity at retirement requires better understanding of the correlates of behavior change during this transition [13, 39]. The most common physical activity among retirement-aged Americans is walking [57]. Walking also is among the most accessible physical activities: it requires no special equipment and is available to persons with a wide range of physical abilities [179]. The correlates of walking may differ depending on its purpose: recreation (for leisure or exercise) or transport (to get places) [133]. Identifying correlates of recreational and transport walking change during the retirement transition may inform the targeting of public health interventions.

Correlates of walking change at retirement have not been explored. However, the Social Ecological Model and prior research on walking among older adults suggests that correlates exist at multiple levels, including the individual- (e.g., gender), interpersonal- (e.g., social support), and community-level (e.g., walking environment) [24]. Identifying correlates from multiple levels is important because interventions targeting multiple levels are more likely effective [24]. 
We aimed to identify correlates of walking change at retirement among participants in the MESA, a diverse cohort of US adults. The objective of this work is to describe individual-, interpersonal-, and community-level correlates of within-person change in recreational and transport walking at retirement to inform the development of interventions to promote walking after retirement.

\subsection{Methods}

\subsubsection{Study Population}

The MESA is a prospective cohort study of the subclinical CVD [125]. Briefly, 6,814 adults aged 45 to 84 years and free of clinical CVD were recruited at six sites: Forsyth County, NC; Northern Manhattan and the Bronx, NY; Baltimore City and Baltimore County, MD; St. Paul, MN; Chicago, IL; and Los Angeles County, CA. This study included MESA participants who were not retired at baseline (2000-2002) and retired during follow-up (by 2010-2012, $\mathrm{N}=1,062$ ). Participants who retired but were missing data on walking before or after retirement $(\mathrm{N}=54)$ or potential correlates $(\mathrm{N}=80)$ were excluded for a final sample size of 928.

\subsubsection{Retirement Classification}

MESA participants self-reported employment status in 10 categories at baseline and at four follow-up exams. Participants who reported being retired and not working, retired and working, or retired and volunteering were classified as retired.

\subsubsection{Walking}

Recreational and transport walking were self-reported by MESA participants at baseline and three follow-up study exams (2000-2002, 2002-2004, 2004-2005, 2010-2012). The MESA physical activity questionnaire was adapted from the Cross-Cultural Activity Participation Study [131]. Participants reported walking frequency (days/week) and duration (min/day), which were multiplied to estimate min/week of each type of walking. Within-person changes in walking at 
retirement were calculated for each participant as the difference in min/week of walking reported at the last study exam prior to and first study exam after retirement. Self-reported measures of walking showed evidence of digit preference. The test-retest reliability of self-reported physical activity is better for categorical compared to continuous measures and categories help to manage data skewness [180]. Therefore, changes in walking were categorized as "maintaining" (change $< \pm 60 \mathrm{~min} /$ week), "decreasing" (change $\leq-60 \mathrm{~min} /$ week), or "increasing" (change $\geq 60$ $\mathrm{min} /$ week) for analyses.

\subsubsection{Correlates}

Potential correlates were selected based on the Social Ecological Model [24] and existing literature $[110,112,150,151]$. Correlates were grouped into three levels: individual-, interpersonal-, and community-level (Table 23).

There were eleven potential individual-level correlates, of which eight were time-fixed (retirement age, gender, race/ethnicity, SEP, MESA site, car ownership, job type, and selfreported occupational physical activity). SEP was a composite measure based on education, preretirement income, and ownership of a home, car, other land/property, and investments [135]. SEP was categorized as low (0 to 4$)$, moderate (5 to 7$)$, or high ( 8 to 10$)$. Three time-varying individual-level correlates were calculated as the difference between pre- and post-retirement exam measures: change in self-rated health (always better, improved, declined, always same/worse than others), number of chronic conditions no chronic conditions, 1 chronic condition, $>1$ chronic condition, more chronic conditions after retirement, fewer chronic conditions after retirement), and BMI $\left(\mathrm{kg} / \mathrm{m}^{2}\right)$.

Potential interpersonal-level correlates were change in partnership and caregiving status, and social support. Change in partnership and caregiving status were defined by the participant's status at the pre- and post-retirement exams. Social support was measured using the ESSI, which 
has good reliability (Cronbach's alpha 0.86) [136]. Scores from the closest pre-retirement exam were used because many participants did not have post-retirement social support scores.

Community-level correlates were 16 measures of the neighborhood environment from the MESA exam closest to each participant's estimated retirement date. Community-level correlates included observed and perceived neighborhood attributes [181]. Observed attributes were assessed using data from local and federal governments and commercial sources (Esri Redlands, CA; NETS) for ZIP codes where five or more MESA participants were living from 2000-2010 using participants' geocoded addresses [111, 145, 146, 182]. Observed measures were: 1-mile density of parks, recreational facilities, walking and social engagement destinations, street connectivity, and population density. Densities were calculated in ArcGIS (Redlands, CA) using a circular 1-mile buffer around participants' homes [111]. Observed neighborhood environment measures were mean centered and scaled so that a 1-unit increase was equivalent to one standard deviation [111].

Perceived neighborhood environment measures included 13 items grouped into four domains: walking environment, aesthetic quality, safety, and social cohesion [183]. MESA participants rated each item (strongly agree to strongly disagree) for their neighborhood, defined as the area within a 20-minute walk or 1-mile of home. Item responses were grouped as favorable (agree/strongly agree) or unfavorable/neutral [184]. Social cohesion was the sum of four items scored so that a higher number corresponded to greater cohesion. Cohesion scores were categorized as low (0-11), moderate (12-15), or high (>15).

\subsubsection{Analyses}

First, the distribution of each potential correlate (Table 23) and within-person change in recreational and transport walking were described. Next, we assessed collinearity between correlates at each level (individual, interpersonal, community). Densities of recreational 
facilities, walking destinations, and social engagement destinations were highly correlated. Based on substantive knowledge from existing literature [111, 185, 186], only the density of walking destinations was included in multivariable models. No other correlates were strongly correlated $(r>0.65)$.

Next, multivariable logistic regression models were constructed to identify correlates of change in walking at retirement. Recreational and transport walking were modeled separately. Participants who reported $0 \mathrm{~min} /$ week both before and after retirement excluded from the models ( $\mathrm{N}=136$ for recreational walking, $\mathrm{N}=41$ for transport walking). Separate logistic regression models were used to compare participants who decreased or increased walking after retirement relative to those who maintained walking levels after retirement. Separate logistic regression models were used rather than multinomial models to improve the interpretability of resulting coefficients. A backward selection strategy was used wherein all potential correlates were included in an initial model then removed sequentially using likelihood ratio tests to compare nested models. A significance threshold of $\alpha=0.2$ was used to determine which variables to retain in models. All models included eight core variables: gender, retirement age, race/ethnicity, SEP, MESA study site, season of pre- and post-retirement exams, and tertile of walking prior to retirement. Categorical correlates were modeled using dummy indicator coding. Continuous correlates were entered as linear terms or categorized if a non-linear relationship was identified in exploratory analyses with flexible model forms (i.e., splines). Pre-retirement walking was categorized as tertiles (recreational walking: $\leq 90 \mathrm{~min} /$ week, $>90$ to $\leq 210 \mathrm{~min} /$ week, $>210$ $\mathrm{min} /$ week; transport walking: $\leq 90 \mathrm{~min} /$ week, $>90$ to $\leq 300 \mathrm{~min} /$ week, $>300 \mathrm{~min} /$ week). 


\subsubsection{Sensitivity Analyses}

Changes in physical activity at retirement may vary by SEP, gender, and retirement age $[19,39]$. To explore variation in correlates by these characteristics, interaction terms were added to models after final variable selection. Interactions between each correlate and SEP (low, high), gender, and retirement age ( $<63, \geq 63$ years) were evaluated in separate models using $\alpha=0.1$.

Eight additional sensitivity analyses were conducted separately related to model specification. First, we replaced the composite SEP measure in final models with separate variables for each component (education, income, ownership of a home, car, land, and investments) and explored interactions by education ( $<$ college degree, $\geq$ Associate degree). Second, final models for change in recreational walking were adjusted for change in transport walking, and vice-versa. Third, analyses were restricted to participants who did not work at all after retirement $(\mathrm{N}=740)$. Fourth, final models were adjusted for population density [147]. Fifth, we substituted density measures with radii of $1 \frac{1}{2}$-mile or 3 -miles for the 1 -mile density measures. Sixth, because the relevance of destinations may decline with distance, we used 1-mile kernel density measures in place of simple density measures. Simple and kernel densities were highly

correlated $(r=0.98)$. Seventh, 1-mile density of parks was added to final models for the subset of participants with park data ( $\mathrm{N}=718$ for recreational walking; $\mathrm{N}=807$ for transport walking). Data on parks were collected for three MESA sites in 2003 and all MESA sites for 2010-2012. Eighth, we excluded participants $(\mathrm{N}=194,21 \%)$ who moved between pre- and post-retirement exams.

\subsection{Results}

Of 928 included MESA participants, 54\% were female, 44\% were non-Hispanic white, $28 \%$ were of low SEP, and $89 \%$ were employed full or part-time (Table 24). Prior to retirement, most participants were married or living with a partner $(66 \%)$ and had at least one chronic condition (58\%). Participants walked a median of $90 \mathrm{~min} /$ week for recreation and $150 \mathrm{~min} / \mathrm{week}$ 
for transport prior to retirement. Most (62\%) participants retired between MESA exams 3 (20042006) and 5 (2010-2012), 16\% retired between exams 2 (2002-2004) and 3 (2004-2006), and $21 \%$ retired between exams 1 (2000-2002) and 2 (2002-2004). Participants excluded due to missing data $(\mathrm{N}=134)$ were more likely non-Hispanic black and of low SEP, had a higher mean BMI, and were less likely to rate their health as better than others their age, to have no chronic conditions, and to have been working full-time prior to retirement compared to included participants $(\mathrm{N}=928)$. Included and excluded participants were similar with respect to proportion female, partnership status, and mean retirement age.

There were 136 (15\%) participants who reported no recreational walking before or after retirement (Table 24). Compared to participants who reported some recreational walking, participants who reported no recreational walking were less likely non-Hispanic white, to have a college degree, to be married or living with a partner, had a higher mean BMI, and reported more TV watching. Participants who did not walk for recreation perceived their neighborhoods to be less attractive, less cohesive, and less favorable environments for walking compared to participants who did walk for recreation.

There were 41 (4\%) participants who reported no transport walking before or after retirement (Table 24). Compared to participants who reported some transport walking, people who did not walk for transport reported less recreational walking and more TV watching. Participants who did not walk for transportation also lived in areas with lower density of recreational facilities, social engagement and walking destinations, and population, and were less likely to report high social cohesion and seeing others exercise in their neighborhood. 


\subsubsection{Recreational Walking}

Among 792 participants who reported some recreational walking before or after retirement, the median change in recreational walking at retirement was a $45 \mathrm{~min} /$ week increase (Table 25). There were 247 participants (31\%) who decreased (median change $-180 \mathrm{~min} / \mathrm{week}$ ), 151 (19\%) who maintained (median change $0 \mathrm{~min} /$ week), and 394 (50\%) who increased recreational walking after retirement (median change $225 \mathrm{~min} /$ week). The distributions of correlates by category of change in recreational walking are shown in Table 28.

In addition to eight core variables, multivariable models identified seven correlates of decreased ( $\geq 60 \mathrm{~min} /$ week) compared to maintaining recreational walking after retirement (Table 26). Higher odds of decreased compared to maintaining recreational walking after retirement were associated with: lower SEP, decline in and consistently same or worse self-rated health, and not perceiving litter in the neighborhood. Lower odds of decreased compared to maintaining recreational walking after retirement were associated with: lower levels of pre-retirement recreational walking and perceiving that it was easy to walk places in one's neighborhood.

Four correlates were identified in addition to eight core variables for increased $(\geq 60$ min/week) compared to maintaining recreational walking after retirement (Table 26). Higher odds of increased compared to maintain recreational walking after retirement were associated with lower SEP and lower levels of pre-retirement recreational walking. Although not statistically significant at $\alpha=0.05$, being unemployed, on-leave, or a homemaker at the preretirement exam, and living in an attractive neighborhood were associated with lower odds of increased compared to maintaining recreational walking after retirement. 


\subsubsection{Transport Walking}

Among 887 participants who reported some transport walking before or after retirement, the median change in transport walking was $0 \mathrm{~min} /$ week (Table 25). There were 353 participants (40\%) who decreased (median change -210 min/week), 172 (19\%) who maintained (median change $0 \mathrm{~min} /$ week), and $362(41 \%)$ who increased their transport walking (median change 270 $\mathrm{min} /$ week). The distribution of correlates by category of change in transport walking is shown in Table 29.

In multivariable models, there were seven correlates and eight core variables of decreased compared to maintaining transport walking after retirement (Table 27). Higher odds of decreased vs. maintain transport walking after retirement were associated with being from the NY MESA site and seeing others walking in one's neighborhood. Lower odds of decreased vs. maintaining transport walking after retirement were associated with being from the CA MESA site, lower levels of pre-retirement transport walking, and higher density of walking destinations within 1mile of home. Although not statistically significant with $\alpha=0.05$, have a partner before but not after retirement was associated with higher odds of decreased transport walking and perceiving the neighborhood not to have a lot of litter and to be easy to walk places were associated with lower odds of decreased transport walking.

Models for increased compared to maintaining transport walking included four correlates and eight core variables (Table 27). Lower odds of increased compared to maintaining transport walking were associated with being from the CA MESA site. Participants who had a preretirement exam in spring (vs. winter), reported a decline in self-rated health, or lived with a partner before but not after retirement had higher odds of increased compared to maintaining transport walking after retirement. 


\subsubsection{Sensitivity Analyses}

There were no significant interactions between SEP and correlates of recreational or transport walking $(\mathrm{p}>0.1)$. Although CIs were wide, there were some potential interactions with both gender and retirement age.

The correlation between recreational walking and self-rated health and chronic conditions may vary by gender. Consistently poor self-rated health was associated with higher odds of decreased vs. maintaining recreational walking after retirement among women (odds ratio (OR) 3.99, 95\% CI: $1.61,9.86$ ) but not men (OR 0.75, 95\% CI: 0.27, 2.07). A decrease in chronic conditions was associated with lower odds of increased vs. maintaining recreational walking among men (OR 0.25, 95\% CI: 0.09, 0.69) but not women (OR 1.77, 95\% CI: 0.59, 5.35).

The correlation between walking and perceived neighborhood attributes may vary by retirement ( $<63$ vs. $\geq 63$ years). Perceiving less litter in the neighborhood was associated with higher odds of decreased vs. maintaining recreational walking among older (OR 4.70, 95\% CI: $1.68,13.12)$ but not younger retirees (OR 0.94, 95\% CI: 0.34, 2.60). Living in a neighborhood where it was easy to walk places was associated with lower odds of decreased vs. maintaining recreational walking among younger $(\mathrm{OR} 0.15,95 \% \mathrm{CI}$ : $0.05,0.48)$ but not older retirees $(\mathrm{OR}$ 1.15, 95\% CI: $0.47,2.82)$. Perceiving an attractive neighborhood was associated with lower odds of increased vs. maintaining recreational walking among younger (OR 0.14, 95\% CI: 0.04, 0.49) but not older retirees (OR 1.49, 95\% CI: 0.66, 3.39). Not identifying violence as a neighborhood problem was associated with higher odds of decreased vs. maintaining transport walking among older (OR 2.52 (95\% CI: 1.10, 5.77) but not younger retirees (OR 0.67 (95\% CI: 0.25, 1.81).

When the composite SEP measure was replaced with component variables, preretirement income was statistically significantly associated with changes in recreational walking, and education and home ownership were statistically significantly associated with changes in 
transport walking. The direction of associations was consistent with the composite SEP measure (e.g., lower income associated with increased odds of decreased vs. maintaining recreational walking after retirement). There were no statistically significant interactions $(\mathrm{p}<0.1)$ between education and other correlates for recreational walking. For transport walking, there may be variation by education in the association between walking and gender, race/ethnicity, retirement age, MESA site, and perception of litter in the neighborhood. Male gender and perceived litter were associated with higher odds of decreased vs. maintaining transport walking among more but not less educated participants. Among people with more education, the odds of increased vs. maintaining transport walking were lower for blacks and Asians and higher for Hispanics compared to non-Hispanic whites. Older retirement age was associated with lower odds of increased vs. maintaining transport walking after retirement only among less educated people. Participants of lower education residing in NC and CA were more likely to maintain transport walking after retirement while higher educated participants residing in NY were less likely to maintain transport walking, compared to participants from IL.

Findings were consistent when: 1) models for recreational walking were adjusted for change in transport walking and vice versa; 2) analyses were restricted to participants who did not work after retirement $(\mathrm{N}=740) ; 3)$ models were additionally adjusted for population density; and, 4) when 1-mile density of walking destinations was replaced with 0.5 -mile density or 1-mile kernel density of walking destinations (data not shown). The coefficient for walking destinations was attenuated when 1-mile density was replaced with 3-mile density of destinations. Where data were available ( $\mathrm{N}=836$ participants), a one-standard deviation increase in 1-mile density of parks was not statistically significantly associated with changes in recreational walking (decreased vs. maintain OR 0.89 (95\% CI 0.60, 1.32); increased vs. maintain OR 0.73 (95\% CI 0.51, 1.04)) or 
transport walking (decreased vs. maintain OR 1.53 (95\% CI 0.94, 2.48); increased vs. maintain OR 1.12 (95\% CI 0.74, 1.69)). Excluding participants who moved between the pre- and postretirement exams primarily affected coefficients related to MESA site (Table 30 and Table 31 when compared to Table 26 and Table 27).

\subsection{Discussion}

In this diverse cohort of US adults, we identified correlates from multiple levels associated with within-person changes in recreational and transport walking after retirement. Correlates at the interpersonal and community levels have not been investigated in most studies of physical activity at retirement [95] and to our knowledge none have focused on changes in walking. In this study, changes in recreational and transport walking after retirement were associated with individual-level correlates including health and community-level correlates such as aesthetic quality and walking environment. Correlates differed for recreational compared to transport walking. Better understanding of the correlates of walking at retirement may inform intervention strategies.

Worse self-rated health and a greater number of chronic conditions were associated with decreased recreational walking after retirement. Chronic conditions may prompt retirement and limit one's physical ability to engage in walking [65]. However, walking also can contribute to secondary prevention and control of chronic conditions [179]. Surprisingly, declining self-rated health also was associated with higher odds of increasing compared to maintaining transport walking. A possible explanation is that health may be a stronger motivator for behavior change among people who are sick than those who are well [39]. Thus, targeting interventions to persons who retire due to ill-health and including promotion of health as a motivation for increasing walking is an approach that could be explored further. 
Lower SEP also may be an important factor in targeting interventions at the retirement transition. Lower SEP was linked to decreased overall physical activity after retirement (Table 17) and higher odds of changes (increased or decreased) in recreational walking after retirement. Decreased walking after retirement among persons of low SEP may be linked to poor health. The prevalence of chronic conditions was higher among MESA participants of lower SEP and persons of lower SEP are more likely to retire due to illness in the US [20,45]. On the other hand, persons of higher SEP may adopt non-walking leisure activities (e.g., tennis) after retirement, whereas persons of lower SEP increase recreational walking because it requires fewer financial and material resources. Future research could explore whether improving walking environments increases recreational walking after retirement among persons of lower SEP.

Changes in walking also were correlated with pre-retirement walking, caregiving, and partnership status. The influence of earlier life experience on later life behavior is a key Life Course Theory principle [23]. Workplace wellness programs that promote walking prior to retirement may contribute to higher prevalence of walking after retirement [62]. However, changes in other life domains such as caregiving and partnership status also impact walking after retirement. Changes in partnership and caregiving status were correlates of changes in transport walking among MESA participants. Interventions could be targeted to retirees who become caregivers or experience a change in partnership status near retirement, potentially focused on social support, which was a facilitator of physical activity among retired women $[12,72,96]$. Surprisingly, social support was not a correlate of changes in walking in this sample. However, the MESA social support index was not specific to walking. In general, interpersonal-level correlates have not been well addressed in existing interventions targeted to the retirement 
transition [39]. Our findings suggest that there may be opportunities to target interventions to retirees who are caregivers or are widowed/divorced near retirement.

Community-level correlates of physical activity are of particular importance given the potential for wide-scale public health impact [40]. Since 2000, there has been growing interest and resources devoted towards policy, systems, and environmental strategies to promote active living [120, 181]. New recommendations from the Community Preventive Services Task Force identified increasing street connectivity, pedestrian infrastructure, and proximity to destinations as effective strategies for promoting physical activity [40]. However, the effect of environmental changes on people's perceptions is not clear. Observed and perceived environment measures may capture different aspects of the environment [138-140]. Physical characteristics influence but do not determine perceptions of the environment [139]. Perceptions of the environment may be particularly relevant to older adults $[138,139]$. Perceived measures were more strongly associated with changes in walking at retirement in this sample, particularly related to aesthetic quality and the walking environment. Qualitative inquiry may provide insights on how perceptions relate to environmental features, including whether environmental improvements are sufficient to change perceptions to support behavior change $[187,188]$.

The association between changes in walking and community level correlates may vary by retirement age. Perceiving litter and violence to be a problem in the neighborhood were associated with lower odds of decreasing recreational and transport walking, respectively, among older but not younger retirees. Lower aesthetics were correlated with increased active transportation among Dutch retirees previously [95]. On the other hand, ease of walking places and attractiveness of the neighborhood were more strongly associated with recreational walking among younger compared to older MESA retirees. In MESA, younger retirees were on average 
of higher SEP compared to older retirees. Younger retirees may be motivated to walk for enjoyment rather than health, making attractiveness and ease of walking to destinations of greater importance to this group. Differences in correlates by retirement age are consistent with the life course theory principle of "timing" which suggests that the same events can impact individuals different depending on when they occur in life [23]. Thus, intervention strategies may need to be tailored by age of retiree.

\subsubsection{Strengths and Limitations}

A strength of this work was inclusion of correlates from multiple levels, including diverse aspects of the neighborhood environment, and a focus on walking, the most prevalent physical activity among older Americans [57]. This is the first study to our knowledge of interpersonaland community-level correlates of walking change at retirement. Although some potentially important factors were not measured (e.g., attitudes towards aging) [95], understanding the role of community-level correlates is important given their potential for population-level reach and sustainability [40]. Further, correlates of changes in transport and recreational walking differed, emphasizing the importance of specificity in physical activity measures when studying behavioral correlates. Also, the MESA is geographically and racially/ethnically diverse, which is important as the population of minority older Americans is projected to increase from 6.3 million (18\% of older Americans) in 2003 to 21.1 million (28\%) in 2030 [63].

Limitations of this work include reliance on self-reported measures of retirement and walking. Perceptions of what it means to be "retired" may vary among MESA participants. Some individuals who consider themselves retired may continue to work full- or part-time. However, findings were consistent among the subset of participants who did not work after retirement $(\mathrm{N}=740)$. Self-reported physical activity measures typically overestimate walking relative to accelerometer measures [4]. It is not clear how over reporting may affect estimates of walking 
change over time. To address over-reporting, we categorized changes in walking (increased, maintained, decreased). Recalling walking also may be more difficult after retirement without the regular structure of work, as supported by stronger correlation between self-reported and accelerometer measures of physical activity among employed vs. non-employed women [189]. However, it is not yet possible to distinguish between recreational and transport walking from accelerometer output alone. Thus, self-reported measures continue to be important to identify correlates of specific domains of walking [190].

Measures of the neighborhood environment also have limitations [181]. First, associations between built environmental features and physical activity may vary depending on the size and composition of the area over which built environment measures are aggregated, known as the modifiable areal unit problem [191]. Because the relevant areal unit for walking was unknown, circular radial buffers were used in MESA. MESA participants reported being active within 1-mile of home, which represents a reasonable walking distance [147]. Findings were robust in sensitivity analyses using a half-mile buffer size or 1-mile kernel density, as in a previous study of walkability among older adults [192]. Associations with 3-mile densities were attenuated. However, research using GPS trackers to determine where people are physically active suggests that circular buffers may have a lower density and diversity of destinations when compared to "activity spaces" defined by GPS tracing [193]. Also, the diversity rather than density of destinations was associated with walking among older Canadians [193]. Diversity of destinations was not measured by MESA. Moreover, the relevant areal unit may differ by neighborhood type, geographic location, walking purpose, and/or individual characteristics [191, 192]. Together these limitations highlight the importance of understanding local community context for tailoring environmental interventions. Second, neighborhood environment measures 
were attributed for the exam closest to retirement, which was prior to retirement for some participants $(\mathrm{N}=446,48 \%)$ and after retirement for others $(\mathrm{N}=482,52 \%)$. Many environmental features change slowly over time, and observed measures of the built environment were highly correlated at pre- and post-retirement exams (correlation coefficient range 0.56 to 0.92 ).

Moreover, findings were primarily the same after excluding people who moved between pre- and post-retirement exams.

Also, this study may over-represent healthier persons who experienced more favorable transitions to retirement. MESA participants were generally healthy at baseline [125], and participants who were sicker or less satisfied with retirement may have been more likely to drop out of the study. In addition, limited sample sizes meant that CIs were wide in some cases, making it more difficult to draw conclusions about correlates.

\subsubsection{Conclusion}

The population of older Americans is projected to grow to 72 million by 2030 [27, 63]. Older adults suffer a large burden of chronic disease with high costs in terms of quality of life and social resources, making health promotion among older adults a public health priority [63, 194]. The retirement transition is a potentially critical window for health promotion in later life when peoples' roles, relationships, and ecological contexts are changing [13, 30]. Our findings suggest that various intervention strategies may help to promote walking during the retirement transition, including targeting to retirees of lower SEP or with chronic conditions and improvement of walking environments. 
Table 23. Potential correlates of change in walking at retirement, MESA (2000-2012)

\begin{tabular}{|c|c|}
\hline Measure & Categories or components and data source \\
\hline \multicolumn{2}{|c|}{ Individual Level Correlates } \\
\hline Gender & Male, female \\
\hline Race/ethnicity & Non-Hispanic white, Chinese American, non-Hispanic black, Hispanic. \\
\hline Retirement age & Estimated at the midpoint between pre- and post-retirement exams. \\
\hline MESA site & $\begin{array}{l}\text { Forsyth County, NC; Northern Manhattan and the Bronx, NY; Chicago, IL; Los } \\
\text { Angeles County, CA; St. Paul, MN; Baltimore City and Baltimore County, MD. }\end{array}$ \\
\hline Socioeconomic position & $\begin{array}{l}\text { Composite measure ( } 0 \text { to } 10) \text { of self-reported education ( } \leq \text { high school, some college } \\
\text { but no degree, associates or bachelor's degree, graduate/ professional degree), pre- } \\
\text { retirement income }(<\$ 25,000, \$ 25,000-39,999, \$ 40,000-74,999, \geq \$ 75,000) \text {, and } \\
\text { ownership of home, car, other land/property, and investments [135]. Categorized as } \\
\text { low (0-4), moderate (5-7), or high (8-10). }\end{array}$ \\
\hline $\begin{array}{l}\text { Job type prior to } \\
\text { retirement }\end{array}$ & $\begin{array}{l}\text { Self-reported employment status at exam prior to retirement: full-time, part-time, or } \\
\text { other (homemaker, on-leave from work, or unemployed) }\end{array}$ \\
\hline $\begin{array}{l}\text { Occupational physical } \\
\text { activity }\end{array}$ & $\begin{array}{l}\text { MET-min/week calculated from self-reported frequency and duration of activity at } \\
\text { work multiplied by metabolic equivalent tasks (MET) assigned by level of perceived } \\
\text { intensity (sitting } 1.5 \mathrm{MET} \text {, standing } 2.5 \mathrm{MET} \text {, moderate } 3.0 \mathrm{MET} \text {, heavy } 7.0 \mathrm{MET} \text { ) }\end{array}$ \\
\hline Change in self-rated health & $\begin{array}{l}\text { Always better than others, improved after retirement, declined after retirement, never } \\
\text { better than others }\end{array}$ \\
\hline $\begin{array}{l}\text { Change in number of } \\
\text { chronic conditions }\end{array}$ & $\begin{array}{l}\text { Never any chronic conditions, always } 1 \text { chronic condition, always }>1 \text { chronic } \\
\text { condition, increase in number of chronic conditions, decrease in number of chronic } \\
\text { conditions. Chronic conditions included: self-reported asthma, emphysema, arthritis } \\
\text { flare up in the past two weeks, measured high cholesterol, hypertension, or diabetes, } \\
\text { and kidney disease, cancer, and cardiovascular disease ascertained from medical } \\
\text { records and hospital billing claims }[111,125] \text {. }\end{array}$ \\
\hline $\begin{array}{l}\text { Change in body mass } \\
\text { index }\end{array}$ & $\begin{array}{l}\text { Difference in body mass index }\left(\mathrm{kg} / \mathrm{m}^{2}\right) \text { at pre- compared to post-retirement exam, } \\
\text { measured by standardized protocol. }\end{array}$ \\
\hline Car ownership & Self-reported ownership of one or more cars at the pre-retirement exam. \\
\hline \multicolumn{2}{|c|}{ Interpersonal Level Correlates } \\
\hline $\begin{array}{l}\text { Change in partnership } \\
\text { status }\end{array}$ & $\begin{array}{l}\text { Married or living with a partner before and after retirement, only before retirement, } \\
\text { only after retirement, or never. Partnership status at exam } 2 \text { was imputed from the } \\
\text { closer of exams } 1 \text { or } 3 \text { [111]. }\end{array}$ \\
\hline Social support & $\begin{array}{l}\text { Self-reported ESSI [136] (6 items) measured prior to retirement. Scores (range } 6 \text { to } 30 \text { ) } \\
\text { set to missing if any items missing and dichotomized as low (score } \leq 12) \text { vs. high } \\
(\text { score }>12 \text { ) [137]. }\end{array}$ \\
\hline Change in caregiver status & $\begin{array}{l}\text { Self-reported caring for children or adults } \geq 150 \mathrm{~min} / \text { week before and after retirement, } \\
\text { only before retirement, only after retirement, or never. }\end{array}$ \\
\hline \multicolumn{2}{|c|}{ Observed Community Level Correlates } \\
\hline Public parks & $\begin{array}{l}\text { 1-mile density of public parks excluding walking trails, dog parks, ornamental parks, } \\
\text { and parks with only walking trails and dog parks (source: local government data and } \\
\text { Esri) [145]. }\end{array}$ \\
\hline Recreational facilities & $\begin{array}{l}\text { 1-mile density of commercial locations for adult physical activity including } \\
\text { conditioning, recreational, team/racquet sports, water activities, and instructional } \\
\text { facilities based on } 114 \text { Standard Industrial Classification codes (source: NETS) [146, } \\
195,196] \text {. }\end{array}$ \\
\hline Walking destinations & $\begin{array}{l}\text { 1-mile density of postal offices, drug store/pharmacy, banks/ credit unions, grocery } \\
\text { stores, eating/ dining places, and non-alcoholic drinking places based on } 137 \text { Standard } \\
\text { Industrial Classification codes (source: NETS) }[144,146] \text {. }\end{array}$ \\
\hline $\begin{array}{l}\text { Social engagement } \\
\text { destinations }\end{array}$ & $\begin{array}{l}\text { 1-mile density of barber/beauty shops, performance based entertainment, participatory } \\
\text { entertainment clubs, sport/professional entertainment, exercise facility, gambling, } \\
\text { amusement park/carnival, membership sport/recreation club, libraries, museum/art } \\
\text { galleries, zoo/aquarium, civil/social/political club, religious institution, eating place, } \\
\text { night club/bar based on } 430 \text { Standard Industrial Classification codes (source: NETS) } \\
{[144,146] \text {. }}\end{array}$ \\
\hline
\end{tabular}




$\begin{array}{ll}\text { Network ratio } & \text { Measure of street connectivity defined as the proportion of 1-mile Euclidean buffer } \\ \text { covered by 1-mile street network buffer. Higher network ratios indicate greater street } \\ \text { connectivity (source: StreetMap and StreetMap Premium for ArcGIS from Esri). }\end{array}$

Abbreviations: ESSI Enhancing Recovery in Coronary Heart Disease Social Support Inventory; MESA Multi-Ethnic Study of Atherosclerosis; MET metabolic equivalent task; NETS National Establishment Time Series 
Table 24. Study participant characteristics prior to retirement, overall and among participants reporting no walking for recreation or transport, MESA 2000-2012 (N=928)

\begin{tabular}{|c|c|c|c|}
\hline Characteristic & $\begin{array}{c}\begin{array}{c}\text { Overall } \\
(\mathbf{N}=928)\end{array} \\
\mathrm{N}(\%) \text { or } \\
\text { Median (IQR) }\end{array}$ & $\begin{array}{c}\text { No Leisure Walking } \\
(\mathbf{N}=\mathbf{1 3 6})^{\mathrm{a}} \\
\mathrm{N}(\%) \text { or } \\
\text { Median (IQR) }\end{array}$ & $\begin{array}{c}\text { No Transport } \\
\text { Walking }(\mathbf{N}=\mathbf{4 1})^{\mathrm{a}} \\
\mathrm{N}(\%) \text { or } \\
\text { Median (IQR) }\end{array}$ \\
\hline Age (years) & $60(56,64)$ & $60(55,65)$ & $62(56,64)$ \\
\hline Female & $501(54 \%)$ & $81(60 \%)$ & $17(41 \%)$ \\
\hline \multicolumn{4}{|l|}{ Race/Ethnicity } \\
\hline Non-Hispanic White & $407(44 \%)$ & $46(34 \%)$ & $17(41 \%)$ \\
\hline Non-Hispanic Chinese & $101(11 \%)$ & $10(7 \%)$ & $6(15 \%)$ \\
\hline Non-Hispanic Black & $251(27 \%)$ & $57(42 \%)$ & $8(20 \%)$ \\
\hline Hispanic & $169(18 \%)$ & $23(17 \%)$ & $10(24 \%)$ \\
\hline \multicolumn{4}{|l|}{ Socioeconomic Position $\mathrm{b}$} \\
\hline Low (0 to 4$)$ & $263(28 \%)$ & $42(31 \%)$ & $11(27 \%)$ \\
\hline Moderate (5 to 7 ) & $361(39 \%)$ & $66(49 \%)$ & $17(41 \%)$ \\
\hline High $(8$ to 10$)$ & $304(33 \%)$ & $28(21 \%)$ & $13(32 \%)$ \\
\hline Own a car & $792(85 \%)$ & $123(90 \%)$ & $39(95 \%)$ \\
\hline \multicolumn{4}{|l|}{ Employment Status } \\
\hline Full-time & $658(71 \%)$ & $103(76 \%)$ & $28(68 \%)$ \\
\hline Part-time & $169(18 \%)$ & $17(13 \%)$ & $6(15 \%)$ \\
\hline Other $^{c}$ & $101(11 \%)$ & $16(12 \%)$ & $7(17 \%)$ \\
\hline \multicolumn{4}{|l|}{ Health } \\
\hline Better & $532(57 \%)$ & $74(54 \%)$ & $23(56 \%)$ \\
\hline Same & $351(38 \%)$ & $57(42 \%)$ & $15(37 \%)$ \\
\hline Worse & $45(5 \%)$ & $5(4 \%)$ & $3(7 \%)$ \\
\hline \multicolumn{4}{|l|}{ Number of chronic conditions ${ }^{d}$} \\
\hline 0 & $393(42 \%)$ & $46(34 \%)$ & $15(37 \%)$ \\
\hline 1 & $351(38 \%)$ & $58(43 \%)$ & $16(39 \%)$ \\
\hline$>1$ & $184(20 \%)$ & $32(24 \%)$ & $10(24 \%)$ \\
\hline Body mass index $\left(\mathrm{kg} / \mathrm{m}^{2}\right)$ & $28(25,32)$ & $30(26,33)$ & $29(26,32)$ \\
\hline Married or living with partner & $612(66 \%)$ & $76(56 \%)$ & $32(78 \%)$ \\
\hline Caregiver before retirement & $199(21 \%)$ & $33(24 \%)$ & $4(10 \%)$ \\
\hline \multicolumn{4}{|l|}{ MESA site } \\
\hline Forsyth County, NC & $178(19 \%)$ & $26(19 \%)$ & $8(20 \%)$ \\
\hline New York City, NY & $156(17 \%)$ & $21(15 \%)$ & $2(5 \%)$ \\
\hline Baltimore and Baltimore County, MD & $123(13 \%)$ & $30(22 \%)$ & $6(15 \%)$ \\
\hline Minneapolis, MN & $176(19 \%)$ & $28(21 \%)$ & $14(34 \%)$ \\
\hline Chicago, IL & $190(20 \%)$ & $16(12 \%)$ & $7(17 \%)$ \\
\hline Los Angeles, CA & $105(11 \%)$ & $15(11 \%)$ & $4(10 \%)$ \\
\hline Leisure walking (min/wk) & $90(0,240)$ & $0(0,0)$ & $0(0,225)$ \\
\hline Transport walking (min/wk) & $150(45,360)$ & $122(40,240)$ & $0(0,0)$ \\
\hline Television watching (hr/wk) & $12.0(6.0,17.5)$ & $14.0(7.0,21.0)$ & $14.0(8.0,21.0)$ \\
\hline
\end{tabular}

Abbreviations: IQR interquartile range; MESA Multi-Ethnic Study of Atherosclerosis

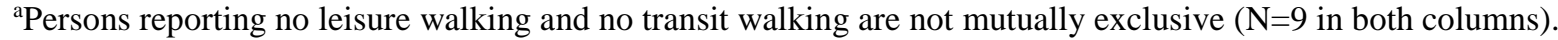

bBased on composite index of education, income, ownership of home, land/property, car, investments [135]

'Includes self-reporting being a homemaker, on-leave from work, or unemployed at the exam prior to retirement.

${ }^{\mathrm{d}}$ Chronic conditions included: self-reported asthma, emphysema, or arthritis flare up in the past two weeks, measured high cholesterol or hypertension, self-reported or measured diabetes, and kidney disease, cancer, and CVD ascertained from medical records and hospital billing claims. 
Table 25. Median (interquartile range) of recreational and transport walking ( $\mathrm{min} /$ week) before and after retirement, overall and by category of change in walking, MESA 2000-2012 ( $\mathrm{N}=919)$

\begin{tabular}{|c|c|c|c|c|}
\hline \multirow[b]{2}{*}{ Walking Domain } & \multirow[b]{2}{*}{$\mathbf{N}$} & \multicolumn{3}{|c|}{ Median (interquartile range) Min/Week Walking } \\
\hline & & Pre-Retirement & Post-Retirement & Change \\
\hline \multicolumn{5}{|l|}{ Recreational walking } \\
\hline Overall & 792 & $120(30,270)$ & $210(60,420)$ & $45(-90,225)$ \\
\hline \multicolumn{5}{|l|}{ Category of Change } \\
\hline Decrease $\geq 60 \mathrm{~min} /$ week & $247(31 \%)$ & $270(150,420)$ & $15(0,180)$ & $-180(-330,-90)$ \\
\hline $\begin{array}{l}\text { Maintain within } 60 \\
\mathrm{~min} / \text { week }\end{array}$ & $151(19 \%)$ & $105(30,240)$ & $120(45,240)$ & $0(-20,30)$ \\
\hline Increase $\geq 60 \mathrm{~min} /$ week & $394(50 \%)$ & $60(0,150)$ & $360(210,600)$ & $225(120,420)$ \\
\hline \multicolumn{5}{|l|}{ Transport walking } \\
\hline Overall & 887 & $180(60,420)$ & $180(60,420)$ & $0(-165,195)$ \\
\hline \multicolumn{5}{|l|}{ Category of Change } \\
\hline Decrease $\geq 60 \mathrm{~min} /$ week & $353(40 \%)$ & $360(210,630)$ & $90(0,210)$ & $-210(-390,-120)$ \\
\hline $\begin{array}{l}\text { Maintain within } 60 \\
\text { min/week }\end{array}$ & $172(19 \%)$ & $75(35,135)$ & $82(27,142)$ & $0(-30,15)$ \\
\hline Increase $\geq 60 \mathrm{~min} /$ week & $362(41 \%)$ & $90(30,210)$ & $420(225,750)$ & $270(145,510)$ \\
\hline
\end{tabular}


Table 26. Multivariable logistic regression of individual-, interpersonal-, and community-level correlates associated with change in recreational walking after retirement, MESA 2000-2012 (N=792)

\begin{tabular}{|c|c|c|c|}
\hline & & $\begin{array}{c}\text { Decrease } \geq \mathbf{6 0} \text { min/week vs. maintain } \\
\text { pre-retirement walking } \\
(\mathrm{N}=247 \text { decrease, } \mathrm{N}=151 \text { maintain })\end{array}$ & $\begin{array}{c}\text { Increase } \geq \mathbf{6 0} \text { min/week vs. maintain } \\
\text { pre-retirement walking } \\
(\mathrm{N}=394 \text { increase, } \mathrm{N}=151 \text { maintain })\end{array}$ \\
\hline Correlate & Comparison & Odds Ratio $(95 \%$ CI) & Odds Ratio (95\% CI) \\
\hline \multicolumn{4}{|l|}{ Core variables } \\
\hline Gender & Male vs. female & $0.94(0.56,1.56)$ & $1.11(0.74,1.69)$ \\
\hline \multirow{2}{*}{ Socioeconomic position } & Low vs. high & $3.07(1.37,6.88)^{*}$ & $2.36(1.25,4.47)^{*}$ \\
\hline & Moderate vs. high & $1.57(0.84,2.93)$ & $1.37(0.84,2.25)$ \\
\hline \multirow[t]{3}{*}{ Race/ethnicity } & Chinese American vs. non-Hispanic white & $1.04(0.37,2.90)$ & $1.17(0.52,2.63)$ \\
\hline & Non-Hispanic black vs. non-Hispanic white & $1.72(0.89,3.31)$ & $1.15(0.66,2.01)$ \\
\hline & Hispanic vs. non-Hispanic white & $1.01(0.45,2.29)$ & $0.65(0.34,1.25)$ \\
\hline Age at retirement & 1-year increase & $0.99(0.96,1.03)$ & $0.98(0.95,1.02)$ \\
\hline \multirow{3}{*}{$\begin{array}{l}\text { Season of pre-retirement } \\
\text { exam }\end{array}$} & Spring vs. winter & $1.93(0.94,3.95)$ & $1.40(0.79,2.47)$ \\
\hline & Summer vs. winter & $1.59(0.76,3.32)$ & $1.29(0.69,2.40)$ \\
\hline & Fall vs. winter & $0.78(0.34,1.73)$ & $1.07(0.58,1.99)$ \\
\hline \multirow{3}{*}{$\begin{array}{l}\text { Season of post- } \\
\text { retirement exam }\end{array}$} & Spring vs. winter & $0.49(0.25,0.96)$ & $1.17(0.67,2.04)$ \\
\hline & Summer vs. winter & $0.70(0.34,1.46)$ & $1.73(0.93,3.22)$ \\
\hline & Fall vs. winter & $0.92(0.45,1.88)$ & $1.45(0.79,2.68)$ \\
\hline \multirow[t]{5}{*}{ MESA site } & NC vs. IL & $1.00(0.42,2.37)$ & $1.00(0.51,1.95)$ \\
\hline & NY vs. IL & $1.64(0.63,4.28)$ & $1.22(0.56,2.69)$ \\
\hline & MD vs. IL & $0.99(0.40,2.44)$ & $0.52(0.24,1.11)$ \\
\hline & MN vs. IL & $1.07(0.41,2.77)$ & $0.58(0.28,1.22)$ \\
\hline & CA vs. IL & $0.98(0.34,2.79)$ & $0.86(0.38,1.93)$ \\
\hline \multirow{2}{*}{$\begin{array}{l}\text { Pre-retirement } \\
\text { recreational walking } \\
\text { tertile }\end{array}$} & $\leq 90$ vs. $>210 \mathrm{~min} /$ week & $0.09(0.05,0.17)^{*}$ & $2.14(1.27,3.59) *$ \\
\hline & $>90$ to $\leq 210$ vs. $>210 \mathrm{~min} /$ week & $0.49(0.27,0.89) *$ & $1.79(1.00,3.20)^{*}$ \\
\hline \multicolumn{4}{|l|}{ Individual level } \\
\hline \multirow[t]{3}{*}{$\begin{array}{l}\text { Self-rated health relative } \\
\text { to others }\end{array}$} & $\begin{array}{l}\text { Improved after retirement vs. always rated } \\
\text { as "better than others" }\end{array}$ & $1.54(0.75,3.17)$ & \\
\hline & $\begin{array}{l}\text { Declined after retirement vs. always rated as } \\
\text { "better than others" }\end{array}$ & $2.86(1.38,5.95)^{*}$ & \\
\hline & $\begin{array}{l}\text { Always rated as "same" or "worse" than } \\
\text { others vs. always rated as "better than } \\
\text { others" }\end{array}$ & $2.04(1.03,4.03)^{*}$ & \\
\hline
\end{tabular}




\begin{tabular}{|c|c|c|c|}
\hline & & $\begin{array}{c}\text { Decrease } \geq 60 \text { min/week vs. maintain } \\
\text { pre-retirement walking } \\
(\mathrm{N}=247 \text { decrease, } \mathrm{N}=151 \text { maintain }) \\
\text { Odds } \text { Ratio }(95 \% \text { CI }\end{array}$ & $\begin{array}{c}\text { Increase } \geq \mathbf{6 0} \text { min/week vs. maintain } \\
\text { pre-retirement walking } \\
(\mathrm{N}=394 \text { increase, } \mathrm{N}=151 \text { maintain }) \\
\text { Odds } \mathrm{Ratio}(\mathbf{9 5 \%} \text {. }\end{array}$ \\
\hline Correlate & Comparison & Odds Ratio (95\% CI) & \\
\hline \multirow[t]{4}{*}{$\begin{array}{l}\text { Change in number of } \\
\text { chronic conditions }{ }^{b}\end{array}$} & $\begin{array}{l}\text { Fewer after retirement vs. no chronic } \\
\text { conditions ever }\end{array}$ & & $0.67(0.33,1.36)$ \\
\hline & $\begin{array}{l}\text { More after retirement vs. no chronic } \\
\text { conditions ever }\end{array}$ & & $1.01(0.58,1.75)$ \\
\hline & $\begin{array}{l}1 \text { chronic condition vs. no chronic } \\
\text { conditions }\end{array}$ & & $1.33(0.72,2.47)$ \\
\hline & $>1$ condition vs. no chronic conditions & & $0.54(0.27,1.05)$ \\
\hline \multirow{2}{*}{$\begin{array}{l}\text { Job type prior to } \\
\text { retirement }\end{array}$} & Part-time vs. full-time & & $0.79(0.46,1.35)$ \\
\hline & Other ${ }^{c}$ vs. full-time & & $0.52(0.26,1.02)$ \\
\hline \multicolumn{4}{|l|}{ Community level } \\
\hline Aesthetic quality: trash & $\begin{array}{l}\text { There is a lot of trash / litter on the street in } \\
\text { my neighborhood (disagree vs. agree) }\end{array}$ & $2.16(1.05,4.44) *$ & \\
\hline $\begin{array}{l}\text { Aesthetic quality: } \\
\text { attractive }\end{array}$ & $\begin{array}{l}\text { My neighborhood is attractive (agree vs. } \\
\text { disagree) }\end{array}$ & & $0.55(0.29,1.06)$ \\
\hline $\begin{array}{l}\text { Walking environment: } \\
\text { easy to walk places }\end{array}$ & $\begin{array}{l}\text { In my neighborhood it is easy to walk places } \\
\text { (agree vs. disagree) }\end{array}$ & $0.49(0.25,0.97)^{*}$ & $0.62(0.34,1.12)$ \\
\hline $\begin{array}{l}\text { Walking environment: } \\
\text { see others exercise }\end{array}$ & $\begin{array}{l}\text { I often see other people exercise (e.g., jog, } \\
\text { bicycle, play sports) in my neighborhood } \\
\text { (agree vs. disagree) }\end{array}$ & $0.60(0.31,1.19)$ & \\
\hline
\end{tabular}

Abbreviations: CI confidence interval; MESA Multi-Ethnic Study of Atherosclerosis

a Socioeconomic position based on composite index of education, income, and four indicators of wealth (ownership of home, land/property, car, investments)

${ }^{\mathrm{b}}$ Chronic conditions included self-reported asthma, emphysema, arthritis flare up in the past two weeks, measured high cholesterol, hypertension, or diabetes, and kidney disease, cancer, and cardiovascular disease ascertained from medical records and hospital billing claims.

${ }^{\mathrm{c}}$ Other includes homemaking, unemployment, and on-leave from work.

$*$ p-value $<0.05$ 
Table 27. Multivariable logistic regression of individual-, interpersonal-, and community-level correlates associated with change in transport walking after retirement, MESA 2000-2012 (N=887)

\begin{tabular}{|c|c|c|c|}
\hline & & $\begin{array}{c}\text { Decrease } \geq \mathbf{6 0} \text { min/week vs. maintain } \\
\text { pre-retirement walking } \\
(\mathrm{N}=353 \text { decrease, } \mathrm{N}=172 \text { maintain })\end{array}$ & $\begin{array}{c}\text { Increase } \geq \mathbf{6 0} \text { min/week vs. maintain } \\
\text { pre-retirement walking } \\
(\mathrm{N}=362 \text { increase, } \mathrm{N}=172 \text { maintain })\end{array}$ \\
\hline Correlate & Comparison & Odds Ratio (95\% CI) & Odds Ratio (95\% CI) \\
\hline \multicolumn{4}{|l|}{ Core variables } \\
\hline Gender & Male vs. female & $1.51(0.88,2.60)$ & $1.08(0.71,1.66)$ \\
\hline \multirow{2}{*}{ Socioeconomic position } & Low vs. high & $2.02(0.91,4.45)$ & $0.98(0.55,1.78)$ \\
\hline & Moderate vs. high & $1.72(0.91,3.24)$ & $1.18(0.71,1.94)$ \\
\hline \multirow[t]{3}{*}{ Race/ethnicity } & Chinese American vs. non-Hispanic white & $2.85(0.96,8.47)$ & $1.04(0.47,2.31)$ \\
\hline & Non-Hispanic black vs. non-Hispanic white & $0.84(0.42,1.65)$ & $0.75(0.45,1.25)$ \\
\hline & Hispanic vs. non-Hispanic white & $2.02(0.80,5.11)$ & $1.51(0.74,3.06)$ \\
\hline Age at retirement & 1-year increase & $0.98(0.94,1.02)$ & $0.98(0.95,1.01)$ \\
\hline \multirow{3}{*}{$\begin{array}{l}\text { Season of pre-retirement } \\
\text { exam }\end{array}$} & Spring vs. winter & $1.78(0.89,3.56)$ & $1.87(1.09,3.20)^{*}$ \\
\hline & Summer vs. winter & $2.03(0.96,4.32)$ & $1.41(0.78,2.58)$ \\
\hline & Fall vs. winter & $2.33(1.05,5.16)^{*}$ & $1.55(0.81,2.97)$ \\
\hline \multirow{3}{*}{$\begin{array}{l}\text { Season of post- } \\
\text { retirement exam }\end{array}$} & Spring vs. winter & $0.65(0.31,1.34)$ & $0.74(0.41,1.32)$ \\
\hline & Summer vs. winter & $0.34(0.16,0.72)^{*}$ & $0.66(0.37,1.17)$ \\
\hline & Fall vs. winter & $0.89(0.41,1.91)$ & $1.08(0.58,2.01)$ \\
\hline \multirow[t]{5}{*}{ MESA site } & NC vs. IL & $0.77(0.32,1.87)$ & $0.58(0.30,1.12)$ \\
\hline & NY vs. IL & $3.50(1.07,11.46)^{*}$ & $1.94(0.85,4.44)$ \\
\hline & MD vs. IL & $1.07(0.41,2.81)$ & $1.14(0.54,2.40)$ \\
\hline & MN vs. IL & $0.97(0.35,2.66)$ & $0.60(0.28,1.30)$ \\
\hline & CA vs. IL & $0.30(0.10,0.84)^{*}$ & $0.24(0.12,0.51)^{*}$ \\
\hline \multirow{2}{*}{$\begin{array}{l}\text { Pre-retirement transport } \\
\text { walking tertile }\end{array}$} & $\leq 90$ vs. $>300 \mathrm{~min} /$ week & $0.01(0.01,0.03)^{*}$ & $0.90(0.47,1.71)$ \\
\hline & $>90$ to $\leq 300$ vs. $>300 \mathrm{~min} /$ week & $0.19(0.10,0.36)^{*}$ & $0.87(0.45,1.66)$ \\
\hline \multicolumn{4}{|l|}{ Individual level } \\
\hline & $\begin{array}{l}\text { Improved after retirement vs. always rated as } \\
\text { "better than others" }\end{array}$ & & $1.24(0.69,2.25)$ \\
\hline \multirow[t]{2}{*}{$\begin{array}{l}\text { Self-rated health relative } \\
\text { to others }\end{array}$} & $\begin{array}{l}\text { Declined after retirement vs. always rated as } \\
\text { "better than others" }\end{array}$ & & $1.94(1.03,3.64)^{*}$ \\
\hline & $\begin{array}{l}\text { Always rated as "same" or "worse" than } \\
\text { others vs. always rated as "better than others" }\end{array}$ & & $0.61(0.36,1.03)$ \\
\hline
\end{tabular}




\begin{tabular}{|c|c|c|c|}
\hline & & $\begin{array}{c}\text { Decrease } \geq \mathbf{6 0} \text { min/week vs. maintain } \\
\text { pre-retirement walking } \\
(\mathrm{N}=353 \text { decrease, } \mathrm{N}=172 \text { maintain })\end{array}$ & $\begin{array}{c}\text { Increase } \geq 60 \text { min/week vs. maintain } \\
\text { pre-retirement walking } \\
(\mathrm{N}=362 \text { increase, } \mathrm{N}=172 \text { maintain })\end{array}$ \\
\hline Correlate & Comparison & & \\
\hline \multicolumn{4}{|l|}{ Interpersonal level } \\
\hline \multirow[t]{3}{*}{$\begin{array}{l}\text { Change in partnership } \\
\text { status }\end{array}$} & $\begin{array}{l}\text { Never married/living with partner vs. always } \\
\text { married/living with partner }\end{array}$ & $1.34(0.73,2.47)$ & $1.11(0.68,1.83)$ \\
\hline & $\begin{array}{l}\text { Married/living with partner before retirement } \\
\text { vs. always married/living with partner }\end{array}$ & $4.22(0.99,17.99)$ & $3.30(1.12,9.76) *$ \\
\hline & $\begin{array}{l}\text { Married/living with partner after retirement } \\
\text { vs. always married/living with partner }\end{array}$ & $3.00(0.64,14.08)$ & $1.01(0.29,3.53)$ \\
\hline \multirow[t]{3}{*}{$\begin{array}{l}\text { Change in caregiver } \\
\text { status }{ }^{b}\end{array}$} & $\begin{array}{l}\text { Caregiver before retirement vs. never a } \\
\text { caregiver }\end{array}$ & $0.68(0.29,1.55)$ & \\
\hline & $\begin{array}{l}\text { Caregiver after retirement vs. never a } \\
\text { caregiver }\end{array}$ & $0.56(0.26,1.21)$ & \\
\hline & Always a caregiver vs. never a caregiver & $2.16(0.83,5.63)$ & \\
\hline \multicolumn{4}{|l|}{ Community level } \\
\hline $\begin{array}{l}\text { 1-mile density of } \\
\text { walking destinations }\end{array}$ & 1-standard deviation unit increase & $0.62(0.41,0.93)^{*}$ & \\
\hline Aesthetic quality: trash & $\begin{array}{l}\text { There is a lot of trash / litter on the street in } \\
\text { my neighborhood (disagree vs. agree) }\end{array}$ & $0.46(0.21,1.04)$ & \\
\hline $\begin{array}{l}\text { Aesthetic quality: } \\
\text { attractive }\end{array}$ & $\begin{array}{l}\text { My neighborhood is attractive (agree vs. } \\
\text { disagree) }\end{array}$ & & $0.64(0.36,1.14)$ \\
\hline Safety: violence & $\begin{array}{l}\text { Violence is a problem in my neighborhood } \\
\text { (disagree vs. agree) }\end{array}$ & $1.53(0.81,2.90)$ & \\
\hline $\begin{array}{l}\text { Walking environment: } \\
\text { easy to walk places }\end{array}$ & $\begin{array}{l}\text { In my neighborhood it is easy to walk places } \\
\text { (agree vs. disagree) }\end{array}$ & $0.56(0.29,1.08)$ & \\
\hline $\begin{array}{l}\text { Walking environment: } \\
\text { see others walk }\end{array}$ & $\begin{array}{l}\text { I often see other people walking in my } \\
\text { neighborhood (agree vs. disagree) }\end{array}$ & $2.36(1.02,5.47)^{*}$ & $1.70(0.91,3.20)$ \\
\hline
\end{tabular}

Abbreviations: CI confidence interval; MESA Multi-Ethnic Study of Atherosclerosis

a Socioeconomic position is a composite index of education, income, and four indicators of wealth (ownership of home, land/property, car, investments)

${ }^{\mathrm{b}}$ Caregiver defined as reporting $>=150 \mathrm{~min} /$ week of caregiving activity to children or adults

* P-value $<0.05$ 
Table 28. Individual-, interpersonal-, and community correlates by category of change in recreational walking after retirement, MESA 2000-2012 (N=792)

\begin{tabular}{|c|c|c|c|}
\hline Correlate & $\begin{array}{c}\text { Decrease } \\
\geq \mathbf{6 0} \text { min/week } \\
\mathrm{N}(\%) \text { or } \\
\text { median (IQR) }\end{array}$ & $\begin{array}{c}\text { Maintain } \\
\mathrm{N}(\%) \text { or } \\
\text { median (IQR) }\end{array}$ & $\begin{array}{c}\text { Increase } \\
\geq \mathbf{6 0} \mathbf{~ m i n} / \text { week } \\
\mathrm{N}(\%) \text { or } \\
\text { median (IQR) }\end{array}$ \\
\hline Total & $247(31 \%)$ & $151(19 \%)$ & $394(50 \%)$ \\
\hline \multicolumn{4}{|l|}{ Individual correlates } \\
\hline \multicolumn{4}{|l|}{ Gender } \\
\hline Female & $145(59 \%)$ & $79(52 \%)$ & $196(50 \%)$ \\
\hline Male & $102(41 \%)$ & $72(48 \%)$ & $198(50 \%)$ \\
\hline \multicolumn{4}{|l|}{ Race / Ethnicity } \\
\hline Non-Hispanic white & $105(43 \%)$ & $79(52 \%)$ & $177(45 \%)$ \\
\hline Chinese American & $22(9 \%)$ & $13(9 \%)$ & $56(14 \%)$ \\
\hline Non-Hispanic black & $67(27 \%)$ & $31(21 \%)$ & $96(24 \%)$ \\
\hline Hispanic & $53(21 \%)$ & $28(19 \%)$ & $65(16 \%)$ \\
\hline \multicolumn{4}{|l|}{ Socioeconomic Position Category a } \\
\hline High & $77(31 \%)$ & $65(43 \%)$ & $134(34 \%)$ \\
\hline Moderate & $97(39 \%)$ & $55(36 \%)$ & $143(36 \%)$ \\
\hline Low & $73(30 \%)$ & $31(21 \%)$ & $117(30 \%)$ \\
\hline Retirement age (years) & $63(59,67)$ & $63(59,69)$ & $63(59,67)$ \\
\hline \multicolumn{4}{|l|}{ MESA site } \\
\hline $\mathrm{NC}$ & $42(17 \%)$ & $28(19 \%)$ & $82(21 \%)$ \\
\hline NY & $48(19 \%)$ & $18(12 \%)$ & $69(18 \%)$ \\
\hline MD & $35(14 \%)$ & $21(14 \%)$ & $37(9 \%)$ \\
\hline $\mathrm{MN}$ & $49(20 \%)$ & $33(22 \%)$ & $66(17 \%)$ \\
\hline $\mathrm{IL}$ & $48(19 \%)$ & $36(24 \%)$ & $90(23 \%)$ \\
\hline $\mathrm{CA}$ & $25(10 \%)$ & $15(10 \%)$ & $50(13 \%)$ \\
\hline \multicolumn{4}{|l|}{ Car ownership } \\
\hline Not owning a car & $42(17 \%)$ & $19(13 \%)$ & $62(16 \%)$ \\
\hline Owning a car & $205(83 \%)$ & $132(87 \%)$ & $332(84 \%)$ \\
\hline \multicolumn{4}{|l|}{ Job type } \\
\hline Full-time & $167(68 \%)$ & $100(66 \%)$ & $288(73 \%)$ \\
\hline Part-time & $46(19 \%)$ & $31(21 \%)$ & $75(19 \%)$ \\
\hline Other ${ }^{b}$ & $34(14 \%)$ & $20(13 \%)$ & $31(8 \%)$ \\
\hline $\begin{array}{l}\text { Occupational physical activity (MET- } \\
\text { min/week) }\end{array}$ & $4050(2520,5760)$ & $4350(2880,6000)$ & $4530(3150,6195)$ \\
\hline \multicolumn{4}{|l|}{ Change in self-rated health } \\
\hline Maintain good health & $90(36 \%)$ & $76(50 \%)$ & $178(45 \%)$ \\
\hline Health improved & $40(16 \%)$ & $26(17 \%)$ & $63(16 \%)$ \\
\hline Health declined & $52(21 \%)$ & $19(13 \%)$ & $59(15 \%)$ \\
\hline Always poor to fair health & $65(26 \%)$ & $30(20 \%)$ & $94(24 \%)$ \\
\hline
\end{tabular}




\begin{tabular}{|c|c|c|c|}
\hline Correlate & $\begin{array}{c}\text { Decrease } \\
\geq \mathbf{6 0} \mathbf{m i n} / \text { week } \\
\mathrm{N}(\%) \text { or } \\
\text { median (IQR) }\end{array}$ & $\begin{array}{c}\text { Maintain } \\
\mathrm{N}(\%) \text { or } \\
\text { median (IQR) }\end{array}$ & $\begin{array}{c}\text { Increase } \\
\geq \mathbf{6 0} \text { min/week } \\
\mathrm{N}(\%) \text { or } \\
\text { median (IQR) }\end{array}$ \\
\hline \multicolumn{4}{|l|}{$\begin{array}{l}\text { Change in number of chronic } \\
\text { conditions }{ }^{c}\end{array}$} \\
\hline Always 0 & $73(30 \%)$ & $39(26 \%)$ & $102(26 \%)$ \\
\hline Increase & $71(29 \%)$ & $41(27 \%)$ & $126(32 \%)$ \\
\hline Decrease & $32(13 \%)$ & $19(13 \%)$ & $35(9 \%)$ \\
\hline Always 1 & $35(14 \%)$ & $26(17 \%)$ & $82(21 \%)$ \\
\hline Always $>1$ & $36(15 \%)$ & $26(17 \%)$ & $49(12 \%)$ \\
\hline Change in body mass index $\left(\mathrm{kg} / \mathrm{m}^{2}\right)$ & $0.29(-0.66,1.42)$ & $0.31(-0.83,1.26)$ & $0.2(-0.65,1.2)$ \\
\hline \multicolumn{4}{|l|}{ Interpersonal correlates } \\
\hline \multicolumn{4}{|l|}{ Change in partnership status } \\
\hline Always with partner & $145(59 \%)$ & $92(61 \%)$ & $252(64 \%)$ \\
\hline Gained partner & $10(4 \%)$ & $5(3 \%)$ & $10(3 \%)$ \\
\hline Lost partner & $15(6 \%)$ & $9(6 \%)$ & $23(6 \%)$ \\
\hline Never had partner & $77(31 \%)$ & $45(30 \%)$ & $109(28 \%)$ \\
\hline \multicolumn{4}{|l|}{ Change in caregiver status ${ }^{d}$} \\
\hline Always caregiver & $25(10 \%)$ & $10(7 \%)$ & $41(10 \%)$ \\
\hline Became caregiver & $26(11 \%)$ & $20(13 \%)$ & $54(14 \%)$ \\
\hline Stopped caregiving & $29(12 \%)$ & $19(13 \%)$ & $42(11 \%)$ \\
\hline Never caregiver & $167(68 \%)$ & $102(68 \%)$ & $257(65 \%)$ \\
\hline Low emotional social support & $9(4 \%)$ & $5(3 \%)$ & $15(4 \%)$ \\
\hline \multicolumn{4}{|l|}{ Community correlates } \\
\hline \multicolumn{4}{|l|}{$\begin{array}{l}\text { There is a lot of trash and litter on the } \\
\text { street in my neighborhood }\end{array}$} \\
\hline Agree / neutral & $37(15 \%)$ & $26(17 \%)$ & $67(17 \%)$ \\
\hline Disagree & $210(85 \%)$ & $125(83 \%)$ & $327(83 \%)$ \\
\hline \multicolumn{4}{|l|}{$\begin{array}{l}\text { There is a lot of noise in my } \\
\text { neighborhood }\end{array}$} \\
\hline Agree & $96(39 \%)$ & $55(36 \%)$ & $142(36 \%)$ \\
\hline Disagree & $151(61 \%)$ & $96(64 \%)$ & $252(64 \%)$ \\
\hline \multicolumn{4}{|l|}{ My neighborhood is attractive } \\
\hline Disagree & $48(19 \%)$ & $15(10 \%)$ & $74(19 \%)$ \\
\hline Agree & $199(81 \%)$ & $136(90 \%)$ & $320(81 \%)$ \\
\hline \multicolumn{4}{|l|}{$\begin{array}{l}\text { I feel safe walking in my neighborhood } \\
\text { day or night }\end{array}$} \\
\hline Disagree & $59(24 \%)$ & $33(22 \%)$ & $96(24 \%)$ \\
\hline Agree & $188(76 \%)$ & $118(78 \%)$ & $298(76 \%)$ \\
\hline \multicolumn{4}{|l|}{$\begin{array}{l}\text { Violence is a problem in my } \\
\text { neighborhood }\end{array}$} \\
\hline Agree & $64(26 \%)$ & $36(24 \%)$ & $97(25 \%)$ \\
\hline Disagree & $183(74 \%)$ & $115(76 \%)$ & $297(75 \%)$ \\
\hline
\end{tabular}




\begin{tabular}{|c|c|c|c|}
\hline Correlate & $\begin{array}{l}\text { Decrease } \\
\geq \mathbf{6 0} \mathbf{m i n} / \text { week } \\
\mathrm{N}(\%) \text { or } \\
\text { median }(\mathrm{IQR})\end{array}$ & $\begin{array}{l}\text { Maintain } \\
\mathrm{N}(\%) \text { or } \\
\text { median (IQR) }\end{array}$ & $\begin{array}{l}\text { Increase } \\
\geq \mathbf{6 0} \text { min/week } \\
\mathrm{N}(\%) \text { or } \\
\text { median (IQR) }\end{array}$ \\
\hline \multicolumn{4}{|l|}{$\begin{array}{l}\text { It is pleasant to walk in my } \\
\text { neighborhood }\end{array}$} \\
\hline Disagree & $34(14 \%)$ & $10(7 \%)$ & $51(13 \%)$ \\
\hline Agree & $213(86 \%)$ & $141(93 \%)$ & $343(87 \%)$ \\
\hline \multicolumn{4}{|l|}{$\begin{array}{l}\text { In my neighborhood, it is easy to walk } \\
\text { to places }\end{array}$} \\
\hline Disagree & $60(24 \%)$ & $20(13 \%)$ & $80(20 \%)$ \\
\hline Agree & $187(76 \%)$ & $131(87 \%)$ & $314(80 \%)$ \\
\hline \multicolumn{4}{|l|}{$\begin{array}{l}\text { I often see other people walking in my } \\
\text { neighborhood }\end{array}$} \\
\hline Disagree & $28(11 \%)$ & $9(6 \%)$ & $43(11 \%)$ \\
\hline Agree & $219(89 \%)$ & $142(94 \%)$ & $351(89 \%)$ \\
\hline \multicolumn{4}{|l|}{$\begin{array}{l}\text { I often see other people exercise (jog, } \\
\text { cycle, play sports) in my neighborhood }\end{array}$} \\
\hline Disagree & $65(26 \%)$ & $20(13 \%)$ & $86(22 \%)$ \\
\hline Agree & $182(74 \%)$ & $131(87 \%)$ & $308(78 \%)$ \\
\hline \multicolumn{4}{|l|}{ Neighborhood social cohesion } \\
\hline Low & $16(6 \%)$ & $8(5 \%)$ & $29(7 \%)$ \\
\hline Moderate & $144(58 \%)$ & $80(53 \%)$ & $221(56 \%)$ \\
\hline High & $87(35 \%)$ & $63(42 \%)$ & $144(37 \%)$ \\
\hline $\begin{array}{l}\text { Density of walking destinations (z- } \\
\text { score) }\end{array}$ & $-0.49(-0.58,0.2)$ & $-0.48(-0.59,-0.04)$ & $-0.46(-0.61,-0.03)$ \\
\hline Density of parks (z-score) ${ }^{\mathrm{e}}$ & $-0.26(-0.68,0.36)$ & $-0.34(-0.65,0.24)$ & $-0.36(-0.68,0.18)$ \\
\hline Network ratio (z-score) & $0.44(0.28,0.55)$ & $0.42(0.29,0.52)$ & $0.43(0.27,0.53)$ \\
\hline Population density (thousands / $\mathrm{mi}^{2}$ ) & $6.2(2.9,17.1)$ & $5.9(2.9,14.6)$ & $6.3(2.6,14.4)$ \\
\hline \multicolumn{4}{|c|}{$\begin{array}{l}\text { Abbreviations: IQR interquartile range; MESA Multi-Ethnic Study of Atherosclerosis; MET metabolic equivalent } \\
\text { task } \\
\text { a Socioeconomic position based on composite index of education, income, and four indicators of wealth } \\
\text { (ownership of home, land/property, car, investments) }\end{array}$} \\
\hline \multicolumn{4}{|c|}{ b Other includes homemaking, unemployment, and on-leave from work. } \\
\hline \multicolumn{4}{|c|}{$\begin{array}{l}{ }^{\circ} \text { Chronic conditions included self-reported asthma, emphysema, arthritis flare up in the past two weeks, measured } \\
\text { high cholesterol, hypertension, or diabetes, and kidney disease, cancer, and CVD ascertained from medical records } \\
\text { and hospital billing claims. }\end{array}$} \\
\hline \multicolumn{4}{|c|}{${ }^{\mathrm{d}}$ Caregiver defined as reporting $>=150 \mathrm{~min} /$ week of caregiving activity to children or adults } \\
\hline${ }^{e}$ Park data only available for $\mathrm{N}=718 \mathrm{pa}$ & & & \\
\hline
\end{tabular}


Table 29. Individual-, interpersonal-, and community correlates by category of change in transport walking after retirement, MESA 2000-2012 (N=887)

\begin{tabular}{|c|c|c|c|}
\hline Correlate & $\begin{array}{c}\text { Decrease } \\
\geq \mathbf{6 0 ~} \mathbf{~ m i n} / \text { week } \\
\mathrm{N}(\%) \text { or } \\
\text { median (IQR) } \\
\end{array}$ & $\begin{array}{c}\text { Maintain } \\
\text { N (\%) or } \\
\text { median (IQR) }\end{array}$ & $\begin{array}{c}\text { Increase } \\
\geq \mathbf{6 0 ~} \mathbf{m i n} / \text { week } \\
\mathrm{N}(\%) \text { or } \\
\text { median (IQR) } \\
\end{array}$ \\
\hline Total & $353(40 \%)$ & $172(19 \%)$ & $362(41 \%)$ \\
\hline \multicolumn{4}{|l|}{ Individual correlates } \\
\hline \multicolumn{4}{|l|}{ Gender } \\
\hline Female & $193(55 \%)$ & $91(53 \%)$ & $200(55 \%)$ \\
\hline Male & $160(45 \%)$ & $81(47 \%)$ & $162(45 \%)$ \\
\hline \multicolumn{4}{|l|}{ Race / Ethnicity } \\
\hline Non-Hispanic white & $160(45 \%)$ & $73(42 \%)$ & $157(43 \%)$ \\
\hline Chinese American & $32(9 \%)$ & $27(16 \%)$ & $36(10 \%)$ \\
\hline Non-Hispanic black & $90(25 \%)$ & $50(29 \%)$ & $103(28 \%)$ \\
\hline Hispanic & $71(20 \%)$ & $22(13 \%)$ & $66(18 \%)$ \\
\hline \multicolumn{4}{|l|}{ Socioeconomic Position Category a } \\
\hline High & $108(31 \%)$ & $61(35 \%)$ & $122(34 \%)$ \\
\hline Moderate & $149(42 \%)$ & $60(35 \%)$ & $135(37 \%)$ \\
\hline Low & $96(27 \%)$ & $51(30 \%)$ & $105(29 \%)$ \\
\hline Retirement age (years) & $63(59,67)$ & $63(59,68)$ & $62(58,67)$ \\
\hline \multicolumn{4}{|l|}{ MESA site } \\
\hline $\mathrm{NC}$ & $70(20 \%)$ & $39(23 \%)$ & $61(17 \%)$ \\
\hline NY & $62(18 \%)$ & $13(8 \%)$ & $79(22 \%)$ \\
\hline MD & $43(12 \%)$ & $22(13 \%)$ & $52(14 \%)$ \\
\hline $\mathrm{MN}$ & $75(21 \%)$ & $27(16 \%)$ & $60(17 \%)$ \\
\hline IL & $74(21 \%)$ & $32(19 \%)$ & $77(21 \%)$ \\
\hline $\mathrm{CA}$ & $29(8 \%)$ & $39(23 \%)$ & $33(9 \%)$ \\
\hline \multicolumn{4}{|l|}{ Car ownership } \\
\hline Not owning a car & $53(15 \%)$ & $16(9 \%)$ & $65(18 \%)$ \\
\hline Owning a car & $300(85 \%)$ & $156(91 \%)$ & $297(82 \%)$ \\
\hline \multicolumn{4}{|l|}{ Job type } \\
\hline Full-time & $246(70 \%)$ & $118(69 \%)$ & $266(73 \%)$ \\
\hline Part-time & $71(20 \%)$ & $33(19 \%)$ & $59(16 \%)$ \\
\hline Other $^{\mathrm{b}}$ & $36(10 \%)$ & $21(12 \%)$ & $37(10 \%)$ \\
\hline $\begin{array}{l}\text { Occupational physical activity (MET- } \\
\mathrm{min} / \text { week) }\end{array}$ & $4500(3150,6120)$ & $4350(2610,6105)$ & $4500(3150,6000)$ \\
\hline \multicolumn{4}{|l|}{ Change in self-rated health } \\
\hline Maintain good health & $156(44 \%)$ & $75(44 \%)$ & $154(43 \%)$ \\
\hline Health improved & $48(14 \%)$ & $27(16 \%)$ & $64(18 \%)$ \\
\hline Health declined & $60(17 \%)$ & $18(10 \%)$ & $67(19 \%)$ \\
\hline Always poor to fair health & $89(25 \%)$ & $52(30 \%)$ & $77(21 \%)$ \\
\hline
\end{tabular}




\begin{tabular}{|c|c|c|c|}
\hline Correlate & $\begin{array}{c}\text { Decrease } \\
\geq \mathbf{6 0} \text { min/week } \\
\mathrm{N}(\%) \text { or } \\
\text { median (IQR) }\end{array}$ & $\begin{array}{c}\text { Maintain } \\
\mathrm{N}(\%) \text { or } \\
\text { median (IQR) }\end{array}$ & $\begin{array}{c}\text { Increase } \\
\geq \mathbf{6 0} \text { min/week } \\
\mathrm{N}(\%) \text { or } \\
\text { median (IQR) }\end{array}$ \\
\hline Always 0 & $97(27 \%)$ & $50(29 \%)$ & $83(23 \%)$ \\
\hline Increase & $105(30 \%)$ & $47(27 \%)$ & $110(30 \%)$ \\
\hline Decrease & $32(9 \%)$ & $20(12 \%)$ & $44(12 \%)$ \\
\hline Always 1 & $72(20 \%)$ & $25(15 \%)$ & $75(21 \%)$ \\
\hline Always $>1$ & $47(13 \%)$ & $30(17 \%)$ & $50(14 \%)$ \\
\hline Change in body mass index $\left(\mathrm{kg} / \mathrm{m}^{2}\right)$ & $0.16(-0.65,1.28)$ & $0.21(-0.76,1.34)$ & $0.29(-0.78,1.32)$ \\
\hline
\end{tabular}

\section{Interpersonal correlates}

Change in partnership status

Always with partner
Gained partner
Lost partner
Never had partner

$205(58 \%)$

$111(65 \%)$

$210(58 \%)$

$13(4 \%)$

$5(3 \%)$

$7(2 \%)$

$20(6 \%)$

$5(3 \%)$

$29(8 \%)$

$115(33 \%)$

$51(30 \%)$

$116(32 \%)$

Change in caregiver status ${ }^{d}$

Always caregiver
Became caregiver
Stopped caregiving
Never caregiver

$44(12 \%)$

$11(6 \%)$

$31(9 \%)$

$39(11 \%)$

$31(18 \%)$

$38(10 \%)$

$44(12 \%)$

$16(9 \%)$

$49(14 \%)$

$226(64 \%)$

$114(66 \%)$

$244(67 \%)$

$14(4 \%)$

$7(4 \%)$

$12(3 \%)$

\section{Community correlates}

There is a lot of trash and litter on the street in my neighborhood
Agree / neutral
Disagree

$66(19 \%)$

$17(10 \%)$

$64(18 \%)$

$287(81 \%)$

$155(90 \%)$

$298(82 \%)$

There is a lot of noise in my neighborhood

$$
\text { Agree }
$$

$140(40 \%)$

$51(30 \%)$

$138(38 \%)$

Disagree

$213(60 \%)$

$121(70 \%)$

$224(62 \%)$

My neighborhood is attractive

Disagree

$62(18 \%)$

$27(16 \%)$

$71(20 \%)$

Agree

$291(82 \%)$

$145(84 \%)$

$291(80 \%)$

I feel safe walking in my neighborhood day or night
Disagree
Agree

$89(25 \%)$

$41(24 \%)$

$85(23 \%)$

$264(75 \%)$

$131(76 \%)$

$277(77 \%)$

Violence is a problem in my neighborhood

$$
\begin{aligned}
& \text { Agree } \\
& \text { Disagree }
\end{aligned}
$$

$92(26 \%)$

$37(22 \%)$

$89(25 \%)$

$261(74 \%)$

$135(78 \%)$

$273(75 \%)$

It is pleasant to walk in my neighborhood

Disagree

$50(14 \%)$

$21(12 \%)$

$42(12 \%)$

Agree

$303(86 \%)$
$320(88 \%)$ 


\begin{tabular}{|c|c|c|c|}
\hline Correlate & $\begin{array}{c}\text { Decrease } \\
\geq \mathbf{6 0} \mathbf{m i n} / \text { week } \\
\mathrm{N}(\%) \text { or } \\
\text { median (IQR) } \\
\end{array}$ & $\begin{array}{c}\text { Maintain } \\
\mathrm{N}(\%) \text { or } \\
\text { median (IQR) } \\
\end{array}$ & $\begin{array}{c}\text { Increase } \\
\geq \mathbf{6 0} \mathbf{m i n} / \mathbf{w e e k} \\
\mathrm{N}(\%) \text { or } \\
\text { median (IQR) } \\
\end{array}$ \\
\hline \multicolumn{4}{|l|}{$\begin{array}{l}\text { In my neighborhood, it is easy to walk to } \\
\text { places }\end{array}$} \\
\hline Disagree & $83(24 \%)$ & $37(22 \%)$ & $70(19 \%)$ \\
\hline Agree & $270(76 \%)$ & $135(78 \%)$ & $292(81 \%)$ \\
\hline \multicolumn{4}{|l|}{$\begin{array}{l}\text { I often see other people walking in my } \\
\text { neighborhood }\end{array}$} \\
\hline Disagree & $38(11 \%)$ & $24(14 \%)$ & $33(9 \%)$ \\
\hline Agree & $315(89 \%)$ & $148(86 \%)$ & $329(91 \%)$ \\
\hline \multicolumn{4}{|l|}{$\begin{array}{l}\text { I often see other people exercise (jog, cycle, } \\
\text { play sports) in my neighborhood }\end{array}$} \\
\hline Disagree & $80(23 \%)$ & $45(26 \%)$ & $78(22 \%)$ \\
\hline Agree & $273(77 \%)$ & $127(74 \%)$ & $284(78 \%)$ \\
\hline \multicolumn{4}{|l|}{ Neighborhood social cohesion } \\
\hline Low & $24(7 \%)$ & $11(6 \%)$ & $28(8 \%)$ \\
\hline Moderate & $196(56 \%)$ & $99(58 \%)$ & $208(57 \%)$ \\
\hline High & $133(38 \%)$ & $62(36 \%)$ & $126(35 \%)$ \\
\hline Density of walking destinations (z-score) & $-0.49(-0.61,-0.04)$ & $-0.49(-0.57,-0.24)$ & $-0.41(-0.59,0.59)$ \\
\hline Density of parks (z-score) ${ }^{\mathrm{e}}$ & $-0.26(-0.68,0.32)$ & $-0.41(-0.67,-0.14)$ & $-0.27(-0.63,0.39)$ \\
\hline Network ratio (z-score) & $0.43(0.26,0.54)$ & $0.43(0.27,0.51)$ & $0.43(0.31,0.53)$ \\
\hline Population density (thousands / $\mathrm{mi}^{2}$ ) & $5.9(2.7,14.8)$ & $6.6(2.6,11.2)$ & $6.7(3.3,19.6)$ \\
\hline
\end{tabular}

Abbreviations: IQR interquartile range; MESA Multi-Ethnic Study of Atherosclerosis; MET metabolic equivalent task

${ }^{\text {a }}$ Socioeconomic position based on composite index of education, income, and four indicators of wealth (ownership of home, land/property, car, investments)

${ }^{\mathrm{b}}$ Other includes homemaking, unemployment, and on-leave from work.

${ }^{\mathrm{c}}$ Chronic conditions included self-reported asthma, emphysema, arthritis flare up in the past two weeks, measured high cholesterol, hypertension, or diabetes, and kidney disease, cancer, and CVD ascertained from medical records and hospital billing claims.

${ }^{\mathrm{d}}$ Caregiver defined as reporting $>=150 \mathrm{~min} /$ week of caregiving activity to children or adults

${ }^{\mathrm{e}}$ Park data only available for $\mathrm{N}=807$ participants 
Table 30. Multivariable logistic regression of individual-, interpersonal-, and community-level correlates associated with change in recreational walking after retirement among participants who did not move during follow-up, MESA 2000-2012 (N=623)

\begin{tabular}{|c|c|c|c|}
\hline Correlate & Comparison & $\begin{array}{c}\text { Decrease } \geq \mathbf{6 0} \text { min/week vs. maintain pre- } \\
\text { retirement walking } \\
(\mathrm{N}=197 \text { decrease, } \mathrm{N}=120 \text { maintain }) \\
\text { Odds Ratio }(\mathbf{9 5 \%} \mathrm{CI})\end{array}$ & $\begin{array}{c}\text { Increase } \geq \mathbf{6 0} \text { min/week vs. maintain pre- } \\
\text { retirement walking } \\
(\mathrm{N}=306 \text { increase, } \mathrm{N}=120 \text { maintain }) \\
\text { Odds Ratio }(\mathbf{9 5 \%} \mathrm{CI})\end{array}$ \\
\hline \multicolumn{4}{|l|}{ Core variables } \\
\hline Gender & Male vs. female & $0.97(0.54,1.74)$ & $0.97(0.61,1.55)$ \\
\hline \multirow[t]{2}{*}{ Socioeconomic position ${ }^{\text {a }}$} & Low vs. high & $4.31(1.64,11.31)^{*}$ & $2.59(1.23,5.42)^{*}$ \\
\hline & Moderate vs. high & $1.96(0.94,4.07)$ & $1.95(1.10,3.46)^{*}$ \\
\hline \multirow[t]{3}{*}{ Race/ethnicity } & Chinese American vs. non-Hispanic white & $1.23(0.37,4.10)$ & $0.82(0.32,2.13)$ \\
\hline & Non-Hispanic black vs. non-Hispanic white & $1.28(0.62,2.66)$ & $0.97(0.53,1.81)$ \\
\hline & Hispanic vs. non-Hispanic white & $0.74(0.29,1.89)$ & $0.45(0.21,0.95)^{*}$ \\
\hline Age at retirement & 1-year increase & $0.99(0.94,1.03)$ & $0.99(0.96,1.03)$ \\
\hline Season of pre-retirement & Spring vs. winter & $1.44(0.63,3.32)$ & $1.24(0.65,2.38)$ \\
\hline \multirow{2}{*}{ exam } & Summer vs. winter & $1.39(0.59,3.27)$ & $1.39(0.67,2.86)$ \\
\hline & Fall vs. winter & $0.73(0.30,1.76)$ & $1.00(0.50,2.00)$ \\
\hline \multirow{3}{*}{$\begin{array}{l}\text { Season of post-retirement } \\
\text { exam }\end{array}$} & Spring vs. winter & $0.34(0.16,0.75) *$ & $1.06(0.55,2.02)$ \\
\hline & Summer vs. winter & $0.62(0.26,1.45)$ & $1.49(0.72,3.09)$ \\
\hline & Fall vs. winter & $0.57(0.25,1.29)$ & $1.07(0.53,2.19)$ \\
\hline \multirow[t]{5}{*}{ MESA site } & NC vs. IL & $0.86(0.32,2.35)$ & $0.80(0.38,1.70)$ \\
\hline & NY vs. IL & $1.01(0.34,2.99)$ & $0.65(0.27,1.55)$ \\
\hline & MD vs. IL & $1.42(0.49,4.11)$ & $0.45(0.19,1.08)$ \\
\hline & MN vs. IL & $1.07(0.34,3.41)$ & $0.43(0.18,1.04)$ \\
\hline & CA vs. IL & $0.54(0.15,1.94)$ & $0.72(0.28,1.86)$ \\
\hline \multirow{3}{*}{$\begin{array}{l}\text { Pre-retirement recreational } \\
\text { walking tertile } \\
\text { Individual level }\end{array}$} & $<90 \mathrm{~min} /$ week vs. $>210 \mathrm{~min} /$ week & $0.07(0.03,0.15)^{*}$ & $2.28(1.25,4.15)^{*}$ \\
\hline & 90 to $210 \mathrm{~min} /$ week vs. $>210 \mathrm{~min} /$ week & $0.42(0.21,0.84)^{*}$ & $1.96(1.02,3.78)^{*}$ \\
\hline & & & \\
\hline \multirow[t]{3}{*}{$\begin{array}{l}\text { Self-rated health relative to } \\
\text { others }\end{array}$} & $\begin{array}{l}\text { Improved after retirement vs. always rated as } \\
\text { "better than others" }\end{array}$ & $1.74(0.77,3.91)$ & \\
\hline & $\begin{array}{l}\text { Declined after retirement vs. always rated as } \\
\text { "better than others" }\end{array}$ & $3.00(1.34,6.71)^{*}$ & \\
\hline & $\begin{array}{l}\text { Always rated as "same" or "worse" than others } \\
\text { vs. always rated as "better than others" }\end{array}$ & $3.07(1.33,7.09) *$ & \\
\hline \multirow[t]{4}{*}{$\begin{array}{l}\text { Change in number of } \\
\text { chronic conditions }{ }^{b}\end{array}$} & $\begin{array}{l}\text { Fewer after retirement vs. no chronic conditions } \\
\text { ever }\end{array}$ & & $0.73(0.31,1.69)$ \\
\hline & $\begin{array}{l}\text { More after retirement vs. no chronic conditions } \\
\text { ever }\end{array}$ & & $1.01(0.54,1.90)$ \\
\hline & 1 chronic condition vs. no chronic conditions & & $1.45(0.71,2.97)$ \\
\hline & $>1$ condition vs. no chronic conditions & & $0.53(0.25,1.16)$ \\
\hline \multirow[t]{2}{*}{ Job type prior to retirement } & Part-time vs. full-time & & $0.71(0.39,1.31)$ \\
\hline & Other ${ }^{c}$ vs. full-time & & $0.41(0.19,0.92)^{*}$ \\
\hline \multicolumn{4}{|l|}{ Community level } \\
\hline Aesthetic quality: trash & There is a lot of trash / litter on the street in my & $1.84(0.80,4.24)$ & \\
\hline
\end{tabular}




\begin{tabular}{|c|c|c|c|}
\hline Correlate & Comparison & $\begin{array}{c}\text { Decrease } \geq \mathbf{6 0} \text { min/week vs. maintain pre- } \\
\text { retirement walking } \\
(\mathrm{N}=197 \text { decrease, } \mathrm{N}=120 \text { maintain }) \\
\text { Odds Ratio }(\mathbf{9 5 \%} \mathrm{CI}) \\
\end{array}$ & $\begin{array}{c}\text { Increase } \geq \mathbf{6 0} \text { min/week vs. maintain pre- } \\
\text { retirement walking } \\
(\mathrm{N}=306 \text { increase, } \mathrm{N}=120 \text { maintain }) \\
\text { Odds Ratio }(\mathbf{9 5 \%} \text { CI })\end{array}$ \\
\hline & neighborhood (disagree vs. agree) & & \\
\hline Aesthetic quality: attractive & $\begin{array}{l}\text { My neighborhood is attractive (agree vs. } \\
\text { disagree) }\end{array}$ & & $0.44(0.21,0.94)^{*}$ \\
\hline $\begin{array}{l}\text { Walking environment: easy } \\
\text { to walk places }\end{array}$ & $\begin{array}{l}\text { In my neighborhood it is easy to walk places } \\
\text { (agree vs. disagree) }\end{array}$ & $0.47(0.21,1.05)$ & $0.64(0.33,1.00)$ \\
\hline $\begin{array}{l}\text { Walking environment: see } \\
\text { others exercise }\end{array}$ & $\begin{array}{l}\text { I often see other people exercise (jog, bicycle, } \\
\text { play sports) in my neighborhood (agree vs. } \\
\text { disagree) }\end{array}$ & $0.57(0.26,1.27)$ & \\
\hline
\end{tabular}

Abbreviations: CI confidence interval; MESA Multi-Ethnic Study of Atherosclerosis

a Socioeconomic position based on composite index of education, income, and four indicators of wealth (ownership of home, land/property, car, investments)

${ }^{\mathrm{b}}$ Chronic conditions included self-reported asthma, emphysema, arthritis flare up in the past two weeks, measured high cholesterol, hypertension, or diabetes, and kidney disease, cancer, and CVD ascertained from medical records and hospital billing claims.

${ }^{c}$ Other includes homemaking, unemployment, and on-leave from work

* P-value $<0.05$ 
Table 31. Multivariable logistic regression of individual-, interpersonal-, and community-level correlates associated with change in transport walking after retirement among participants who did not move during follow-up, MESA 2000-2012 (N=704)

\begin{tabular}{|c|c|c|c|}
\hline Correlate & Comparison & $\begin{array}{c}\text { Decrease } \geq \mathbf{6 0} \text { min/week vs. maintain } \\
\text { pre-retirement walking } \\
(\mathrm{N}=278 \text { decrease, } \mathrm{N}=139 \text { maintain }) \\
\text { Odds Ratio }(\mathbf{9 5 \%} \mathrm{CI}) \\
\end{array}$ & $\begin{array}{c}\text { Increase } \geq \mathbf{6 0} \text { min/week vs. maintain } \\
\text { pre-retirement walking } \\
(\mathrm{N}=287 \text { increase, } \mathrm{N}=139 \text { maintain }) \\
\text { Odds Ratio }(\mathbf{9 5 \%} \mathrm{CI})\end{array}$ \\
\hline \multicolumn{4}{|l|}{ Core variables } \\
\hline \multirow{3}{*}{$\begin{array}{l}\text { Gender } \\
\text { Socioeconomic position }{ }^{a}\end{array}$} & Male vs. female & $1.50(0.80,2.80)$ & $1.03(0.64,1.66)$ \\
\hline & Low vs. high & $2.25(0.88,5.72)$ & $0.90(0.47,1.74)$ \\
\hline & Moderate vs. high & $1.86(0.88,3.93)$ & $1.14(0.66,1.95)$ \\
\hline \multirow[t]{3}{*}{ Race/ethnicity } & Chinese American vs. non-Hispanic white & $1.74(0.50,6.02)$ & $1.15(0.48,2.80)$ \\
\hline & Non-Hispanic black vs. non-Hispanic white & $0.81(0.38,1.76)$ & $0.88(0.51,1.53)$ \\
\hline & Hispanic vs. non-Hispanic white & $1.20(0.41,3.49)$ & $1.18(0.53,2.62)$ \\
\hline \multirow{4}{*}{$\begin{array}{l}\text { Age at retirement } \\
\text { Season of pre-retirement } \\
\text { exam }\end{array}$} & 1-year increase & $0.99(0.94,1.03)$ & $0.98(0.95,1.02)$ \\
\hline & Spring vs. winter & $1.70(0.78,3.70)$ & $1.71(0.95,3.08)$ \\
\hline & Summer vs. winter & $2.05(0.88,4.79)$ & $1.65(0.85,3.19)$ \\
\hline & Fall vs. winter & $1.99(0.81,4.85)$ & $1.67(0.83,3.33)$ \\
\hline \multirow{3}{*}{$\begin{array}{l}\text { Season of post-retirement } \\
\text { exam }\end{array}$} & Spring vs. winter & $0.54(0.24,1.22)$ & $0.96(0.51,1.80)$ \\
\hline & Summer vs. winter & $0.30(0.12,0.70)^{*}$ & $0.81(0.43,1.54)$ \\
\hline & Fall vs. winter & $0.92(0.39,2.17)$ & $1.35(0.67,2.72)$ \\
\hline \multirow[t]{5}{*}{ MESA site } & NC vs. IL & $1.02(0.37,2.81)$ & $0.68(0.33,1.41)$ \\
\hline & NY vs. IL & $5.58(1.38,22.59)^{*}$ & $2.54(1.00,6.44)^{*}$ \\
\hline & MD vs. IL & $1.25(0.42,3.69)$ & $1.08(0.48,2.40)$ \\
\hline & MN vs. IL & $2.17(0.63,7.55)$ & $0.78(0.32,1.90)$ \\
\hline & CA vs. IL & $0.60(0.18,2.00)$ & $0.31(0.13,0.71)^{*}$ \\
\hline \multirow{2}{*}{$\begin{array}{l}\text { Pre-retirement transport } \\
\text { walking tertile }\end{array}$} & < $90 \mathrm{~min} /$ week vs. > $300 \mathrm{~min} /$ week & $0.01(0.00,0.03)^{*}$ & $1.00(0.49,2.06)$ \\
\hline & 90 to $300 \mathrm{~min} /$ week vs. $>300 \mathrm{~min} /$ week & $0.15(0.07,0.31)^{*}$ & $1.01(0.49,2.07)$ \\
\hline
\end{tabular}


Correlate

Decrease $\geq 60 \mathrm{~min} /$ week vs. maintain pre-retirement walking

$(\mathrm{N}=278$ decrease, $\mathrm{N}=139$ maintain $)$

ndividual level

Self-rated health relative

to others

Improved after retirement vs. always rated as

"better than others"

Odds Ratio (95\% CI)

Increase $>60 \mathrm{~min} /$ week vs. maintain

pre-retirement walking

$\mathrm{N}=287$ increase, $\mathrm{N}=139$ maintain)

Odds Ratio (95\% CI)

Declined after retirement vs. always rated as

"better than others"

$1.30(0.68,2.49)$

Always rated as "same" or "worse" than

others vs. always rated as "better than others"

$2.06(1.02,4.18) *$

\section{Interpersonal level}

Change in partnership

status

Never married/living with partner vs. always married/living with partner

Married/living with partner before retirement

vs. always married/living with partner

Married/living with partner after retirement

vs. always married/living with partner

Change in caregiver status

Caregiver before retirement vs. never a

caregiver

Caregiver after retirement vs. never a

caregiver

Always a caregiver vs. never a caregiver

\section{Community level}

1-mile density of walking

destinations

\section{1-SD unit increase}

Aesthetic quality: trash

There is a lot of trash / litter on the street in

my neighborhood (disagree vs. agree)

My neighborhood is attractive (agree vs.

Aesthetic quality:

attractive

disagree)

Violence is a problem in my neighborhood

(disagree vs. agree)

Walking environment: In my neighborhood it is easy to walk places

easy to walk places

(agree vs. disagree)

$0.70(0.39,1.25)$

$1.10(0.55,2.20)$

$0.98(0.57,1.69)$

$2.23(0.43,11.49)$

$3.00(0.80,11.36)$

$2.97(0.30,29.95)$

$1.08(0.16,7.16)$

$0.57(0.23,1.42)$

\section{$0.30(0.12,0.75) *$}

$2.38(0.76,7.46)$

\section{$0.56(0.36,0.89) *$}

$0.54(0.22,1.36)$

$0.66(0.35,1.25)$

$1.32(0.65,2.69)$

$0.78(0.36,1.68)$

$1.89(0.68,5.27)$

$1.27(0.60,2.71)$

others walking neighborhood (agree vs. disagree)

Abbreviations: CI confidence interval; MESA Multi-Ethnic Study of Atherosclerosis

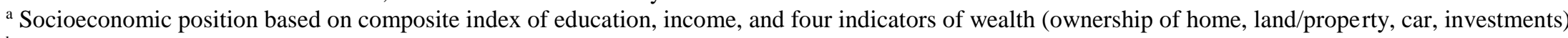

${ }^{\mathrm{b}}$ Caregiver defined as reporting $>=150 \mathrm{~min} /$ week of caregiving activity to children or adults

* P-value $<0.05$ 


\section{CHAPTER 7. PHYSICAL ACTIVITY FACILITATORS AND BARRIERS AMONG RETIRED WOMEN: A QUALITATIVE STUDY}

\subsection{Introduction}

Regular physical activity reduces the risk of chronic disease in later life, such as cardiovascular disease, diabetes, and cancer [5, 6, 42]. However, many older adults do not engage in sufficient physical activity and the burden of preventable diseases is high among older Americans. In the United States (US), only half of older adults meet recommendations for engaging in at least $150 \mathrm{~min} /$ week of aerobic physical activity [197]. Moreover, over one-third of older adults reported some type of disease or disability in 2013 [63], including arthritis, cardiovascular disease, and diabetes. These diseases come with a high price for wellbeing and healthcare [63]. As the population of older Americans grows from nearly 45 million to 72 million by 2030 [27], high costs will strain healthcare systems making it increasingly important for communities to support physical activity in later life.

The retirement transition may be a window of opportunity to promote physical activity among older adults. Retirement is an important transition involving shifts in daily routines, social networks, and access to resources as well as changes in levels of physical activity [18, 19]. We conducted a sequential mixed methods study to estimate changes in physical activity associated with retirement and to inform interventions to promote physical activity after retirement. The study was guided Life Course Theory and the Social Ecological Model. Life Course Theory provides a theoretical underpinning for behavior change at retirement as a life transition wherein alteration in personal and social identity offer opportunities for behavior change [23]. The Social Ecological Model identifies multiple levels of influence on behavior, from the individual to the 
society, and has been used to inform physical activity interventions, which are more likely effective when targeting determinants from multiple levels [24]. The study began with quantitative analyses of data from the Multi-Ethnic Study of Atherosclerosis (MESA) [Jones et al., 2017, under review] followed by qualitative research (reported here). The MESA collected longitudinal data on 6,814 adults from six US communities from 2000 to 2012 [125].

Quantitative analyses of MESA data found that retirement was associated with decreased overall MVPA, particularly among persons of lower SEP [Jones et al., 2017, under review]. Declining health and loss of occupational physical activity contributed to decreased overall MVPA, and health and neighborhood characteristics were important correlates of changes in walking after retirement among MESA participants.

Based on these findings, this qualitative study sought to gain a more in-depth understanding of the factors identified as contributing to physical activity in retirement among a socio-economically diverse sample of women who had retired from a range of physically active to sedentary occupations at one of the MESA study locations. This study focused on women because they are more likely than men to be insufficiently active and to reduce their physical activity as they age [58]. Evidence further suggests that women are less likely to increase their physical activity after retirement than men [19]. Women also are more likely than men to serve in caregiving roles [124], which can limit physical activity [38]. Thus, some interventions to promote physical activity after retirement may need to be gender-specific. Information on factors that promote or discourage physical activity after retirement among women is sparse [39]. 


\subsection{Methods}

We conducted semi-structured qualitative interviews with a purposeful sample of 15 retired women living in Forsyth County, North Carolina (NC), US.

\subsubsection{Study Location}

We selected Forsyth County, NC as the study catchment area because it was one of six locations of the MESA [125]. Forsyth County is located in western NC, has an area of $1070 \mathrm{~km}^{2}$, and is the fourth most populous NC county (total population 366,543). One in five county residents is aged 60 or older [198]. Among older Forsyth County residents, 19\% are African American, 79\% are non-Hispanic white, 29\% live below 200\% Federal Poverty Level, 30\% live alone, and 33\% have at least one disease or disability [198]. Eighty-five percent of county residents live in census tracts located within a half-mile of a park or within one-mile (urban areas) or three-miles (rural areas) of a recreational facility [199]. However, walkability and public transportation are limited. Winston-Salem, the largest city in the county, has an average Walk Score ${ }^{\circledR}$ of two on a scale from zero to 100 , indicating low walkability and almost complete car dependence.

\subsubsection{Participant Recruitment}

Upon approval from the University of NC at Chapel Hill Institutional Review Board, we contacted leaders at senior centers, civic organizations, and religious networks in Forsyth County. We sought a racially/ethnically diverse sample of women who had retired from a variety of sedentary to physically active occupations. The study was described to potential participants at four community events. Study flyers were posted in community centers, senior centers, and libraries. Flyers also were posted to social media by a church network and included in the senior center e-newsletter. Interested participants were provided a study information sheet and eligibility criteria. Eligibility criteria were: female, resident of Forsyth County, aged 55 to 75, 
and retired within the previous 5 years. Eligibility was assessed in person or by phone.

Recruitment stopped when data saturation was achieved [156].

\subsubsection{Study Questionnaire}

Prior to beginning the interview, women completed a brief study questionnaire about their socio-demographic information, physical activity, and neighborhood perceptions. Sociodemographic questions included age, race/ethnicity, highest education completed, prior job title and occupational physical activity level (sedentary, light standing, moderate activity, or vigorous activity), and time since retirement. Current physical activity was assessed using the MESA physical activity questionnaire, adapted from the Cross-Cultural Activity Participation Study [131]. Participants reported the frequency and duration of activity in six domains: household and yard work, caregiving, walking for recreation and transportation, sports and conditioning, and work/ volunteering. Participants also reported the frequency and duration of TV watching. Women's perceptions of their neighborhoods were assessed using 13 items from the MESA neighborhood questionnaire [183], which covered four domains: walking environment (4 items), aesthetic quality (3 items), safety (2 items), and social cohesion (4 items). Each item was rated on a five-point Likert scale from strongly agree to strongly disagree. The Walk Score® (www.walkscore.com) also was recorded for each participants' home address to characterize the walkability of participants' neighborhoods. Previously, a higher Walk Score ${ }^{\circledR}$ was positively associated with walking among MESA participants [117].

\subsubsection{Interview Guide}

A semi-structured interview guide (APPENDIX 1) was developed based on the research question, findings from quantitative studies [Jones et al., 2017, under review] and existing literature $[17,72]$. Interview questions were informed by the Social Ecological Model [24] and Life Course Theory [23]. Questions asked participants to describe their physical activity and 
sedentary behavior before and after retirement, barriers and facilitators of physical activity after retirement, and ideas for supporting physical activity among retired women. Physical activity was defined for participants as "anything that gets you moving like walking in your neighborhood or to go somewhere, gardening, doing sports or exercise, or playing with grandchildren". Sedentary behavior was defined as "watching TV, using the computer/phone, reading, or other things you might do sitting down". The interview guide was piloted with two retired women.

\subsubsection{Interviews}

Seventeen women were invited to schedule interviews between April and June 2017. Thirteen participants were interviewed by phone, two participants were interviewed in person, and two women did not respond to the invitation. All interviews were conducted by the first author, who has training in qualitative methods. Interviews lasted on average 40 minutes (range 25 to 75 minutes). Participants received $\$ 20$ in recognition of their time. Field notes regarding quality of interaction, key observations, and ideas for future data collection were documented after each interview. All interviews were digitally recorded and transcribed verbatim. Data were saved using ID numbers to ensure anonymity and questionnaire responses, transcripts, and field notes were uploaded to ATLAS.ti software (Berlin, Germany) for analysis.

\subsubsection{Analysis}

First, we described the socio-demographic and neighborhood characteristics of study participants using questionnaire data. We then compared qualitative study participants with female MESA participants from NC who retired during MESA follow-up (through 2012).

Second, interview transcripts were reviewed using a pragmatic approach to directed content analysis to identify facilitators and barriers to physical activity after retirement [160]. Directed content analysis is appropriate to extend or revise current theory where a body of 
research exists [161]. Each transcript was independently coded by the first author and a second trained coder, with discrepancies resolved by consensus. Codes were selected a priori based on the underlying theories and research questions, and inductively derived based on interview transcripts. We maintained a codebook including code definitions, example quotations, and code modifications. In most cases, full paragraphs were coded to maintain contextual meaning. Codes were not applied to all text exhaustively. Themes were developed through review and discussion of coded quotations. Some themes included multiple linked concepts, each of which was identified as a subtheme within the over-arching theme. Our team compared similarities and differences between women who retired from physically active $(n=7)$ and sedentary occupations $(n=8)$.

\subsection{Results}

A total of 15 women participated in this study (Table 32). Participants were on average 68 years old. Seven participants were African American and eight were non-Hispanic white. Sixty percent of participants had completed less than a Bachelor's degree, one-third were married, $40 \%$ were widowed, and one-third were caregivers for family members. On average, women had been retired for three years and $53 \%$ retired from sedentary occupations. Most women did not live in walkable neighborhoods (average Walk Score ${ }^{2} 23$ on a scale from 0 to 100). After retirement, participants' physical activities included walking for recreation $(n=7)$ and for transportation $(n=2)$, exercise classes $(n=5)$, gardening $(n=3)$, and light household chores $(n=15)$ (Table 33). Participants' post-retirement sedentary behaviors included TV watching, computer use (including laptop and tablet), reading, and sewing or other crafts.

Participants in this qualitative study were similar to female MESA participants from NC who retired during study follow-up ( $n=97)$. The samples were alike with respect to proportion African American, educational achievement, car ownership, caregiving, and neighborhood 
walking environment, aesthetic quality, and social cohesion. However, participants in this qualitative study were slightly older (mean age 68 vs. 65), less likely to be married (33\% vs. $55 \%$ ), and more likely to perceive their neighborhoods to be safe ( $80 \%$ vs $69 \%$ ) compared to retired female MESA participants. Qualitative study participants also reported more TV watching, more non-walking leisure activities (e.g., aerobics, yoga) and less walking, household, and overall MVPA compared to retired female MESA participants (data not shown).

\subsubsection{Barriers and Facilitators of Physical Activity after Retirement}

Interview transcripts were analyzed to identify barriers and facilitators of physical activity after retirement. Facilitators and barriers were grouped into six themes. One theme related to development of leisure-time physical activity habits over the lifespan. The other five themes described how physical activity after retirement was influenced by: prior occupational physical activity, life transitions concurrent with retirement, health, social interaction and support, and characteristics of the community environment. Themes are described next with illustrative quotations included in Table 34 .

Theme 1: Women's leisure-time physical activity habits develop over the lifespan. All participants who engaged in leisure-time physical activity prior to retirement continued to engage in some regular physical activity after retirement (Table 33). Active women reported that they initiated leisure-time physical activities as children or in early adulthood. In contrast, women who were inactive outside of work continued to be so after retirement.

Theme 2: How women perceived changes in their physical activity and sedentary behavior after retirement depended on their prior occupational physical activity level. Women who retired from physically active occupations described retirement as an opportunity to slow down (subtheme 2.1); whereas women who retired from sedentary jobs described retirement as a chance to get out from behind the desk and move around (subtheme 2.2). 


\section{Subtheme 2.1. Women viewed retirement from a physically active job as an opportunity}

to slow down. Six of seven women who retired from physically active jobs reported that their physical activity decreased and sedentary behavior increased after retirement (Table 33).

Decreased physical activity was attributed to loss of occupational physical activity and spending more time at home. Spending more time at home facilitated sedentary pursuits for which women had not had time or energy prior to retirement (e.g., social media, television, crafts). Some women also found it difficult to maintain physical activity routines without the structure of a work routine. However, one woman who retired from a physically active job became more physically active after retirement, in part because physical activity was more enjoyable to her since she had more free time and no longer needed to rush.

\section{Subtheme 2.2. Retirement from sedentary jobs freed women to get up and move around.}

Among women who retired from sedentary jobs $(n=8)$, four reported that their physical activity increased and all reported that their sedentary behavior decreased after retirement (Table 33). After retiring from a sedentary job, participants wanted to be physically active because they were no longer required to sit during the work day. For the four women who increased their physical activity, retirement provided more time, energy, and flexibility. Increased free time reduced the need to rush and made physical activity more enjoyable. Increased schedule flexibility allowed women to be active at preferred times of day. Women who were not "morning people" could exercise during working hours, and those who were concerned about traffic or crime could avoid walking during rush hour or after dark.

On the other hand, four women who retired from sedentary occupations did not report increased physical activity after retirement. These women took an active role in community 
organizations and/or underwent other life transitions (discussed further in Theme 3) and therefore did not feel that they had more time for physical activity after retirement.

Theme 3: Concurrent life transitions shaped women's opportunities for physical activity after retirement. Women's control of their post-retirement routines, including physical activity, was constrained by transitions in other areas of life, such as onset of illness, moving, remarrying, or becoming a widow or caregiver. Caregiving responsibilities, in particular, disrupted physical activity routines, kept women at home, and led to fatigue and stress that prevented women from being physically active. Moving to a new city after retirement disrupted women's social networks making it more difficult to find people to be active with and to find out about physical activity opportunities in their new community.

However, the influence of concurrent life transitions on physical activity was not always negative and changed as additional transitions occurred. For example, one woman retired immediately after marrying her second husband, who passed away only 15 months later. She had been active throughout her life, but abandoned her physical activities when she remarried, only to return to them a widow.

Theme 4: Declining health was a barrier and motivator of physical activity after retirement. Physical limitations associated with chronic diseases made it more difficult for women to be physically active (subtheme 4.1). However, some women were motivated to be physically active by their beliefs about the physical and mental health benefits of physical activity, including for management and prevention of disease (subtheme 4.2).

Subtheme 4.1. Physical limitations associated with chronic diseases made it harder for women to be physically active after retirement. For example, one woman increasingly limited her trips out because walking to do errands and appointments became too difficult as her kidney 
disease progressed. On the other hand, some women remained active despite new physical limitations by adapting the type or intensity of physical activity (e.g., substituting water aerobics for regular aerobics).

Subtheme 4.2. Beliefs about physical and mental health benefits of physical activity motivated women to be active. Women with chronic conditions believed that regular physical activity helped manage their condition or reduced the need for medications or surgery. Active women also believed that regular physical activity would help them to "stay healthy" (2) and "live longer, younger" (8). Staying healthy meant maintaining the ability to do activities they enjoyed (e.g., travel) and "keeping up" with family, particularly grandchildren. Women who had observed or cared for loved ones in ill-health also believed that physical activity could help them avoid similar health issues. In addition, women associated physical activity with improved mental health, including feeling better about oneself and releasing stress.

However, awareness of physical and mental health benefits associated with physical activity was not sufficient to motivate all women to be physically active. Inactive women explained that although they felt they "should" be doing more physical activity, they did not initiate physical activity routines because they found physical activity boring or unpleasant. Retirement compounded this lack of motivation because it was perceived as a time when one should be able to do what one wanted.

Theme 5: Social support and interaction facilitated physical activity. Socializing was a key component of physical activity, both among women who exercised and those who did not. Social networks provided information and encouragement to be physically active (subtheme 5.1) and opportunities to socialize motivated some women to participate in group exercise (subtheme 
5.2). For otherwise inactive women, serving the community was a key source of physical activity (subtheme 5.3).

Subtheme 5.1. Social networks provided information and encouragement for physical activity. Many women learned about the physical activity programs they were a part of through word-of-mouth from friends, classmates, or at church. Social support from family members and friends also encouraged women to participate in physical activity.

Subtheme 5.2. Socializing was a reason for women to engage in physical activity, but some women lacked physical activity companions. Active women were motivated to participate in group exercise because it allowed them spend time with friends and to make new friends, and made physical activity more enjoyable. However, some inactive women did not want to participate if they felt they could not keep up with the group or find companions with shared interests and abilities. For these women, lack of physical activity companions was a barrier.

Subtheme 5.3. For otherwise inactive women, serving the community was a key source of physical activity. Outside of light household chores, commitments to community organizations (e.g., church, senior center, civic and cultural organizations) were their primary source of physical activity. The pleasure of helping others motivated women who did not otherwise enjoy physical activity to volunteer for events that required hours of standing and walking.

Theme 6: Women relied on neighborhood environments and community resources to support physical activity after retirement. The neighborhood environment was an important determinant of walking (subtheme 6.1), whereas community recreational facilities were important determinants of non-walking exercise (subtheme 6.2).

Subtheme 6.1. Pleasant environments and access to destinations facilitated walking, but traffic, hills, and weather were barriers. More women walked for recreation $(\mathrm{n}=7)$ than 
transportation $(n=2)$. Walking for recreation was facilitated by pleasant walking environments. Women described multiple neighborhood characteristics that worked in concert to make a pleasant walking environment, including green, friendly, and clean streetscapes where other people walked and they felt safe. On the other hand, walking for transportation was facilitated primarily by access to destinations. The two women who reported walking for transportation lived in the neighborhoods with the highest Walk Scores ${ }^{\circledR}$, reflecting more destinations within walking distance of home. One of these women did not own a car and walked out of necessity. The other chose to live in a walkable neighborhood because she and her husband enjoyed walking to get places.

Barriers to walking for both recreation and transportation included hilly terrain, cold or rainy weather, traffic, and fear of crime. These attributes made walking unpleasant or hazardous. Most women lived in neighborhoods without sidewalks. However, lack of sidewalks was not identified as a barrier to walking by women living in neighborhoods that had little or no car traffic. Although most participants felt safe in their neighborhoods, fear of crime was often identified as a reason that people their age would not go out walking.

Subtheme 6.2. Community recreational facilities supported non-walking leisure-time physical activity. Active and inactive women agreed that recreational facilities in their community offered a wide variety of activities to fit different interests and ability levels. Active women used senior centers, community recreation centers, and the mall for physical activity. Indoor spaces made it possible for women to be active in cold or rainy weather, and reduced fears of falling relative to walking alone outdoors. Moreover, women valued facilities that were low-cost, conveniently located in their neighborhoods, included people of all ages, and where they could adapt the intensity of activities to fit their physical abilities. Five women reported that 
it was easier to use recreational facilities after they retired because of SilverSneakers®, a program wherein their health insurance company provided free access to any Y location.

On the other hand, barriers to using recreational facilities included transportation and discrimination. Although most study participants had cars to drive to recreational facilities, they identified lack of public transportation as a barrier for friends. For some African American women, another very important barrier was racism and the legacy of segregation. One woman spoke at length about how feeling unwelcome or unsafe prevented African Americans from using community recreational facilities.

\subsection{Discussion}

We identified six themes pertaining to facilitators and barriers to physical activity after retirement from interviews with 15 retired women. Our findings can inform the targeting of physical activity interventions to retired women. Intervention strategies include emphasizing health benefits of physical activity, and improving walking environments and access to recreational facilities. Women who have no history of leisure-time physical activity, retire from physically demanding jobs, become caregivers, or move after retirement may be particularly in need of support for physical activity after retirement.

Belief in the health benefits of physical activity was a commonly identified facilitator of physical activity after retirement in this and prior studies $[15,16,33,38,96,98,200]$. Participants in this study were motivated to be active by the belief that physical activity could help prevent and manage chronic diseases. However, the onset of physical limitations (e.g., joint pain) was a barrier to physical activity after retirement for women in this study, and others [16, $31,38,96,200]$. Our findings suggest that interventions should emphasize physical and mental health benefits of physical activity and help women develop strategies to continue physical activity despite physical limitations [201]. Nonetheless, awareness of health benefits was not 
sufficient motivation for women to engage in physical activity in this or other studies [15, 96]. Thus, consistent with the Social Ecological Model [24], it is important that interventions also address other factors, including environmental supports for physical activity [96, 97].

Environmental supports for physical activity identified by women in this study included neighborhood attributes and recreational facilities. Pleasant, green, and safe environments facilitated recreational walking and access to destinations facilitated transport walking among women in this study. Similarly, in quantitative analyses of MESA participants, access to destinations, aesthetic quality, and walking environment attributes were correlated with changes in transport and recreational walking after retirement [Jones et al., 2017, unpublished]. These findings suggest that improvements to pedestrian infrastructure recommended by the Community Preventive Taskforce [40], such as adding sidewalks in higher traffic areas, could facilitate walking among retired US women. However, other barriers to walking (e.g., hills and bad weather) are difficult to address, as noted previously [96, 99], underscoring the importance of access to recreational facilities (e.g., gym, senior center).

Women in this study generally agreed that sufficient recreational facilities existed in their community, including low-cost or free options such as SilverSneakers®. This contrasts with prior studies where lack of high-quality and affordable physical activity resources were barriers to physical activity after retirement [39]. However, women in this study were recruited from community organizations and events, and therefore may be more aware of local resources than other retirees. Indeed, participants identified a need for better promotion of existing physical activity resources in the community. In addition, addressing discrimination to create inclusive public spaces is essential to ensure equitable access to local physical activity resources. 
Although recreational facilities were important for active women, women who did not participate in leisure-time physical activity before retirement also did not do so after retirement. This finding is consistent with the Life Course Theory principle of lifespan development, which suggests that behavior in later life is linked to the formative years of life course development [23]. Women who were the most active after retirement participated in leisure-time physical activity in childhood or earlier adulthood, similar to previous studies [15, 33, 38, 72]. Thus, promotion of leisure-time physical activity among younger and mid-life adults may contribute to physical activity in later life. For women without a history of leisure-time physical activity, postretirement interventions can address barriers such as not enjoying or valuing leisure-time physical activities, for instance through utilitarian physical activity (e.g., community service) rather than exercise [74].

In addition to earlier leisure-time physical activity, prior occupational physical activity was a key determinant of physical activity after retirement. Women who retired from physically active occupations reported being less physically active after retirement whereas women who retired from sedentary occupations frequently reported being more physically active after retirement. This pattern was identified previously among retirees from the US, United Kingdom, and Belgium $[17,37,96,99]$ and is consistent with loss of occupational activity contributing to declines in overall MVPA after retirement among MESA participants [Jones et al., 2017, under review]. Different views of retirement likely reinforce this pattern. Women in this study who retired from active jobs viewed retirement as a time to slow down, which meant leaving home less frequently and engaging in more sedentary behavior. Loss of daily routines also was a barrier for these participants. In contrast, women who retired from sedentary jobs viewed retirement as a time to get moving and described increased free time and flexible schedules as 
facilitators of physical activity. Although other studies identified loss of routines as a barrier [17, 96, 98] and increased free time as a facilitator [17, 31, 33], none linked these factors to prior occupational physical activity. For women retiring from physically active occupations, intervention strategies could address perceptions of retirement as a time for rest and foster a structured physical activity routine outside the home $[15,96]$.

Reasons for retirement and concurrent transitions during retirement also may be important considerations for targeting interventions [97]. Reason for retirement was not identified as a theme in this study. However, retirement reasons may be linked to other factors that were identified as themes, such as health and undergoing concurrent transitions (e.g., retiring because of the need to become a caregiver). Experiencing multiple transitions was associated with decreased physical activity among adults in a systematic review of quantitative studies [110]. Similarly, becoming a caregiver and moving posed unique barriers to physical activity after retirement for women in this study. Women associated caregiving with multiple barriers, including disruption of leisure-time physical activity routines, inability to leave home, fatigue, and stress, similar to a sample of retired British women [38]. Spousal caregiving also was associated with decreased physical activity among participants in the US Health and Retirement Study [202]. Surprisingly, caregiving responsibilities did not interfere with exercise routines among healthy, physically active older adults from Virginia [33]. Becoming a caregiver after retirement also was associated with maintaining pre-retirement levels of walking for recreation and transportation among MESA participants [Jones et al., 2017, unpublished]. Differences in the type and intensity of caregiving could contribute to variation in findings across studies. For retired women facing caregiving-related barriers, incorporating physical activity into caregiver support groups or respite services could reduce stress and provide time for physical activity. 
Whereas becoming a caregiver limited time and energy for physical activity, moving after retirement disrupted women's social networks. A small social network and difficulty making social contacts also were barriers to physical activity among British adults[96]. Moreover, robust evidence suggests that social support and companionship facilitate physical activity among retired women $[12,39]$. In the future, greater geographic movement and rising rates of divorce and childlessness may increase the number of women entering retirement with weak social networks [46]. Thus, interventions that provide opportunities for social interaction may be of increasing importance.

\subsubsection{Strengths and Limitations}

There were three primary strengths of this study. First, participants in this study were racially and socioeconomically diverse. Including the perspectives of retirees from minority racial/ethnic and lower socioeconomic status groups is essential to reduce persistent health disparities. Second, we focused on facilitators and barriers of physical activity from multiple levels, including the community environment. The Social Ecological Model suggests that interventions targeting multiple levels are more likely effective [24]. Also, community-level changes have a potential for broad public health benefit [40]. Third, this research was conducted in conjunction with quantitative, longitudinal studies of physical activity and sedentary behavior after retirement [Jones et al. 2017, under review]. Combining quantitative and qualitative approaches enriched our understanding of mechanisms of physical activity change during the retirement transition. Both quantitative and qualitative studies highlighted individual health, occupational physical activity, and community environments as determinants of physical activity after retirement. This qualitative study further identified earlier life leisure-time physical activity and concurrent life transitions as important factors, which were not well captured in quantitative data. 
Limitations include that the findings from this research are particular to the place and time of data collection: Forsyth County, NC in 2017. Forsyth County has a growing and diverse older adult population, many resources from local universities and a large network of public parks, but is geographically dispersed with limited public transportation. Women in this study were active participants in community organizations, making their experiences unique from those of women who might be less active in the community or more isolated. This was in part a consequence of how women were recruited.

\subsubsection{Conclusions}

Retired women are a heterogeneous population with diverse needs and goals [99]. Thus, promoting physical activity among growing populations of retired women likely will require multiple intervention strategies. Findings from this qualitative study suggest that interventions should address barriers and facilitators from all levels of the Social Ecological Model, including individual health and the neighborhood environment [24]. In addition, distinct intervention strategies may be appropriate depending on the context within which women retire, including earlier life experiences and concurrent life transitions (e.g., becoming a caregiver). Such interventions are of increasing public health importance given the rapid growth of older adult populations and high burden of preventable disease associated with aging. 
Table 32. Participant characteristics, overall and by prior occupational physical activity $(n=15)$

$\begin{array}{ccc}\text { Total } & \text { Active Job } & \\ (\mathrm{N}=15) & (\mathrm{N}=7) & \text { Sedentary Job }(\mathrm{N}=8)\end{array}$

\begin{tabular}{|c|c|c|c|}
\hline Characteristic & $\mathrm{N}(\%)$ or Mean $(\mathrm{SD})$ & $\mathrm{N}(\%)$ or Mean $(\mathrm{SD})$ & $\mathrm{N}(\%)$ or Mean $(\mathrm{SD})$ \\
\hline Age, years & $68(3)$ & $67(4)$ & $70(2)$ \\
\hline \multicolumn{4}{|l|}{ Race } \\
\hline African American & $7(47 \%)$ & $4(57 \%)$ & $3(38 \%)$ \\
\hline White & $8(53 \%)$ & $3(43 \%)$ & $5(63 \%)$ \\
\hline \multicolumn{4}{|l|}{ Education } \\
\hline$<$ Bachelor's degree & $9(60 \%)$ & $4(57 \%)$ & $5(63 \%)$ \\
\hline$\geq$ Bachelor's degree & $6(40 \%)$ & $3(43 \%)$ & $3(38 \%)$ \\
\hline \multicolumn{4}{|l|}{ Partnership status } \\
\hline Married & $5(33 \%)$ & $2(29 \%)$ & $3(38 \%)$ \\
\hline Widowed & $6(40 \%)$ & $2(29 \%)$ & $4(50 \%)$ \\
\hline Divorced / single & $4(27 \%)$ & $3(43 \%)$ & $1(12 \%)$ \\
\hline Retirement duration, years & $3(1)$ & $3(1)$ & $3(1)$ \\
\hline Caregiver & $5(33 \%)$ & $2(29 \%)$ & $3(38 \%)$ \\
\hline Neighborhood Walk Score ${ }^{\circledR}$ & $23(20)$ & $29(24)$ & $15(17)$ \\
\hline \multicolumn{4}{|l|}{ Physical activities } \\
\hline Walking & $9(60 \%)$ & $5(71 \%)$ & $4(50 \%)$ \\
\hline Regular non-walking exercise & $5(33 \%)$ & $0(0 \%)$ & $5(63 \%)$ \\
\hline Television watching, hours/week & $30(28)$ & $45(34)$ & $17(13)$ \\
\hline \multicolumn{4}{|l|}{ Prior occupational activity } \\
\hline Moderate activity & $3(20 \%)$ & $3(43 \%)$ & - \\
\hline Light activity & $4(27 \%)$ & $4(57 \%)$ & - \\
\hline Sedentary & $8(53 \%)$ & - & $8(100 \%)$ \\
\hline
\end{tabular}

Abbreviation: SD standard deviation 
Table 33. Physical activity before (work and non-work) and after retirement among participants $(\mathrm{n}=15)$

\section{Pre-retirement physical activity}

\begin{tabular}{llll}
\cline { 2 - 4 } Study ID & Work & Non-work & Post-retirement physical activity \\
\hline 1 & Sedentary & None & None
\end{tabular}

$2 \quad$ Standing, walking $\quad$ Walking (occasional), Walking, stationary bike (occasional) (light activity) stationary bike

$3 \quad$ Standing, walking, lifting None

(moderate activity)

None

Standing, walking

Water aerobics

(light activity)

Standing, walking, lifting, None

carrying

(moderate activity)

Sedentary

None

Sedentary

Line dancing, walking (dog)

Walking (dogs)

(light activity)

Sedentary

Walking (dogs), treadmill

(moderate activity)

$11 \quad$ Standing, walking

(light activity)

Walking, dancing (occasional)

None

Walking, water aerobics, Zumba

Walking (dogs), gardening, light

\section{Impact of retirement}

No change

$\downarrow$ physical activity, $\uparrow$ sedentary behavior

Loss of work activity

$\downarrow$ physical activity, $\uparrow$ sedentary behavior

Loss of work activity, time/energy for television watching /computer

$\downarrow$ physical activity, $\uparrow$ sedentary behavior Loss of work activity, not leaving home

$\downarrow$ physical activity, $\uparrow$ sedentary behavior Loss of work activity due to ill health

$\uparrow$ physical activity, $\downarrow$ sedentary behavior "On the go", more energy

$\uparrow$ physical activity, $\downarrow$ sedentary behavior Increased time/energy replaced sedentary work with activities

$\downarrow$ physical activity, $\uparrow$ sedentary behavior Caring for parents replaced work activity

No change: $\downarrow$ physical activity when remarried and retired, then $\uparrow$ when widowed; $\downarrow$ sedentary behavior because not required to sit at work

$\downarrow$ physical activity, $\uparrow$ sedentary behavior Loss of work activity, time/energy for television watching/computer

Walking, gardening, gym (occasional) $\uparrow$ physical activity, $\downarrow$ sedentary behavior

Increased time/less stress, not required to sit at work 


\begin{tabular}{|c|c|c|c|c|}
\hline 12 & Sedentary & Exercise classes (occasional) & $\begin{array}{l}\text { Yoga, cardio class, T'ai Chi, gardening, } \\
\text { walking for transportation, biking } \\
\text { (occasional) }\end{array}$ & $\begin{array}{l}\uparrow \text { physical activity, } \downarrow \text { sedentary behavior } \\
\text { Increased time, not required to sit at work }\end{array}$ \\
\hline 13 & Sedentary & Aerobics (occasional) & Water aerobics (regularly) & $\begin{array}{l}\text { Physical activity } \uparrow \text { briefly then } \downarrow \text { when began caring } \\
\text { for parents; } \downarrow \text { sedentary behavior not required to sit at } \\
\text { work }\end{array}$ \\
\hline 14 & Sedentary & None & None & $\begin{array}{l}\uparrow \text { physical activity, } \downarrow \text { sedentary behavior } \\
\text { "On the go" for organizations, not required to sit at } \\
\text { work }\end{array}$ \\
\hline 15 & Sedentary & Aerobics & Walking, yoga, aerobics & $\begin{array}{l}\downarrow \text { physical activity, } \downarrow \text { sedentary behavior } \\
\text { Caring for parents limited ability to attend exercise } \\
\text { classes, but less sedentary than work }\end{array}$ \\
\hline
\end{tabular}


Table 34. Themes and subthemes related to barriers and facilitators of physical activity after retirement

\begin{tabular}{|c|c|c|}
\hline Theme & Subtheme & Illustrative Quotations \\
\hline $\begin{array}{l}\text { 1. Leisure-time } \\
\text { physical activity } \\
\text { habits develop } \\
\text { over the lifespan }\end{array}$ & & $\begin{array}{l}\text { "Well, for the ones [of my retired friends] that are [physically] } \\
\text { active [since retiring], they've always been active. They're like me" } \\
\text { (Participant 7) }\end{array}$ \\
\hline $\begin{array}{l}\text { 2. Perceived } \\
\text { changes in } \\
\text { physical activity } \\
\text { and sedentary } \\
\text { behavior after } \\
\text { retirement } \\
\text { depended on prior } \\
\text { occupational } \\
\text { physical activity }\end{array}$ & $\begin{array}{l}\text { 2.1 Retirement from } \\
\text { a physically active } \\
\text { job was an } \\
\text { opportunity to slow } \\
\text { down }\end{array}$ & $\begin{array}{l}\text { "I just wanted to take a nice rest and not do anything because I've } \\
\text { worked since I was } 15 \text { years old. I am going on } 70 \text { now. So, I just } \\
\text { wanted to take a rest and do nothing for a while." (Participant 10) } \\
\text { "Well, before I retired, I probably would get off of work, I would go } \\
\text { to the Y, I would get into my physical activities... But now that I'm } \\
\text { not leaving home, I've gotten into a habit of not wanting to leave } \\
\text { home much." (Participant 4) }\end{array}$ \\
\hline level & $\begin{array}{l}2.2 \text { Retirement from } \\
\text { sedentary jobs freed } \\
\text { women to get up and } \\
\text { move around }\end{array}$ & $\begin{array}{l}\text { "I can plan it better and do it better [since I retired] because when } \\
\text { you're working you have a schedule you have to keep. A lot of times } \\
\text { in the winter time [when you're working], you don't want to go out. } \\
\text { You get home and it's dark." (Participant 7) }\end{array}$ \\
\hline
\end{tabular}

\section{Concurrent life transitions shaped opportunities for physical activity after retirement}

Well, when I first retired, I was very active because I had all my mornings free... And then, my parents became ill... so I had to put the $Y$ and everything on the back burner for a while... I'll tell you, that took up pretty much my whole life for a while." (Participant 13)

“But I really don't know that many people here. I mean, when I lived in [previous state], I always... [had a] big group of friends so when I did have leisure time there was always somebody to do something with. It's less so here. I know quite a few less people." (Participant 8)

"[Arthritis] is why I don't do aerobics as much because it seems to feel like it's, I wouldn't say injuring me, but it seems to be more difficult. So, I prefer the water aerobics because I don't feel pain." (Participant 15)

\section{Physical limitations and declining health limited and motivated physical activity}

\subsection{Physical} limitations made it harder to be physically active, but some women adopted lower intensity activities
4.2 Beliefs about physical and mental health benefits of physical activity motivated some women to be active, but were not always enough
"I tell myself as I'm walking, 'Well, you're doing this for this problem. And you're doing this for the other problem.' Mentally, it makes me feel as if I have more control over the health conditions I have." (Participant 11)

"It's everywhere, you read it, it's on television, your doctor tells you, 'you need to do this, it's important, you'll live longer.' So, I think the problem is just me: the motivation." (Participant 1) 


\begin{tabular}{|c|c|c|}
\hline Theme & Subtheme & Illustrative Quotations \\
\hline \multirow{4}{*}{$\begin{array}{l}\text { 5. Social support } \\
\text { and interaction } \\
\text { facilitated } \\
\text { physical activity }\end{array}$} & $\begin{array}{l}\text { 5.1 Social networks } \\
\text { provided information } \\
\text { and encouragement }\end{array}$ & $\begin{array}{l}\text { "We're both of us [my husband and I] together really trying to keep } \\
\text { in shape, stay in shape... So anyway, we sort of both motivate each } \\
\text { other." (Participant 12) }\end{array}$ \\
\hline & $\begin{array}{l}5.2 \text { Socializing was a } \\
\text { reason for women to } \\
\text { engage in physical }\end{array}$ & $\begin{array}{l}\text { "[Physical activity is] also a good way to socialize. You know, you } \\
\text { just get out of the house and you're being with other people. I think } \\
\text { that's really important too." (Participant 2) }\end{array}$ \\
\hline & $\begin{array}{l}\text { activity, but some } \\
\text { women lacked } \\
\text { physical activity } \\
\text { companions }\end{array}$ & $\begin{array}{l}\text { "I don't do much because I don't have anybody to do it with. You } \\
\text { know, maybe if I had a little partner or a friend that wanted to get } \\
\text { involved in activities and such, then I probably would do more. But } \\
\text { by me being by myself, I don't do anything." (Participant 3) }\end{array}$ \\
\hline & $\begin{array}{l}5.3 \text { For otherwise } \\
\text { inactive women, } \\
\text { serving the } \\
\text { community was a } \\
\text { source of physical } \\
\text { activity }\end{array}$ & $\begin{array}{l}\text { "I guess because I'm involved in so many different organizations, } \\
\text { the physical activity primarily is getting out of bed, getting dressed, } \\
\text { getting to the car and going to meetings." (Participant 6) }\end{array}$ \\
\hline
\end{tabular}

6. Women relied on neighborhood environments and community resources to support physical activity after retirement

6.1 Pleasant
environments and
access to
destinations
facilitated walking,
but traffic, hills, and
weather were
barriers

6.2 Community recreational facilities supported nonwalking leisure-time physical activity, but potential barriers were lack of transportation and discrimination
“'And it's just, it's a beautiful [neighborhood]... It's pretty, they keep it up and it just makes a nice place to get out and exercise or walk... Well, it's really pleasant because the atmosphere is nice and the people in the neighborhood are nice." (Participant 4)

"In this neighborhood, there are huge hills... There's no route around this house that I could take that didn't require a lot of hills. So, if I was going to walk, I would probably have to go somewhere else." (Participant 1)

"Anything that we want to do is out there waiting, and most of it is free or minimal cost." (Participant 1)

"Being African-American sometimes we feel that 'Oh, no, that's for white people.' I have friends who tell me that all the time when I try to get them to be involved in something. They will tell me, 'Oh, that's for white people. '... They feel like it's not for the AfricanAmerican people, it's for white people... I'll hear, 'They don't want us around them.' I say, 'How do you know until you go and see?,', (Participant 13) 


\section{CHAPTER 8: CONCLUSIONS AND PUBLIC HEALTH IMPLICATIONS}

\subsection{Summary of Findings}

This research contributes to the understanding of physical activity and sedentary behavior during the retirement transition among diverse US adults. It provides substantive knowledge regarding patterns of physical activity and sedentary behavior associated with retirement and guidance for development and targeting of interventions among retirees. Aim 1 estimated changes in physical activity, overall and by domain, and TV watching associated with retirement, as well as differences by SEP. Aim 2 identified correlates of changes in walking after retirement that could be addressed by interventions targeting walking, the most common physical activity among older Americans. Finally, Aim 3 identified facilitators and barriers that help explain physical activity and sedentary behavior changes after retirement and direct targeting of interventions.

How do physical activity and TV watching change during the retirement transition?

Among MESA participants, retirement was associated with increased recreational walking, household/yard activities, and TV watching. Among persons of low SEP, retirement was associated with decreased overall MVPA, indicating that increased leisure-time physical activity was not sufficient to compensate for loss of occupational physical activity after retirement in this group. Declines in overall MVPA after retirement were attenuated among participants who were healthy throughout follow-up, suggesting that poor health contributed to but did not entirely account for MVPA declines associated with retirement. This research 
suggests that the retirement transition may be an important period for promotion of physical activity and reduction TV watching in later life, particularly among persons of low SEP. What are correlates of changes in walking during the retirement transition?

Correlates of changes in walking after retirement differed by type of walking (recreational vs. transport). A decline in recreational walking after retirement was associated with lower SEP, worse self-rated health, poorer neighborhood aesthetic quality, and difficulty walking places. A decline in transport walking after retirement was associated with lower density of walking destinations and seeing others walking in the neighborhood. An increase in transport walking after retirement was associated with loss of a partner and worse self-rated health. These findings highlight the importance of addressing correlates at multiple levels to promote positive changes in walking after retirement. Further, some correlates of change in walking after retirement may vary by retirement age, gender, and education, which may indicate a need for tailoring of intervention strategies to specific demographic groups.

What are barriers and facilitators of physical activity after retirement?

We identified six themes from interviews with $\mathrm{NC}$ women related to barriers and facilitators of physical activity after retirement. Changes in physical activity and sedentary behavior after retirement were shaped by women's earlier life leisure-time and occupational physical activity, the latter of which influenced women's view of retirement as a time to rest or to get moving. Further, physical activity after retirement was constrained by concurrent transitions in other areas of life, such as becoming a caregiver. Thus, women who have no history of leisure-time physical activity, retire from physically demanding jobs, become caregivers, or move after retirement may be particularly in need of support for physical activity. 
Findings also suggest that intervention strategies include emphasizing health benefits of physical activity, and improving walking environments and access to recreational facilities.

\subsection{Strengths}

This research had a number of important strengths, notably the sequential combination of quantitative and qualitative research, use of domain-specific measures of physical activity, inclusion of sedentary behavior, racially/ethnically and socioeconomically diverse study participants, and a focus on community-level correlates of physical activity during the retirement transition.

First, sequentially linking quantitative and qualitative research enabled us to explore the associations observed in quantitative analyses through qualitative inquiry [158]. For example, quantitative analyses identified health and perceptions of the neighborhood environment as correlates of changes in walking after retirement. The qualitative study clarified how ill health could be both a physical activity facilitator (i.e., provide motivation) and barrier (i.e., physical limitation), and how multiple environmental attributes acted in concert to create the perception of a good walking environment. For example, women preferred to walk in aesthetically pleasing places. However, it also was important to see other people walking. Aesthetically pleasing places where no one else was walking were perceived as boring and/or less safe.

Also, the qualitative study allowed exploration of two Life Course Theory principles that were not well captured in MESA: lifespan development and linked-lives. Lifespan development emphasizes the importance of earlier life experience as determinants of later life behavior. Linked lives describes how transitions in one person's life often entail transitions for others. Early life physical activity was not measured in MESA and almost no data were available regarding participants' interactions with family/friends. Qualitative analyses allowed in-depth consideration of these principles, which were both important determinants of women's physical 
activity after retirement: early life leisure-time physical activity facilitated whereas caring for a family member constrained physical activity after retirement. Future quantitative studies would be strengthened by including measures of earlier life physical activity and documenting later life transitions other than retirement, such as becoming a caregiver, death of a person for whom a participant was providing care, or moving in with children or family members.

Second, quantitative analyses included domain-specific measures of physical activity. Two limitations of prior longitudinal studies of physical activity during the retirement transition were measurement of only one domain (leisure-time physical activity) and use of a single-item physical activity measure, which may be less sensitive to change over time. Failure to include measures of occupational physical activity meant that it was not clear whether increased leisuretime physical activity after retirement was sufficient to compensate for loss of occupational physical activity. Our research suggests that loss of occupational physical activity was not recouped after retirement among persons of low SEP, despite increases in some leisure-time physical activity domains. Moreover, the magnitude and direction of physical activity changes and correlates of change in walking differed across domains of physical activity, underscoring the importance of using domain-specific measures in future research as physical activity interventions are more likely effective when targeted to specific domains of activity [190].

Third, in addition to physical activity, we also investigated sedentary behavior during the retirement transition. Extended periods of sitting are highly prevalent among older adults and have been linked to increased risk of chronic diseases, including CVD and diabetes [10, 50, 53]. However, fewer studies of the retirement transition have addressed sedentary behavior. We found that retirement was associated with increased TV watching among MESA participants of both low and high SEP. Further, qualitative data suggested that increased sedentary behavior 
after retirement was facilitated by spending more time at home, particularly among women who retired from physically active jobs. Given these findings, and a previous study that suggested that few retirees are aware of the risks associated with sedentary behavior [99], comprehensive measures of sedentary behavior should be included in future research and interventions should target physical activity as well as sedentary behaviors among retirees.

Fourth, study participants were racially/ethnically and socioeconomically diverse. Sixty percent of MESA participants and $47 \%$ of participants in the qualitative study were from minority racial/ethnic groups. Further, we evaluated multiple dimensions of SEP in MESA, including education, income, and wealth, and $60 \%$ of qualitative study participants had less than a college education. Including the perspectives of retirees from minority racial/ethnic and lower socioeconomic status groups is essential to reduce persistent health disparities. In addition, although it was not feasible to interview MESA participants, qualitative study participants were from Forsyth County, NC, which was one of the MESA catchment areas.

Fifth, we explored community-level correlates of physical activity. National recommendations encourage community-level changes to promote physical activity because of the potential for broad public health benefit [40]. This research was the first exploration of social and physical environmental correlates of walking during the retirement transition. Walking is the most common physical activity among older Americans and an important target of public health interventions, including the Surgeon General's Step It Up! campaign [57, 179]. Our findings can help communities prioritize changes that may be relevant to retirees, such creating green, friendly spaces with sidewalks and lower speed limits. 


\subsection{Limitations}

This research also is subject to a number of limitations. Three key limitations were related to measurement of retirement, physical activity and sedentary behavior, and neighborhood environment characteristics. A fourth limitation was sample selection in the MESA and qualitative study.

First, in both MESA and the qualitative study, retirement status was self-reported and date of retirement was estimated. A concern for the MESA study is that some people report being retired while continuing to work full- or part-time, which could attenuate the association between retirement and behavior changes by limiting changes in discretionary time [22]. Increased discretionary time was a facilitator of increased physical activity and sedentary behavior after retirement among qualitative study participants. MESA participants who were "retired and working" $(\mathrm{N}=184)$ may not have had increased discretionary time after retirement. Among "retired and working" MESA participants (N=184), retirement was not associated with changes in MVPA, recreational walking, or non-walking leisure activity (Aim 1). However, retirement was associated with similar increases in household/yard activities and TV watching among retirees who were and were not working (Aim 1). Both the qualitative and quantitative data suggest that retirement also may affect physical activity and sedentary behavior through pathways other than discretionary time, for example, self-perception related to aging [130]. In addition, we estimated MESA participants' retirement date as the mid-point between the pre- and post-retirement exams. Resulting error in the measurement of time since retirement was unlikely differential with respect to physical activity and TV watching.

Second, limitations of self-reported physical activity and sedentary behavior included recall bias, social-desirability bias, and a lack of comprehensive sedentary behavior measures. Recall and social-desirability biases typically lead to over-reporting of physical activity and 
underreporting of sedentary behavior. As a result, researchers often advocate for sensor-based measures in addition to self-report since current sensor technologies do not capture the domain of behavior [4, 108, 109]. Few longitudinal studies among retirement-aged adults have repeated sensor-based measures. To address over-reporting, we excluded persons reporting $>18$ hours per day of physical activity (Aim 1) and categorized changes in walking after retirement (Aim 2). Differential error in recall with respect to retirement also could bias findings. Whether and how recall of physical activity and sedentary behavior may be effected by retirement remains unclear. Employed compared to non-employed status was associated with increased correlation between self-reported physical activity and accelerometer measures [189], but no studies have explored this issue in relation to retirement specifically. This would be a useful avenue for future research along with longitudinal, sensor-based measures of physical activity and sedentary behavior.

With respect to sedentary behavior, TV watching was the only domain consistently measured in the MESA. We were not able to assess changes in overall sedentary behavior after retirement among MESA participants. Among Belgian adults, retirement was associated with increases in both TV watching and overall sedentary behavior [86]. However, some participants in our qualitative study reported more TV watching but less overall sedentary behavior after retirement, and many reported sedentary time reading and using social media in addition to watching TV after retirement. There is a need for future studies with domain-specific and overall measures of sedentary behavior, including occupational sitting, reading, and non-TV screen time.

Third, objective environmental measures were defined using radial buffers around participants' homes. Associations between environmental features and physical activity may vary depending on the size and composition of the area measured [191]. In sensitivity analyses, associations between neighborhood destinations and change in walking was similar across buffer 
sizes (half-mile to three-miles). However, circular buffers may not accurately represent the areas within which adults are active [203]. Future studies would be strengthened by using "activity spaces" defined using Geographic Positioning System traces [193, 203] and could explore the effect of retirement on the size and shape of activity spaces as well as perceptions of the neighborhood environment.

A fourth limitation to this work was selection of participants in the MESA and qualitative study. The MESA eligibility criteria required that participants were free of clinical CVD, aged $\geq 45$, and willing to participate in a longitudinal research study at enrollment [125]. Findings from this relatively healthy cohort may not be generalizable to the US population. Also, differences by race/ethnicity and MESA site were difficult to interpret because by design the racial/ethnic composition of the sample varies by site (e.g., all Chinese American participants were recruited in IL and CA). Therefore, we focused on differences by SEP but not race/ethnicity or geographic location. In addition, there was attrition from the MESA cohort due to death and loss to follow-up. Findings were robust after statistical adjustment for attrition (Aim 1). However, adults who continued to participate in MESA may have experienced a better adjustment to retirement than people lost to follow-up, which could result in an overly beneficial estimate of association between retirement and physical activity and TV watching. Also, participants in the MESA and the qualitative study were from predominately urban and suburban areas. Although $81 \%$ of older Americans live in metropolitan areas [63], future studies should include retirees from rural areas, who likely have distinct patterns of physical activity and sedentary behavior and behavioral determinants during the retirement transition. 


\subsection{Public Health Significance}

This research contributed insight regarding two prevalent health risk factors in later life: physical inactivity and sedentary behavior. The health of older adults is of increasing public health importance given current demographic trends. Older adults are a growing proportion of the US population. Currently, 44.7 million Americans (one in seven) are aged 65 or older [63]. The population of older adults is projected to rise to 72 million by 2030 [27]. Among US older adults, the prevalence of physical activity is low and the prevalence of sedentary behavior is high $[55,56]$. Increased physical activity and reduced sedentary behavior can contribute to primary and secondary prevention of chronic disease in later life [6, 42]. Even small increases in physical activity could substantially reduce disease burden and population healthcare costs given the high burden among older adults [76, 204], leading to calls for promotion of physical activity in later life [30,62]. The evidence of changes in physical activity and TV watching associated with retirement in this study provide support for the retirement transition as a potential window of opportunity for physical activity promotion in later life [30].

We believe this research can benefit community leaders, public health practitioners, and researchers working to promote physical activity among older adults. Our findings suggest that a variety of intervention strategies may be required to effectively promote a physically active lifestyle among retirees. An initial step could include incorporating information on physical activity and sedentary behavior into existing retirement preparation resources to increase awareness of the potential impact of retirement on health behaviors. Further, physical activity interventions could be targeted to retirees based on SEP, gender, prior leisure-time and occupational physical activity, and other transitions concurrent with retirement (e.g., becoming a caregiver). For example, incorporating physical activity into caregiver respite or support programs could help retired caregivers to be more physically active. Other effective intervention 
strategies may include emphasizing health benefits of physical activity, including for chronic disease management and mental health, and improving perceived neighborhood walkability and access to low-cost recreational facilities. Federally funded programs support enhancement of communities to promote physical activity $[52,179]$. Our findings could guide selection of environmental and policy changes more likely to support physical activity among growing populations of retirees. For example, improvements to the aesthetic appeal of neighborhood walking environments. Findings also can inform implementation of existing policies and plans. For example, a goal of the 2015-2019 NC Aging Services Plan is to expand older adults' access to and participation in health promotion activities [205]. Findings from this research suggest that efforts in Forsyth County, NC concentrate on promoting use of extant recreational facilities, which were important facilitators of physical activity among retired women.

\subsection{Future Directions}

These findings point to three important areas for future research. First, observational studies could explore the influence of reasons for and patterns of retirement on behavior, as well as policies to increase retirement ages. Second, future research could investigate changes in other health-related behaviors during the retirement transition, in addition to physical activity and sedentary behavior, and sustainment of behavior changes in the longer-term. Third, experimental research could test intervention strategies suggested by observational research findings.

Reasons for and patterns of retirement may influence changes in physical activity and sedentary behavior $[45,94]$. For example, in a previous study, retirement due to disability was associated with negative changes in physical activity whereas statutory retirement was associated with positive changes in physical activity [22]. Our qualitative data also highlighted the importance of reasons for retirement: women who retired to care for family members had less time for physical activity after retirement. Moreover, gradual retirement patterns (Figure 2) could 
be differently associated with physical activity and sedentary behavior compared to a more abrupt retirement transition. If some patterns of retirement are predictive of worse behavior changes, this could serve as another way to target interventions. This type of research will require more frequent and detailed assessments of employment status, work hours, and reasons for retirement than were available in MESA. Further, cross-national comparisons may be useful to explore the impact on physical activity and sedentary behavior of policies to increase ages for statutory retirement or retirement benefit eligibility, which many developed nations are currently adopting in response to ongoing demographic shifts [45, 68].

Behaviors other than physical activity and sedentary behavior also may change during the retirement transition, including diet, smoking, and alcohol consumption [18, 94]. Comprehensive evaluation of changes across health behaviors may elucidate the holistic effect of retirement on health in later life and inform comprehensive interventions to address multiple health risks during retirement [18]. Also, studies with longer follow-up after retirement could elucidate whether behavior changes during the retirement transition are sustained in the longer-term. There is some evidence that increased leisure-time physical activity associated with retirement may not be sustained [88], but few extant studies have sufficient follow-up to address this question.

Experimental research also is needed to identify efficacious intervention strategies. To date, few physical activity interventions have targeted the retirement transition [79]. Findings from this and other research on the topic can guide intervention development. For example, the feasibility of including physical activity in caregiving support and respite services, and other community volunteer programs targeting older adults could be evaluated. On-going environmental changes in communities also could provide opportunities for natural experiments regarding the effect of environmental changes on physical activity after retirement. 
In coming decades, continued technological developments may further change physical activity opportunities for retired adults. For example, in-home robotic devices may further reduce the effort expended on household chores [206]. At the same time, advances in artificial intelligence could provide new opportunities for tailored reminders, coaching, and encouragement for daily physical activity [207]. Outside of the home, self-driving cars may make it easier for older adults to access community resources, whereas driving cessation is associated with health declines [208]. Thus, changes in physical activity and sedentary behavior associated with retirement, as well as barriers and facilitators of physical activity after retirement are likely to differ for future generations of retirees.

Future research in all of these areas also could address limitations faced in this dissertation. For instance, sensor-based and self-reported measures could be combined to better quantify overall and domain-specific physical activity and sedentary behavior, including sedentary behaviors other than TV watching. Use of location tracking devices in addition to activity sensors would further improve understanding of the relevant geographic area for physical activity after retirement and specification of environmental correlates of behavior among retirees. In addition, multiplicative statistical models were used in this research; however, future work could explore additive interactions between socioeconomic position and behavior change at retirement. On the other hand, the mixed-method approach was a strength of this dissertation that could be applied in future research. In conjunction with quantitative data collection, qualitative interviews repeated before and after retirement could provide insight on opportunities to intervene before and during the retirement transition. 


\subsection{Conclusions}

Transitioning to retirement was associated with positive and negative changes in physical activity, with differences by SEP, and with negative changes in TV watching. Individual health, access to destinations, and perceptions of the neighborhood environment were associated with changes in walking after retirement and were barriers and facilitators to physical activity after retirement among retired women. Earlier life leisure-time and occupational physical activity and concurrent life transitions also were important determinants of physical activity among retired women. Regular physical activity in later life prevents and delays disease and disability, reduces medical care costs, and improves mental health [6]. This dissertation research increases our understanding of physical activity and sedentary behavior during the retirement transition and highlights opportunities for development and targeting of interventions. 


\section{APPENDIX 1: QUALITATIVE DATA COLLECTION TOOLS}

\section{Study Questionnaire}

Study ID:

1. What is your current age: (years)

2. What is your race/ethnicity: $\square$ Hispanic Non-Hispanic Black/African American Non-Hispanic White

Other: (please specify)

3. What is your current retirement status: $\square$ Volunteering / not working for pay

\section{$\square$ Working for pay part time}

$\square$ Other: (please specify)

4. What was your last job title before you retired:

5. Before you retired, which best described your usual activity at work:

$\square$ Light effort while sitting most of the time (e.g., in an office, laboratory, child care, etc.)

$\square$ Light effort while standing (e.g., filing, clerking, assembly, nursing, farming, etc.)

$\square$ Moderate effort while standing and/or walking (e.g. nursing, custodian, housekeeping), lifting and pushing, sustained walking (e.g., making deliveries)

$\square$ Heavy effort (e.g., manual labor, ranch hand, farm labor, (un)loading trucks)

6. When did you retire?

7. Below is a list of reasons why some people retire. Please indicate whether, for you, these were important reasons for retirement.

a. Poor health

Very Moderately Somewhat Not at all

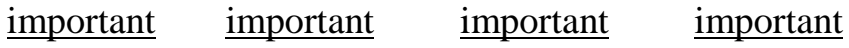

b. Wanted to do other things

c. Didn't like the work

d. Wanted to spend more time with family

8. What is the highest education you completed: $\square$ Less than high school

$\square$ High school or GED

Some college or Associates degree

Bachelor's degree

Graduate degree (e.g., Masters)

9. What is your marital status: $\square$ Married / living as married / living with partner Widowed 
$\square$ Divorced

$\square$ Separated

$\square$ Never married 
10. Neighborhood Questionnaire

Study ID:

For each of the statements below, please tell me whether you agree by choosing the best option. Please think of your neighborhood as the area within about a 20 minute walk (or about a mile) from your home.

\begin{tabular}{|c|c|c|c|c|c|}
\hline & $\begin{array}{l}\text { Strongly } \\
\text { agree }\end{array}$ & Agree & $\begin{array}{c}\text { Neutral } \\
\text { (neither } \\
\text { agree or } \\
\text { disagree) }\end{array}$ & Disagree & $\begin{array}{l}\text { Strongly } \\
\text { disagree }\end{array}$ \\
\hline $\begin{array}{l}\text { a. It is pleasant to walk in my } \\
\text { neighborhood }\end{array}$ & $\square$ & $\square$ & $\square$ & $\square$ & $\square$ \\
\hline $\begin{array}{l}\text { b. In my neighborhood it is easy to walk } \\
\text { places }\end{array}$ & $\square$ & $\square$ & $\square$ & $\square$ & $\square$ \\
\hline $\begin{array}{l}\text { c. I often see other people walking in my } \\
\text { neighborhood }\end{array}$ & $\square$ & $\square$ & $\square$ & $\square$ & $\square$ \\
\hline $\begin{array}{l}\text { d. I often see other people exercise in my } \\
\text { neighborhood }\end{array}$ & $\square$ & $\square$ & $\square$ & $\square$ & $\square$ \\
\hline $\begin{array}{l}\text { e. There is a lot of noise in my } \\
\text { neighborhood }\end{array}$ & $\square$ & $\square$ & $\square$ & $\square$ & $\square$ \\
\hline $\begin{array}{l}\text { f. There is a lot of trash and litter on the } \\
\text { streets in my neighborhood }\end{array}$ & $\square$ & $\square$ & $\square$ & $\square$ & $\square$ \\
\hline g. My neighborhood is attractive & $\square$ & $\square$ & $\square$ & $\square$ & $\square$ \\
\hline $\begin{array}{l}\text { h. I feel safe walking in my neighborhood } \\
\text { at day or at night }\end{array}$ & $\square$ & $\square$ & $\square$ & $\square$ & $\square$ \\
\hline $\begin{array}{l}\text { i. Violence is a problem in my } \\
\text { neighborhood }\end{array}$ & $\square$ & $\square$ & $\square$ & $\square$ & $\square$ \\
\hline $\begin{array}{l}\text { j. People around here are willing to help } \\
\text { their neighbors }\end{array}$ & $\square$ & $\square$ & $\square$ & $\square$ & $\square$ \\
\hline $\begin{array}{l}\text { k. People in this neighborhood generally } \\
\text { do not get along with each other }\end{array}$ & $\square$ & $\square$ & $\square$ & $\square$ & $\square$ \\
\hline $\begin{array}{l}\text { 1. People in this neighborhood can be } \\
\text { trusted }\end{array}$ & $\square$ & $\square$ & $\square$ & $\square$ & $\square$ \\
\hline $\begin{array}{l}\text { m. People in this neighborhood do not } \\
\text { share the same values }\end{array}$ & $\square$ & $\square$ & $\square$ & $\square$ & $\square$ \\
\hline
\end{tabular}




\section{Physical Activity Questionnaire}

Please think about the types of physical activities you did in a typical week in the past month. Please indicate whether you did or did not perform each of the following activities in a typical week. For each item that you responded 'yes', please indicate the number of days in a typical week you did these activities and the average amount of time per day in hours and minutes.

\begin{tabular}{|c|c|c|c|}
\hline \multirow[t]{2}{*}{ Intensity levels: } & Light & Moderate & Heavy \\
\hline & Easy effort & Harder effort & All out \\
\hline
\end{tabular}

\begin{tabular}{|c|c|c|c|c|}
\hline \multirow{2}{*}{$\begin{array}{l}\text { Activity } \\
\text { Household Chores }\end{array}$} & & & \multirow[t]{2}{*}{ Days/week } & \multirow[t]{2}{*}{ Hours:Min } \\
\hline & & & & \\
\hline $\begin{array}{l}\text { Light effort: such as cooking, dishes, ironing, straightening } \\
\text { up, laundry, shopping }\end{array}$ & $\mathrm{Y}$ & $\mathrm{N}$ & 1234567 & : \\
\hline $\begin{array}{l}\text { Moderate or heavy effort: such as heavy cleaning, home } \\
\text { repairs, scrubbing, mopping, washing car, vacuuming }\end{array}$ & $\mathrm{Y}$ & $\mathrm{N}$ & 1234567 & $:$ \\
\hline \multicolumn{5}{|l|}{ Lawn/Yard/Garden/Farm } \\
\hline $\begin{array}{l}\text { Moderate effort: such as weeding, mowing, raking, cleaning } \\
\text { garage, sweeping }\end{array}$ & $\mathrm{Y}$ & $\mathrm{N}$ & 1234567 & : \\
\hline $\begin{array}{l}\text { Heavy effort: such as digging, shoveling snow, mending } \\
\text { fences, chopping wood }\end{array}$ & $\mathrm{Y}$ & $\mathrm{N}$ & 1234567 & : \\
\hline \multicolumn{5}{|l|}{ Care of Children/Adults } \\
\hline $\begin{array}{l}\text { Light effort: such as bathing, feeding, changing diapers, play } \\
\text { with child }\end{array}$ & $\mathrm{Y}$ & $\mathrm{N}$ & 1234567 & $:$ \\
\hline $\begin{array}{l}\text { Moderate effort: such as lifting and carrying, pushing } \\
\text { wheelchair or stroller }\end{array}$ & $\mathrm{Y}$ & $\mathrm{N}$ & 1234567 & : \\
\hline \multicolumn{5}{|l|}{ Walking (not at work) } \\
\hline Walking to get places - to the bus, car, work, into the store & Y & $\mathrm{N}$ & 1234567 & : \\
\hline $\begin{array}{l}\text { Walking for exercise, pleasure, social reasons, walking } \\
\text { during work breaks, walking the dog }\end{array}$ & $\mathrm{Y}$ & $\mathrm{N}$ & 1234567 & $:$ \\
\hline \multicolumn{5}{|l|}{ Dancing/Sport Activities } \\
\hline Dancing in church, ceremonies, or for pleasure & Y & $\mathrm{N}$ & 1234567 & $:$ \\
\hline Team sports - softball, volleyball, basketball, soccer & Y & $\mathrm{N}$ & 1234567 & $:$ \\
\hline Dual sports - tennis, racketball, paddleball & $\mathrm{Y}$ & $\mathrm{N}$ & 1234567 & $:$ \\
\hline Individual activities - golf, bowling, yoga, T'ai Chi & Y & $\mathrm{N}$ & 1234567 & : \\
\hline
\end{tabular}




\begin{tabular}{|c|c|c|c|}
\hline Activity & & Days/week & Hours:Mins \\
\hline \multicolumn{4}{|l|}{ Conditioning Activities } \\
\hline $\begin{array}{l}\text { Moderate effort: low impact aerobics, slow bicycling, } \\
\text { rowing, leisurely swimming, health club machines }\end{array}$ & $\mathrm{Y} \quad \mathrm{N}$ & 1234567 & : \\
\hline $\begin{array}{l}\text { Heavy effort: high impact aerobics, fast bicycling, running, } \\
\text { jogging, fast swimming, health club machines, judo, } \\
\text { kickboxing, karate }\end{array}$ & $\mathrm{Y} \quad \mathrm{N}$ & 1234567 & $:$ \\
\hline \multicolumn{4}{|l|}{ Leisure Activities } \\
\hline Sit or recline and watch TV & $\mathrm{Y} \quad \mathrm{N}$ & 1234567 & $:$ \\
\hline \multicolumn{4}{|l|}{ Occupational or Volunteer Activities } \\
\hline $\begin{array}{l}\text { Light effort: while sitting (e.g., in an office, lab, childcare, } \\
\text { etc.) }\end{array}$ & $\mathrm{Y} \quad \mathrm{N}$ & 1234567 & $:$ \\
\hline $\begin{array}{l}\text { Light effort: while standing (e.g., filing, copying, clerking, } \\
\text { assembly, nursing, farming, etc.) }\end{array}$ & $\mathrm{Y} \quad \mathrm{N}$ & 1234567 & : \\
\hline $\begin{array}{l}\text { Moderate effort: while standing and/or walking (e.g., } \\
\text { nursing, custodian, housekeeping), lifting and pushing, } \\
\text { sustained walking (e.g., making deliveries) }\end{array}$ & $\mathrm{Y} \quad \mathrm{N}$ & 1234567 & $:$ \\
\hline $\begin{array}{l}\text { Heavy effort: manual labor, ranch hand, farm labor, lifting, } \\
\text { carrying, climbing, loading/unloading trucks }\end{array}$ & $\mathrm{Y} \quad \mathrm{N}$ & 1234567 & $:$ \\
\hline
\end{tabular}

\section{FOR STUDY USE:}

WalkScore ${ }^{\mathrm{TM}}$ :

Wish to receive dissemination materials?: Yes No 


\section{Semi-Structured Interview Guide}

\section{Physical activity and sedentary behavior before and after retirement}

First, I'd like to talk about physical activity. By physical activity I mean anything that gets you moving like walking in your neighborhood or to go somewhere, gardening, doing sports or exercise, or playing with grandchildren.

1. Let's start by talking about what kind of physical activity you do these days.

a. Probe, as needed: How often do you do [activity]? Where and with whom?

2. Thinking back to before you retired, tell me about what your physical activity was like when you were working?

a. Probe, as needed: What about physical activity at work? Near your workplace?

3. How would you compare the physical activity you did when you were working to what it is like now?

a. What do you think accounts for the difference in your physical activity since you retired?

b. Since you retired, what, if anything, makes it easier to do physical activity? What makes it harder?

c. Probe, as needed: What is your goal (or motivation) for doing physical activity?

d. Probe, as needed: What benefits do you experience?

4. How, if at all, does the physical activity you did at work have to do with the physical activity that you do now?

5. We've been talking about physical activity. What about "sedentary behavior" like watching TV, using the computer/phone, reading, or other things you might do sitting down.

a. What kind of sedentary behaviors do you do these days?

b. How would you compare your sedentary behavior now to when you were working?

c. What do you think accounts for the difference in your sedentary behavior since you retired?

\section{Context: community, neighborhood, household}

6. Next, let's talk about your community and where you live. Can you tell me about the community where you live?

a. How does living in your community influences what physical activity you do?

i. Probe, as needed: social groups or organizations?

7. How does living in your neighborhood influence what physical activity you do?

a. Probe, as needed: Where could you be active? What would be your concerns?

b. Probe, as needed: If you wanted to walk in your neighborhood, do you think you could do that? What makes you say that?

c. In your neighborhood, do you see people like you out walking?

d. How long have you lived in your neighborhood? 
i. How much were you thinking about being able to walk in your neighborhood compared to other factors when you decided to live there?

8. Sometimes other people influence what we do. What other people, if any, play a role in the physical activity you do?

a. What do you think is the most important thing that influences the physical activity you do now that you're retired?

\section{Intervention ideas}

9. Imagine that you are a leader with the power and resources to make changes in your community. You can change anything you want. How would you help retired people in your community to be more physically active?

a. Probe, as needed: What would you do first? How would you do this?

b. Probe, as needed: Please tell me a few reasons why retirees like you might not be physical active?

c. Probe, as needed: Why might retirees want to be more physically active?

10. What would you do to help retired people in your community reduce their sedentary time?

a. Probe, as needed: What would you do first? How would you do this?

\section{Social norms}

11. What are expectations in your community for physical activity after people retire?

a. Probe, as needed: What do you think that people like family or friends think of retired people being physically active?

b. Probe, as needed: Would you say this affects what you do? 


\section{REFERENCES}

1. Golden S, Earp J. The social ecological model in practice: How far have we come? SOPHE National Conference. 2008.

2. O'Rand AM. 2010 SSS presidential address: The devolution of risk and the changing life course in the united states. Social Forces 2011;90(1):1-16.

3. Caspersen CJ, Powell KE, Christenson GM. Physical activity, exercise, and physical fitness: Definitions and distinctions for health-related research. Public Health Rep. 1985;100(2):126-131.

4. Prince SA, Adamo KB, Hamel ME, Hardt J, Connor Gorber S, Tremblay M. A comparison of direct versus self-report measures for assessing physical activity in adults: A systematic review. Int J Behav Nutr Phys Act. 2008;5:56.

5. Chodzko-Zajko WJ. American College of Sports Medicine position stand: Exercise and physical activity for older adults. Med Sci Sport Exer. 2009;41(7):1510-1530.

6. US Department of Health Human Services. 2008 Physical Activity Guidelines for Americans. Be active, healthy, and happy. 2008. http://www.health.gov/paguidelines/pdf/paguide.pdf. Accessed: August 2015.

7. Colditz GA. Economic costs of obesity and inactivity. Med Sci Sports Exerc. 1999;31(11 Suppl):S663-667.

8. Carlson SA, Fulton JE, Schoenborn CA, Loustalot F. Trend and prevalence estimates based on the 2008 Physical Activity Guidelines for Americans. Am J Prev Med. 2010;39(4):305-313.

9. Evenson KR, Wen F, Metzger JS, Herring AH. Physical activity and sedentary behavior patterns using accelerometry from a national sample of United States adults. Int J Behav Nutr Phys Act. 2015;12(1):20.

10. Owen N, Healy GN, Matthews CE, Dunstan DW. Too much sitting: The population health science of sedentary behavior. Exerc Sport Sci Rev. 2010;38(3):105-113.

11. Kenter EJ, Gebhardt WA, Lottman I, van Rossum M, Bekedam M, Crone MR. The influence of life events on physical activity patterns of Dutch older adults: A life history method. Psychol Health. 2015;30(6):627-651.

12. Barnett I, Guell C, Ogilvie D. The experience of physical activity and the transition to retirement: A systematic review and integrative synthesis of qualitative and quantitative evidence. Int J Behav Nutr Phys Act. 2012;9:97.

13. Hirvensalo M, Lintunen T. Life-course perspective for physical activity and sports participation. Eur Rev Aging Phys Act. 2011;8(1):13-22. 
14. Felner RD, Farber SS, Primavera J. Transitions and stressful life events: A model for primary prevention. Prev Psychol. 1983:199-215.

15. Beck F, Gillison F, Standage M. A theoretical investigation of the development of physical activity habits in retirement. Brit J Health Psych. 2010;15:663-679.

16. Berg J, Levin L, Abramsson M, Hagberg JE. Mobility in the transition to retirement - the intertwining of transportation and everyday projects. J Transport Geogr. 2014;38:48-54.

17. McDonald S, O'Brien N, White M, Sniehotta FF. Changes in physical activity during the retirement transition: A theory-based, qualitative interview study. Int J Behav Nutr Phys Act. 2015;12:25.

18. Zantinge EM, van den Berg M, Smit HA, Picavet HS. Retirement and a healthy lifestyle: Opportunity or pitfall? A narrative review of the literature. Eur J Public Health. 2014;24(3):433-439.

19. Barnett I, van Sluijs EM, Ogilvie D. Physical activity and transitioning to retirement: A systematic review. Am J Prev Med. 2012;43(3):329-336.

20. Henretta JC, Chan CG, O'Rand AM. Retirement reason versus retirement process: Examining the reasons for retirement typology. J Gerontol. 1992;47(1):S1-7.

21. O'Rand AM. The changing life course. In: Ritzer G, ed. The Wiley-Blackwell Companion to Sociology. Chichester, UK: John Wiley \& Sons, Ltd; 2011:197-211.

22. Feng X, Croteau K, Kolt GS, Astell-Burt T. Does retirement mean more physical activity? A longitudinal study. BMC Public Health. 2016;16(1):605.

23. Elder GJ, Kirkpatrick Johnson M, Crosnoe R. The emergence and development of life course theory. In: Mortimer JT, Shanahan MJ, eds. Handbook of the Life Course. New York: Kluwer Academic/Plenum Publishers; 2003:3-19.

24. Sallis J, Owen N, Fisher E. Ecological models of health behavior. In: Glanz K, Rimer B, Viswanath K, eds. Health Behavior and Health Education: Theory, Research, and Practice. San Francisco, CA: Jossey-Bass; 2008:465-485.

25. Sprod J, Ferrar K, Olds T, Maher C. Changes in sedentary behaviours across the retirement transition: A systematic review. Age Ageing. 2015;44(6):918-925.

26. Roberts CA. Designing spaces for healthy aging. NC Med J. 2008;69(5):401-403.

27. Centers for Disease Control and Prevention. The State of Aging and Health in America 2013. Atlanta, GA: CDC, US Department of Health and Human Services; 2013. https://www.cdc.gov/aging/pdf/state-aging-health-in-america-2013.pdf. Accessed: July 2016. 
28. Yazdanyar A, Newman AB. The burden of cardiovascular disease in the elderly: Morbidity, mortality, and costs. Clin Geriatr Med. 2009;25(4):563-577.

29. Prince MJ, Wu F, Guo Y, Gutierrez Robledo LM, O'Donnell M, Sullivan R, et al. The burden of disease in older people and implications for health policy and practice. Lancet. 2015;385(9967):549-562.

30. Kelly S, Martin S, Kuhn I, Cowan A, Brayne C, Lafortune L. Barriers and facilitators to the uptake and maintenance of healthy behaviours by people at mid-life: A rapid systematic review. PLOS ONE. 2016;11(1):e0145074.

31. Smeaton D, Barnes H, Vegeris S. Does retirement offer a "window of opportunity" for lifestyle change? Views from English workers on the cusp of retirement. J Aging Health. 2016;29(1):25-44.

32. Syse A, Veenstra M, Furunes T, Mykletun RJ, Solem PE. Changes in health and health behavior associated with retirement. J Aging Health. 2017;29(1):99-127.

33. Scanlon-Mogel J, Roberto K. Older adults' beliefs about physical activity and exercise: Life course influences and transitions. Qual Ageing Older Adults. 2004;5(3):33-44.

34. Chastin SF, Fitzpatrick N, Andrews M, DiCroce N. Determinants of sedentary behavior, motivation, barriers and strategies to reduce sitting time in older women: A qualitative investigation. Int J Environ Res Public Health. 2014;11(1):773-791.

35. Rosenkoetter MM, Gams JM, Engdahl RA. Postretirement use of time: Implications for preretirement planning and postretirement management. Activities Adaptation Aging. 2001;25(3-4):1-18.

36. Ding D, Grunseit AC, Chau JY, Vo K, Byles J, Bauman AE. Retirement-a transition to a healthier lifestyle?: Evidence from a large Australian study. Am J Prev Med. 2016;51(2):170-178.

37. Chung S, Domino ME, Stearns SC, Popkin BM. Retirement and physical activity: Analyses by occupation and wealth. Am J Prev Med. 2009;36(5):422-428.

38. Carmichael F, Duberley J, Szmigin I. Older women and their participation in exercise and leisure-time physical activity: The double edged sword of work. Sport Society. 2015;18(1):42-60.

39. Baxter S, Blank L, Johnson M, Everson-Hock E, Woods HB, Goyder E, et al. Interventions to promote or maintain physical activity during and after the transition to retirement: An evidence synthesis. Public Health Res. 2016;4(4).

40. Community Preventive Services Taskforce. Physical activity: Built environment approaches combining transportation system interventions with land use and environmental design. 2016.

https://www.thecommunityguide.org/sites/default/files/assets/PA- Built- 
Environments.pdf. Updated April 2017. Accessed July 2017.

41. Saelens BE, Sallis JF, Frank LD, Cain KL, Conway TL, Chapman JE, et al. Neighborhood environment and psychosocial correlates of adults' physical activity. Med Sci Sports Exerc. 2012;44(4):637-646.

42. Blair SN, Morris JN. Healthy hearts--and the universal benefits of being physically active: Physical activity and health. Ann Epidemiol. 2009;19(4):253-256.

43. Paterson DH, Govindasamy D, Vidmar M, Cunningham DA, Koval JJ. Longitudinal study of determinants of dependence in an elderly population. J Am Geriatr Soc. 2004;52(10):1632-1638.

44. Labarthe D. Chapter 9: Physical Inactivity. Epidemiology and Prevention of Cardiovascular Diseases: A Global Challenge. Sudbury, MA: Jones and Bartlett Publishers; 2011:191-221.

45. Lytle MC, Clancy ME, Foley PF, Cotter EW. Current trends in retirement: Implications for career counseling and vocational psychology. J Career Dev. 2015;42(3):170-184.

46. Strobl H, Brehm W, Tittlbach S. Physical activity during the transition period between occupation and retirement. Zeitschrift Fur Gerontologie Und Geriatrie. 2010;43(5):297302.

47. Potocnik K, Sonnentag S. A longitudinal study of well-being in older workers and retirees: The role of engaging in different types of activities. J Occup Organizational Psychol. 2013;86(4):497-521.

48. Wang F, McDonald T, Reffitt B, Edington DW. BMI, physical activity, and health care utilization/costs among Medicare retirees. Obes Res. 2005;13(8):1450-1457.

49. Chomistek AK, Manson JE, Stefanick ML, Lu B, Sands-Lincoln M, Going SB, et al. Relationship of sedentary behavior and physical activity to incident cardiovascular disease: Results from the Women's Health Initiative. J Am Coll Cardiol. 2013;61(23):2346-2354.

50. Dunstan DW, Howard B, Healy GN, Owen N. Too much sitting--a health hazard. Diabetes Res Clin Pract. 2012;97(3):368-376.

51. Healy GN, Matthews CE, Dunstan DW, Winkler EA, Owen N. Sedentary time and cardio-metabolic biomarkers in US adults: NHANES 2003-06. Eur Heart J. 2011;32(5):590-597.

52. Watson KB, Carlson SA, Gunn JP, Galuska DA, O'Connor A, Greenlund KJ, et al. Physical inactivity among adults aged 50 years and older - United States, 2014. Morb Mortal Wkly Rep. 2016;65(36):954-958. 
53. Jones SA, Wen F, Herring AH, Evenson KR. Correlates of US adult physical activity and sedentary behavior patterns. J Scie Med Sport. 2016;19(12):1020-1027.

54. Tucker JM, Welk GJ, Beyler NK. Physical activity in U.S.: Adults compliance with the Physical Activity Guidelines for Americans. Am J Prev Med. 2011;40(4):454-461.

55. Evenson KR, Buchner DM, Morland KB. Objective measurement of physical activity and sedentary behavior among US adults aged 60 years or older. Prev Chronic Dis. 2012;9:149.

56. Keadle SK, McKinnon R, Graubard BI, Troiano RP. Prevalence and trends in physical activity among older adults in the United States: A comparison across three national surveys. Prev Med. 2016;89:37-43.

57. Centers for Disease Control and Prevention. Vital signs: Walking among adults -- United States, 2005 and 2010. Morb Mortal Wkly Rep. 2012;61(31):595-601.

58. Shaw BA, Liang J, Krause N, Gallant M, McGeever K. Age differences and social stratification in the long-term trajectories of leisure-time physical activity. J Gerontol Psycholo Sci Soc Sci. 2010;65(6):756-766.

59. Ussery EN, Carlson SA, Whitfield GP, Watson KB, Berrigan D, Fulton JE. Walking for transportation or leisure among U.S. women and men - National Health Interview Survey, 2005-2015. Morb Mortal Wkly Rep. 2017;66(25):657-662.

60. Gardiner PA, Eakin EG, Healy GN, Owen N. Feasibility of reducing older adults' sedentary time. Am J Prev Med. 2011;41(2):174-177.

61. Rhodes RE, Mark RS, Temmel CP. Adult sedentary behavior: A systematic review. Am J Prev Med. 2012;42(3):e3-28.

62. Morrow-Howell N, Putnam M, Lee YS, Greenfield JC, Inoue M, Chen HJ. An investigation of activity profiles of older adults. J Gerontol Psychol Sci Soc Sci. 2014;69(5):809-821.

63. Administration on Aging. A Profile of Older Americans: 2014. Administration on Aging, Administration for Community Living, US Department of Health and Human Services; 2014. http://www.aoa.acl.gov/aging_statistics/profile/2014/docs/2014-Profile.pdf. Accessed: October 2015.

64. Szinovacz ME, Martin L, Davey A. Recession and expected retirement age: Another look at the evidence. Gerontologist. 2014;54(2):245-257.

65. National Institute on Aging. Growing older in America the Health and Retirement Study. Bethesda, MD: National Institute on Aging, National Institutes of Health, US Department of Health and Human Services. 2007. https://www.nia.nih.gov/sites/default/files/201706/health_and_retirement_study_0.pdf. Accessed September 2015. 
66. Munnell AH. What is the average retirement age? Chestnut Hill, MA: The Center for Retirement Research, Boston College; 2010. https://www.soa.org/News-andPublications/Newsletters/Pension-Section-News/2012/february/What-Is-The-AverageRetirement-Age-.aspx. Accessed September 2015.

67. Reitzes DC, Mutran EJ. The transition to retirement: Stages and factors that influence retirement adjustment. Int J Aging Human Dev. 2004;59(1):63-84.

68. O'Rand AM, Hamil-Luker J. Late employment careers, transitions to retirement and retirement income in the U.S. In: Kurz K, Buchholz S, Blossfeld H-P, eds. Aging Populations, Globalization and the Labor Market: Comparing Late Working Life and Retirement in Modern Societies. Cheltenham: Edward Elgar Publishing; 2011:283-307.

69. Institute of Medicine Committee on the Long-Run Macroeconomic Effects of the Aging US Population. Labor force participation and retirement. Aging and the Macroeconomy: Long-Term Implications of an Older Population. Washington, DC: National Academies Press; 2012.

70. Kampfen F, Maurer J. Time to burn (calories)? The impact of retirement on physical activity among mature Americans. J Health Econ. 2015;45:91-102.

71. Kuvaja-Kollner V, Valtonen H, Komulainen P, Hassinen M, Rauramaa R. The impact of time cost of physical exercise on health outcomes by older adults: The DR's EXTRA Study. Eur J Health Econ. 2013;14(3):471-479.

72. Barnett I, Guell C, Ogilvie D. How do couples influence each other's physical activity behaviours in retirement? An exploratory qualitative study. BMC Public Health. 2013;13:1197.

73. Van Holle V, McNaughton SA, Teychenne M, Timperio A, Van Dyck D, De Bourdeaudhuij I, et al. Social and physical environmental correlates of adults' weekend sitting time and moderating effects of retirement status and physical health. Int J Environ Res Public Health. 2014;11(9):9790-9810.

74. Witcher CS, Holt NL, Spence JC, Cousins SO. A case study of physical activity among older adults in rural Newfoundland, Canada. J Aging Phys Act. 2007;15(2):166-183.

75. Wilson DM, Palha P. A systematic review of published research articles on health promotion at retirement. J Nursing Scholarship. 2007;39(4):330-337.

76. Fries JF, Bloch DA, Harrington H, Richardson N, Beck R. Two-year results of a randomized controlled trial of a health promotion program in a retiree population: The Bank of America Study. Am J Med. 1993;94(5):455-462.

77. Varma VR, Tan EJ, Gross AL, Harris G, Romani W, Fried LP, et al. Effect of community volunteering on physical activity a randomized controlled trial. Am J Prev Med. 2016;50(1):106-110. 
78. Heaven B, Brown LJ, White M, Errington L, Mathers JC, Moffatt S. Supporting wellbeing in retirement through meaningful social roles: Systematic review of intervention studies. Milbank Q. 2013;91(2):222-287.

79. Baxter S, Johnson M, Payne N, Buckley-Woods H, Blank L, Hock E, et al. Promoting and maintaining physical activity in the transition to retirement: A systematic review of interventions for adults around retirement age. Int J Behav Nutr Phys Act. 2016;13(1):12.

80. Werkman A, Hulshof PJ, Stafleu A, Kremers SP, Kok FJ, Schouten EG, et al. Effect of an individually tailored one-year energy balance programme on body weight, body composition and lifestyle in recent retirees: A cluster randomised controlled trial. $B M C$ Public Health. 2010;10:110.

81. Lara J, O'Brien N, Godfrey A, Heaven B, Evans EH, Lloyd S, et al. Pilot randomised controlled trial of a web-based intervention to promote healthy eating, physical activity and meaningful social connections compared with usual care control in people of retirement age recruited from workplaces. PLoS ONE. 2016;11(7):e0159703.

82. Maher CA, Burton NW, van Uffelen JG, Brown WJ, Sprod JA, Olds TS. Changes in use of time, activity patterns, and health and wellbeing across retirement: Design and methods of the Life After Work Study. BMC Public Health. 2013;13:952.

83. Barnett I, van Sluijs E, Ogilvie D, Wareham NJ. Changes in household, transport and recreational physical activity and television viewing time across the transition to retirement: Longitudinal evidence from the EPIC-Norfolk cohort. J Epidemiol Community Health. 2014;68(8):747-753.

84. Koeneman MA, Chinapaw MJM, Verheijden MW, van Tilburg TG, Visser M, Deeg DJH, et al. Do major life events influence physical activity among older adults: The Longitudinal Aging Study Amsterdam. Int J Behav Nutr Phy. 2012;9:147.

85. Lahti J, Laaksonen M, Lahelma E, Rahkonen O. Changes in leisure-time physical activity after transition to retirement: A follow-up study. Int J Behav Nutr Phys Act. 2011;8:36.

86. Menai M, Fezeu L, Charreire H, Kesse-Guyot E, Touvier M, Simon C, et al. Changes in sedentary behaviours and associations with physical activity through retirement: A 6-year longitudinal study. PLOS ONE. 2014;9(9):e106850.

87. Sjosten N, Kivimaki M, Singh-Manoux A, Ferrie JE, Goldberg M, Zins M, et al. Change in physical activity and weight in relation to retirement: The French GAZEL Cohort Study. BMJ Open. 2012;2(1):11.

88. Stenholm S, Pulakka A, Kawachi I, Oksanen T, Halonen JI, Aalto V, et al. Changes in physical activity during transition to retirement: A cohort study. Int J Behav Nutr Phys Act. 2016;13(1):51.

89. Oshio T, Kan M. The dynamic impact of retirement on health: Evidence from a nationwide ten-year panel survey in Japan. Prev Med. 2017;100:287-293. 
90. Van Dyck D, Cardon G, De Bourdeaudhuij I. Longitudinal changes in physical activity and sedentary time in adults around retirement age: What is the moderating role of retirement status, gender and educational level? BMC Public Health. 2016;16(1):1125.

91. Holstila A, Manty M, Rahkonen O, Lahelma E, Lahti J. Statutory retirement and changes in self-reported leisure-time physical activity: A follow-up study with three time-points. BMC Public Health. 2017;17(1):528.

92. Evenson KR, Rosamond WD, Cai J, Diez-Roux AV, Brancati FL. Influence of retirement on leisure-time physical activity: The Atherosclerosis Risk in Communities Study. Am J Epidemiol. 2002;155(8):692-699.

93. Touvier M, Bertrais S, Charreire H, Vergnaud AC, Hercberg S, Oppert JM. Changes in leisure-time physical activity and sedentary behaviour at retirement: A prospective study in middle-aged French subjects. Int J Behav Nutr Phys Act. 2010;7:14.

94. Henkens K, van Solinge H, Gallo WT. Effects of retirement voluntariness on changes in smoking, drinking and physical activity among Dutch older workers. Eur J Public Health. 2008;18(6):644-649.

95. Van Dyck D, Cardon G, De Bourdeaudhuij I. Which psychological, social and physical environmental characteristics predict changes in physical activity and sedentary behaviors during early retirement? A longitudinal study. PeerJ. 2017;5:e3242.

96. Kosteli MC, Williams SE, Cumming J. Investigating the psychosocial determinants of physical activity in older adults: A qualitative approach. Psychol Health. 2016;31:730749.

97. Heaven B, O'Brien N, Evans EH, White M, Meyer TD, Mathers JC, et al. Mobilizing resources for well-being: Implications for developing interventions in the retirement transition. Gerontologist. 2016;56(4):615-629.

98. Liechty T, Genoe MR, Marston HR. Physically active leisure and the transition to retirement: The value of context. Ann Leis Res. 2017;20(1):23-38.

99. Van Dyck D, Mertens L, Cardon G, De Cocker K, De Bourdeaudhuij I. Opinions toward physical activity, sedentary behavior, and interventions to stimulate active living during early retirement: A qualitative study in recently retired adults. J Aging Phys Act. 2017;25:277-286.

100. Clark B, Peeters G, Gomersall S, Pavey T, Brown W. Nine year changes in sitting time in young and mid-aged Australian women: Findings from the Australian Longitudinal Study for Women's Health. Prev Med. 2014;64:1-7.

101. Lee M. Pre-and post-retirement leisure in South Korea and the implications for life satisfaction. World Leisure J. 2005;47(4):23-31. 
102. Godfrey A, Lord S, Galna B, Mathers JC, Burn DJ, Rochester L. The association between retirement and age on physical activity in older adults. Age Ageing. 2014;43(3):386-393.

103. van der Goot M, Beentjes JWJ, Van Selm M. Meanings of television in older adults' lives: An analysis of change and continuity in television viewing. Ageing Society. 2012;32:147-168.

104. Administration on Aging. Minority aging. Administration on Aging, Administration for Community Living, US Department of Health and Human Services; 2015. http://www.aoa.acl.gov/Aging_Statistics/Minority_Aging/index.aspx. Accessed January 2016.

105. Brownson RC, Housemann RA, Brown DR, Jackson-Thompson J, King AC, Malone BR, et al. Promoting physical activity in rural communities: Walking trail access, use, and effects. Am J Prev Med. 2000;18(3):235-241.

106. Shores KA, West ST. Physical activity outcomes associated with African American park visitation in four community parks. J Park Recreat Admin. 2008;26(3):75-92.

107. Strath SJ, Kaminsky LA, Ainsworth BE, Ekelund U, Freedson PS, Gary RA, et al. Guide to the assessment of physical activity: Clinical and research applications: A scientific statement from the American Heart Association. Circ. 2013;128(20):2259-2279.

108. Aguilar-Farias N, Brown WJ, Olds TS, Geeske Peeters GM. Validity of self-report methods for measuring sedentary behaviour in older adults. $J$ Sci Med Sport. 2015;18(6):662-666.

109. Lee IM, Shiroma EJ. Using accelerometers to measure physical activity in large-scale epidemiological studies: Issues and challenges. Br J Sports Med. 2014;48(3):197-201.

110. Engberg E, Alen M, Kukkonen-Harjula K, Peltonen JE, Tikkanen HO, Pekkarinen H. Life events and change in leisure time physical activity: A systematic review. Sports Med. 2012;42(5):433-447.

111. Hirsch JA, Moore KA, Clarke PJ, Rodriguez DA, Evenson KR, Brines SJ, et al. Changes in the built environment and changes in the amount of walking over time: Longitudinal results from the Multi-Ethnic Study of Atherosclerosis. Am J Epidemiol. 2014;180(8):799-809.

112. Saelens BE, Handy SL. Built environment correlates of walking: A review. Med Sci Sports Exerc. 2008;40(7 Suppl):S550-566.

113. Humpel N, Marshall AL, Leslie E, Bauman A, Owen N. Changes in neighborhood walking are related to changes in perceptions of environmental attributes. Ann Behav Med. 2004;27(1):60-67.

114. Turrell G, Hewitt B, Haynes M, Nathan A, Giles-Corti B. Change in walking for transport: A longitudinal study of the influence of neighbourhood disadvantage and 
individual-level socioeconomic position in mid-aged adults. Int J Behav Nutr Phys Act. 2014;11:151.

115. Mendes de Leon CF, Cagney KA, Bienias JL, Barnes LL, Skarupski KA, Scherr PA, et al. Neighborhood social cohesion and disorder in relation to walking in communitydwelling older adults: A multilevel analysis. J Aging Health. 2009;21(1):155-171.

116. Steindorf K, Chang-Claude J, Flesch-Janys D, Schmidt ME. Determinants of sports, cycling, walking and overall leisure-time physical activity among postmenopausal women in Germany. Public Health Nutr. 2010;13(11):1905-1914.

117. Hirsch JA, Moore KA, Evenson KR, Rodriguez DA, Diez Roux AV. Walk Score® and Transit Score ${ }^{\circledR}$ and walking in the Multi-Ethnic Study of Atherosclerosis. Am J Prev Med. 2013;45(2):158-166.

118. Van Cauwenberg J, Cerin E, Timperio A, Salmon J, Deforche B, Veitch J. Park proximity, quality and recreational physical activity among mid-older aged adults: Moderating effects of individual factors and area of residence. Int J Behav Nutr Phys Act. 2015;12:8.

119. Chaudhury H, Campo M, Michael Y, Mahmood A. Neighbourhood environment and physical activity in older adults. Soc Sci Med. 2016;149:104-113.

120. Lieberman L, Golden SD, Earp JA. Structural approaches to health promotion: What do we need to know about policy and environmental change? Health Edu Behav. 2013;40(5):520-525.

121. Yen IH, Anderson LA. Built environment and mobility of older adults: Important policy and practice efforts. J Am Geriatr Soc. 2012;60(5):951-956.

122. Jones SA, Moore LV, Moore K, Zagorski M, Brines SJ, Diez Roux AV, et al. Disparities in physical activity resource availability in six US regions. Prev Med. 2015;78:17-22.

123. Creswell J, Klassen A, Plano Clark V, Smith K. Best practices for mixed methods research in the health sciences. Office of Behavioral and Social Sciences Research, National Institutes of Health; 2011. https://obssrarchive.od.nih.gov/mixed_methods_research/. Accessed March 2016.

124. Muller C, Volkov O. Older women: Work and caregiving in conflict? A study of four countries. Soc Work Health Care. 2009;48(7):665-695.

125. Bild DE, Bluemke DA, Burke GL, Detrano R, Diez Roux AV, Folsom AR, et al. MultiEthnic Study of Atherosclerosis: Objectives and design. Am J Epidemiol. 2002;156(9):871-881.

126. Stewart PA, Stewart WF, Siemiatycki J, Heineman EF, Dosemeci M. Questionnaires for collecting detailed occupational information for community-based case control studies. Am Ind Hyg Assoc J. 1998;59(1):39-44. 
127. Bourbonnais R, Meyer F, Theriault G. Validity of self reported work history. Br J Ind Med. 1988;45(1):29-32.

128. Rona RJ, Mosbech J. Validity and repeatability of self-reported occupational and industrial history from patients in EEC countries. Int J Epidemiol. 1989;18(3):674-679.

129. Myrtveit SM, Ariansen AM, Wilhelmsen I, Krokstad S, Mykletun A. A population based validation study of self-reported pensions and benefits: The Nord-Trondelag Health Study (HUNT). BMC Res Notes. 2013;6:27.

130. Perras MG, Strachan SM, Fortier MS. Possible selves and physical activity in retirees: The mediating role of identity. Res Aging. 2016;38(8):819-841.

131. Ainsworth BE, Irwin ML, Addy CL, Whitt MC, Stolarczyk LM. Moderate physical activity patterns of minority women: The Cross-Cultural Activity Participation Study. $J$ Womens Health Gend Based Med. 1999;8(6):805-813.

132. Ainsworth BE, Drowatzky K. Evaluation of the CAPS Typical Week Physical Activity Survey (TWPAS) among minority women. Proc Comm Prev Res Women's Health Conf; Bethesda, MD: National Institutes of Health; 2000.

133. Van Holle V, Deforche B, Van Cauwenberg J, Goubert L, Maes L, Van de Weghe N, et al. Relationship between the physical environment and different domains of physical activity in European adults: A systematic review. BMC Public Health. 2012;12:807.

134. Leask CF, Harvey JA, Skelton DA, Chastin SF. Exploring the context of sedentary behaviour in older adults (what, where, why, when and with whom). Eur Rev Aging Phys Act. 2015;12:4.

135. Lemelin ET, Diez Roux AV, Franklin TG, Carnethon M, Lutsey PL, Ni H, et al. Lifecourse socioeconomic positions and subclinical atherosclerosis in the Multi-Ethnic Study of Atherosclerosis. Soc Sci Med. 2009;68(3):444-451.

136. Mitchell PH, Powell L, Blumenthal J, Norten J, Ironson G, Pitula CR, et al. A short social support measure for patients recovering from myocardial infarction: The ENRICHD Social Support Inventory. J Cardiopulm Rehabil. 2003;23(6):398-403.

137. Mezuk B, Diez Roux AV, Seeman T. Evaluating the buffering vs. direct effects hypotheses of emotional social support on inflammatory markers: The Multi-Ethnic Study of Atherosclerosis. Brain Behav Immun. 2010;24(8):1294-1300.

138. Koohsari MJ, Badland H, Sugiyama T, Mavoa S, Christian H, Giles-Corti B. Mismatch between perceived and objectively measured land use mix and street connectivity: Associations with neighborhood walking. Journal of urban health : bulletin of the New York Academy of Medicine. 2015;92:242-252

139. Arvidsson D, Kawakami N, Ohlsson H, Sundquist K. Physical activity and concordance between objective and perceived walkability. Med Sci Sports Exerc. 2012;44:280-287 
140. McGinn AP, Evenson KR, Herring AH, Huston SL, Rodriguez DA. Exploring associations between physical activity and perceived and objective measures of the built environment. Journal of urban health : bulletin of the New York Academy of Medicine. 2007;84:162-184

141. Humpel N, Owen N, Leslie E. Environmental factors associated with adults' participation in physical activity: A review. American journal of preventive medicine. 2002;22:188199

142. Chudyk AM, Winters M, Moniruzzaman M, Ashe MC, Gould JS, McKay H. Destinations matter: The association between where older adults live and their travel behavior. J Transp Health. 2015;2:50-57

143. Davis MG, Fox KR, Hillsdon M, Coulson JC, Sharp DJ, Stathi A, et al. Getting out and about in older adults: The nature of daily trips and their association with objectively assessed physical activity. Int J Behav Nutr Phy. 2011;8

144. Hoehner CM, Schootman M. Concordance of commercial data sources for neighborhoodeffects studies. Journal of Urban Health-Bulletin of the New York Academy of Medicine. 2010;87:713-725

145. Evenson KR, Wen F. Using geographic information systems to compare municipal, county, and commercial parks data. Prev Chronic Dis. 2013;10:E93

146. Walls and Associates. National establishment time-series (nets) database: 2012 database description 2013;2016

147. Diez Roux AV, Evenson KR, McGinn AP, Brown DG, Moore L, Brines S, et al. Availability of recreational resources and physical activity in adults. American journal of public health. 2007;97:493-499

148. Frizzelle BG, Evenson KR, Rodriguez DA, Laraia BA. The importance of accurate road data for spatial applications in public health: Customizing a road network. International journal of health geographics. 2009;8:24

149. Rothman KJ. Modern epidemiology. Philadelphia: Wolters Kluwer Health/Lippincott Williams \& Wilkins; 2008.

150. Smith L, Gardner B, Fisher A, Hamer M. Patterns and correlates of physical activity behaviour over 10 years in older adults: Prospective analyses from the English Longitudinal Study of Ageing. BMJ Open. 2015;5(4):e007423.

151. Bauman AE, Reis RS, Sallis JF, Wells JC, Loos RJ, Martin BW, et al. Correlates of physical activity: Why are some people physically active and others not? Lancet. 2012;380(9838):258-271. 
152. Shea S, Lima J, Diez-Roux A, Jorgensen NW, McClelland RL. Socioeconomic status and poor health outcome at 10 years of follow-up in the Multi-Ethnic Study of Atherosclerosis. PLoS ONE. 2016;11(11):e0165651.

153. Howe CJ, Cole SR, Lau B, Napravnik S, Eron JJ, Jr. Selection bias due to loss to follow up in cohort studies. Epidemiol. 2016;27(1):91-97.

154. James P, Berrigan D, Hart JE, Hipp JA, Hoehner CM, Kerr J, et al. Effects of buffer size and shape on associations between the built environment and energy balance. Health Place. 2014;27:162-170.

155. Maxwell JA. Qualitative Research Design: An interactive approach. Thousand Oaks, CA: Sage Publications; 2005.

156. Francis JJ, Johnston M, Robertson C, Glidewell L, Entwistle V, Eccles MP, et al. What is an adequate sample size? Operationalising data saturation for theory-based interview studies. Psychol Health. 2010;25(10):1229-1245.

157. Tong A, Sainsbury P, Craig J. Consolidated criteria for reporting qualitative research (COREQ): A 32-item checklist for interviews and focus groups. Int J Qual Health Care. 2007;19(6):349-357.

158. Miles MB. Qualitative Data Analysis: An expanded sourcebook. Thousand Oaks, CA: Sage; 1994.

159. Ulin PR. Qualitative Methods in Public Health: A field guide for applied research. San Francisco, CA: Jossey-Bass; 2005.

160. Savin-Baden M. Qualitative Research: The essential guide to theory and practice. New York: Routledge; 2013.

161. Hsieh HF, Shannon SE. Three approaches to qualitative content analysis. Qual Health Res. 2005;15(9):1277-1288.

162. Gibbs G. Analysing Qualitative Data. London: Sage; 2007.

163. Charmaz K. Constructing Grounded Theory. London: Sage; 2014.

164. Yin RK. Case Study Research : Design and methods. Los Angeles, CA: Sage; 2009.

165. Gelman A. Data analysis using regression and multilevel/hierarchical models. New York: Cambridge University Press; 2007.

166. Champely S. Pwr: Basic functions for power analysis. R Package version 1.1-4. 2016. http://CRAN.R-project.org/package=pwr. Accessed: August 2016. 
167. Bertoni AG, Whitt-Glover MC, Chung H, Le KY, Barr RG, Mahesh M, et al. The association between physical activity and subclinical atherosclerosis: The Multi-Ethnic Study of Atherosclerosis. Am J Epidemiol. 2009;169(4):444-454.

168. Joseph JJ, Echouffo-Tcheugui JB, Golden SH, Chen H, Jenny NS, Carnethon MR, et al. Physical activity, sedentary behaviors and the incidence of Type 2 diabetes mellitus: The Multi-Ethnic Study of Atherosclerosis (MESA). BMJ Open Diabetes Res Care. 2016;4(1):e000185.

169. King DE, Xiang J. Retirement and healthy lifestyle: A National Health and Nutrition Examination Survey (NHANES) data report. J Am Board Fam Med. 2017;30(2):213-219.

170. Gassoumis Z, Linkcoln K, Vega W. How low-income minorities get by in retirement: Poverty levels and income sources. Los Angeles, CA: USC Edward R. Roybal Institute on Aging; 2011. http://roybal.usc.edu/Minorities-RetirementIncome.pdf. Accessed: Oct 2015.

171. Celidoni M, Rebba V. Healthier lifestyles after retirement in europe? Evidence from SHARE. Eur J Health Econ. 2017;18(7):805-830.

172. Hirsch JA, Diez Roux AV, Moore KA, Evenson KR, Rodriguez DA. Change in walking and body mass index following residential relocation: The Multi-Ethnic Study of Atherosclerosis. Am J Public Health. 2014;104(3):e49-56.

173. Allison PD. Fixed effects regression methods for longitudinal data: Using SAS. Cary, NC: SAS Institute; 2005.

174. Krieger N, Williams DR, Moss NE. Measuring social class in us public health research: Concepts, methodologies, and guidelines. Annu Review Public Health. 1997;18:341-378.

175. Ory M, Kinney Hoffman M, Hawkins M, Sanner B, Mockenhaupt R. Challenging aging stereotypes: Strategies for creating a more active society. Am J Prev Med. 2003;25(3 Suppl 2):164-171.

176. Yen L, Schultz AB, McDonald T, Champagne L, Edington DW. Participation in employer-sponsored wellness programs before and after retirement. Am J Health Behav. 2006;30(1):27-38.

177. Van Cauwenberg J, De Bourdeaudhuij I, De Meester F, Van Dyck D, Salmon J, Clarys P, et al. Relationship between the physical environment and physical activity in older adults: A systematic review. Health Place. 2011;17(2):458-469.

178. Toossi M. Labor force projections to 2022: The labor force participation rate continues to fall. Monthly Labor Review. Washington, DC: US Bureau of Labor Statistics. 2013. doi.org/10.21916/mlr.013.40. Accessed March 2017.

179. US Department of Health and Human Services. Step it up! The Surgeon General's Call to Action to Promote Walking and Walkable Communities. Washington, DC: Office of the 
Surgeon General. 2015. https://www.surgeongeneral.gov/library/calls/walking-andwalkable- communities/call-to-action-walking-and-walkable-communites.pdf. Accessed July 2017.

180. Patterson P. Reliability, validity, and methodological response to the assessment of physical activity via self-report. Res $Q$ Exerc Sport. 2000;71(2 Suppl):S15-20.

181. Diez Roux AV, Mujahid MS, Hirsch JA, Moore K, Moore LV. The impact of neighborhoods on CV risk. Global heart. 2016;11(3):353-363.

182. Bureau of the Census, US Department of Commerce. Census 2000 Gateway: Summary Files 1 and 3. 2007. https://www.census.gov/main/www/cen2000.html. Updated July 2013. Accessed July 2013.

183. Echeverria SE, Diez-Roux AV, Link BG. Reliability of self-reported neighborhood characteristics. J Urban Health. 2004;81(4):682-701.

184. Evenson KR, Block R, Diez Roux AV, McGinn AP, Wen F, Rodriguez DA. Associations of adult physical activity with perceived safety and police-recorded crime: The MultiEthnic Study of Atherosclerosis. Int J Behav Nutr Phy Act. 2012;9:146.

185. Nathan A, Pereira G, Foster S, Hooper P, Saarloos D, Giles-Corti B. Access to commercial destinations within the neighbourhood and walking among Australian older adults. Int J Behav Nutr Phys Act. 2012;9:133.

186. Sugiyama T, Neuhaus M, Cole R, Giles-Corti B, Owen N. Destination and route attributes associated with adults' walking: A review. Med Sci Sports Exerc. 2012;44(7):1275-1286.

187. Moran M, Van Cauwenberg J, Hercky-Linnewiel R, Cerin E, Deforche B, Plaut P. Understanding the relationships between the physical environment and physical activity in older adults: A systematic review of qualitative studies. Int J Behav Nutr Phys Act. 2014;11:79.

188. Ward Thompson C, Curl A, Aspinall P, Alves S, Zuin A. Do changes to the local street environment alter behaviour and quality of life of older adults? The 'DIY Streets' intervention. Br J Sports Med. 2014;48(13):1059-1065.

189. Jones SA, Evenson KR, Johnston LF, Trost SG, Samuel-Hodge C, Jewell DA, et al. Psychometric properties of the modified RESIDE Physical Activity Questionnaire among low-income overweight women. J Sci Med Sport. 2015;18(1):37-42.

190. Heath GW, Parra DC, Sarmiento OL, Andersen LB, Owen N, Goenka S, et al. Evidencebased intervention in physical activity: Lessons from around the world. Lancet. 2012;380(9838):272-281. 
191. Houston D. Implications of the modifiable areal unit problem for assessing built environment correlates of moderate and vigorous physical activity. Applied Geogr. 2014;50:40-47.

192. Villanueva K, Knuiman M, Nathan A, Giles-Corti B, Christian H, Foster S, et al. The impact of neighborhood walkability on walking: Does it differ across adult life stage and does neighborhood buffer size matter? Health Place. 2014;25:43-46.

193. Hirsch JA, Winters M, Ashe MC, Clarke P, McKay H. Destinations that older adults experience within their GPS activity spaces relation to objectively measured physical activity. Environ Behav. 2016;48(1):55-77.

194. Frank L, Kerr J, Rosenberg D, King A. Healthy aging and where you live: Community design relationships with physical activity and body weight in older Americans. $J$ Phys Act Health. 2010;7 Suppl 1:S82-90.

195. Powell LM, Slater S, Chaloupka FJ, Harper D. Availability of physical activity-related facilities and neighborhood demographic and socioeconomic characteristics: A national study. Am J Public Health. 2006;96(9):1676-1680.

196. Gordon-Larsen P, Nelson MC, Page P, Popkin BM. Inequality in the built environment underlies key health disparities in physical activity and obesity. Pediatrics. 2006;117(2):417-424.

197. Centers for Disease Control and Prevention. Adult participation in aerobic and musclestrengthening physical activities--United States, 2011. Morb Mortal Wkly Rep. 2013;62(17):326-330.

198. North Carolina Department of Health and Human Services. Forsyth County Aging Profile 2015. 2015. https://www.ncdhhs.gov/divisions/daas/data-reports. Accessed August 2017.

199. County Health Rankings and Roadmaps. County Health Rankings: Forsyth County, NC. 2017. http://www.countyhealthrankings.org/app/northcarolina/2017/rankings/forsyth/county/outcomes/overall/snapshot. Updated 2017. Accessed October 2017.

200. Kosma M, Cardinal BJ. Theory-based physical activity beliefs by race and activity levels among older adults. Ethn Health. 2016;21:181-195.

201. Franke T, Tong C, Ashe MC, McKay H, Sims-Gould J, The Walk the Talk Team. The secrets of highly active older adults. J Aging Stud. 2013;27(4):398-409.

202. Queen TL, Butner J, Berg CA, Smith J. Activity engagement among older adult spousal caregivers. J Gerontol Psychol Sci Soc Sci. 2017. doi:10.1093/geronb/gbx106.

203. Holliday KM, Howard AG, Emch M, Rodriguez DA, Evenson KR. Are buffers around home representative of physical activity spaces among adults? Health Place. 2017;45:181-188. 
204. Institute of Medicine Committee on the Long-Run Macroeconomic Effects of the Aging US Population. Saving and Retirement Security. Aging and the Macroeconomy: LongTerm Implications of an Older Population. Washington, DC: National Academies Press; 2012.

205. Division of Aging and Adult Services. North Carolina Aging Services Plan, Booming Forward: Working together to improve lives. Raleigh, NC: North Carolina Department of Health and Human Services. 2015.

https://files.nc.gov/ncdhhs/documents/files/NC\%20Aging\%20Services\%20Plan\%202015 $\% 20$ to\%202019.pdf. Accessed August 2017.

206. Smarr CA, Mitzner TL, Beer JM, Prakash A, Chen TL, Kemp CC, et al. Domestic robots for older adults: Attitudes, preferences, and potential. Int J Social Robotics. 2014;6:229247.

207. Ofli F, Kurillo G, Obdrzalek S, Bajcsy R, Jimison HB, Pavel M. Design and evaluation of an interactive exercise coaching system for older adults: Lessons learned. IEEE J Biomed Health Informatics. 2016;20:201-212.

208. Chihuri S, Mielenz TJ, DiMaggio CJ, Betz ME, DiGuiseppi C, Jones VC, et al. Driving cessation and health outcomes in older adults. J Am Geriatr Soc. 2016;64:332-341. 